CAROLINA ATTAS CHAUD

\title{
ANÁLISE DA MOBILIDADE URBANA VOLTADA PARA INCLUSÃO DE VEÍCULOS ELÉTRICOS DE CARGA VISANDO UMA LOGÍSTICA SUSTENTÁVEL
}

São Paulo. 
CAROLINA ATTAS CHAUD

\section{ANÁLISE DA MOBILIDADE URBANA VOLTADA PARA INCLUSÃO DE VEÍCULOS ELÉTRICOS DE CARGA VISANDO UMA LOGÍSTICA SUSTENTÁVEL}

Dissertação apresentada à Escola Politécnica da Universidade de São Paulo para obtenção de título de Mestre em Engenharia Elétrica Área de concentração: Sistemas de Potência Orientador: Prof. Dr. Luiz Cláudio Ribeiro Galvão 
Este exemplar fol revisado e corrigido em relação à versão original, sob responsabilidade única do autor e com a anuência de seu orientador.

São Paulo. 7 de julho de 2013.

Assinatura do autor Gavolina ftas Chand

FICHA CATALOGRÁFICA

Chaud, Carolina Attas

Análise da mobilidade urbana voltada para inclusão de veículos elétricos de carga visando uma logística sustentável / C.A. Chaud. - versão corr. - São Paulo, 2013.

$229 \mathrm{p}$.

Dissertação (Mestrado) - Escola Politécnica da Universidade de São Paulo. Departamento de Engenharia de Energia e Automação Elétricas.

1.Veículos especiais 2.Veiculos de carga 3.Transportes 4.Logistica 5.Sustentabilidade I.Universidade de São Paulo. Escola Politécnica. Departamento de Engenharia de Energia e Automação Elétricas li.t. 
FOLHA DE APROVAÇÃo

Carolina Attas Chaud

Análise da Mobilidade Urbana Voltada para Inclusão de Veículos de Carga Visando uma Logística Sustentável

Dissertação apresentada à Escola Politécnica da Universidade de São Paulo para obtenção de título de Mestre em Engenharia Elétrica

Área de concentração:

Sistemas de Potência

Aprovado em

Banca Examinadora 
"Não há nada como o sonho para criar o futuro." Victor Hugo 


\section{AGRADECIMENTOS}

Agradeço ao Professor Cláudio Galvão pela orientação e pelo constante estímulo transmitido durante todo o trabalho.

Agradeço ao Professor Miguel Udaeta pela disponibilidade na orientação inicial.

Agradeço a Professora Patrícia Matai pelas oportunidades, ensinamentos, incentivos e apoio ao longo desses anos.

A meu esposo Nelson Fernandes pelo amor, incentivo, paciência, enfim, por tudo, para que este sonho se realizasse.

Aos meus pais Armando Attas Chaud e Eliana Chaud, pelo amor e dedicação ao longo desses anos

A todos os demais professores e funcionários do PEA/Poli pelo privilégio de compartilharem seus conhecimentos e experiências em sala de aula.

A todos meus amigos do grupo de pesquisa do GEPEA/EPUSP pelo convívio, e troca de experiências, durante esta minha etapa de estudos e pesquisas,

E principalmente a Deus, por permitir a conclusão desta etapa. 


\section{RESUMO}

Esta dissertação tem por objetivo elaborar uma metodologia integrada de análise do impacto e do desenvolvimento do veículo elétrico ao longo do tempo atrelado à inserção de estações de carregamento em grandes cidades. Esta metodologia está dividida em duas etapas. A primeira representa a caracterização do veículo em termos das variáveis que determinam o seu desempenho tais como: avaliação das velocidades em $(\mathrm{Km} / \mathrm{h})$; a distância percorrida em $(\mathrm{Km})$; fonte de energia (acumuladores eletroquímicos); sistema de acionamento dos veículos elétricos determinado como motores elétricos em função da potência (W) e da Tensão (V). Ainda, metodologicamente foi desmembrado em 4 ciclos.

A segunda retrata sobre um estudo voltado para inserção de estações de carregamento em uma metrópole como a cidade de São Paulo analisando o comportamento otimizado da oferta de energia elétrica na cidade em questão, diante de diferentes taxas hipotéticas de penetração de veículos elétricos, para diferentes perfis de recarga dos veículos (recarga inteligente e sem controle). Foi realizado um estudo comparativo de possíveis ganhos ambientais, econômicos, sociais e políticos com a inserção desses veículos movidos a bateria substituindo os movidos a diesel.

Bons resultados, tanto do ponto de vista ambiental (dada a redução do número de emissões e de veículos), quanto de competitividade (custos em geral), puderam ser observados, ratificando e estimulando o uso desse tipo de conceito. Assim, com o intuito de promover a mobilidade elétrica com vistas à sustentabilidade do setor de transportes, surgem novas propostas de arranjos das formas de entregas nas cidades como meio de solucionar os transtornos dessa circulação de mercadorias (seja pela intrusão poluição sonora e visual, aumento do número de emissões). 


\begin{abstract}
This thesis aims at developing an integrated methodology for analyzing and impact the development of electric vehicle over time pegged the inclusion of charging stations in major cities. This methodology is divided into two stages. The first step is the characterization of the vehicle in terms of the variables that determine its performance such as: evaluation of speeds $(\mathrm{km} / \mathrm{h})$ in the distance $(\mathrm{km})$; energy source (electrochemical batteries); drive system of electric vehicles such as electric motors determined as a function of power (W) and voltage (V). Still, methodologically was divided into 4 cycles. The second case of the study portrays the insertion of charging stations in a metropolis like São Paulo investigating the optimal mix of electricity supply in Brazil, in the long term, for different hypothetical rates of electric vehicles penetration, and different recharging profiles for vehicles (smart and dumb recharging).

Good results, either under the environmental point of view (reduction of pollution levels and of moving vehicles), or under the competitive framework (cost reduction), were observed, which endorse and stimulate the adoption of this novel concept. But, due to the growing volumes of urban cargo, mainly in the CBDs, the subject "urban cargo" is receiving much more attention recently, particularly when proposing measures to improve environmental conditions in these centers.
\end{abstract}




\section{FIGURAS}

Figura 1 - O custo da energia elétrica no Brasil e no Mundo............................30

Figura 2 - O Esquema do Motor Construído por Faraday..............................32

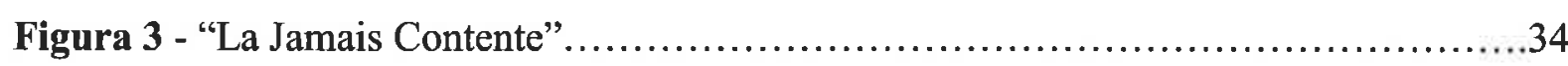

Figura 4 - Porsche Lohner-Wagen............................................ 40

Figura 5 - Um dos primeiros veículos híbridos chamado Mixt-Wagen.......................40

Figura 6 - Modelo Light Electric fabricado pela Milburn Wagon........................41

Figura 7 - Electric Motor Drive Selection Issues for HEV Propulsion Systems: A

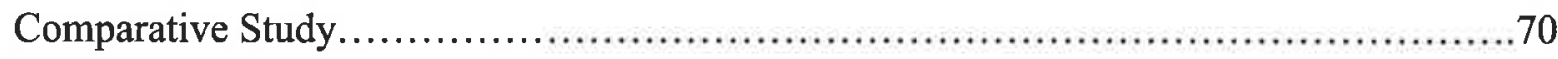

Figura 8 - Problemas no transporte urbano de cargas..................................... 73

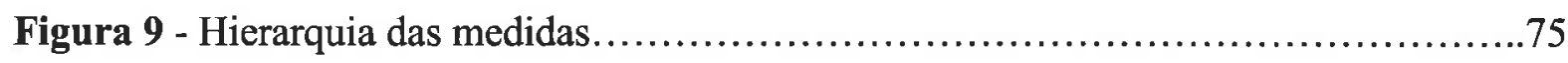

Figura 10 - Caracterização da propulsão elétrica em veículos...........................77

Figura 11 - Evolução das Baterias.................................................78

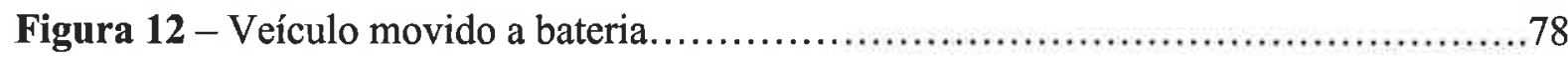

Figura 13 - "ECOTRAN", voltado à distribuição urbana...............................79

Figura 14 - Veículos elétricos usados no transporte de cargas-containeres apoiados sobre o

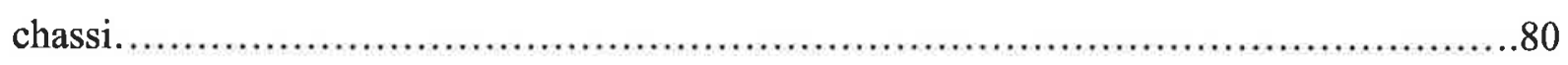

Figura 15 - "Éco-Mobilité”, voltado à distribuição urbana.................................80

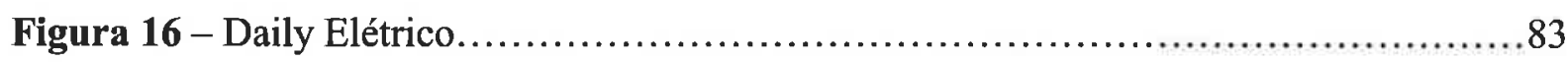

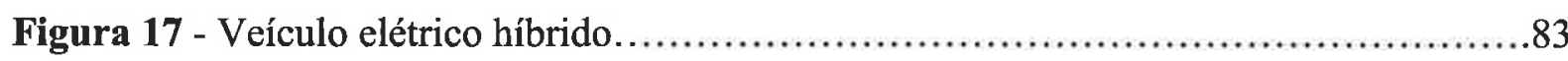

Figura 18 - Operação de um veículo MCI e um veículo híbrido no ciclo urbano............85

Figura 19 - Operação de um veículo MCI e um veículo VEH no ciclo rodoviário............86

Figura 20 - Veículo Eletromecânico com volante de inércia............................87

Figura 21 - Veículo Elétrico Híbrido de Série (topologia)...............................88

Figura 22 - Veículo Elétrico Híbrido de Série (configuração)...........................89

Figura 23 - Veículo Elétrico Híbrido Paralelo (topologia)................................90

Figura 24 - Veículo Elétrico Híbrido Paralelo (configuração)............................90

Figura 25 - Veículo Elétrico Movido por Células a Combustível.........................95

Figura 26 - Motores elétricos de CC com campo de enrolamento: (a) em série (series),(b) em derivação (shunt) e (c) com campo independente (separately

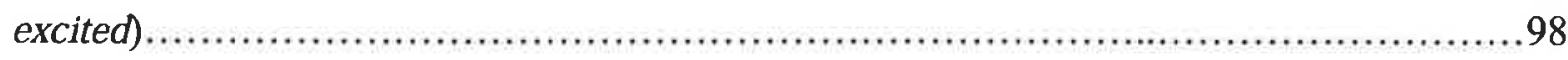

Figura 27- Motor de indução trifásico............................................ 101

Figura 28- Motor Síncrono de Imã Permanente (Nissan) ...................................102 
Figura 29 - Reabastecimento - Carregamento.

Figura 30 - Padronização de normativas em alguns países.

Figura 31- Locais onde as pessoas deixam os veículos por pelo menos 30 minutos. .118

Figura 32- Troca de baterias

Figura 33- Cabo de Carregamento 122

Figura 34- Relação de carregamentos a serem realizados em Québec. .125

Figura 35 Eletroposto HYDRO-QUÉBEC. 126

Figura 36- Mapa de localização dos eletropostos. .126

Figura 37 - Mobilidade, acessibilidade e os efeitos por ela gerados.......................129

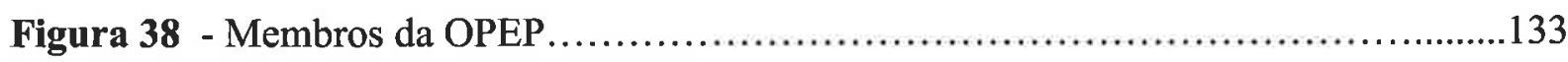

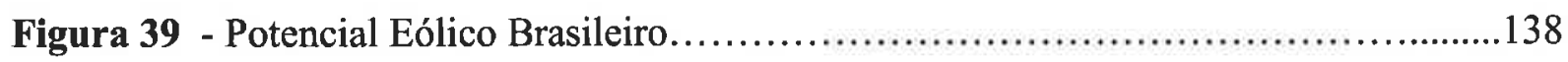

Figura 40 - Associação entre energias renováveis e veículos elétricos....................142

Figura 41 - Refino do petróleo - óleo diesel......................................146

Figura 42 - Evolução do Abastecimento do Diesel Automotivo...........................152

Figura 43 - Cogeração aplicado a aquecimento solar em escala doméstica.................154

Figura 44- Estação de abastecimento solar.............................................155

Figura 45- Sistema de Distribuição com Geração Centralizada $x$ Geração Distribuída..................................................................... 158

Figura 46- Unidades de caminhões com mais de 20 anos quantificado por região.

Figura 47 - Tamanho Fonte e Composição do material particulado........................174

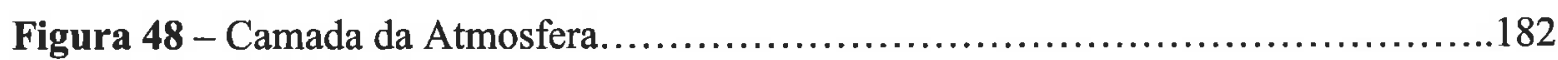

Figura 49 - Representação da análise de ciclo de vida efetuada pelo GREET ("Greenhouse gases, Regulated Emissions, and Energy use in Transportation").......................186

Figura 50 - Vias atingidas pela restrição à circulação de caminhões em São Paulo. .197

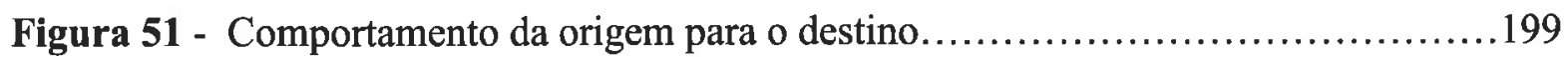

Figura 52 - Custo para o destino do veículo elétrico.................................205

Figura 53 - Diagrama de implementação........................................209 


\section{LISTA DE TABELAS}

Tabela1- Evolução das baterias elétricas. 31

Tabela 2 Evolução dos veículos elétricos entre $(1837$ - 1912).......................... .37 .39

Tabela 4 - Evolução dos veículos elétricos entre (1912 - 1973). .46

Tabela 5 - Evolução dos veículos elétricos entre (1974 - 1996). .54

Tabela 6 - Evolução dos veículos elétricos entre 1996 até os dias atuais. .63

Tabela 7 - Conjunto de seis objetivos políticos específicos. .72

Tabela 8 - Frota brasileira cresceu $121 \%$ nos últimos 10 anos.

Tabela 9- Comparativo relacionado à tecnologia de motores para veículos elétricos.

Tabela 10 - Características dos Principais tipos de baterias. 109

Tabela 11 - Principais tipos de baterias

Tabela 12 - Modos de Recarga

Tabela 13 - Custo de Infra-Estrutura do Eletroposto.

Tabela 14 - Vantagem ao utilizar os veículos elétricos .125

Tabela 15 - Os quinze países que mais consumiram petróleo em 2011.

Tabela 16 - Dez potências mundiais em energia renovável. 135

Tabela 17 - Participação de Fontes Renováveis de Produção de Eletricidade. 140

Tabela 18 - Limites das emissões perante fases do PROCONVE para veículos pesados. .166

Tabela 19 - Poluentes, Características e Fontes Principais 
Tabela 20-Parâmetros ambientais utilizados como base para definir "transporte sustentável" 172

Tabela 21- Fator de Emissão Médio (tCO2/MWh) do Grid Brasileiro. .185

Tabela 22 - Intensidade dos sons. 187

Tabela 23 - Limites de tolerância para ruído contínuo ou intermitente .187

Tabela 24 - Impactos do transporte de carga na sustentabilidade. .189

Tabela 25 - Potencial anual de variação da mortalidade mediante cenários de penetração de veículos elétricos na Região Metropolitana de São Paulo respectiva valoração econômica.

Tabela 26 - Potência em KW disponibilizada a uma bateria .210

Tabela 27 - Opções de carregamento

Tabela 28 - Quantidade de postos carregamento 


\section{LISTA DE GRÁFICOS}

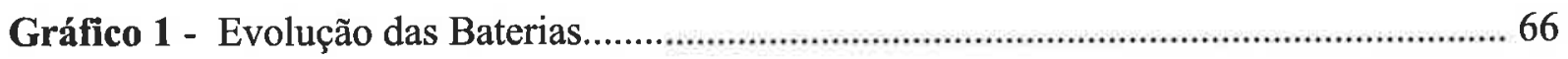

Gráfico $2-1{ }^{\circ} \mathrm{Ciclo}$ - Veículos Elétricos $(1837$ - 1912).....................................................67

Gráfico 3 - $2^{\circ}$ Ciclo - Veículos Elétricos $(1912$ - 1973) …....................................................68

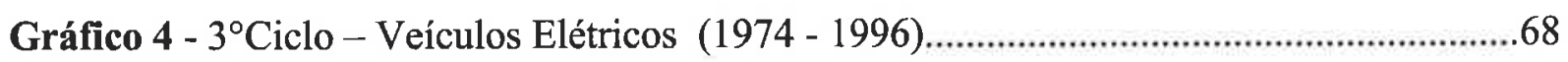

Gráfico $5-4^{\circ}$ Ciclo - Veículos Elétricos (1997 até os dias atuais).....................................69

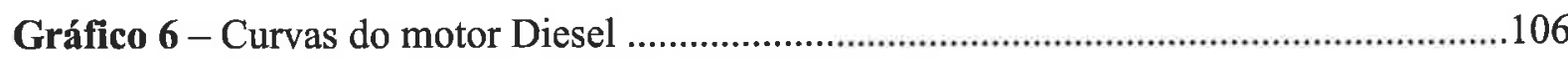

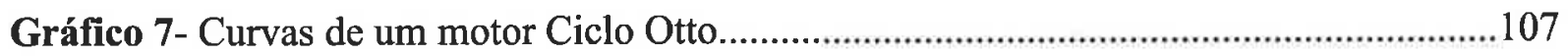

Gráfico 8 - Variação do torque com a velocidade para um motor de indução................107

Gráfico 9 - Energia Específica e Potência Específica das Principais Baterias.......................109

Gráfico 10- Energia Específica de Veículos Esportivos a Bateria / Gasolina...................... 111

Gráfico 11- Raio de alcance da tecnologia de Íons de Lítio até 2020............................... 112

Gráfico 12 - Utilização e Recarga dos Veículos Elétricos.................................................120

Gráfico 13 - Produção e consumo de petróleo....................................................................134

Gráfico 14 - Brasil e Mundo. Participação de Renováveis na Matriz Elétrica ....................139

Gráfico 15 - Consumo de Energia nos Transportes...........................................................144

Gráfico 16 - Matriz energética Brasileira, (2011)............................................................145

Gráfico 17 - Produção de diesel no Brasil.......................................................................149

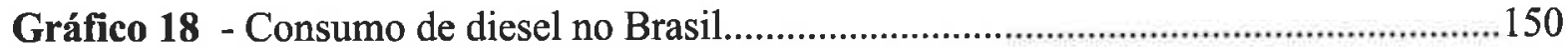

Gráfico 19 - Emissões ao longo das fases do PROCONVE para veículos pesados. $\ldots 166$

Gráfico 20 - Idade da frota e a propriedade dos veículos...............................................168

Gráfico 21- Fases do Proconve e a propriedade dos veículos .........................................169

Gráfico 22 - Contribuição das categorias de veículos na emissão de material particulado no

Estado de São Paulo em 2011 .175

Gráfico 23 - Concentrações médias mensais (2005-2010) de MP10 $\left(\mu \mathrm{g} / \mathrm{m}^{3}\right)$ das estações da 
RMSP

Gráfico 24 - Contribuição das categorias de veículos na emissão de SO2, Estado de São Paulo em 2011

Gráfico 25 - Contribuição das categorias de veículos na emissão de óxidos de nitrogênio no Estado de São Paulo em 2011 179

Gráfico 26 - Contribuição das categorias de veículos na emissão de monóxido de carbono no Estado de São Paulo em 2011 180

Gráfico 27- Contribuição das categorias de veículos na emissão de $\mathrm{CO} 2$ no Estado de São Paulo em 2011 182

Gráfico 28 -Emissão associada aos veículos elétricos movidos a bateria. 184

Gráfico 29 - Tempo de Recarga .... .211

Gráfico 30 - Estações de recarga ao longo de uma rota .212 


\section{LISTA DE SIGLAS}

ABNT - $\quad$ Associação Brasileira de Normas Técnicas

ANP - Agência Nacional do Petróleo

BEN - Balanço Energético Nacional

CA - Corrente Alternada

CC - Corrente Contínua

CETESB - Companhia de Tecnologia de Saneamento Ambiental

EPE - Empresa de Pesquisa Energética

EV - Veículo Elétrico (do inglês: Electric Vehicle)

Flex - Veículo a Combustivel Flexivel (misturas de etanol e gasolina)

HEV - Veículo Híbrido Elétrico (do inglês: Hybrid Electric Vehicle)

IEA- Agência Internacional de Energia

IBAMA - Instituito Brasileiro de Meio Ama

ICEV - Veículo a Combustão Interna (do inglês: Intern Combustion Engine

Vehicle)

IEC - International Electrotechnical Comission

Li-Ion - Bateria de Lítio-lon

$\mathrm{MCl}$ - Motor de Combustão Interna

ME - Motor Elétrico

MME- Ministério de Minas e Energia

MIT - Instituto de Tecnologia de Massachussets

MP - Material Particulado

$\mathrm{NiCd}$ - Bateria de Níquel-Cádmio

$\mathrm{NiMH}$ - Bateria de Níquel-Metal-Hidreto

OCDE- Organização para Cooperação e Desenvolvimento Econômico

OPEP_ Organização dos Países Exportadores de Petróleo

ONS - Operador Nacional do Sistema Elétrico

PM - $\quad$ Motor de Magneto Permanente (do inglês: Permanent Magnet)

SIN - Sistema Interligado Nacional

SLI - Bateria de Partida, lluminação e Ignição (do inglês: Starter, Lightning and Ignition)

tep - $\quad$ Tonelada Equivalente de Petróleo

USABC - Consórcio Americano para Baterias Avançadas 
VECC - Veículo Elétrico Movido por Células a Combustivel

VEHS - Veículo Elétrico em Série

VEHP - Veículo Elétrico Híbrido Paralelo

VEHP -in - Veículo Elétrico Híbrido Plug -in

VRLA - Bateria de Chumbo-Ácido Regulada à Válvula (do inglês: Valve Regulated Lead Acid) 


\section{SUMÁRIO}

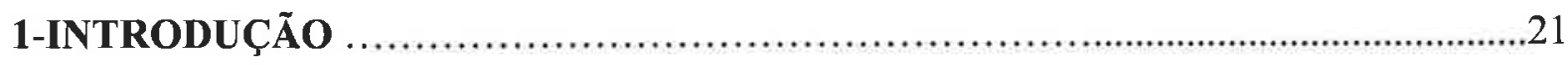

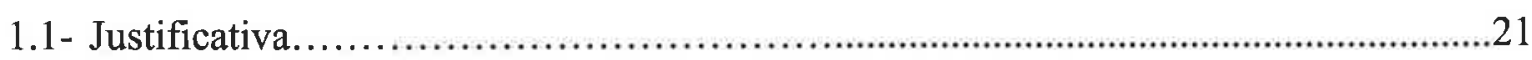

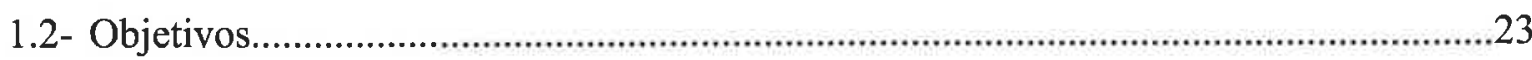

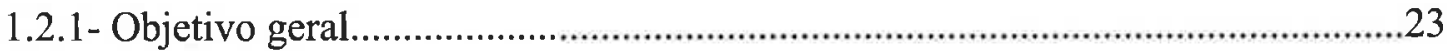

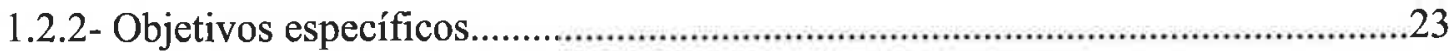

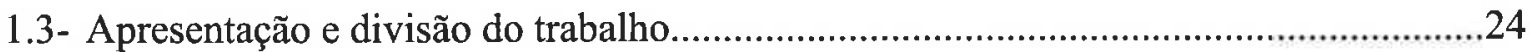

2-ESTADO DA ARTE DO DESENVOLVIMENTO DO VEÍCULO

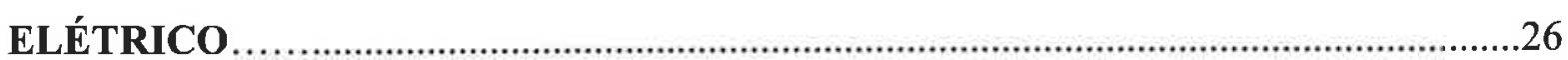

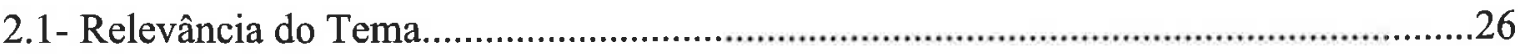

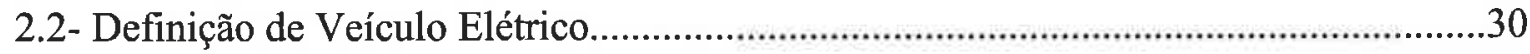

2.3- Contexto Técnico Evolutivo dos Veículos Elétricos...................................................31

2.3.1 - Primeiro Ciclo Analítico dos Veículos Elétricos (1837 - 1912).......................34

2.3.2- Segundo Ciclo Analítico dos Veículos Elétricos (1912 - 1973)......................41

2.3.3- Terceiro Ciclo Analítico dos Veículos Elétricos (1974 - 1996)........................46

2.3.4-Quarto Ciclo Analítico dos Veículos Elétricos (1997 até os dias atuais)..........55

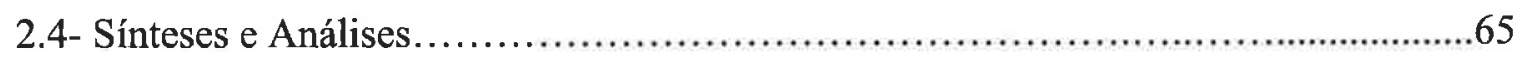

3- VEÍCULO ELÉTRICO E SUAS CARACTERÍSTICAS ..................................71

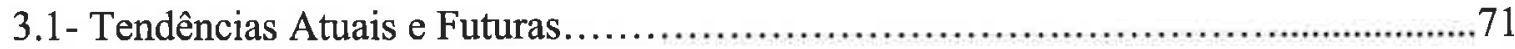

3.2- Caracterizando os Veículos Elétricos...........................................76

3.2.1- Formas de Propulsão dos Veículos Elétricos................................77

3.3- Componentes de um Veículo Elétrico: Motores e Baterias.......................95

3.4- Motores Elétricos.............................................................. 95

3.4.1- Motores Elétricos de Corrente Contínua (Componentes).....................98

3.4.2- Motores Elétricos com Campo de Enrolamento em Série .....................99

3.4.3- Motores Elétricos com Campo de Enrolamento em Derivação....................99

3.4.4- Motores Elétricos em Campo Independente...............................99

3.4.5- Motores Elétricos de Corrente Alternada.....................................99

3.4.6- Motores Elétricos de Indução (Trifásico e Monofásico) ......................100

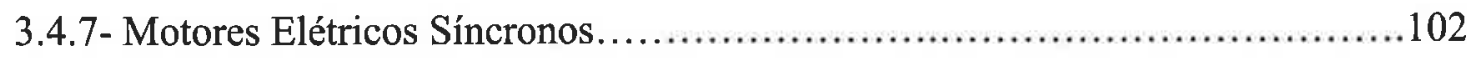

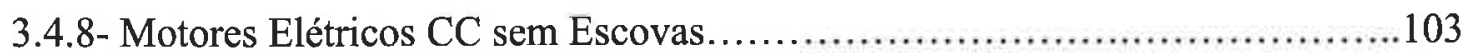


3.4.9- Motores Elétricos de Relutância Variável......................................103

3.4.10- Panorama atual - Motores Elétricos.................................... 104

3.4.11- Comparativo entre os motores......................................... 106

3.5- Acumulador Eletroquímico - Bateria........................................ 108

3.6- Formas de Carregamento e sua Infra-estrutura.................................113

3.6.1- Requisitos para construção da logística de carregamento....................115

3.6.2- Infra- Estrutura do carregamento e à rede elétrica...........................119

3.6.3- Troca de Bateria........................................................ 120

3.6.4- Carga lenta.......................................................... 121

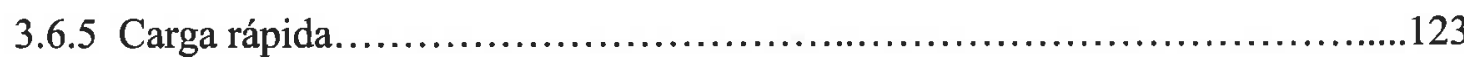

3.6.6 Infra-estrutura para carregamento planejado em Québec (Canadá)..............124

4- INTROduÇÃo da MOBILIDAdE ELÉTRICA ATRAVÉS DA ANÁliSE do CONSUMO DE ENERGIA NO SETOR DE TRANSPORTES .......................127

4.1- Mobilidade no Transporte..................................................... 127

4.1.1- Mobilidade Sustentável................................................... 128

4.2- Geração de Eletricidade Através de Fontes Renováveis............................132

4.3- Consumo de Energia Elétrica no Setor de Transportes de Carga...............................143

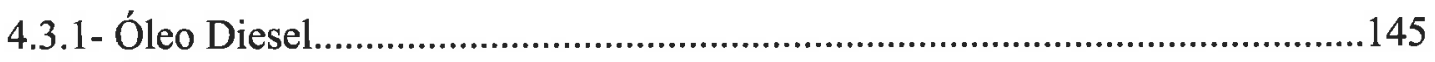

4.3.2- Diesel Metropolitano................................................................................151

4.3.3- O Uso Eficaz dos Combustíveis não Renováveis........................................152

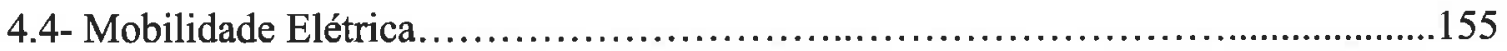

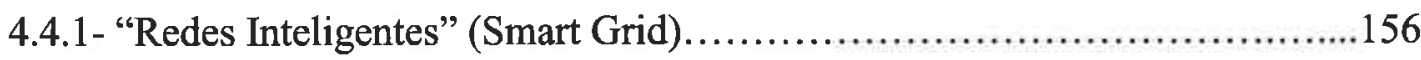

4.4.2- Países que aplicam projetos para Smart Grids.............................159

5- GESTÃo DA MOBILIDADE ATRAVÉS DAS ANÁLISES AMBIENTAL, SOCIAL,

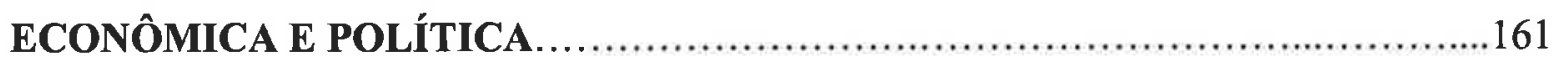

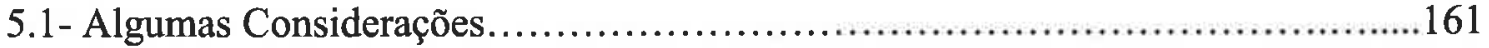

5.2- Inter-Relacionamento de dados ambientais e de saúde no setor de Transportes....163

5.2.1- Poluentes Atmosféricos.................................................169

5.2.2- Material Particulado....................................................... 173

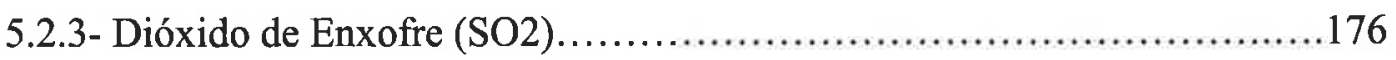

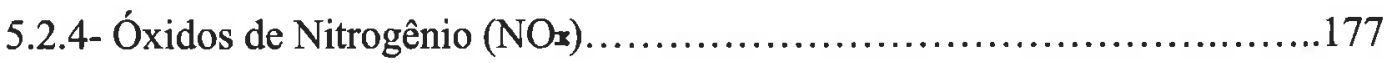

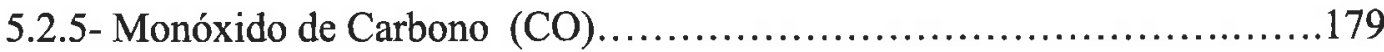

5.2.6- Emissão de Gases de Efeito Estufa.................................180

$5.3-$ Poluição Sonora....................................................... 186 
5.4- Síntese Conclusiva .188

6- ESTAÇÕES DE CARREGAMENTO UTILIZADAS PARA OS VEÍCULOS ELÉTRICOS: UM ESTUDO METODÓLOGICO ..................................195

6.1 - Algumas considerações..........................................................

6.2- Desenvolvimento da Metodologia para Análise dos Atributos Utilizados para Localização das Estações de Carregamentos...........................................197

6.3- Desenvolvimento de Rotas de Estação de Carregamentos.............................198

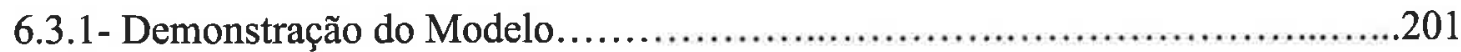

6.4- Otimização do Método de Localização para Estação de Carregamento.................203

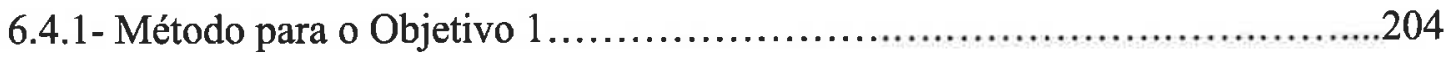

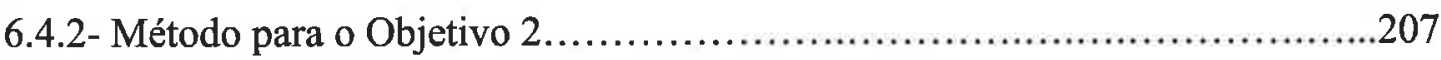

6.4.2.1- Demonstração da Fórmula................................................................208

6.5- Implementação do Método de Localização ideal........................................................209

6.6-A importância das Baterias e das Estações de Carregamento.......................................210

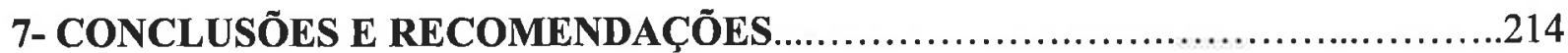

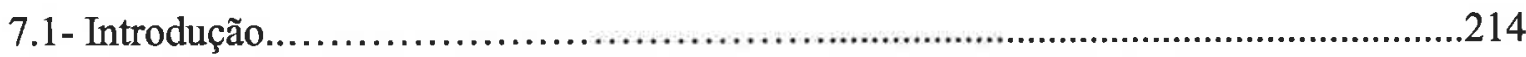

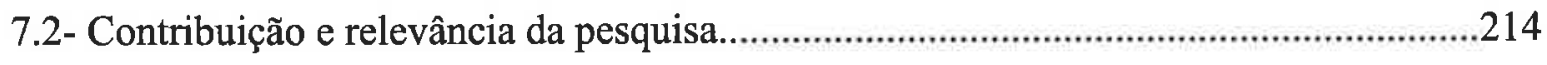

7.3- Sobre o estudo metodológico e os dados aplicados....................................................215

7.4- Validade e confiabilidade da pesquisa...................................................................216

7.5- Recomendações para futuras pesquisas......................................................................216

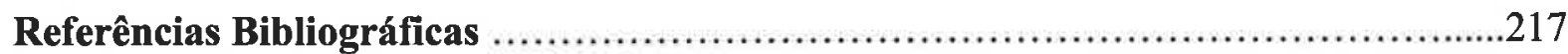




\section{INTRODUÇÃO}

\subsection{JUSTIFICATIVA}

O problema gerado pela movimentação de mercadorias em áreas urbanas não é novo, mas raramente foi considerado no planejamento clássico de transporte urbano. Essa visão vem mudando rapidamente dada a crescente conscientização dos cidadãos a respeito dos grandes problemas gerados pelo tráfego de carga (PETRI e NIELSEN, 2002).

As preocupações relacionadas aos transportes e à mobilidade urbana e elétrica são de suma importância para o desenvolvimento urbano sustentável, uma vez que os atuais padrões de mobilidade têm refletido em inúmeras deseconomias para as cidades, além de afetarem de forma direta a qualidade de vida de seus cidadãos. As questões relacionadas à mobilidade, por sua vez, foram concebidas até o presente momento apenas como uma questão de acesso físico aos meios de transporte. Deste modo, a forma de planejar as cidades e seus sistemas de circulação tem sido revista, resultando na construção de um novo modelo para a mobilidade urbana e elétrica.

Entretanto, este modelo reconhece que os problemas relacionados à mobilidade também envolvem as seguintes questões:

- Ambientais: como a degradação ambiental evidenciada pela poluição, ruído;

- Social: qualidade de vida;

- Econômicas: devido à descontinuidade de ações e investimentos em políticas que viabilizem a mobilidade elétrica e urbana afetando de certa forma a sociedade como um todo.

Assim, o modelo em desenvolvimento resulta em políticas voltadas à inserção de veículos elétricos urbanos de carga visando a melhoria da qualidade de vida pela não emissão de material particulado $(\mathrm{CO})$ e dióxido de enxofre $\left(\mathrm{SO}_{2}\right)$ vislumbrando a construção e manutenção do que se denomina mobilidade elétrica.

Um dos principais desafios que o setor de transportes enfrenta está associado à sua dependência quase total de derivados de petróleo como fonte de energia. Mundialmente, cerca de $95 \%$ do consumo energético do setor de transportes ocorre na forma de derivados de petróleo (IEA, 2011a), enquanto que, no Brasil, esta participação gira em torno de $82 \%$ 
(MME, 2011). A principal diferença da matriz energética do setor de transportes do Brasil em relação à mundial é o elevado consumo de álcool etílico (anidro e hidratado) pelo setor.

Conforme o MME (2011), desde 1980, o setor de transportes é o segundo maior usuário de energia final no Brasil. Sua participação varia entre 25 e $30 \%$ de energia, sendo responsável pela demanda de $55 \%$ dos derivados de petróleo consumidos no país.

Em 2011, o consumo final energético do setor de transportes no país foi de 69 milhões de toneladas equivalentes de petróleo (TEP), dos quais mais de $92 \%$ foram consumidos por veículos rodoviários (MME, 2012). Uma das formas de reduzir a dependência do setor de transportes e as emissões de poluentes locais e globais é a partir do uso de novas tecnologias que permitirão a interação do setor de transportes com o sistema elétrico.

Dentre as opções, merecem destaque, os veículos puramente elétricos a bateria (Battery Electric Vehicles - BEV) que possuem uma única fonte de energia a eletricidade proveniente da rede, armazenada eletroquimicamente (PLUGINCARS, 2012).

As vantagens desses veículos em relação aos convencionais movidos a combustão incluem a não (ou baixa) produção direta de gases de exaustão, operação com pouco ruído e, frequentemente, possuem maior eficiência do tanque à roda (tank to wheel) devido à maior eficiência do motor elétrico (CAMPANARI et al., 2009).

Uma visão otimista de longo prazo do uso da eletricidade pelo setor de transportes, aliado à constante necessidade de expansão do sistema elétrico para atendimento da demanda, pode indicar uma relação de interação entre os setores. Ou seja, pode originar um tipo de simbiose a partir de uma ligação bidirecional do fluxo de energia entre veículos e sistema elétrico. Este sistema, onde os veículos elétricos têm a capacidade de, não apenas consumir, mas também de gerar energia para a rede elétrica, é conhecido como vehicle-to-grid (V2G). Entretanto, para a implementação do V2G, há a necessidade de modificações tecnológicas tanto na construção dos veículos como na estrutura de fornecimento de energia elétrica. A idéia, apesar de ainda incipiente, indica para a consolidação de um sistema elétrico, conhecido como smart grid, que possui uma infra-estrutura de medição avançada (Advanced Metering Infrastructure - AMI). Isto se refere a medidores ditos inteligentes e a uma rede de comunicações que permite uma comunicação bidirecional entre fornecedor de eletricidade e medidor. Neste formato, fornecedores têm acesso à informações em tempo real sobre o consumo de eletricidade de seus clientes (HLEDIK, 2009).

A construção de uma infra-estrutura para alocação de estações de carregamento tornase fator prioritário. $\mathrm{O}$ armazenamento de energia pode trazer benefícios adicionais para $\mathrm{o}$ sistema energético, uma vez que linhas de transmissão que transportam energia de fontes 
energéticas com baixo fator de capacidade (como por exemplo, algumas fontes renováveis) são subutilizadas. Alternativamente, pode-se utilizar o armazenamento de energia próximo à geração de fontes renováveis de forma que o excesso gerado seja armazenado e entregue à rede em momentos de menor produção. Desta forma, o fator de capacidade da linha de transmissão pode ser maior e menos linhas de transmissão serão necessárias para entregar a energia para o mercado (DENHOLM e SIOSHANSI, 2009).

Sem a formulação de políticas que resultem em geração elétrica no formato descentralizado, o uso de eletricidade pelo setor de transportes estará relacionado ao aumento da demanda elétrica e à possível necessidade de aumento da capacidade de geração de energia elétrica. Mais do que isso, a penetração dos veículos elétricos no sistema pode ocasionar sobrecarga em transformadores e linhas de distribuição e, principalmente, dependendo do momento e forma da recarga, sobrepico no sistema elétrico (KIVILUOMA e MEIBOM, 2011; HADLEY e TSVETKOVA, 2008; GREEN II et al.,2011; LIN et al., 2010).

As desvantagens dos veículos elétricos estão associadas às deficiências do armazenamento eletroquímico de energia. Em relação aos combustíveis convencionais, a bateria destes veículos possuem baixa energia específica em termos de volume e massa, e baixa taxa de reabastecimento / recarga (BRADLEY e FRANK, 2009).

\subsection{OBJETIVOS}

\subsubsection{Objetivo Geral}

Analisar a viabilidade da introdução de estações de carregamento destinadas aos veículos elétricos urbanos de carga, na cidade de São Paulo, partindo do pressuposto da inserção dos mesmos, dada a delimitação criada pela Prefeitura Municipal que instituiu a ZMRC (Zona Máxima de Restrições a Caminhões) impedindo a circulação de caminhões em áreas centrais, sendo permitido somente os VUCS (Veículos Urbanos de Carga).

\subsubsection{Objetivos Específicos}

- Estudar e esmiuçar o desenvolvimento do veículo elétrico e os componentes ao longo do tempo;

- Revisar as experiências internacionais sobre o tema, mobilidade elétrica e consumo energético no setor de transportes; 
- Realizar um estudo ambiental ressaltando possíveis ganhos com a introdução de veículos elétricos como a redução de poluentes e de ruídos;

- Contextualizar a questão sócio-política avaliando suas necessidades e possibilidades e, em seguida, associá-la ao setor de cargas substituindo os veículos movidos a diesel por elétricos;

- Realizar um estudo logístico para criação de uma infra-estrutura utilizada paras as estações de carregamento.

\subsection{APRESENTAÇÃO E DIVISÃO DO TRABALHO}

Este capítulo inicial será seguido conforme descrito abaixo:

- Capítulo 2: Estado da Arte do Desenvolvimento do Veículo Elétrico

Metodologicamente o desempenho dos veículos elétricos foi desmembrado em 4 ciclos, abrangendo tais épocas: $1^{\circ}$ ciclo de $1837-1912 ; 2^{\circ}$ ciclo de $1912-1973 ; 3^{\circ}$ de $1973-$ 1996; $4^{\circ}$ ciclo de 1996 até os dias atuais. Essa análise aponta as vulnerabilidades e as potencialidades minuciosamente decorrentes à introdução destes veículos, na linha do tempo.

- Capítulo 3: Veículos Elétricos: Características e Formulação

Serão apresentadas topologias e características do veículo elétrico urbano de carga, assim como, a questão do carregamento realizado pelos acumuladores eletroquímicos.

- Capítulo 4: Introdução da Mobilidade Elétrica Através da Análise do Consumo de Energia no Setor dos Transportes também voltado às questões já tratadas nos capítulos anteriores, este capítulo objetiva uma nova política de geração de eletricidade a partir de fontes renováveis.

- Capítulo 5: Gestão da Mobilidade Através das Análises Ambiental, Social, Econômica e Política. Dando continuidade aos conceitos anteriormente apresentados, esse capítulo tem por fim apresentar análise ambiental, social e econômica através da gestão ambiental como um todo. 
- Capítulo 6: Estações de Carregamento Utilizadas para os Veículos Elétricos: Um Estudo Metodológico. Trata-se do procedimento metodológico. Aqui, serão apresentados os dados a serem aplicados e analisados, propondo alocação de estações de carregamento.

- Capítulo 7: Conclusões e Recomendações

Serão feitas as possíveis análises decorrentes dos capítulos anteriores, objetivandose a aceitação ou refutação de algumas hipóteses, levando-se em consideração a realidade proposta. 
Este capítulo tem por objetivo apresentar o "estado da arte" do processo do desenvolvimento do veículo elétrico por meio da descrição dos estudos e métodos adotados. Fica caracterizado que os veículos movidos à eletricidade ressurgem como instrumentos para solucionar problemas enfrentados dentro de grandes centros urbanos e suas diferentes nuances econômicas, sociais, ambientais e geográficas. Serão postas as recentes políticas em mobilidade elétrica com vistas à sustentabilidade da movimentação de mercadorias nos grandes centros e a influência que tem no direcionamento de novas propostas voltadas à melhoria na distribuição da carga urbana.

\section{ESTADO DA ARTE DO DESENVOLVIMENTO DO VEÍCULO ELÉTRICO}

\subsection{Relevância do Tema}

A mobilidade urbana do século XXI vem com uma série de limitações, indo desde os problemas da disponibilidade de recursos essenciais e disposição dos resíduos até a velocidade média de transporte de mercadorias e de pessoas, fato que leva a discutir o papel futuro do automóvel nas cidades. Isto é pensar e implementar mudanças fundamentais nos conceitos e modelos de transportes padronizados do século passado, mesmo porque os carros, caminhões e outras mobilidades que viabilizaram a urbanização sinônimo de desenvolvimento são na atualidade os fatores que colapsam as metrópoles (BROWN, 2003).

Dos inúmeros fatores negativos relativos à mobilidade urbana no sentido completo, tem-se na poluição local, o maior alvo de minimização de efeitos do bem-estar humano. Nesse sentido surge como parte da solução, não desconhecida pelas urbes, a mobilidade elétrica, mesmo porque ao contrário do que se possa parecer, os primeiros veículos elétricos surgiram ainda na passagem do século XIX para o XX e precederam a invenção do motor por combustão da gasolina (por Daimler e Benz, na Alemanha em 1885). Propriamente, antes da indústria automobilística consolidar-se para o desenvolvimento e produção de veículos à combustão interna direcionando-se como sinônimo de mobilidade, a história do desenvolvimento socioeconômico ocidental demonstrava que as indústrias de veículos elétricos foram prósperas. Linhas de ônibus elétricos, por exemplo, ganhavam espaços nas ruas de Londres por volta de 1886. Este fato se deu em decorrência da supremacia das pesquisas realizadas por Gustave Trouvé, na França, em 1881, que vieram permitir a recarga das baterias. 
O uso regular dos veículos elétricos se manteve por um bom tempo, prova disso são os avanços notáveis, como a construção do carro elétrico que alcançou a incrível velocidade, para a época, de $100 \mathrm{~km} / \mathrm{h}$ (pelo belga Camille Jenatzy em 1899). Assim como em 1918, na cidade do Rio de Janeiro foi inaugurada a linha de ônibus elétricos entre a Praça Mauá e o, então existente Palácio Monroe, conhecidos como os confortáveis ônibus de tração elétricos movidos à bateria, com rodas de borracha maciça, sem barulho, sem vibração, sem fumaça $\mathrm{e}$ sem os inconvenientes da gasolina (Peres, 2003).

Apesar destas qualidades, as limitações do tempo de recarga e autonomia não se mostraram suficientes para suplantarem o sucesso iniciado com o lançamento do Ford T, em 1909, que contou, pouco depois, com aperfeiçoamentos, como o da partida elétrica. Esta inovação veio a desempenhar importante papel na ascensão de um dos produtos mais almejados e disputados pela sociedade de consumo: o automóvel. $O$ ingresso das grandes empresas de petróleo, neste cenário, a exemplo da Texaco, em 1902, nos EUA, puderam oferecer o suporte necessário de combustíveis, pois em 1892 Rudolf Diesel já havia inventado o famoso motor cujo ciclo receberia o seu próprio nome, conforme Peres (2003).

Em virtude da consciência ambiental sobre os malefícios causados ao meio ambiente, decorrente da queima do petróleo pelos veículos movidos a motor de combustão interna e a evolução tecnológica da motorização elétrica das últimas décadas, fez com que a mobilidade elétrica fosse vista sob um novo contexto resultando no aumento da quantidade de veículos movidos a propulsão elétrica em circulação em todo o mundo.

Em termos gerais, pode-se afirmar que, nos grandes centros populacionais, os veículos automotores, fonte bastante significativa de emissões contaminadoras do ar, contribuem, muitas vezes, com cerca de $100 \%$ dos poluentes emitidos para a atmosfera (MMA, 1999; CAMPI et al, 2004).

Segundo Braga (2002), as primeiras preocupações com a qualidade do ar tiveram início na era pré-cristã devido ao uso do carvão e da lenha como combustível. As cidades dessa época já apresentavam ares de qualidade aquém do desejável. No século XIII, a Inglaterra já havia baixado alguns atos de controle de emissão de fumaça.

$\mathrm{Na}$ era moderna, após a revolução industrial e a disseminação do automóvel como meio de transporte no decorrer do século $\mathrm{XX}$, os níveis de poluição têm se tornado um problema grave. Alguns casos de mortes por poluição excessiva foram relatados nos Estados Unidos e Europa, ainda segundo Braga (2002): 
[...] Alguns anos após, um episódio semelhante ao que ocorreu durante os últimos cinco dias do mês de outubro de 1948, na cidade de Donora, Pensilvânia. Os produtos da combustão das indústrias locais permaneceram sobre a cidade devido à ocorrência de inversões térmicas que impediram a dispersão destes poluentes. Inversão térmica é um fenômeno meteorológico onde ocorre a presença de uma camada de ar frio, alguns metros acima da superfície, que impede a dispersão e a movimentação de massas de ar mais quentes localizadas próximas do solo. Essa camada mais fria age como se fosse a tampa de uma panela concentrando vapor no seu interior. Durante este período foram observadas 20 mortes ao invés das duas mortes esperadas normalmente em uma comunidade de 14.000 pessoas. Porém, o mais clássico e mais grave dos episódios acerca dos efeitos deletérios dos poluentes do ar foi o acontecido em Londres. Durante o inverno de 1952, um episódio de inversão térmica impediu a dispersão de poluentes, gerados então pelas indústrias e pelos aquecedores domiciliares que utilizavam carvão como combustível, e uma nuvem, composta principalmente por material particulado e enxofre (em concentrações até nove vezes maiores do que a média de ambos), permaneceu estacionada sobre a cidade por aproximadamente três dias, levando a um aumento de 4.000 mortes em relação à média de óbitos em períodos semelhantes. (Braga e outros, 2002, p.2).

Contudo, ações ambientais, tais como o protocolo de Kyoto, especialmente relativas à queima dos derivados do petróleo nos veículos movidos a motor de combustão interna, desencadeou nos últimos tempos a evolução tecnológica da motorização elétrica. Além disso, as mobilidade elétrica e urbana adquirem um novo papel na sociedade moderna tanto pelo incremento da disponibilidade quanto pelo uso dos veículos elétricos no mundo.

Propiciar a construção de uma eco-economia no sentido de um desenvolvimento socioeconômico sustentável que inclua a mobilidade nas grandes metrópoles parece irreversível no século XXI. Significa podermos viver em um mundo onde a energia venha de 
fontes limpas, como por exemplo de turbinas eólicas, e não de minas de carvão; onde as indústrias de reciclagem substituam indústrias de mineração; e onde as cidades sejam planejadas para pessoas e não para carros. Uma economia sustentável que inclua o bem-estar das gerações futuras (BROWN, 2003).

Como premissa, o veículo elétrico se mostra propício às questões ambientais da mobilidade urbana, visto que as emissões são sensivelmente reduzidas, onde se deve incluir o barulho. Porém, a recarga das baterias (ponto nevrálgico da inclusão da mobilidade elétrica), incorpora novos conceitos à rede elétrica comercial e deverá ser planejado dentro das fontes alternativas de geração de energia de cada país. Em todo caso, com relação ao Brasil, dada a característica da produção de energia elétrica ser predominantemente hidroelétrica, a mobilidade elétrica como opção de mobilidade urbana sustentável para as grandes metrópoles, como a cidade de São Paulo, é significativa (PERES, 2000).

Assim, torna-se inquestionável a importância que tem um sistema de transportes eficiente, eficaz e flexível à atividade econômica e à qualidade de vida. Um sistema de transportes que atenda às necessidades de deslocamento de uma população, dando-lhe mobilidade, por si só representa uma grande ameaça ao ambiente e à saúde humana ("demasiado tráfego destrói o tráfego"). A chave para encontrar a solução de equilíbrio entre essas "forças" está no encontro de políticas que integrem considerações ambientais e de sustentabilidade na tomada de decisões sobre transportes e políticas afins. São vários os grupos que têm papel a desempenhar no processo de integração: decisores em todos os níveis nas áreas de transportes, ambiente, economia, desenvolvimento regional e ordenamento do território, bem como, as indústrias, os operadores de transportes e usuários (TERM, 2000).

Londres, por exemplo, segundo legislação imposta, cada veículo que adentrar em seu perímetro urbano deverá pagar taxa a não ser que seja elétrico. A energia elétrica apresenta um valor diferenciado comparado aos produtos petrolíferos, nomeadamente na Europa, em que a gasolina e o gasóleo têm elevados impostos. Assim, a operação de um veículo movido à propulsão elétrica poderá custar em pouco mais de $1 € / 100 \mathrm{~km}$, cerca de um décimo do custo associado a um veículo movido à combustão, segundo Martins Jorge et Brito Francisco, 2011. Na Figura 1 podemos conferir o custo da energia para a indústria no Brasil e no mundo em ( $\mathrm{R} \$ \mathrm{MWh}$ ). O Brasil tem a $4^{\mathrm{a}}$ tarifa mais cara, em média, pagamos $\mathrm{R} \$ 329,00$ por megawatthora, quase $50 \%$ a mais que a média de 27 países concorrentes de 215 por MWh. 


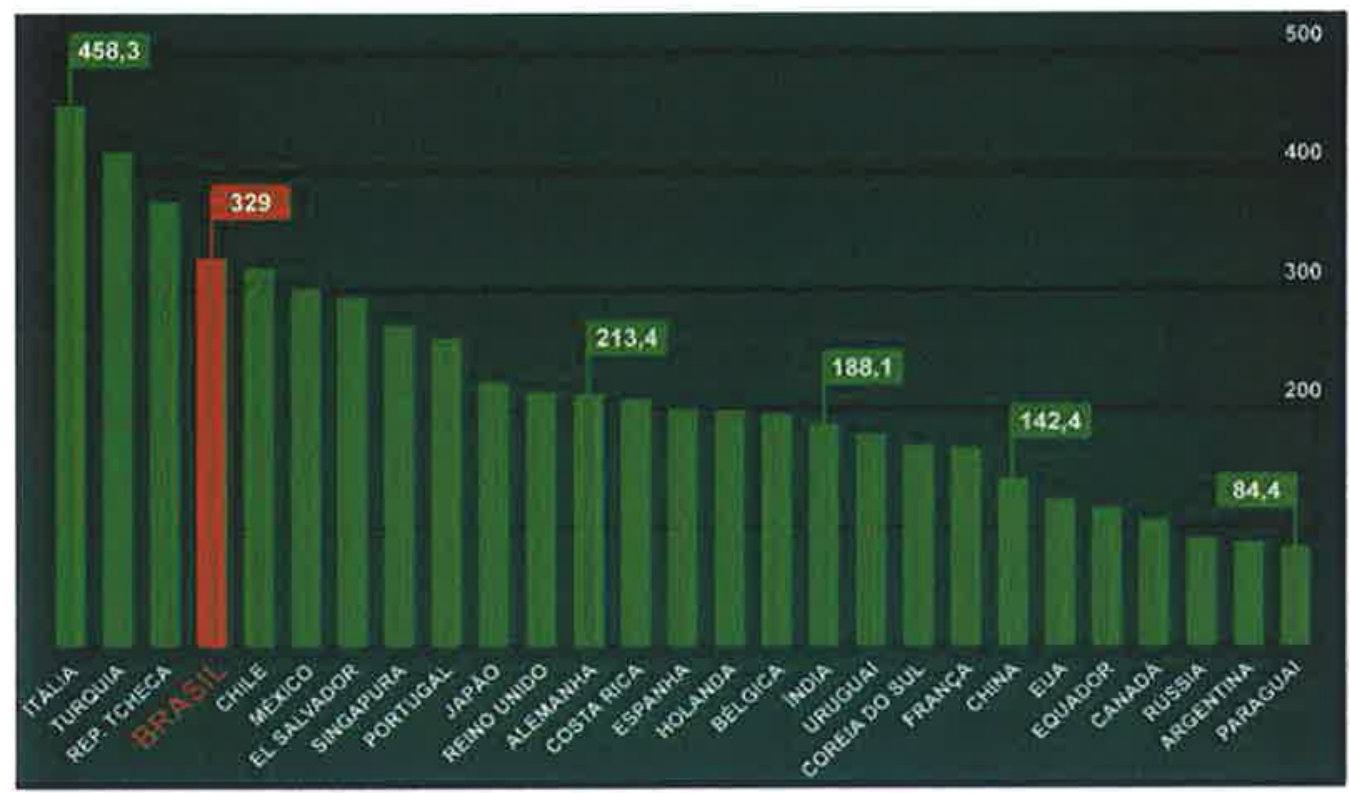

Figura 1 - O custo da energia elétrica no Brasil e no mundo

Fonte:.EPE

\subsection{Definição de Veículo Elétrico}

A princípio, um veículo elétrico na sua acepção básica pode ser entendido como sendo um automóvel com um motor elétrico ligado ao eixo dianteiro através de uma caixa de velocidades com uma ou duas velocidades, existindo várias outras possíveis variações nas arquiteturas do sistema propulsor. Uma variação significativa é a utilização de quatro pequenos motores em cada roda, em troca de somente um motor de acionamento, como originalmente concebido nos primórdios do carro elétrico (DELUCCHI e LIPMAN. 2010).

Mais ainda, no contexto deste trabalho, a mobilidade elétrica visa o entorno relativo a conduzir pessoas, objetos ou uma carga específica. Porém, o veículo elétrico neste caso, independente de outras variantes tecnológicas, será compreendido genericamente como um sistema cuja fonte de energia é a bateria que ficará com a incumbência de acionar um ou mais motores elétricos do automóvel. Neste caso específico da mobilidade elétrica, assume-se genericamente que o determinante do tipo de veículo é a alimentação energética, assim, por exemplo, um metrô ou trólebus segue uma rota pré-determinada pelos trilhos ou rede de distribuição elétrica (BOTTURA, 1986).

A pluralidade dos sistemas existentes de veículos elétricos nos obriga a limitar a extensão deste trabalho para um determinado tipo de aplicação (carros e veículos utilitários destinados a cargas). 
Em consonância aos apontamentos acima podemos fazer uma analogia analisando o contexto histórico evolutivo dos veículos elétricos que serão parametrizados em fases considerando ainda a tecnologia empregada e a relevância socioeconômica relativa ao período.

\subsection{Contexto Técnico Evolutivo dos Veículos Elétricos}

É importante destacar a tecnologia de propulsão elétrica que provém da descoberta dos acumuladores de energia e do motor elétrico utilizado como sistema de tração. Para maior compreensão, um dos precursores foi Alessandro Volta que em 1800 constatou o princípio da eletrólise concluindo que era possível obter uma tensão elétrica ("voltagem") contínua ao se utilizar certos fluidos como condutores para promover a reação química entre os metais. Volta também havia percebido que as células individuais podiam ser associadas em série para aumentar a diferença de potencial entre seus terminais. Dessa forma, surge a primeira bateria conhecida como "bateria de Volta". A Tabela 1 mostra como evoluíram as baterias no decorrer do tempo.

Tabela1 - Evolução das bateria elétricas

\begin{tabular}{|c|c|c|}
\hline Ano & Autor & Descrição \\
\hline 1600 & Gilbert (UK) & Estudos realizados em tomo do princípio da eletrólise. \\
\hline 1791 & Galvani (Itália) & Descobrimento da eletricidade em animais. \\
\hline 1800 & Volta (Itália) & Invenção da primeira célula de voltagem. \\
\hline 1802 & Cruikshank (UK) & Primeira bateria elétrica de produção em série. \\
\hline 1820 & Ampere (França) & Geração da eletricidade através do magnetismo. \\
\hline 1833 & Faraday (UK) & Publicação da lei de Faraday. \\
\hline 1836 & Daniell (UK) & Invenção da célula de Daniell. \\
\hline 1839 & Grove (UK) & Invenção da célula de combustível. \\
\hline 1859 & Planté (França) & Invenção da bateria de chumbo-ácido. \\
\hline 1868 & Leclanché (França) & Invenção da célula de Leclanché. \\
\hline 1888 & Gassner (USA) & Conclusão da célula seca (sólida). \\
\hline 1899 & Jugner (Suécia) & Invenção das baterias de níquel-cadmium. \\
\hline 1901 & Edison (USA) & Invenção das baterias de níquel-ferro. \\
\hline
\end{tabular}




\begin{tabular}{|c|c|c|}
\hline 1932 & Shlecht \& Ackermann (GER) & Invenção da placa de pólo sintetizado. \\
\hline 1947 & Neumann (França) & Selado exitoso das baterias de níquel-cadmium. \\
\hline 1960 & Union Carbide (USA) & Desenvolvimento das primeiras pilhas alcalinas. \\
\hline 1970 & ..................... & Desenvolvimento das baterias de chumbo-ácido com válvula. \\
\hline 1990 & ....................... & Comercialização das baterias de níquel-metal hidreto. \\
\hline 1991 & Sony (Japão) & Disponibilização no mercado das baterias de lítio-íon. \\
\hline
\end{tabular}

Fonte: Batteries as a Power Source", http://batteryuniversity.com/. 10/06/2012

O físico Hans Christian Orsted publicou um trabalho em 1820 defendendo a idéia de que uma corrente elétrica passando por um fio condutor produz um efeito magnético circulando ao redor desse fio. Ele dizia que a agulha tendia a girar para um lado quando posta em cima do fio, mas tendia a girar para o outro lado quando posta embaixo do fio. Michael Faraday, se convenceu da idéia de Orsted, ou seja, de que o efeito era realmente circular. Foi a partir desta conclusão que ele desenvolveu o motor homopolar em 1821. Em princípio, o circuito fechado de um motor elétrico de Faraday é simples, podendo ser especificado como um condutor elétrico líquido (mercúrio), um ímã permanente, fiação apropriada e uma bateria, conforme se vê na Figura 2 o lado esquerdo da figura representa a versão com ímã girante em torno de uma haste fixa condutora de corrente elétrica. $O$ lado direito representa a versão contrária, de haste girante em torno do ímã fixo.
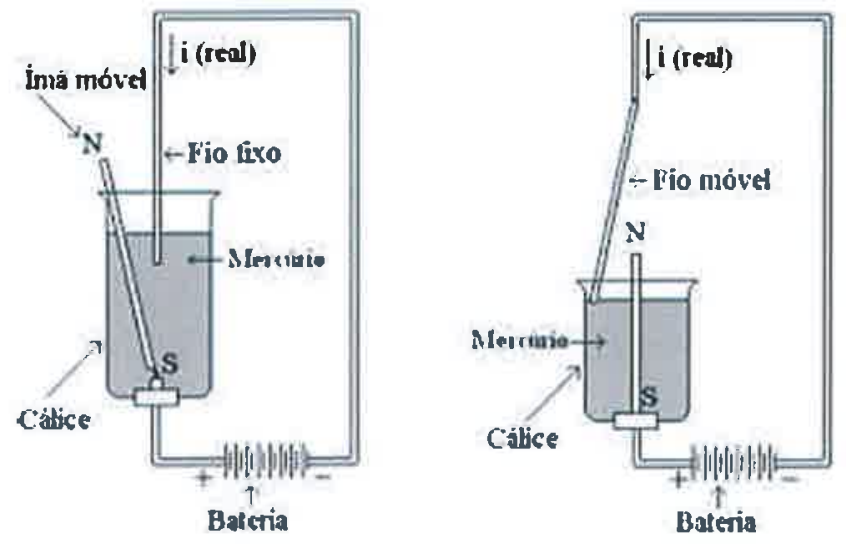

Figura 2 - O Esquema do Motor Construído por Faraday. Fonte:. Faraday, (1844)

Com a descoberta da indução eletromagnética em 1831 se demonstrou a relação íntima entre magnetismo e corrente elétrica permitindo a consolidação da tecnologia elétrica e eletrônica incluindo motores e geradores elétricos. A partir desse pressuposto, todas as descobertas relacionadas à operação de um motor elétrico subsidiaram os inventores a 
pensarem na possibilidade de usar a "bateria de Volta" para acionar um motor elétrico conectado às rodas de um veículo leve.

Em contrapartida, 1859 foi considerado um marco após a descoberta de Gastón Plante introduzindo a primeira bateria recarregável de chumbo-ácido, que é a tecnologia atualmente utilizada em aquiescência à maioria das aplicações que requerem o armazenamento de energia. Dessa forma, com a invenção das baterias recarregáveis e seu posterior desenvolvimento por Camille Aphonse Faure, aumentando a capacidade de tais baterias, conduzindo à produção em escala industrial, possibilitou em 1881 a proliferação de veículos elétricos autônomos.

Os primeiros veículos elétricos foram desenvolvidos em torno de 1830 utilizando baterias não recarregáveis. Com o advento das baterias recarregáveis os veículos elétricos foram lançados comercialmente no final do século XX, de acordo com Larminie \& Lowry (2003).

Em função dos aspectos observados, o aparecimento do veículo elétrico ocorre em função do surgimento de dispositivos práticos de estocagem de energia elétrica através dos chamados acumuladores de energia (baterias) que, combinados com a descoberta de métodos de conversão de energia elétrica para mecânica, forneceram a possibilidade de um método novo, silencioso e limpo de propulsão.

Ao mesmo tempo, segundo Bottura (1986), em 1837, Robert Davison Aberdeen construía na Inglaterra a primeira carruagem elétrica. $O$ veículo era movido por uma bateria rústica de ferro-zinco, e impulsionado por um motor elétrico, já contendo todos os elementos básicos empregados nos modernos veículos elétricos.

$\mathrm{Na}$ mesma época, outras baterias foram desenvolvidas como, por exemplo, a bateria de ferro-zinco. Em 1901, Thomas Edison, interessado no potencial dos veículos elétricos, desenvolveu a bateria níquel-ferro, com capacidade de armazenamento $40 \%$ maior que a da bateria de chumbo, só que com custo de produção muito mais elevado. As baterias níquelzinco e zinco-ar foram também criadas no final do século XIX (BARAN e LEGEY, 2011).

Assim, o primeiro veículo elétrico (um triciclo) a utilizar a bateria de chumbo-ácido, desenvolvida por Planté, como fonte de energia foi demonstrada na França por Mr. Trouvé, em 1881. Neste período, outros triciclos elétricos com baterias de chumbo também foram apresentados nos EUA e Reino Unido. Neste contexto, vale lembrar que apenas em 1885, o alemão Karl Benz demonstrou o primeiro veículo movido à combustão, o Pantentmotorwagen (HOYER, 2008). 
$\mathrm{Na}$ França, experiências eram realizadas por Charles Jeantaud e Raffard, enquanto Werner Siemens, na Alemanha, aperfeiçoava o motor elétrico. Nessa vertente, se por um lado, o carro a vapor começava a se impor, principalmente na área do transporte coletivo, o veículo elétrico mostrava-se ideal no trânsito urbano, por não emitir ruídos e por ter um sistema de tração que não poluía o ambiente (BOTTURA, 1986).

Por não envolverem qualquer tipo de combustão, os automóveis elétricos estavam livres de fuligem e de graxa, sendo assim muito limpos. Dispondo basicamente de um veículo com graduações para três, quatro, e até nove velocidades, não eram obrigados a carregar aquela parafernália de comandos, que era uma das características dos carros a gasolina e a vapor (LARMINIE \& LOWRY 2003).

\subsubsection{Primeiro Ciclo Analítico dos Veículos Elétricos (1837 - 1912)}

No final do século XIX, um veículo movido a bateria estabeleceu o primeiro recorde de velocidade em terra, na França. Em 1898, o belga Camille Jenatzy, em seu carro elétrico em forma de torpedo, o "La Jamais Contente tornou-se o primeiro carro a ultrapassar os 100 quilometros por hora". (LARMINIE \& LOWRY, 2003). A Figura 3 contempla o modelo projetado pelo belga, em seu carro elétrico em forma de torpedo.

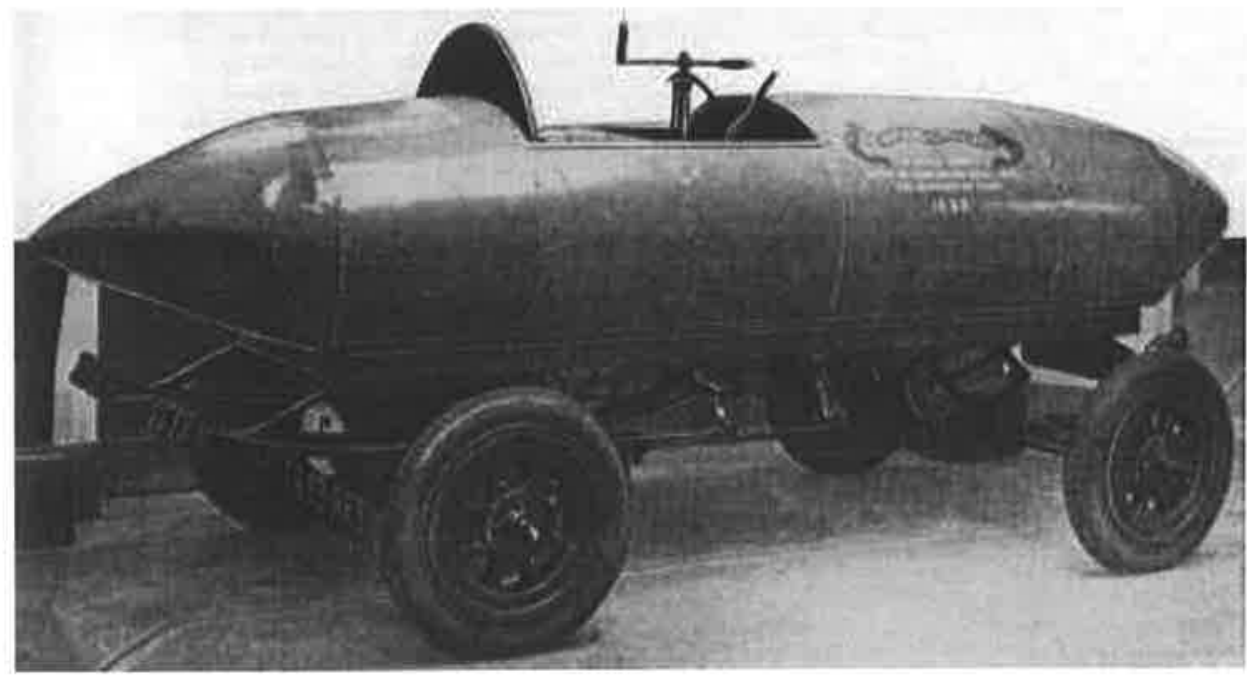

Figura 3 - "La Jamais Contente"

Fonte:. Larminie \& Lowry,2003, p.2.

Em uma escala global, a partir do ano de 1837 foi iniciada a fabricação dos veículos elétricos, a seguir podemos observar a sua evolução: 
- 1837

- O escocês Robert Davidson é o responsável por desenvolver a primeira locomotiva elétrica;

- 1881

- William Ayrton e John Perry construíram o primeiro triciclo elétrico com rodas traseiras, sendo a direita movida por um motor elétrico de meio cavalo de potência com dez células de ácido e chumbo e a capacidade de $1 \frac{1}{2} \mathrm{kWh}$;

- 1890

- William Morrison idealizou o primeiro transporte coletivo elétrico. A carga do motor era regulada através de interruptores que controlavam o número de células de baterias ativas;

- 1897

- Walter Bersey Hummingbird concebeu os primeiros táxis elétricos operados em Londres com motores Lundell com 3,5 cv de potência;

- Henry Morris inspirado no modelo Electrobat original em uma versão melhorada com menos da metade dos $1930 \mathrm{~kg}$ adaptou esse novo veículo para táxi. Os pneus insufláveis substituíram as rodas de ferro do modelo inicial;

- O coronel Albert Pope decidiu entrar no mercado de carruagens lançando a Landaulet com um motor elétrico com 2 cv de potência;

- 1899

- O belga Camille Jenatzy ficou famoso por ter concebido o veículo mais veloz do planeta (La Jamais Contente). A carroceria feita em liga leve de alumínio tungstênio e magnésio tinha uma forma aerodinâmica fazendo lembrar um torpedo. Dois motores elétricos Postel-Vinay de $34 \mathrm{cv}$ (cada um com o dobro da potência em pico) ligavam-se diretamente às rodas traseiras, podendo funcionar em série ou em paralelo (peso: $1500 \mathrm{Kg}$ );

- 1900

- Surge o primeiro Porsche elétrico, primeiro projeto automóvel completado por Ferdinand Porsche . Feito em madeira, incorporou pela primeira vez na história motores montados diretamente nas rodas com $3.5 \mathrm{cv}$ (7 de pico cada), eliminando as complexas transmissões e aumentando drasticamente a eficiência energética ( a primeira patente de um motor-in-wheel é da autoria de Wellington, (peso: $1130 \mathrm{Kg}$ ); 
- 1902

- Desponta o então Electric Runabout, primeiro Studebaker elétrico. O motor estava suspenso do chassis e tinha uma transmissão ao eixo traseiro por corrente. Um dos primeiros proprietários foi Thomas Edison (peso: $612 \mathrm{Kg}$ );

- 1908

- O Ommibus, o autocarro elétrico de $2500 \mathrm{~kg}$ feito pela Studebaker, tinha a capacidade para 14 passageiros, 2 motores de $1 \mathrm{cv}$ cada e $20 \mathrm{~A}$ e uma bateria com 40 células. A Studebaker fez também ambulâncias, furgonetas e camionetas elétricas com capacidade de carga de até $4500 \mathrm{~kg}$;

- 1911

- A Baker Electric Motor Vehicle Company (1897-1915) fundada por Walter Baker e sedeada em Cleveland (EUA) foi uma das marcas de carros elétricos mais populares da era dourada do veículo elétrico. Este modelo orgulhava-se de ter batido o recorde de distância percorrida entre recargas, com $393,5 \mathrm{Km}$, utilizando as inovadoras baterias de níquel-ferro;

Schiffer (1994) ressalta que o carro elétrico alimentado por baterias recarregáveis parecia ter um grande futuro há cerca de um século atrás. Dos 4192 carros produzidos nos EUA em $190028 \%$ eram elétricos. Alguns dos inventores mais prestigiosos, incluindo Thomas Edison, promoviam os carros elétricos ou tomavam parte do seu desenvolvimento. $\mathrm{E}$ as primeiras indústrias a produzir carros em série estavam manufaturando carros elétricos. No início do século $\mathrm{XX}$, carros elétricos, a vapor e a gasolina competiam mais ou menos em condições de igualdade. Muitos analistas da época acreditavam que cada tipo de carro iria encontrar o seu próprio "espaço de atuação" e que iriam coexistir indefinidamente. Entretanto, ao final dos anos 20, o carro elétrico era um produto comercialmente morto. $\mathrm{O}$ carro movido a gasolina havia conquistado todo o espaço com sua impressionante velocidade, desempenho e acabamento."Um tropeço espetacular" extraído de "The electric automobile in America". A Tabela 2 mostra esquematicamente, análise de desempenhos alcançados em cada ano pelos respectivos veículos elétricos parametrizados em velocidade, autonomia, bateria, potência e tensão no período áureo relativo ao $1^{\circ}$ ciclo que se encaixa de (1837 a 1912). 
Tabela 2 - Evolução dos veículos elétricos entre (1837 - 1912)

\begin{tabular}{|c|c|c|}
\hline Ano & Velocidade & Autonomia \\
\hline 1837 & $6 \mathrm{Km} / \mathrm{h}$ & $2 \mathrm{Km}$ \\
\hline 1881 & $15 \mathrm{Km} / \mathrm{h}$ & $40 \mathrm{Km} / \mathrm{h}$ \\
\hline 1890 & $14 \mathrm{Km} / \mathrm{h}$ & $23 \mathrm{Km}$ \\
\hline 1897 & $15 \mathrm{Km} / \mathrm{h}$ & $48 \mathrm{Km}$ \\
\hline 1897 & $32 \mathrm{Km} / \mathrm{h}$ & $40 \mathrm{Km}$ \\
\hline 1897 & $24 \mathrm{Km} / \mathrm{h}$ & $50 \mathrm{Km}$ \\
\hline 1899 & $105,8 \mathrm{Km} / \mathrm{h}$ & \\
\hline 1900 & $58 \mathrm{Km} / \mathrm{h}$ & \\
\hline 1902 & $21 \mathrm{Km} / \mathrm{h}$ & $64 \mathrm{Km}$ \\
\hline 1908 & $16 \mathrm{~km} / \mathrm{h}$ & \\
\hline 1911 & $37 \mathrm{Km} / \mathrm{h}$ & $60 \mathrm{Km}$ \\
\hline
\end{tabular}

\begin{tabular}{|c|}
\hline Bateia \\
\hline Zinco-ácido \\
\hline Chumbo \\
\hline 24 células \\
\hline Chumbo \\
\hline \\
\hline 44 células \\
\hline \\
\hline Chumbo \\
\hline Ni-Fe \\
\hline 40 células \\
\hline Ni-Fe \\
\hline
\end{tabular}

\begin{tabular}{|c|c|c|}
\hline \multicolumn{3}{|c|}{ Motor (Potência / Tensão Tipo) } \\
\hline $5 \mathrm{KW}$ & & \\
\hline $0,37 \mathrm{KW}$ & $20 \mathrm{~V}$ & MCC \\
\hline $3 \mathrm{KW}$ & $58 \mathrm{~V}$ & \\
\hline $2.6 \mathrm{KW}$ & & \\
\hline $2 \times 1,1 \mathrm{KW}$ & & \\
\hline $1.5 \mathrm{KW}$ & & \\
\hline $2 \times 50 \mathrm{KW}$ & $200 \mathrm{~V}$ & MCC \\
\hline $2 \times 5,15 \mathrm{KW}$ & $80 \mathrm{~V}$ & \\
\hline $1 \mathrm{KW}$ & $40 \mathrm{~V}$ & \\
\hline & $40 \mathrm{~V}$ & \\
\hline $6 \mathrm{KW}$ & $84 \mathrm{~V}$ & \\
\hline
\end{tabular}

Fonte: Elaboração própria

Anderson e Anderson (2010) ressaltam que em 1900, três tecnologias de propulsão concorriam no mercado de automóveis: o carro elétrico, a vapor, e o veículo movido à gasolina. O mercado era dividido sem indicação clara de que tipo de tecnologia iria dominar. Os veículos movidos a vapor tinham velocidade e eram preponderantemente menos caros, mas, em contrapartida, era preciso um longo tempo para aquecer a água sendo necessárias paradas freqüentes para repor a água o que dificultava sem inviabilizar a introdução da tecnologia.

Ainda, conforme Larminie \& Lowry (2003), logo no início do desenvolvimento de veículos elétricos, um motor de combustão interna que acionava um gerador e é usado juntamente com um ou mais motores elétricos era chamado de veículo híbrido.

No sentido de aumentar as eficiências ambiental e energética do sistema e a qualidade de vida das populações, em 1900 também surge o primeiro veículo híbrido adaptado por Ferdinand Porsche, outro modo complementar e alternativo, se apresentando como estratégia de sustentabilidade ambiental e energética com uma configuração de série em que o motor de combustão apenas gera eletricidade, não estando mecanicamente ligado às rodas. Reduzindo o tamanho das baterias, foram utilizados 2 motores de combustão monocilíndricos de Dion Bouton arrefecidos à água, de 2,7 cv cada um. Estes geravam independentemente 2,5 cv de potência $(20 \mathrm{~A}, 90 \mathrm{~V})$ exclusivamente para alimentar os dois motores-in-wheel carregando as baterias com o excedente. Isso possibilitava uma autonomia maior. Como desvantagem, o seu 
peso de $1.200 \mathrm{Kg}$ danificava os pneus. Atingia a velocidade de $35 \mathrm{Km} / \mathrm{h}$. Em 2007 foi feita uma réplica funcional deste veículo.

O carro movido a gasolina além de poluir era mais difícil de dar a partida e moderadamente mais caro, mas sua principal vantagem era proporcionar subsídios para viagem a longas distâncias a uma velocidade razoável, sem parar. Os veículos elétricos não poluíam e eram silenciosos mas eram lentos e caros. Cada tecnologia tinha como vantagem competitiva no mercado aberto, ter um desempenho e um custo que resultasse em desenvolvimento para o mercado automotivo.

De acordo com Schiffer (1994), a eletricidade preenche melhor os requisitos de um sistema de tração do que as máquinas a vapor ou mesmo os motores a explosão.

Dentro dos diferentes estágios do ciclo de vida do veículo elétrico, a cada ano era acompanhado a derrocada desta tecnologia veicular. Já em 1903, havia cerca de quatro mil automóveis registrados na cidade de Nova Iorque, sendo 53\% a vapor, $27 \%$ a gasolina e $20 \%$ elétricos. No tocante a Londres, em 1903 havia uma quantidade maior de veículos elétricos que veículos com motores à combustão interna, porém a situação não prosseguiu por muito tempo.

Ocasionalmente, por volta de 1905, o veículo movido a gasolina começou a se sobressair com relação aos veículos elétricos em questão. A autonomia de 63 milhas (cerca de $100 \mathrm{~km}$ ) alcançada pelo veículo à combustão era mais que o dobro da autonomia de um carro elétrico (30 milhas ou seja, aproximadamente $50 \mathrm{~km}$ ). O investimento inicial assim como o custo operacional dos automóveis elétricos era maior que os movidos à gasolina. Os números disponíveis indicam que em 1.900, os carros a gasolina custavam entre US $\$ 1.000,00$ e US $\$ 2.000,00$ enquanto que um carro elétrico custava de US $\$ 1.250,00$ a US $\$ 3.500,00$. O custo operacional de um carro a gasolina era de U\$0.01/milha passando para US\$0.02 a 0.03/milha para um carro elétrico. Em 1901, foram descobertos no Texas, grandes campos de petróleo fazendo cair os custos do mesmo tornando-se uma vantagem competitiva sustentável.

Todavia, em 1912, a frota de carros elétricos nos Estados Unidos atingiu o ápice de 30 mil unidades, a quantidade de automóveis à gasolina já era trinta vezes maior beirando 900.000 unidades (STRUBEN e STERMAN 2006). Nesse mesmo período entre 1900 e 1912, surgiram iniciativas na busca da melhoria da distância percorrida e do desempenho dos veículos elétricos por meio da adoção da configuração híbrida. 
Com base nas premissas apresentadas a trajetória dos carros elétricos seguiu em forte queda. Entre os principais fatores apontados para o declínio dos carros elétricos a partir de então, pode-se citar (DOE, 2009):

I. A vantagem competitiva conquistada pelo desenvolvimento do sistema de produção em série, por Henry Ford, permitiu um incremento na fabricação dos carros movidos à combustão. Por volta de 1909 a produção de carros elétricos produzidos caiu consideravelmente, cerca de $4.4 \%$ do número de carros movidos à combustão como apresentado na Tabela 3;

Tabela 3 - Número de veículos construídos nos EUA no início do século XX

\begin{tabular}{|c|c|c|}
\hline Ano & Elétricos & Gasolina \\
\hline 1899 & 1.575 & 936 \\
\hline 1904 & 1.425 & 18.699 \\
\hline 1909 & 3.826 & 120.393 \\
\hline 1914 & 4.669 & 564.385 \\
\hline 1919 & 2.498 & 1.649 .127 \\
\hline 1924 & 391 & 3.185 .490 \\
\hline 1929 & 757 & 4.454 .421 \\
\hline 1933 & - & 1.560 .599 \\
\hline
\end{tabular}

Fonte: Adaptado pelo autor de Bottura, (1986)

II. Eliminação da manivela utilizada para acionar os veículos movidos à combustão. Invenção da partida elétrica, em 1912, (ANDERSON e ANDERSON, 2010);

III. Em meados do ano de 1920, as rodovias dos Estados Unidos já interligavam diversas cidades, o que demandava veículos capazes de percorrer longas distâncias (DOE 2012);

IV. As descobertas de petróleo no Texas reduziram o preço da gasolina, tornando-a um combustível atrativo para o setor de transportes (YERGIN, 1991).

V. Desenvolvimento de técnicas de destilação em regime contínuo e o conseqüente barateamento dos derivados de petróleo resultam na ampliação do desenvolvimento tecnológico da indústria automobilística dirigido para os veículos movidos à gasolina (BOTTURA, 1986). 
Um exemplo marcante de conjunto de soluções para a sustentabilidade em mobilidade na época consta na Figura 4, o modelo Lohner-Wagen, o carro elétrico projetado por Porsche no século XX com dois motores acoplados às rodas dianteiras.

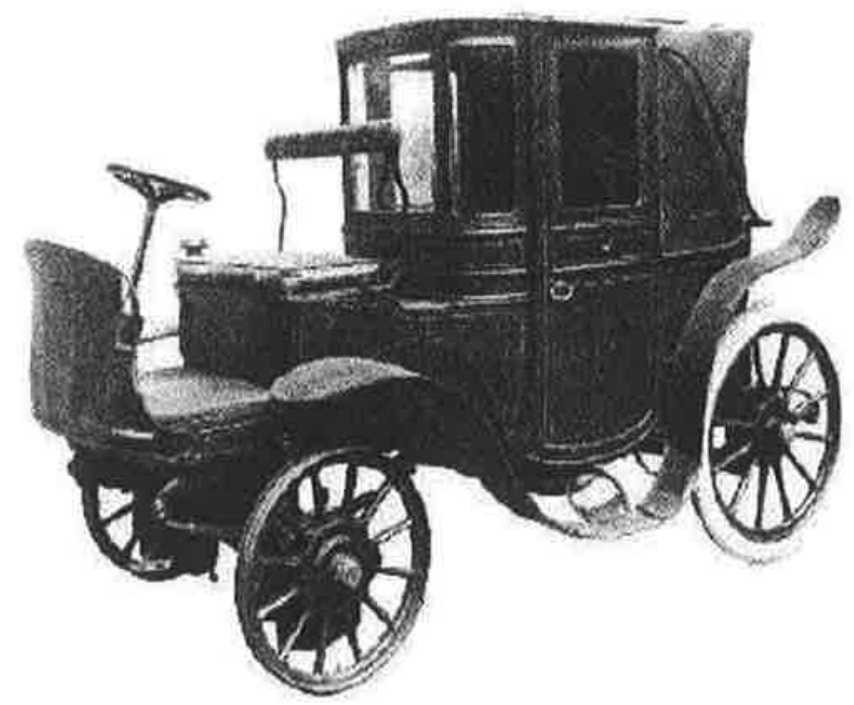

Figura 4 - Porsche Lohner-Wagen

Fonte: Westbrook, (2001), p.17

Porsche foi considerado o precursor dos veículos híbridos, desenvolveu o Mixt-Wagen visto na Figura 5. Nesse veículo, um motor à gasolina acionava um gerador responsável pela recarga das baterias que por sua vez ofereciam a potência necessária para os motores elétricos localizados nas rodas dianteiras.

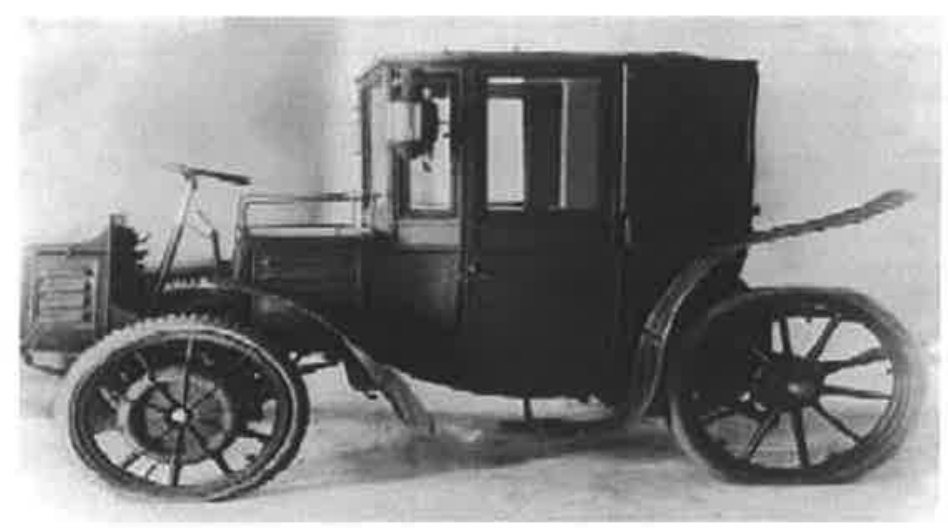

Figura 5 - Um dos primeiros veículos híbridos chamado Mixt-Wagen Fonte:. Westbrook, (2001), p.17 


\subsubsection{Segundo Ciclo Analítico dos Veículos Elétricos (1912 - 1973)}

Após as descobertas de campos de petróleo, os veículos a gasolina e posteriormente, a diesel, rapidamente atingiram níveis de desempenho que resultavam em uma velocidade, uma aceleração maior e um peso menor comparado aos veículos elétricos. A indústria petrolífera desenvolveu-se com supremacia a um ponto que praticamente todos os seus produtos derivados passaram apresentar vantagem de custo pelo consumo em alta escala.

Mesmo na Inglaterra sendo comercializado o Brougham, de Partridge Wilson, movido por uma bateria de $60 \mathrm{~V}$ e $34 \mathrm{Ah}$, que possibilitava uma velocidade de $51,5 \mathrm{Km} / \mathrm{h}$ e um raio de ação de $97 \mathrm{~km}$ por carga de bateria, as vendas foram mínimas (Barreto, 1986). A Figura 6 mostra o modelo Light Electric fabricado pela Milburn Wagon Company.

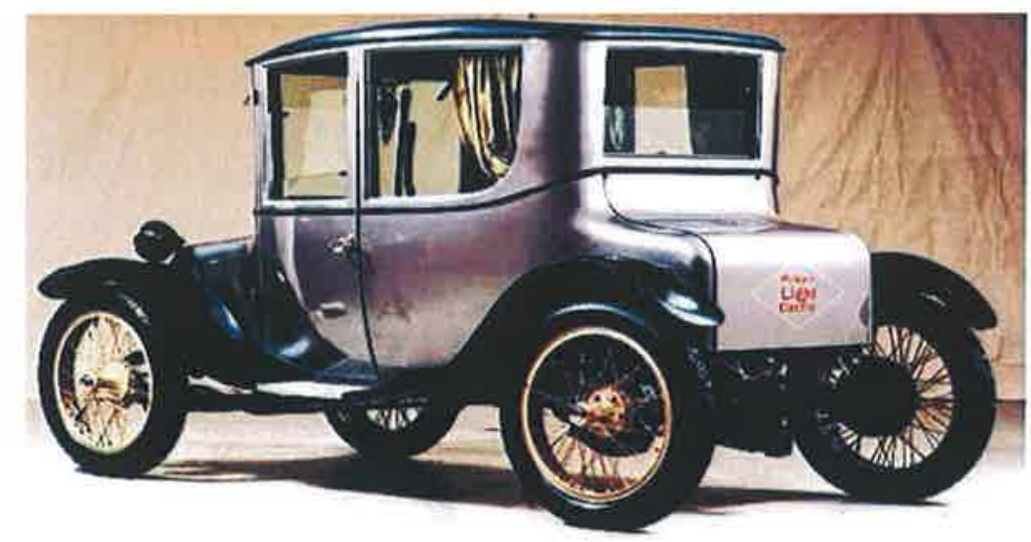

Figura 6 - Modelo Light Electric fabricado pela Milburn Wagon Fonte:. Westbrook, (2001), p.20

Com base nessas premissas, já iniciando o $2^{a}$ ciclo por volta de 1912 , ressurgiu o entusiasmo pelo carro elétrico acompanhando o aparecimento de alguns desenvolvimentos técnicos. Thomas Edison havia aperfeiçoado e realizado os primeiros testes utilizando as baterias de níquel-ferro, que tiveram um aumento de $35 \%$ na capacidade de armazenamento entre 1910 e 1925. A vida útil destas baterias também aumentou ao mesmo tempo em que os custos de manutenção diminuíram. 
No entanto, este ressurgimento foi mais marcante na área de pequenos caminhões de entrega em companhias que possuíam frotas ao redor de 60 veículos e que poderiam ter suas próprias centrais de recarga de baterias.

Ainda em 1912, o advento do motor de arranque elétrico para os veículos a explosão tornou estes carros ainda mais atraentes.

Vale ressaltar, que os produtores de gasolina não conseguiam acompanhar o crescimento da demanda e consequentemente os preços do petróleo começaram a aumentar. Um barril de petróleo na época custava cerca de US\$0.65, na virada do século XX passou para US\$2.35, no ano de 1913. A Ford, no entanto, começou a produzir veículos a gasolina, em série na primeira linha de montagem industrial, na planta de Highland Park no mesmo ano.

O advento da Primeira Guerra Mundial em 1914 provocou o aumento dos preços do petróleo e aumentou ainda mais o otimismo nos carros elétricos. Mas apesar dos esforços comerciais e de marketing, o número de caminhões elétricos caiu de 10\% em 1913 para apenas 3 a 4\% em 1925, conforme Schiffer (1994).

Adiante consta descrito as características, as vulnerabilidades e potencialidades decorrentes da introdução dos veículos elétricos:

\section{- 1915}

- O modelo Light Electric tinha autonomia de $160 \mathrm{~km}$ e uma velocidade máxima de 25 ou $30 \mathrm{~km} / \mathrm{h}$. Já o Sedan de 1918 tinha uma autonomia de 160 $\mathrm{km}$ e uma velocidade máxima de $50 \mathrm{~km} / \mathrm{h}$. A partir daquele ano, as baterias começaram a possuir um invólucro para as baterias providas de roletes, o que facilitava as trocas rápidas;

- 1916

- Surge o modelo de carruagem Rauch e Lang. Tal como Woods, dispunha de comandos duplicados para permitir a condução nos bancos dianteiros ou traseiros, permitindo selecionar 6 velocidades dianteiras e três em marcha atrás;

- 1917

- Os veículos da Detroit Electric eram oferecidos sob a garantia de autonomia de $160 \mathrm{~km}$ de carga, o dobro oferecido pelas baterias de chumbo. Em vez de volante e acelerador, esses veículos possuíam duas alavancas, uma de direção e a outra para regular a velocidade. Recentemente, apropriadamente 2008, a 
marca foi retomada por um investidor chinês para fabricar veículos elétricos na Europa.

Consideravelmente, até o final da Segunda Guerra Mundial em 1945, a produção de modelos elétricos de grande difusão cessou, pois, durante este período este tipo de veículo era irrelevante, e no entre-guerras não havia condições financeiras nem a possibilidade de os fabricar. No entanto, nomeadamente na França ocupada, a ausência generalizada de combustíveis levou alguns pequenos construtores a desenvolverem carros elétricos mesmo com a racionalização da energia, pois, o carregamento ocorria a noite.

- 1941

- Paris-Rhone, um carro clássico, com valor de compra compatível a época tinha 3 rodas de tração e foi produzido entre 1941-1950 (peso: $210 \mathrm{Kg}$ );

- Compagnie Générale d'Électricités foi um veículo que surgiu através de uma iniciativa governamental francesa. Tinha características peculiares, com uma caixa de 4 velocidades. Por se estar em guerra nesse ano e haver pouco aço disponível, os chassis eram em alumínio e dispunha de um sistema de frenagem regenerativa (peso: $460 \mathrm{Kg}$ );

- 1947

- Dois anos após o final da $2^{\mathrm{a}}$ Guerra Mundial, a Nissan apresentou o seu primeiro carro elétrico, o chamado Tama de 4 lugares. Vale relembrar que a antiga fábrica de aviões (Tachikawa) foi renomeada "Carros Elétricos de Tóquio", e seguidamente chamou-se Companhia de Automóveis Price, que realizou uma parceria com a Nissan (peso: $975 \mathrm{Kg}$ );

Em termos gerais, os anos entre 1920 e 1970 foram uma época de queda constante dos automóveis elétricos. Numa escala global, a depressão da década de 1930, seguida pela Segunda Guerra Mundial, prejudicou um possível ressurgimento dos veículos elétricos e novos experimentos com veículos movidos a combustíveis alternativos. Naquele período, poucos trabalhos e pesquisas científicas foram elaborados para veículos elétricos. Mesmo no período de prosperidade econômica do pós-guerra, os projetos de veículos elétricos permaneceram guardados diante da pouca preocupação com segurança energética da época, devido à existência de combustível abundante e barato e veículos com MCI maiores e mais rápidos (ANDERSON e ANDERSON, 2010). 
- 1960

- Pioneer foi produzido pela Nicl-Silver Battery Company de Santa Ana, na Califórnia. Este veículo possuía 2 lugares descapotável em fibra de vidro e com tração elétrica. A bateria era desenvolvida por essa empresa e tinha 2 motores ligados a cada roda traseira. $\mathrm{O}$ acelerador tinha 2 posições, ligando o motor a $24 \mathrm{~V}$ ou a $48 \mathrm{~V}$ (peso: $270 \mathrm{Kg}$ );

Nos Estados Unidos, um exíguo renascimento dos veículos elétricos aconteceu na década de 60. A tecnologia dos carros era básica, com motores de corrente contínua com escovas. Porém, em termos de acumuladores de energia havia alguma variedade, além das normais de chumbo-ácido, havia as de chumbo-cobalto e as de níquel-cádmio.

- 1960

- Electro Dyne, um pequeno carro de 2 lugares era fabricado na Califórnia em 1960 adequando-se ao cotidiano (peso: $425 \mathrm{~kg}$ );

- 1961

- Electra King era um pequeno carro básico fabricado pela californiana B \& Z Electric Car Company. Tinha 3 rodas (uma à frente) e 2 lugares (peso: $305 \mathrm{~kg}$ );

- 1966

- Mars I foi o primeiro carro transformado em elétrico, um Renault Dauphine;

- 1967

- Ford Comuta foi desenhado na Inglaterra, contendo 2 motores elétricos, perfazendo $5 \mathrm{cv}$ e 4 baterias de $12 \mathrm{~V}$. O Focus elétrico fabricado em 2010 mostra a evolução com o passar dos anos deste carro;

- 1968

- Delta, este pequeno carro foi o precursor dos tratores elétricos de jardim fabricados pela General Electric (GE) na década de 70 (motor corrente contínua);

Concretamente, a tecnologia de tração elétrica voltou a ser pouco explorada, retornando o seu desenvolvimento a partir dos anos 60 quando o veículo elétrico foi visto como uma saída para superação de problemas ambientais ocasionados por emissões provenientes aos veículos movidos a combustão. Vale ressaltar que a maioria dos veículos elétricos produzidos na década de 60 foi decorrente da conversão de veículos convencionais. 


\section{- 1969}

- Gulton-American Motors foi outra criação do "pai dos carros híbridos", Victor Wouk, tratava-se de um carro puramente elétrico;

A partir da década de 1970 , com a eclosão e agravamento da crise do petróleo, as discussões em torno da problemática ambiental nos grandes centros urbanos tornou-se um fator preocupante para os dirigentes governamentais. $\mathrm{O}$ veículo elétrico passou a ser considerado como alternativa energética principalmente em países com muita geração hidroelétrica ou termoelétrica a base de carvão. Houveram diversas iniciativas de inserí-los novamente ao mercado no período, mas nem os automóveis elétricos puros, nem os híbridos, estavam aptos a competir no mercado com os automóveis convencionais que detinham uma vantagem competitiva sustentável (BARAN e LEGEY, 2011).

- 1971

- Fabricado o Mitsubishi Minica elétrico. Foram destinadas 150 unidades deste veículo para departamentos governamentais e empresas de eletricidade;

- 1972

- BMW 1602 Electric foi produzido para os jogos olímpicos em Munique, de modo a poder seguir as competições sem emissão de poluentes para os atletas. A autonomia era escassa, mas suficiente para cumprir a maratona;

- 1973

- Cerca de 120 Enfields foram construídos na ilha de Wight, ao Sul da GrãBretanha, a maioria sendo usada pelas empresas de eletricidade do sul da Inglaterra (energia da bateria: $21 \mathrm{KW} / \mathrm{h}$ );

- Electra Spider foi fabricado através de uma conversão americana do FIAT 850 Spider. Usava 3 motores elétricos e um conversor de potência que os ligava às rodas traseiras. Porém, as baterias de chumbo faziam deste, um carro pesado. Dispunha de frenagem regenerativa, o controle era efetuando ligando 1, 2 ou 3 motores como geradores (peso: $1290 \mathrm{Kg}$ ); 
Assim, os desempenhos alcançados em cada ano pelos respectivos veículos elétricos parametrizados em velocidade, autonomia, bateria, potência e tensão relativo ao $2^{\mathbf{o}}$ ciclo que se enquadra de (1912 a 1973) são resumidamente apresentados na Tabela 4.

Tabela 4 - Evolução dos veículos elétricos entre (1912 - 1973)

\begin{tabular}{|c|c|c|}
\hline Ало & Velocidade & Autonomia \\
\hline 1915 & $50 \mathrm{Km} / \mathrm{h}$ & $161 \mathrm{Km}$ \\
\hline 1916 & $42 \mathrm{Km} / \mathrm{h}$ & $60 \mathrm{Km}$ \\
\hline 1917 & $40 \mathrm{Km} / \mathrm{h}$ & $340 \mathrm{Km}$ \\
\hline 1941 & $60 \mathrm{Km} / \mathrm{h}$ & $50 \mathrm{Km}$ \\
\hline 1947 & $75 \mathrm{Km} / \mathrm{h}$ & $65 \mathrm{Km}$ \\
\hline 1960 & $70 \mathrm{Km} / \mathrm{h}$ & $160 \mathrm{Km}$ \\
\hline 1961 & $50 \mathrm{Km} / \mathrm{h}$ & $55 \mathrm{Km}$ \\
\hline 1966 & $100 \mathrm{Km} / \mathrm{h}$ & $210 \mathrm{Km}$ \\
\hline 1967 & $60 \mathrm{Km} / \mathrm{h}$ & $60 \mathrm{Km}$ \\
\hline 1968 & $85 \mathrm{Km} / \mathrm{h}$ & $190 \mathrm{Km}$ \\
\hline 1972 & $60 \mathrm{Km} / \mathrm{h}$ & $140 \mathrm{Km}$ \\
\hline 1973 & $85 \mathrm{Km} / \mathrm{h}$ & $60 \mathrm{Km}$ \\
\hline
\end{tabular}

\begin{tabular}{|c|}
\hline Bateia \\
\hline Chumbo \\
\hline Chumbo \\
\hline Ni-Fe \\
\hline Chumbo \\
\hline Chumbo \\
\hline Chumbo \\
\hline Chumbo \\
\hline Pb-Co \\
\hline Chumbo \\
\hline Ni-Cd \\
\hline Chumbo \\
\hline Chumbo \\
\hline
\end{tabular}

\begin{tabular}{|c|c|c|}
\hline \multicolumn{3}{|c|}{ Motor (Potência / Tensão Tipo) } \\
\hline $32 \mathrm{KW}$ & $76 \mathrm{~V}$ & \\
\hline $1.8 \mathrm{KW}$ & $80 \mathrm{~V}$ & \\
\hline & & \\
\hline & $96 \mathrm{~V}$ & \\
\hline & $36 \mathrm{~V}$ & \\
\hline $2 \times 6 \mathrm{KW}$ & $48 \mathrm{~V}$ & \\
\hline $2 \times 6 \mathrm{KW}$ & $48 \mathrm{~V}$ & MCC \\
\hline $57 \mathrm{KW}$ & $120 \mathrm{~V}$ & $\mathrm{MCC}$ \\
\hline $3.7 \mathrm{KW}$ & $48 \mathrm{~V}$ & \\
\hline & & MCC \\
\hline $32 \mathrm{KW}$ & $144 \mathrm{~V}$ & \\
\hline $3 \times 2,5 \mathrm{KW}$ & $48 \mathrm{~V}$ & \\
\hline
\end{tabular}

Fonte: Elaboração própria

Por sua importância e relevância para esse estudo, como uma espécie de medida complementar, ao visualizar a tabela acima, um dos principais pontos impactantes pela não introdução dos veículos elétricos no mercado era decorrente de sua pequena autonomia (entre 50 a $100 \mathrm{~km})$, velocidade média reduzida $(50$ a $100 \mathrm{Km} / \mathrm{h}$ ) conforme observado nas tabelas anteriores, demora na recarga de baterias (em torno de 8 horas) e falta de infra-estrutura de atendimento ao usuário.

Segundo Valle Real e Balassiano (2002), basicamente, existem dois caminhos a serem tomados. O primeiro deles seria tornar os veículos mais eficientes do ponto de vista do consumo energético (bem como para a quantidade de emissões), e em segundo lugar, por meio de restrições e adoção de taxas específicas, levar o usuário a diminuir o uso do automóvel particular e demais veículos automotores.

\subsubsection{Terceiro Ciclo Analítico dos Veículos Elétricos (1974 - 1996)}

Além de menos poluente (dependendo do tipo de energia que é utilizada), os carros elétricos fabricados e convertidos ao final da década de 60 utilizavam certas técnicas de 
conservação na tentativa de aumentar sua autonomia e velocidade máxima. Era prioritário que estes veículos procurassem alcançar o patamar de desempenho oferecido pelos veículos movidos à combustão, cujo desenvolvimento tinha sido significativo durante todo o século.

Concretamente, por volta do ano de 1973, a crise do petróleo associada ao embargo imposto pela OPEP, trouxeram novas perspectivas para os carros elétricos, no entanto, os EUA dependiam significativamente do petróleo dos países árabes e o Congresso americano estava determinado a reduzir esta dependência. Havia também uma motivação econômica dada pela balança comercial americana. As questões ambientais não eram efetivamente críticas, pois não se considerava que apenas o uso de carros elétricos fosse melhorar a qualidade do ar, de acordo com Schiffer (1994). O interesse pelos veículos elétricos aumentou de forma considerável somente no final dos anos 1980, quando o problema de poluição do ar das grandes cidades passou a ser debatido com mais freqüência (Delucchi e Lipman, 2010). Com relação ao Brasil não se pode esquecer a fundamental importância do engenheiro João Augusto Conrado do Amaral Gurgel (1926-2009) em produzir o primeiro carro elétrico brasileiro, o Itaipu, em 1974, com autonomia de $60 \mathrm{~km}$.

De maneira geral nesta época, os avanços na eletrônica possibilitaram um aumento na eficiência dos motores de combustão e, no Brasil, ainda cabe citar o sucesso do programa governamental "Proálcool", inviabilizando comercialmente a produção de veículos elétricos.

Cada ciclo descrito tem sua peculiaridade de expansão e desenvolvimento. Qualquer adaptação de tecnologia deverá ser apontado. Abaixo consta as descrições referentes ao $3^{\circ}$ ciclo:

- 1974

- O Witcar (carro branco em holandês) foi fabricado justamente para o projeto de "aluga-se um carro elétrico". Era composto por 5 estações onde os 35 carros eram carregados e os 4500 usuários registrados poderiam levar o carro utilizado. $O$ projeto deveria ter crescido ao longo dos anos para 150 estações e 1000 veículos, mas isso nunca chegou a acontecer. O usuário introduzia um código no sistema, que permitia liberar o carro e debitar diretamente o custo na conta bancária. $\mathrm{O}$ carro levava 2 pessoas a uma baixa velocidade, tinha pouca autonomia e demorava muito tempo a carregar, operação que era feita enquanto estava parado na estação. Um ponto relevante era a localização das estações e toda a logística, pois, os carros normalmente eram levados para onde não havia procura (energia das baterias: $1.3 \mathrm{KWh}$ e peso: $400 \mathrm{Kg}$ ); 
- Zagato Zele/Elcar, um veículo pequeno construído na Itália pela Zagato, mais conhecida pelas carrocerias que fizeram para grandes e luxuosas marcas. Este carro foi projetado majoritariamente de fibra de vidro, sendo que o seu motor de 1.3 cavalos não the permitia grandes velocidades, pois, este carro era visto como perigoso (energia das baterias $7.7 \mathrm{KWh} /$ peso: $550 \mathrm{Kg}$ );

- Sebring Citicar foi produzido perante à crise do petróleo. Cerca de 4400 unidades foram fabricadas durante o período de (1974-1977) e (1978-1880), os chamados Comuta Car. Era um veículo pequeno, básico e perigoso em colisões. As várias versões foram evoluindo desde os $2.5 \mathrm{cv}$ até aos $6 \mathrm{cv}$ do modelo de 1977 (peso: $570 \mathrm{Kg}$ );

- 1976

- O Sebring Citivan foi baseado no CitiCar (versão de $6 \mathrm{cv}$ ), com um maior comprimento sendo também produzido pela Sebring-Vanguard. O motor era mais potente com 12 cavalos, continha 1 velocidade. (peso: $590 \mathrm{Kg}$ );

- 1977

- A empresa suíça Sbarro Vessa Pilcar/Carville desenvolveu o Pilcar, um citadino com carroceria de poliéster, dos quais vendeu 23 unidades. Em 1979 o nome mudou de Pilcar para Carville (energia da bateria: $20 \mathrm{KWh} /$ peso: 460 $\mathrm{kg}$;

- 1978

- O carro ElecTrek foi construído no Colorado, vendido em versões de 2 ou 4 lugares. Dispunha de frenagem regenerativa (peso: $1200 \mathrm{~kg}$ ).

- 1979

- HM Vehicles Free-Way era um carro muito pequeno de um lugar e 3 rodas. Por serem pequenos, as cores disponíveis eram muito visíveis: amarela, laranja e vermelho (peso:408 $\mathrm{kg}$ ).

- 1980

- Frua Exar, o protótipo deste veículo foi desenhado inicialmente pela BMW e construído na Itália pela Frua (empresa fabricante de carros especiais para as marcas Lamborghini, Ferrari, Maserati, etc.) e enviado para os EUA onde foi transformado em elétrico. $\mathrm{O}$ carro era extremamente aerodinâmico (consumo de energia da bateria: $110 \mathrm{Wh} / \mathrm{Km}$ ); 
- A empresa Jet Industries realizou cerca de 3000 conversões de carros elétricos durante os anos 80 . $\mathrm{Na}$ maioria o motor elétrico era acoplado às caixas de velocidade originais dos carros em que eram baseados e chamados de Electrica 007;

- Electrica Ford Escort dispunha de um motor de corrente contínua e bateria de chumbo;

- 1981

- Electrica Van Motor foi produzido também com bateria de chumbo e motor de corrente contínua ( energia da bateria: $22 \mathrm{KWh}$ );

- O Golf City Stormer MK1 foi lançado nos anos 80. A Volkswagen fabricou 20 unidades elétricas (energia da bateria: 11,5 KWh);

- 1983

- O Hope Whisper foi lançado e fabricado na Dinamarca onde foram produzidos cerca de 30 protótipos e 14 carros acabados em desenho diferente (energia da bateria: $14 \mathrm{KWh} /$ consumo de energia da bateria: $200 \mathrm{Wh} / \mathrm{Km}$ / peso: $800 \mathrm{Kg}$ );

- 1984

- O Pohlmann El foi um veículo alemão projetado para o primeiro Grande Prémio-E a ser realizado na Suíça em 1986. Foi um dos carros elétricos mais promissores da época sendo bastante aerodinâmico. $\mathrm{O}$ carro foi desenvolvido para ser comercializado, mas o elevado custo fez com que o projeto fosse abandonado (peso: $1170 \mathrm{Kg}$ );

- 1987

- O BMW E30 elétrico era um veículo equipado com baterias de sódioenxofre. Uma pequena frota destes carros foi fabricada e testada. Na fabricação foi utilizada uma caixa manual de duas velocidades;

- 1989

- A marca Citroën foi uma das que apostou incisivamente na mobilidade elétrica, tendo produzido centenas de carros, geralmente vendidos a empresas de eletricidade. Foram vendidos 13.000 carros elétricos, incluindo as versões Berlingo (1749 unidades) e Partner (6500). Antes de fabricar o veículo Berlingo ou os $\mathrm{AX}$, a Citroën já tinha produzido várias unidades dos carros C15 elétricos, esse carro foi baseado no modelo Peugeot 205 elétrico de 1984 
conservando a caixa manual de 5 velocidades (energia da Bateria: $15 \mathrm{KWh} /$ peso: $1400 \mathrm{Kg}$ );

Objetivamente, como dito anteriormente na década de 80 , interesses governamentais voltaram-se para as vantagens oriundas dos veículos movidos à propulsão veicular elétrica, principalmente devido à questão ambiental. Assim, vê-se que as medidas políticas de governo foram introduzidas mundialmente na busca da redução de emissões veiculares urbanas. $O$ principal exemplo foi o California Air Resources Board's (CARB) que, em 1990, implementava as primeiras normas regulatórias de emissão zero veicular na Califórnia. Uma série de veículos modernos foi introduzida pelas montadoras entre as décadas de 1980 e 1990 . Junto com o início da venda de veículos, tais como o General Motors EV-1, o Toyota RAV4EV e o Ford Ranger EV, diversos estudos de custos de baterias foram desenvolvidos para avaliar as perspectivas comerciais destes veículos (Delucchi e Lipman, 2010). Embora fossem mais eficientes do que os carros convencionais, essa vantagem tinha pouco valor na época quando o preço do petróleo era dos mais baixos da história (YERGIN, 1991).

- 1990

- O carro ETX-II foi uma continuação do projeto ETX-I, o estudo final deste projeto levou à conclusão de que seria utilizada uma transmissão automática de 2 velocidades às rodas traseiras. As relações destas velocidades foram selecionadas de modo a proporcionar simultaneamente velocidades elevadas. A frenagem regenerativa absorvia uma potência de $60 \mathrm{KW}$. O motor que rodava até as $11000 \mathrm{rpm}$ (peso: $1795 \mathrm{~kg}$ );

- A General Motors iniciou uma nova era para os veículos elétricos apresentando o GM Impact. Este carro tinha 2 motores ligados às rodas da frente, com $110 \mathrm{cv}$ no total e $11900 \mathrm{rpm}$ de velocidade máxima. Um destes carros modificados bateu o recorde de velocidade para veículos elétricos com $295 \mathrm{Km} / \mathrm{h}$ (energia da bateria: 13,6 KWh / peso: $1315 \mathrm{Kg}$ );

- A empresa Elcat Oy ao longo de sua história modificou inúmeros carros para funcionamento elétrico. Alguns exemplos são o Talbot Horizon, FIAT Panda, Citroën AX, Volvo 460 e os WW Carocha e Tranporter. A Elcat ficou conhecida pela transformação feita no veículo de origem japonesa (Subaru Sanbar) que resultou em um elétrico chamado Cityvan. Essa alteração se deu 
na Finlândia entre 1990 e 2002 (consumo de energia da bateria: $240 \mathrm{Wh} / \mathrm{Km}$ / peso: $1400 \mathrm{Kg}$ );

- Carbon foi um dos primeiros protótipos fabricados pela Horlacher, uma empresa Suíça fundada em 1962 e especialista em materiais compósitos e moldes para a sua produção. Todos os seus carros são otimizados em termos de peso e aerodinâmica, de modo a terem o mínimo de consumo energético (consumo de energia da bateria: $50 \mathrm{Wh} / \mathrm{Km} /$ peso: $440 \mathrm{Kg}$ );

- 1991

- O Iza era um veículo japonês, tinha quatro motores dentro das rodas. Obteve 2 recordes mundiais, o de velocidade máxima $(176 \mathrm{Km} / \mathrm{h})$ e o de distância percorrida, $270 \mathrm{Km}$ a $100 \mathrm{Km} / \mathrm{h}$ (energia da bateria de $29 \mathrm{KWh}$ );

- O Sport I foi desenhado para ser mais eficiente possível, chegando atingir uma autonomia de $547 \mathrm{~km}$ em 1992, sem efetuar o carregamento de baterias. Esse veículo percorreu $162.000 \mathrm{~km}$ com as mesmas baterias, até 1998 . Utilizava baterias Zebras de alta temperatura, as mais eficientes (consumo de energia da bateria: $180 \mathrm{Wh} / \mathrm{Km} /$ peso: $500 \mathrm{Kg}$ );

- A BMW pretendia produzir o veículo $\mathrm{E} 1 \mathrm{em}$ grande escala, mas o projeto não teve sucesso, pois o veículo pegou fogo durante um carregamento, levantando problemas de segurança. Estes foram ocasionados pelas baterias de sódioenxofre que funcionam a alta temperatura. Como a maioria dos carros da BMW, a tração era na parte traseira (energia da bateria: $29 \mathrm{KWh}$ );

- O veículo Panda Elettra foi baseado no FIAT Panda e desenvolvido pela Daimler. $\mathrm{O}$ custo era sensivelmente o dobro comparado à versão à gasolina (peso: $1050 \mathrm{Kg}$ );

- Express foi um carro produzido pela Renault a partir deste ano e usado em várias empresas, nomeadamente nos correios franceses. $\mathrm{O}$ motor, bem incorporado no eixo frontal, era pouco potente;

1992

- A segunda versão do carro produzido pela BMW, o E2 foi lançado no salão de Los Angeles sendo projetado em alumínio, o que lhe permitia um baixo peso, desenhado para o mercado americano. Enquanto o E1 foi desenvolvido na Alemanha, o E2 foi desenvolvido nos EUA;

- Cinquecento Elettra elétrico surge baseado na versão Panda, com algumas melhorias. Em 2010 foi apresentado um novo Cinquecento elétrico; 
- O City II teve um motor com melhor desempenho em comparação ao City (consumo de energia da bateria: $100 \mathrm{Wh} / \mathrm{Km} /$ peso: $550 \mathrm{Kg}$ );

- 1993

- O pequeno Hotzenblitz El-Sport foi construído por uma empresa suíça fabricante de máquinas de lavar, entre 1993 e 1996. Usava um tipo alternativo de bateria, conhecido pelo nome de "flow battery", com 2 depósitos entre os quais circula um líquido (eletrólito). Nas placas de baterias ocorre um processo de deposição do zinco e a produção de corrente elétrica. A bateria pode ser carregada de forma convencional ligando à corrente (o zinco passa novamente para o liquido) ou o liquido pode ser substituído. Foram fabricadas 120 unidades (consumo de energia da bateria: $100 \mathrm{Wh} / \mathrm{Km} /$ peso: $780 \mathrm{Kg}$ );

- O Ford Ecostar foi um veículo elétrico desenvolvido e testado nos anos 90, com 75 cavalos e baterias de sódio-enxofre. Estas baterias foram inventadas e desenvolvidas pela Ford a uma temperatura alta de $\left(300^{\circ} \mathrm{C}\right)$. Esta tecnologia era propensa a incêndios durante os carregamentos (energia da bateria: $37 \mathrm{KWh} /$ peso: $1400 \mathrm{Kg}$ );

- 1994

- Os vários veículos PIV da empresa Pivco (Personal Independent Vehicle Company) foram desenvolvidos na Dinamarca e fabricados na Noruega. Uma frota de 10 unidades do modelo PIV2 foi destinada aos Jogos Olímpicos de inverno em Lillehammer (Noruega), em 1994. O chassi era em alumínio e a carroceria em polietileno (energia da bateria: $12 \mathrm{KWh}$ );

- Surge o Daihatsu Hijet EV, um pequeno veículo de origem japonesa que foi convertido em elétrico (energia da bateria: $15 \mathrm{KWh}$ );

- 1995

- O Golf City Stormer MK3 - a Volkswagen trabalhou em conjunto com a Siemens que desenvolveu o motor de imanes permanentes e com a empresa Varta que desenvolveu as baterias de chumbo-gel. No total foram produzidas 300 unidades (energia da Bateria: $15 \mathrm{KWh}$ );

- Foi lançado o modelo de carro PIV3, conhecido como "City Bee", dos quais se fabricaram cerca de 120 unidades (energia da bateria: $12 \mathrm{KWh}$ );

- O veículo de nome Tropica foi fabricado na Flórida, mas as dificuldades financeiras limitaram a produção de 16 unidades. A potência era fornecida a cada roda de trás por um motor de $25 \mathrm{cv}$ (energia da bateria: $11 \mathrm{KWh}$ ); 
- O Clio Electrique da Renault foi um carro bem popular na segunda metade dos anos 90. As baterias utilizadas de níquel-cádmio tinham o problema de terem de ser carregadas freqüentemente com água (consumo de energia da bateria: $230 \mathrm{Wh} / \mathrm{Km}$ / peso: $1215 \mathrm{Kg}$ );

- 1996

- O carro EV1 foi o sucessor do modelo GM Impact. A GM resolveu produzir uma série de 1117 unidades. Os EV1 iniciais tinham baterias de chumbo que lhes davam uma autonomia de pouco mais de $100 \mathrm{~km}$. Em 1999, a nova versão tinha baterias de NiMH (hidretos metálicos de níquel), que lhe conferia uma autonomia elevada. Em 2003, a GM abandonou este projeto decidindo recolher e destruir todos os carros existentes, com exceção de alguns doados a museus e universidades, mas com os motores desativados de modo a nunca poderem ser guiados. A razão apresentada foi o custo da rede de assistência e de peças de substituição que, por lei, seria necessário manter por 15 anos, no caso destes veículos continuarem a circular (energia da bateria :26 KWh / consumo de energia da bateria: $80 \mathrm{Wh} / \mathrm{Km}$ );

- O Prairie Joy foi o primeiro veículo a usar baterias de íons de lítio. Essas baterias eram cilíndricas, tal como as pilhas. Cerca de 150 destes foram fabricados e testados no Japão, mas também nos EUA, nomeadamente na Califórnia (energia da bateria: $35 \mathrm{KWh}$.);

- As especificações do veículo Seicento Elettra são ligeiramente superiores às do Cinquecento, principalmente na versão com baterias de íon de lítio. Em 2000, uma frota de 130 destas viaturas adentrou no projeto europeu ZEUS (Zero Emission Vehicles in Urban Society). No todo foram fabricados 450 veículos (motor de Indução com energia proveniente da bateria de $16 \mathrm{KWh}$ );

- Saxi foi um modelo de veículo pequeno fabricado na Alemanha utilizando as portas traseiras como entrada. Um ponto relevante é que elas abriam eletricamente (motor de Indução com consumo da bateria de $150 \mathrm{Wh} / \mathrm{Km}$ );

- O veículo Pantila foi desenvolvido propriamente, por uma empresa tailandesa, Pantila (energia fornecida pela bateria atingindo $25 \mathrm{KWh}$ );

Tomando por base os desempenhos alcançados em cada ano pelos respectivos veículos elétricos parametrizados em velocidade, autonomia, bateria, potência e tensão relativo aos ciclos anteriores, segue abaixo na Tabela 5, as variáveis oriundas do $3^{\circ}$ ciclo. 
Tabela 5 - Evolução dos veículos elétricos entre (1974 - 1996)

\begin{tabular}{|c|c|c|c|c|c|c|}
\hline \multirow{2}{*}{$\begin{array}{l}\text { Ano } \\
1974\end{array}$} & \multirow{2}{*}{\begin{tabular}{|c|} 
Velocidade \\
$60 \mathrm{Km} / \mathrm{h}$
\end{tabular}} & \multirow{2}{*}{$\begin{array}{c}\text { Autonomia } \\
70 \mathrm{Km}\end{array}$} & \multirow{2}{*}{$\begin{array}{c}\text { Bateia } \\
\text { Chumbo }\end{array}$} & \multicolumn{3}{|c|}{ Motor (Potência / Tensão Tipo) } \\
\hline & & & & $4.4 \mathrm{KW}$ & $48 \mathrm{~V}$ & MCC \\
\hline 1976 & $60 \mathrm{Km} / \mathrm{h}$ & $90 \mathrm{Km}$ & Chumbo & $8.8 \mathrm{KW}$ & $72 \mathrm{~V}$ & $\mathrm{MCC}$ \\
\hline 1977 & $105 \mathrm{Km} / \mathrm{h}$ & $100 \mathrm{Km}$ & Chumbo & $17 \mathrm{KW}$ & $84 \mathrm{~V}$ & MCC \\
\hline 1978 & $120 \mathrm{Km} / \mathrm{h}$ & $160 \mathrm{Km}$ & Chumbo & $24 \mathrm{KW}$ & $36 \mathrm{~V}$ & \\
\hline 1980 & $105 \mathrm{Km} / \mathrm{h}$ & $115 \mathrm{Km}$ & Chumbo & $18 \mathrm{KW}$ & $96 \mathrm{~V}$ & MCC \\
\hline 1981 & $81 \mathrm{Km} / \mathrm{h}$ & $80 \mathrm{Km}$ & Chumbo & $15 \mathrm{KW}$ & $102 \mathrm{~V}$ & \\
\hline 1983 & $80 \mathrm{Km} / \mathrm{h}$ & $110 \mathrm{Km}$ & Chumbo & $10 \mathrm{KW}$ & $72 \mathrm{~V}$ & \\
\hline 1984 & $50 \mathrm{Km} / \mathrm{h}$ & $115 \mathrm{Km}$ & Chumbo & $24 \mathrm{KW}$ & $84 \mathrm{~V}$ & \\
\hline 1987 & $100 \mathrm{Km} / \mathrm{h}$ & $80 \mathrm{Km}$ & $\mathrm{Na}-\mathrm{S}$ & $17 \mathrm{KW}$ & $200 \mathrm{~V}$ & MCC \\
\hline 1989 & $90 \mathrm{Km} / \mathrm{h}$ & $100 \mathrm{Km}$ & Chumbo & $18 \mathrm{KW}$ & $96 \mathrm{~V}$ & MCC \\
\hline 1990 & $105 \mathrm{Km} / \mathrm{h}$ & $150 \mathrm{Km}$ & Chumbo & $60 \mathrm{KW}$ & $320 \mathrm{~V}$ & MI \\
\hline 1991 & $120 \mathrm{Km} / \mathrm{h}$ & $276 \mathrm{Km}$ & $\mathrm{Ni}-\mathrm{Cd}$ & $30 \mathrm{KW}$ & $200 \mathrm{~V}$ & $\mathrm{MCC}$ \\
\hline 1992 & $110 \mathrm{Km} / \mathrm{h}$ & $170 \mathrm{Km}$ & $\mathrm{Na}-\mathrm{NiCl}$ & $62 \mathrm{KW}$ & $120 \mathrm{~V}$ & MCC \\
\hline 1993 & $120 \mathrm{Km} / \mathrm{h}$ & $90 \mathrm{Km}$ & $\mathrm{ZnBr} 2$ & $12 \mathrm{KW}$ & $168 \mathrm{~V}$ & MI \\
\hline 1994 & $85 \mathrm{Km} / \mathrm{h}$ & $100 \mathrm{Km}$ & $\mathrm{NiCd}$ & $30 \mathrm{KW}$ & $240 \mathrm{~V}$ & MI \\
\hline 1995 & $90 \mathrm{Km} / \mathrm{h}$ & $160 \mathrm{Km}$ & Chumbo & $2 \times 18 \mathrm{KW}$ & $72 \mathrm{~V}$ & MCC \\
\hline 1996 & $100 \mathrm{Km} / \mathrm{h}$ & $90 \mathrm{Km}$ & Li-ion & $30 \mathrm{KW}$ & $216 \mathrm{~V}$ & MI \\
\hline
\end{tabular}

Fonte: Elaboração própria

Dos vários direcionamentos demonstrados em torno do desenvolvimento efetivo dos veículos elétricos, somente no final da década de 80 houve um progresso marcante, tanto psicologicamente quanto tecnologicamente. Obviamente, isso angariou o apoio maciço de governantes, de ambientalistas e de fabricantes de automóveis ao redor do mundo. Os governantes provenientes dos Estados Unidos motivados em minimizar a dependência do petróleo dos países árabes, principalmente após a Guerra do Iraque em 1991, criaram duas iniciativas que merecem ser mencionadas:

$\checkmark$ O surgimento do "United States Advanced Battery Consortium" agrupando os três principais fabricantes de automóveis dos EUA;

O estado da Califórnia aprova e regulamenta a legislação extremamente restritiva com relação às emissões de gases poluentes, exigindo que uma fração da frota de automóveis venha a se enquadrar na categoria de ZEV ("Zero emission vehicles").

Também, não se pode esquecer de mencionar que em outros países tais como o Japão, iniciativas similares tiveram repercussão adquirindo novos argumentos listados abaixo: 
$\checkmark \quad$ O fato do petróleo continuar sendo utilizado e queimado nas usinas termoelétricas centrais não é necessariamente um agravante, pois apresenta uma eficiência energética maior comparada à queima realizada em um automóvel;

$\checkmark$ Outros tipos de combustíveis podem ser usados em usinas termoelétricas, tais como o carvão, o gás natural e mesmo combustíveis nucleares. Estes outros combustiveis podem abater os índices de emissões de poluentes atmosféricos (em relação ao petróleo);

$\checkmark$ Existem usinas hidroelétricas que não fazem uso de combustíveis fósseis;

$\checkmark \quad$ Os controles de poluição podem ser implementados de uma forma bastante eficaz em usinas elétricas centralizadas, sendo difícil alcançar os mesmos patamares de desempenho em uma frota imensa de automóveis.

\subsubsection{Quarto Ciclo Analítico dos Veículos Elétricos (1997 até os dias atuais)}

Dentro dos diferentes estágios do ciclo de vida, atualmente, os veículos híbridos, elétricos e plug-ins estão ressurgindo como instrumentos orientados para solucionar questões emblemáticas, como segurança energética e impacto climático. Segundo Anfavea (2011), a Cadeia de Suprimentos automotiva brasileira reúne um espectro de diversidade étnica nas nacionalidades de suas montadoras, sendo que aqui estão reunidas montadoras provenientes de nada menos que nove diferentes países; Alemanha, Brasil, Coréia do Sul, Estados Unidos, França, Índia, Itália, Japão e Suécia. Essa diversidade étnica não se tem registro em nenhum outro pólo produtor de veículos do planeta.

A maioria destas montadoras que compõem a cadeia do segmento automotivo realiza pesquisas em formato integrado com universidades visando desenvolver modelos de carros híbridos e elétricos. O primeiro grande passo desse recente movimento surgiu, em 1997, quando a Toyota, fabricante japonesa de automóveis, lançou o Prius no Japão, um sedã híbrido de quatro portas, seguido pela Honda, primeira empresa a lançar um híbrido no mercado americano, o Insight, em 1998 (DIJIK e YARIME, 2010).

Desde o lançamento do Toyota Prius, foram vendidos 1,9 milhão de veículos HEVs (Hybrid Electric Vehicles) e 60,0 mil veículos PHEVs (Plug-in Hybrid Electric Vehicles) e BEVs (Battery Electric Vehicles) no mercado norte-americano (DOE, 2012). Esse fato pode ser atribuído, em grande parte, ao incentivo do governo americano aos fabricantes e consumidores de veículos híbridos e elétricos. Mundialmente, durante a última década foram 
vendidos diversos modelos de HEVs, PHEVs e BEVs totalizando mais de 2,5 milhões de veículos e, no início de 2011, a penetração destas tecnologias no mercado está se aproximando de $2 \%$ nos Estados Unidos e $9 \%$ no Japão (IEA, 2011). Serão apresentadas a seguir uma abordagem descritiva dando início ao $4^{\circ}$ ciclo:

- 1997

- Cerca de 1500 unidades dos veículos Toyota RAVA EV foram fabricadas e alugadas na Califórnia. Há relatos de utilizadores que alcançaram autonomia de 240 quilômetros utilizando as mesmas baterias sem troca. Um dos pontos relevantes que foram preponderantes ao término da sua produção foi a impossibilidade da fabricação das baterias NiMH, cuja patente passou da GM para Chevron, que proibiu sua montagem. Prevê-se que em 2012 seja lançado um novo modelo deste carro com o suporte da Tesla montadora (energia da bateria: $27 \mathrm{KWh}$ );

- O veículo lançado pela Toyota de nome E-com teve 50 unidades produzidas. O acesso a este carro fazia-se por cartão eletrônico. Dessa forma, os veículos podem ser alugados por minuto, a cada hora, bem como a cada dia (peso: 770 $\mathrm{Kg}$;

- O carro Nissan Altra EV foi um dos primeiros veículos desta época a usar baterias de ions de lítio (em paralelo com o Nissan Prairie Joy), o que lhe dava a melhor autonomia entre os carros elétricos. O motor era muito avançado para época, pois, era de imanes permanentes, usando neodímio, atingindo até $13.000 \mathrm{rpm}$. Passados 15 anos, estas duas tecnologias tornaram-se ponto de referência neste segmento de carros movidos à propulsão elétrica. Foram fabricadas cerca de 200 unidades sendo o carregamento indutivo mais seguro que o processo condutivo (motor de ímanes permanentes / consumo de energia da bateria: $200 \mathrm{Wh} / \mathrm{Km} /$ peso: $1649 \mathrm{Kg}$ );

- 1998

- O Ranger EV é uma pick-up de tração traseira fabricada pela Ford entre 1998 e 2002, tendo-se produzido cerca de 1500 unidades. Embora, grande parcela tenha sido alugada a empresas, algumas foram vendidas a clientes particulares. As iniciais tinham baterias de chumbo, mas a maioria foi entregue com baterias 
de hidretos metálicos de níquel (motor de indução / energia da bateria: 30 $\mathrm{KWh}$ / consumo de energia da bateria: $150 \mathrm{Wh} / \mathrm{Km}$ / peso: $1910 \mathrm{Kg}$ );

- 1999

- O veículo Hypermini foi projetado para dois lugares feitos de tubos de alumínio e painéis de plástico começando a ser comercializado no Japão em 2000. O carregamento é indutivo, não ocorrendo contatos mecânicos. Foram fabricados 219 destes veículos, sendo vinte e seis utilizados na Califórnia (motor de ímanes permanentes / energia da bateria: $15 \mathrm{kWh} /$ peso: 840);

- TH!NK foi o nome dado à versão PIV4 dos carros de 4 lugares desenvolvidos pela Pivco (Personal Independent Vehicle Company). Em 1999, a Pivco foi vendida à Ford, que continuou a investir neste projeto, de modo que o PIV4 fosse um veículo significativamente superior aos dos seus predecessores. $O$ chassi em alumínio passou a ter elementos em aço e a carroceria continuou a ser em polietileno, mas, o freio passou a ser em ABS (Anti-lock Braking System). Foram fabricadas 1005 unidades (motor de indução / energia da bateria: $11.5 \mathrm{KWh}$ / peso: $940 \mathrm{Kg}$ );

- 2000

- Cerca de quinze protótipos do automóvel Mercedes Classe A foram fabricados na versão elétrica obedecendo às leis californianas. As baterias usadas eram do tipo $\mathrm{Na}-\mathrm{NiCl}$, de nome Zebra, que funciona a temperatura elevada, mas com boas características. Esta bateria, desenvolvida pela Daimler-Benz, funciona por volta dos $300^{\circ} \mathrm{C}$ contendo um bom isolamento térmico para não perder calor para o exterior. Um dos pontos relevantes deste veículo é que as baterias podiam ser colocadas em um espaço projetado no interior. $O$ desenvolvimento destas baterias finalizou em 2000. Foi incorporado neste veículo as baterias íon-lítio, tendo sido fabricadas cerca de quinhentas unidades (energia da bateria: $36 \mathrm{KWh}$ );

\section{- 2000}

- A Ford lançou o carro Ford Ka na versão elétrica, as baterias utilizadas eram de lítio e a redução do peso se deu pela utilização de alumínio e de polímeros na carroceria e nos painéis. Mesmo assim, não houveram vendas significativa; 
- 2002

- O veiculo Elect'road e Electri'cité da Renault era um dos poucos elétricos de cinco lugares, disponíveis no mercado desde 2002. Podia ser elétrico ou incluir um pequeno motor de $14 \mathrm{cv}$ para carregar as baterias. A produção total foi de cerca de 500 unidades. Ano: Electri'cité (2002) Elect'road (2003) (motor de ímanes permanentes / energia da bateria: $13.2 \mathrm{KWh} /$ consumo de energia da bateria: $250 \mathrm{Wh} / \mathrm{Km}$ / Peso: $940 \mathrm{Kg}$ );

- 2007

- Em 2006 a empresa KamKorp entrou em falência e foi logo mais comprada e renomeada para TH!NK Global, e em 2007 a produção do novo TH!NK City começou, tendo sido fabricados 100 veículos, antes de ter novamente problemas financeiros. A partir do final de 2009, a produção passou a fazer-se na Finlândia, e em 2010, nos Estados Unidos, mas foi suspensa novamente em 2011 por problemas financeiros (motor de indução / energia da bateria: 24 $\mathrm{KWh}$ / peso: $1040 \mathrm{~kg}$ );

- O carro eBox é uma alteração do Toyota Scion para a versão elétrica feita pela AC Propulsion. Foi utilizado baterias de lítio (motor de indução / Peso: $1350 \mathrm{Kg})$.

- 2008

- O Lumeneo Smera, pequeno e principalmente estreito $(80 \mathrm{~cm})$, automóvel francês, está na fronteira entre os carros e as scooters. Têm dois motores, um para cada roda traseira, ligados à estas por correias (motor de ímanes permanentes / energia da bateria: $110 \mathrm{KWh}$ );

- A Stevens Vehicles é uma empresa inglesa responsável pela fabricação dos carros elétricos ZecCar e a ZeVan. Foram utilizados dois motores, cada um ligado a uma roda traseira (motor de indução);

- 2009

- A Fuji, proprietária do Subaru, fabricou em 2008, cinco protótipos elétricos do automóvel Stella para serem usados em teste. Em 2009 e 2011, a intenção é produzir quatrocentas unidades de Stellas elétricos (motor de ímanes permanentes / energia da bateria: 9,2 KWh / peso: $1060 \mathrm{Kg}$ ); 
- O iMiEV (Mitsubishi Innovative Electric Vehicle) é um dos primeiros carros elétricos produzidos por uma grande montadora, Mitsubishi. Embora quatro adultos possam sentar-se confortavelmente, é bastante compacto. $\mathrm{O}$ motor de $63 \mathrm{cv}$ traciona as rodas traseiras. As baterias de Li-ion são colocadas no fundo do carro de modo a baixar-lhe o centro de gravidade e não ocupar espaço. $O$ iMiEV tem duas ligações de carregamento, uma ficha SAE J1772 (na direita do veículo) e uma ligação para carregamento rápido de corrente contínua (CHAdeMO), situada na esquerda (motor de ímanes permanentes / consumo de energia da bateria: $125 \mathrm{Wh} / \mathrm{Km} /$ peso: $1060 \mathrm{Kg}$ );

- Uma série de quinhentos veículos Minis elétricos foram testados ao longo de dois anos por condutores nos Estados Unidos e na Europa. Tanto as baterias de lítio como o motor eram arrefecidos por ar. Uma das queixas dos condutores era o pouco aquecimento, inadequado aos rigores do inverno no Norte da Europa. Além disso, no inverno, a autonomia é menor comparado a outros meses. Neste automóvel só é permitida a entrada de duas pessoas, pois a traseira está ocupada com as baterias (motor de indução / consumo de energia da bateria: $140 \mathrm{Wh} / \mathrm{Km}$ / peso: $1465 \mathrm{Kg}$ );

- 2010

- O MIEV da Mitsubishi foi fabricado com base no Colt EV (2005) que tinha dois motores de $27 \mathrm{cv}$ em cada roda traseira. Em 2010, o novo Colt apresenta semelhanças à versão passada com motores elétricos dentro das rodas traseiras (motor de ímanes permanentes / energia da bateria: $13 \mathrm{KWh}$ );

- Em um ano cerca de vinte mil unidades do veículo Leaf foram vendidas ao redor do mundo. As baterias estão situadas na base do carro, por razões de espaço e também integridade mecânica, além de baixarem o centro da gravidade. O Leaf utiliza uma ligação SAE J1772 para o carregamento de baixa potência e uma ficha CHAdeMO para carregamentos rápidos. Neste caso, ambas estão localizadas lado a lado, na frente do carro. O carregamento rápido (corrente contínua, $400 \mathrm{~V}$ ) leva 20 minutos para carregar as baterias até $80 \%$ (motor de ímanes permanentes / consumo de energia da bateria: 150 $\mathrm{Wh} / \mathrm{Km}$ / peso: $1465 \mathrm{Kg}$ ); 
- Uma frota de 50 veículos Volvos C30 elétricos foi produzida e testada na Suécia (energia da bateria: $24 \mathrm{KWh}$ );

- A Ford e a Azure Dynamics juntaram-se para produzir uma versão elétrica do veículo Transit Connect. Este modelo é indicado para as empresas que sabem parametrizar a quantidade de quilômetros rodados por dia. Além do custo da energia ser significativamente menor, a manutenção é bem inferior;

\section{- 2011}

- O automóvel BMW i3 Megacity é construído com materiais (plástico reforçado com fibra de carbono) e processos que minimizem a sua massa. $\mathrm{O}$ motor elétrico de $170 \mathrm{cv}$ ligado às rodas traseiras (energia da bateria: 16 a 22 $\mathrm{KWh}$ / peso: $1100 \mathrm{Kg}$ );

- Em resposta a um pedido dos correios franceses em 2007, a Venturi começou a produzir a segunda versão elétrica do Citroën Berlingo (apresentado em Frankfurt em 2009). As baterias são de Zebra ( $\left.\mathrm{Na} / \mathrm{NiCl}_{2}\right)$, funcionando a temperatura elevada $\left(300^{\circ} \mathrm{C}\right)$ obrigando o uso de um bom isolamento (motor de indução / energia da bateria: $23.5 \mathrm{KWh}$ );

- A empresa francesa Heuliez construiu veículos elétricos próprios, o Mia (Friendly) e o Pondicherry. O Mia tem capacidade para três pessoas e foi inicialmente apresentado no salão de Paris em 2008. Haverá mais duas versões maiores, a MIA L e a Mia Box Van, todas com a mesma especificação (energia da bateria: $12 \mathrm{KWh} /$ peso: $750 \mathrm{Kg}$ );

- A Nissan apresentou uma versão elétrica do veículo NV200. Os correios e os taxistas japoneses testarão durante dois meses uma dessas unidades convertidas;

- O carro Fluence da Renault não foi um veículo desenhado para ser elétrico (é uma conversão), as baterias estão colocadas atrás dos bancos traseiros, limitando o volume do porta-malas (energia da bateria: $22 \mathrm{KWh}$ );

- Na versão do carro Kangoo ZE da Renault, as baterias são de lítio, com maior autonomia. Há duas versões: o Express e o Maxi. O volume de carga não é alterado das versões como motor de combustão. O preço deste automóvel não inclui as baterias que são alugadas (a um pouco mais de $70 € /$ mês + IVA), isso significa que este valor engloba uma quilometragem máxima anual de 15.000 
Km. Esses veículos são extremamente utilizados por instituições francesas como os correios (consumo de energia da bateria: $250 \mathrm{Wh} / \mathrm{Km} /$ energia da bateria: $22 \mathrm{KWh}$ );

- A Tata, sendo a maior fabricante de automóveis da Índia, decidiu comercializar o Indica Vista em versão elétrica. As especificações são superiores comparado a outro veículo elétrico indiano, o Reva. Comercialmente, o Indica Vista apresenta valores mais em conta no ato da compra (energia da bateria: $26,5 \mathrm{KWh} /$ peso: $1291 \mathrm{Kg}$ );

- O Focus Electric da Ford é um carro com um modelo elétrico que foi construído pelo menos nos Estados Unidos, na mesma linha de montagem do Focus com motor à combustão. No desenvolvimento foi utilizado uma regulação muito sofisticada da temperatura das baterias, de modo a retirar-lhes o seu maior potencial e prolongar a sua vida útil. Relativamente ao carregamento, a Ford afirma que demorará cerca da metade do tempo necessário para carregar o Leaf (Nissan) (energia da bateria: $23 \mathrm{KWh} /$ peso: $1675 \mathrm{Kg})$;

- A empresa Li-ion Motors Corp inicialmente conhecida por Hybrid Technologies sempre trabalhou no desenvolvimento e na construção de veículos elétricos e híbridos. O veículo projetado por ela, o Wave II, foi desenhado com a eficiência aerodinâmica como prioridade máxima. Sendo um veículo de dois lugares, oferece um grande espaço para bagagem atrás dos ocupantes não contendo caixa de velocidades (energia da bateria: $40 \mathrm{KWh} /$ peso: $1065 \mathrm{Kg}$ );

- O veículo Scion iQ (Toyota) inicialmente com capacidade de atingir uma autonomia de $80 \mathrm{Km}$, este carro possui três lugares para adultos e uma criança. A sinergia entre a Toyota e a Tesla deverá implicar que os motores sejam de indução, poupando o elevadíssimo custo;

- O Coda é um veículo baseado no Hafei Saibao, produzido na China desde 2005 com desenho da Pininfarina e um chassi Mitsubishi. O veículo, que anteriormente era conhecido por Miles XS500, será vendido pela Miles Electric Vehicles na Califórnia com o nome Coda Seda. As baterias estão 
colocadas sob o habitáculo, de modo a reduzir ao mínimo a ocupação de espaço interior (energia da bateria: $34 \mathrm{KWh} /$ peso: $1670 \mathrm{Kg}$ );

\section{- 2012}

- A terceira versão do carro Smart elétrico, que será feito em Hambach, França, foi lançado em 2012. As cem unidades da primeira versão foram testadas em Londres. A segunda geração, com mais de 2000 Smarts foi distribuída em dezoito países (energia da bateria: 17,6 KWh).

Vê-se que, mesmo sendo necessário priorizar variáveis mencionadas em cada ciclo histórico retratado anteriormente, em princípio, percebe-se que o motor elétrico é a unidade de propulsão ideal. Devido à forte competição e às crescentes exigências dos consumidores, as empresas da área de transporte tentam reduzir custos operacionais e logísticos, ao mesmo tempo em que buscam melhorar os serviços. $O$ veículo elétrico vai ao encontro por ter atributos compatíveis como: silencioso, altamente eficiente, tem excelentes características de torque $\times$ velocidade e não polui.

Além disso, nos $1^{\circ}$ e $2^{\circ}$ ciclos propriamente no contexto de um veículo, todas estes aspectos positivos eram prejudicados pelas limitações fundamentais das baterias como fonte de energia.

Neste ínterim, a gasolina obteve uma relativa vantagem por apresentar uma densidade energética de aproximadamente $12500 \mathrm{Wh} / \mathrm{kg}$ superior a uma bateria de chumbo-ácido convencional que consegue armazenar apenas $25 \mathrm{Wh} / \mathrm{kg}$. Como consequência, um carro puramente elétrico possui um enorme e pesado sistema de baterias, associado à uma autonomia sofrível, conforme Dettmer (2001).

Ainda em relação aos acumuladores de energia, conhecidos como baterias, demoram um tempo significativo (6 a 12 hs) para serem recarregadas. Em consonância, um tanque de gasolina demora cerca de 2 a 3 minutos para ser preenchido, o que significa um fluxo de potência da ordem de 20 a $30 \mathrm{MW}$ durante o período de abastecimento em um posto de gasolina, segundo Hermance e Sasaki (1998).

Sem dúvida, a gasolina se tornava um combustível ideal ,mas também tinha suas adversidades como: a eficiência era muito baixa e, em baixas rotações, o torque disponível é baixo. $\mathrm{O}$ torque é que determina a capacidade de aceleração e, em um carro convencional, esta aceleração é definida pela combinação da caixa de engrenagens e pelo sobredimensionamento 
do motor à explosão (o que acarreta uma ineficiência ainda maior). Por exemplo, o MercedesBenz CL600 possui um motor de $367 \mathrm{CV}$, de 12 cilindros e consegue acelerar seus $2380 \mathrm{~kg}$ de 0 a 60 milhas $/ \mathrm{h}$ (aproximadamente $100 \mathrm{~km} / \mathrm{h}$ ) em $6.3 \mathrm{~s}$. Para aumentar sua eficiência existe um mecanismo que desativa 6 cilindros quando não há necessidade de torque elevado, segundo Dettmer (2001). A Tabela 6 mostra as variáveis retratadas no $4^{\circ}$ ciclo.

Tabela 6: Evolução dos veículos elétricos entre 1996 até os dias atuais

\begin{tabular}{|c|c|c|c|c|c|c|}
\hline \multirow{2}{*}{$\begin{array}{l}\text { Ano } \\
1997\end{array}$} & \multirow{2}{*}{$\begin{array}{l}\text { Velocidade } \\
100 \mathrm{Km} / \mathrm{h}\end{array}$} & \multirow{2}{*}{$\begin{array}{c}\text { Autonomia } \\
100 \mathrm{Km}\end{array}$} & \multirow{2}{*}{$\begin{array}{l}\text { Bateia } \\
\text { NiMH }\end{array}$} & \multicolumn{3}{|c|}{ Motor (Potência / Tensão Tipo) } \\
\hline & & & & $18.5 \mathrm{KW}$ & $288 \mathrm{~V}$ & MS \\
\hline 1998 & $120 \mathrm{Km} / \mathrm{h}$ & $185 \mathrm{Km}$ & NiMH & $84 \mathrm{KW}$ & & MI \\
\hline 1999 & $100 \mathrm{Km}$ & $115 \mathrm{Km}$ & Li-ion & $24 \mathrm{KW}$ & $300 \mathrm{~V}$ & MIP \\
\hline 2000 & $130 \mathrm{Km} / \mathrm{h}$ & $200 \mathrm{Km}$ & Li-ion & $65 \mathrm{KW}$ & $345 \mathrm{~V}$ & MIP \\
\hline 2002 & $120 \mathrm{Km} / \mathrm{h}$ & $80 \mathrm{Km}$ & $\mathrm{NiCd}$ & $44 \mathrm{KW}$ & $180 \mathrm{~V}$ & MIP \\
\hline 2007 & $150 \mathrm{Km} / \mathrm{h}$ & $290 \mathrm{Km}$ & Li-ion & $150 \mathrm{KW}$ & $355 \mathrm{~V}$ & MI \\
\hline 2008 & $110 \mathrm{Km} / \mathrm{h}$ & $100 \mathrm{Km}$ & Li-ion & $2 \times 15 \mathrm{KW}$ & $144 \mathrm{~V}$ & MIP \\
\hline 2009 & $150 \mathrm{Km} / \mathrm{h}$ & $210 \mathrm{Km}$ & Li-ion & $150 \mathrm{KW}$ & $380 \mathrm{~V}$ & MI \\
\hline 2010 & $140 \mathrm{Km} / \mathrm{h}$ & $300 \mathrm{Km}$ & Li-ion & $200 \mathrm{KW}$ & $380 \mathrm{~V}$ & MIP \\
\hline 2011 & $145 \mathrm{Km} / \mathrm{h}$ & $270 \mathrm{Km}$ & Li-ion & $47 \mathrm{KW}$ & $360 \mathrm{~V}$ & MI \\
\hline 2012 & $120 \mathrm{Km} / \mathrm{h}$ & $120 \mathrm{Km}$ & Li-ion & $55 \mathrm{KW}$ & $300 \mathrm{~V}$ & MIP \\
\hline
\end{tabular}

Fonte: Elaboração própria

Cabe aqui, mais uma vez, ressaltar que as principais mudanças que se deram, principalmente nos $3^{\circ}$ e $4^{\circ}$ ciclos históricos dos veículos elétricos vão desde ao desmembramento de novas tecnologias, através do desenvolvimento de novos motores, conversores de potência, carregadores de baterias e acumuladores de energia.

Broussely (2010), diz que as propriedades específicas dos veículos elétricos variam de acordo com o tamanho da bateria e tipo de veículo. Os carros elétricos precisam de maior energia específica por volume, enquanto que os veículos híbridos, em contrapartida, necessitam de baterias que ofereçam o máximo de potência no menor tamanho possível (BROUSSELY, 2010).

Nesse sentido, a razão pela qual a produção de automóveis elétricos permanece estática relaciona-se com alguns indicadores como elevados custos de produção que se traduzem na baixa penetração, ausência de redes logísticas para os veículos poderem abastecer e autonomia pouco satisfatória. Isso sem dúvidas, é um fator preocupante para os países, fabricantes e clientes finais ao longo da cadeia automotiva. 
Hall (2008), Reis (2008) e Junior (2002) apontam em alguns estudos, que a bateria de íon de lítio deverá ocupar um lugar de destaque nos veículos elétricos nos dias de hoje devido à sua maior energia específica, em termos de volume e massa, elevado rendimento energético (perto de 100\%), longo ciclo de vida (aproximadamente 3.000 ciclos com uma profundidade de descarga de $80 \%$ ), baixa taxa de auto-descarga e ausência de efeito de memória, no qual a bateria perde capacidade ao ser recarregada. A produção em massa e o desenvolvimento de materiais nano-estruturados oferecem uma margem considerável para a redução de custos. Observamos sua utilização em grande escala a partir do ano de 1996 referente ao $4^{0}$ ciclo.

Com, base nestes fatores, Bradley e Frank (2009) ressaltam que as desvantagens dos veículos elétricos estão associadas às deficiências do armazenamento eletroquímico de energia. Em relação aos combustíveis convencionais, a bateria dos carros elétricos possui baixa energia específica em termos de volume e massa e baixa taxa de reabastecimento / recarga.

Deste modo, outro aspecto deficiente segundo Kiviluoma e Meibom (2011), Hadley e Tsvetkova (2008), Green II et al. ( 2011) Lin et al. (2010) está associado ao uso de eletricidade pelo setor de transportes relacionado ao aumento da demanda elétrica e a possível necessidade de aumento da capacidade de geração de energia elétrica. Mais do que isso, a penetração dos veículos elétricos no sistema elétrico pode ocasionar sobrecarga em transformadores e linhas de distribuição e, principalmente, dependendo do momento e forma da recarga, sobrepico no sistema elétrico.

Em função destes aspectos, por outro lado, como vantagens em relação aos veículos convencionais incluem a não (ou baixa) produção direta de gases de exaustão, operação com pouco ruído, a maior eficiência do tanque à roda (tank to wheel) resultante a eficácia do motor elétrico (Campanari et al., 2009). Os possíveis benefícios mais amplos envolvidos com a utilização de eletricidade pelo sistema de transportes vão desde a redução do consumo conseqüente de dependência do petróleo pelo setor, incluindo redução das emissões de poluentes locais gerados pelos veículos automotores, que afetam a saúde humana de diferentes formas de acordo com Loureiro (2005).

Segundo Kempton e Letendre (1997), uma visão otimista de longo prazo do uso da eletricidade pelo setor de transportes, aliado à constante necessidade de expansão do sistema elétrico para atendimento da demanda, pode indicar uma relação de interação entre os setores. Ou seja, pode originar um tipo de simbiose a partir de uma ligação bidirecional do fluxo de energia entre veículos e sistema elétrico. Este sistema, onde os veículos elétricos têm a capacidade de, não apenas consumir, mas também de gerar energia para a rede elétrica, é 
conhecido como vehicle-to-grid (V2G). Entretanto, para a implementação do V2G, há a necessidade de modificações tecnológicas tanto na construção dos veículos como na estrutura de fornecimento de energia elétrica. No que se refere a está iniciativa, apesar de estar em um estado embrionário promove a consolidação de um sistema elétrico inteligente, conhecido como smart grid.

Para Hledik, (2009), de um modo geral, a base da definição do smart grid é a infraestrutura de medição avançada (Advanced Metering Infrastructure - AMI). As principais tecnologias disponíveis para a construção do AMI são a precificação dinâmica, tecnologias automatizadas (que permitem ligar e desligar aparelhos de acordo com a precificação dinâmica e a necessidade do usuário) e mostradores do consumo do usuário em tempo real. Isto se refere a medidores ditos inteligentes e a uma rede de comunicações que permite uma comunicação bidirecional entre fornecedor de eletricidade e medidor. Neste formato, fornecedores têm acesso a informações em tempo real sobre o consumo de eletricidade de seus clientes.

Hall (2008), no que se refere aos possíveis benefícios de longo prazo da eletrificação do setor de transportes, com o a implementação do V2G, o uso de eletricidade a partir da rede elétrica pelos veículos pode estimular a produção de energia elétrica de fontes renováveis. Entretanto, os principais problemas das fontes renováveis, baseadas em fluxo e não em estoque de energia, residem na sua maior variabilidade no tempo, o que pode dificultar o atendimento da demanda de energia em todos os momentos, gerando instabilidade na rede, na forma de oscilações de baixa freqüência. A solução para os dois problemas é o armazenamento de energia, que é fundamental para a ampla implantação das energias renováveis.

\subsection{Sínteses e Análises}

É irrefutável a importância das baterias em um veículo elétrico, sendo assim as principais características de um acumulador de energia são a energia específica, a potência específica e o tempo de vida útil. A energia específica consiste na quantidade energia armazenada pela bateria por unidade de massa, a potência específica é a potência fornecida por unidade de massa, o tempo de vida útil corresponde ao número de ciclos de carga/descarga a que pode ser sujeita.

No Gráfico 1 pode-se verificar um avanço numa linha de tempo em tamanho e em peso dos vários tipos de baterias As baterias do tipo: $\mathrm{Pb}-\mathrm{SO} 4, \mathrm{Ni}-\mathrm{Cd}$, Ni-MH estão estagnadas 
em termos de energia e densidade específica. A relação entre a Energia Específica $\mathrm{Wh} / \mathrm{kg}$ e a Densidade Específica Wh/1, como se pode ver é a seguinte: quanto maior a densidade volumétrica menores são as baterias, logo ocupam menos espaço, quanto maior a energia especifica, mais leves se tornam as baterias, mais energia disponível para veículos elétricos.

Peças Lopes, Soares, Almeida, Moreira da Silva (2009) ressaltam que com os novos desenvolvimentos de baterias, os veículos movidos a tração elétrica têm a capacidade de armazenamento entre 20 e cerca de $60 \mathrm{kWh}$, permitindo a sua interligação com a rede elétrica de distribuição, através do consumo de energia e, num futuro muito próximo, fornecendo energia de acordo com as necessidades da rede, através de uma funcionalidade de Veículo Ligado à Rede (VLR).

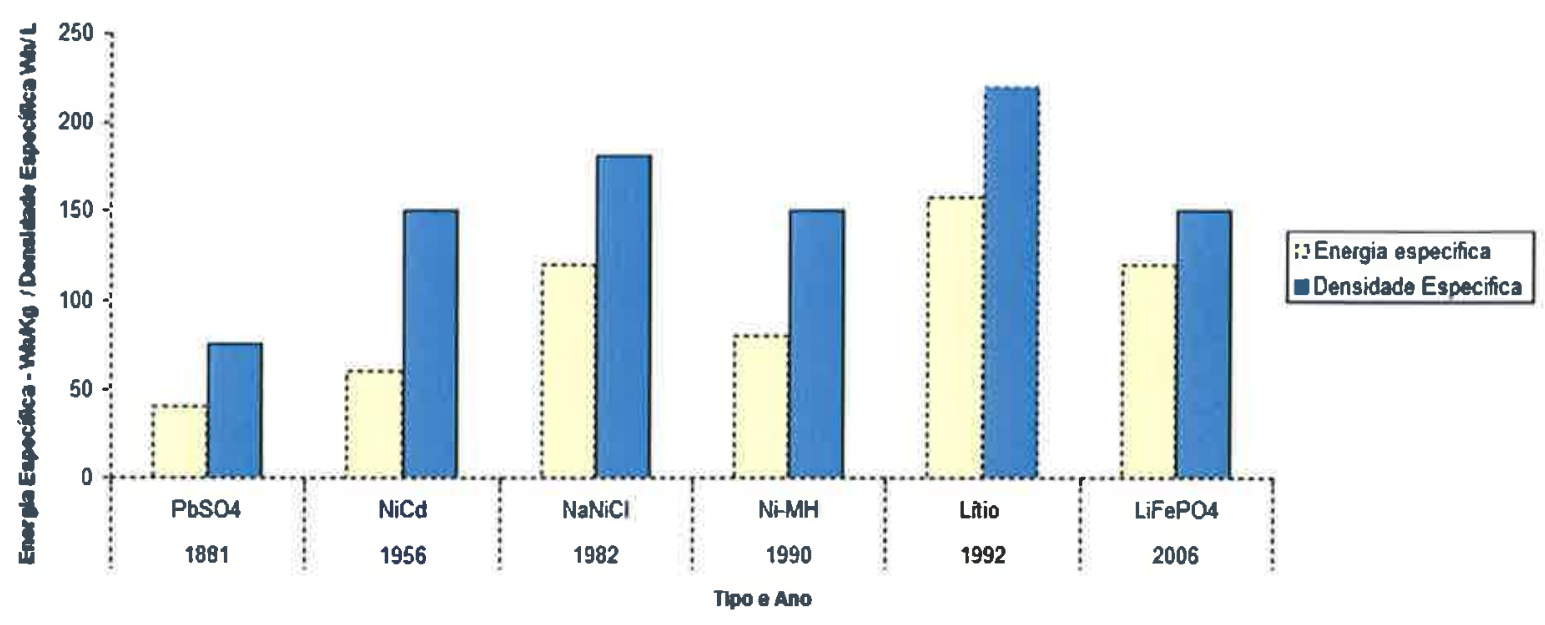

Gráfico 1 - Evolução das Baterias

Fonte: Elaboração própria

Em face disto, os requerimentos técnicos exigidos para os acumuladores de energia são diferentes para cada tipo de veículo. Os veículos elétricos necessitam de baterias com maiores densidades de energia, limitando-as devido às massas e volumes associados, o que contribui para uma baixa autonomia destes tipos de veículos. Uma vez que nos veículos elétricos puros as baterias constituem a única fonte de energia, estas acabam sofrendo descargas mais profundas, exigindo-se baterias mais robustas, com tempo de vida longo e aceitação de um número elevado de ciclos de carga e recarga. No entanto, aumentar a autonomia de veículos elétricos requer maiores baterias, aumentando consideravelmente a massa do veículo. Inversamente, reduzir a autonomia de veículos elétricos permite ter uma maior eficiência energética efetiva. Nos Gráficos 2, 3, 4 e 5 podemos visualizar a evolução da 
autonomia e velocidade perante os 4 ciclos levando em consideração fatores apresentados anteriormente que foram primordiais para evolução destes veículos.

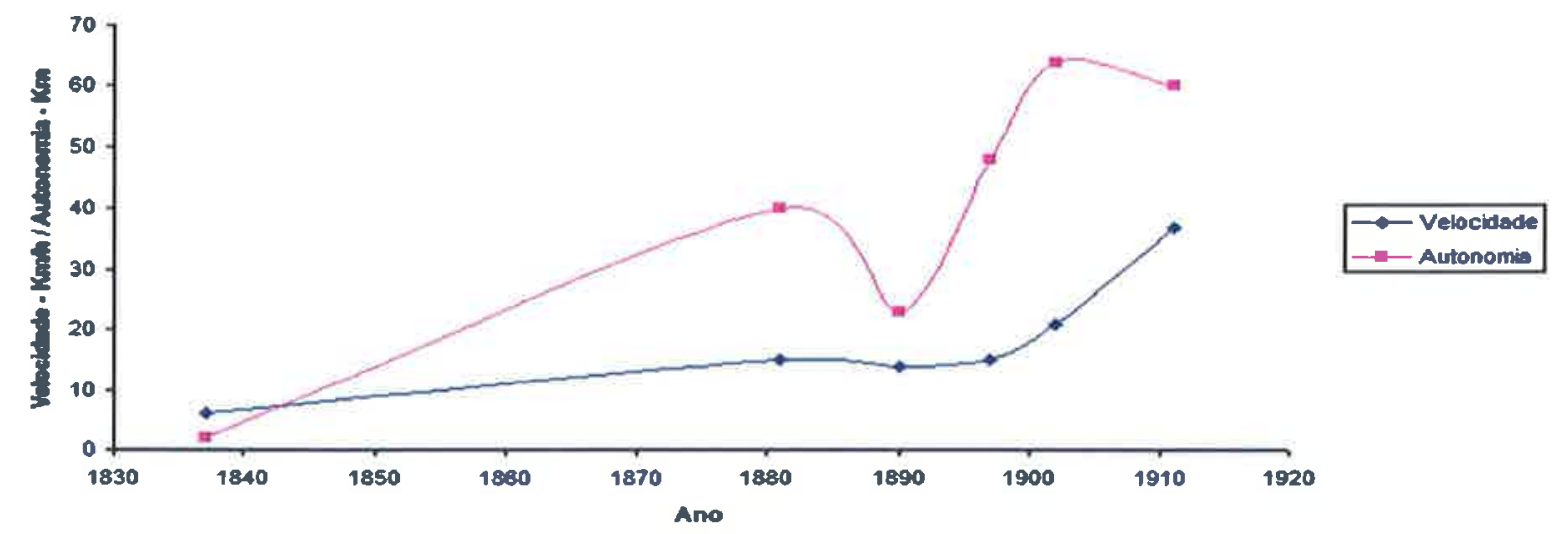

Gráfico $2-1^{\circ}$ Ciclo - Veículos Elétricos (1837 - 1912)

Fonte: Elaboração própria

Vale, aqui, ressaltar que, as baterias de chumbo-ácidas $(\mathrm{Pb})$ são as mais conhecidas sendo utilizadas nos ciclos $1^{\circ}, 2^{\circ}$ e $3^{\circ}$ tendo até 2012 maior aplicação. Estas baterias são as mais baratas e requerem pouca manutenção, no entanto, apresentam reduzidas energia e potência específicas, $40 \mathrm{Wh} / \mathrm{kg}$ e $350 \mathrm{~W} / \mathrm{kg}$, respectivamente. O tempo médio de vida útil destas baterias é um dos seus limitantes, cerca de 500 ciclos carga/descarga. Os primeiros veículos elétricos retratados no $1^{\circ}$ e $2^{\circ}$ ciclos não tinham condições de competir com os veículos movidos à combustão, pois as baterias de chumbo - ácido não eram suficientemente compactas e leves. Isso acarretava em uma autonomia mínima comparada aos veículos fabricados atualmente. 


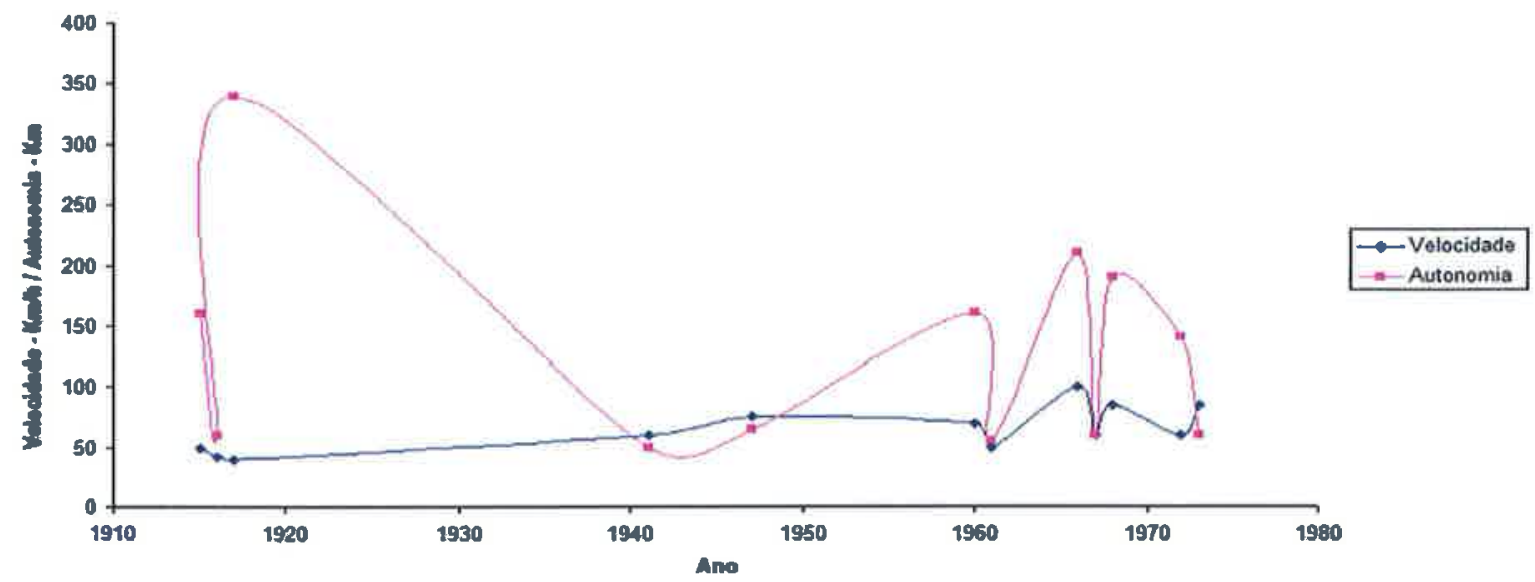

Gráfico 3 - $2^{\circ}$ Ciclo - Veículos Elétricos (1912 - 1973)

Fonte: Elaboração própria.

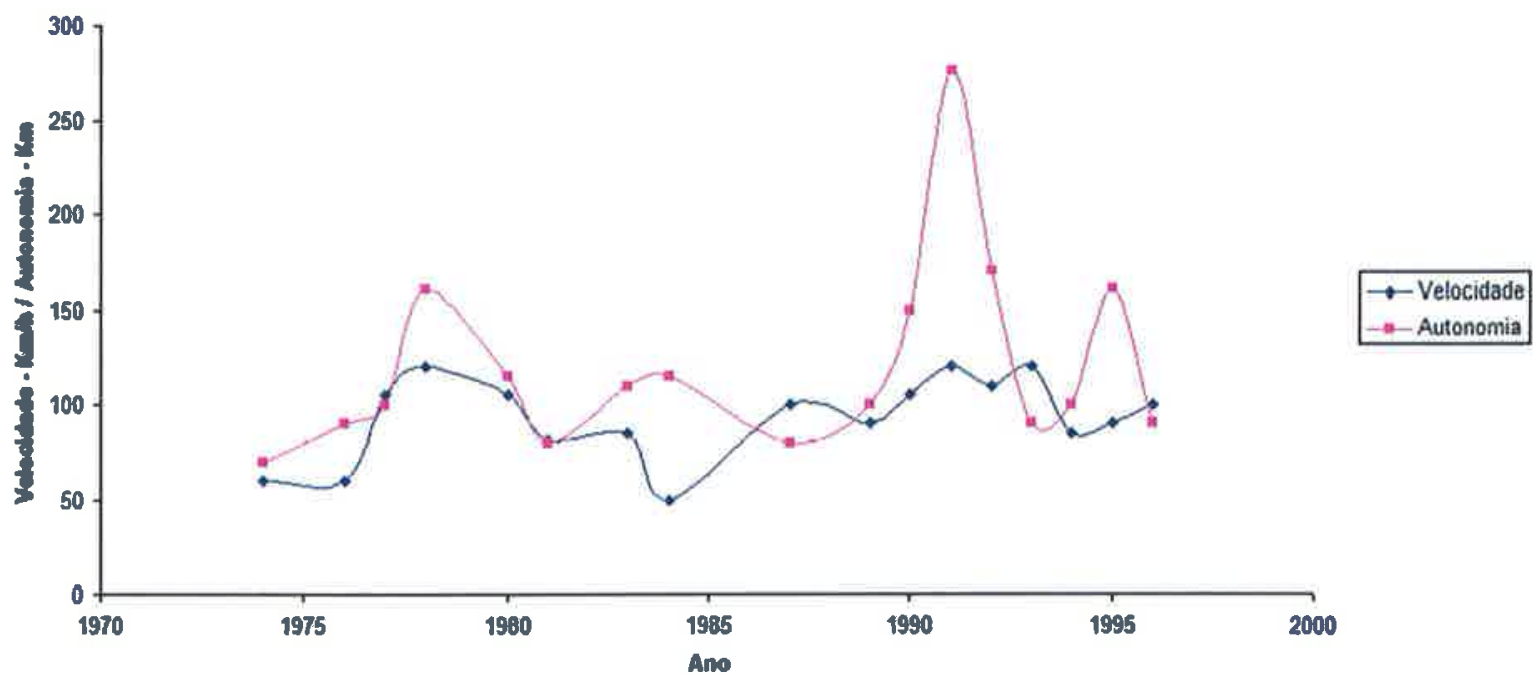

Gráfíco 4 - $3^{\circ}$ Ciclo - Veículos Elétricos (1974 - 1996)

Fonte: Elaboração própria 
Faia (2006), exemplifica que o tipo de bateria mais promissor apresentado nos últimos anos foi o de íon de lítio ( $L i$-Ion).Esta bateria utilizada intrinsecamente no $4^{\circ}$ ciclo apresenta energia específica de mais de $150 \mathrm{Wh} / \mathrm{kg}$ e potências específicas que podem ir até aos 2.000 $\mathrm{W} / \mathrm{kg}$. A sua vida útil é de cerca de 1.200 ciclos carga/descarga. As desvantagens deste tipo de baterias derivam do fato de necessitarem de um sistema de carga preciso, devido à sua reduzida tolerância a picos de potência e de serem ainda relativamente caras para veículos elétricos puros.

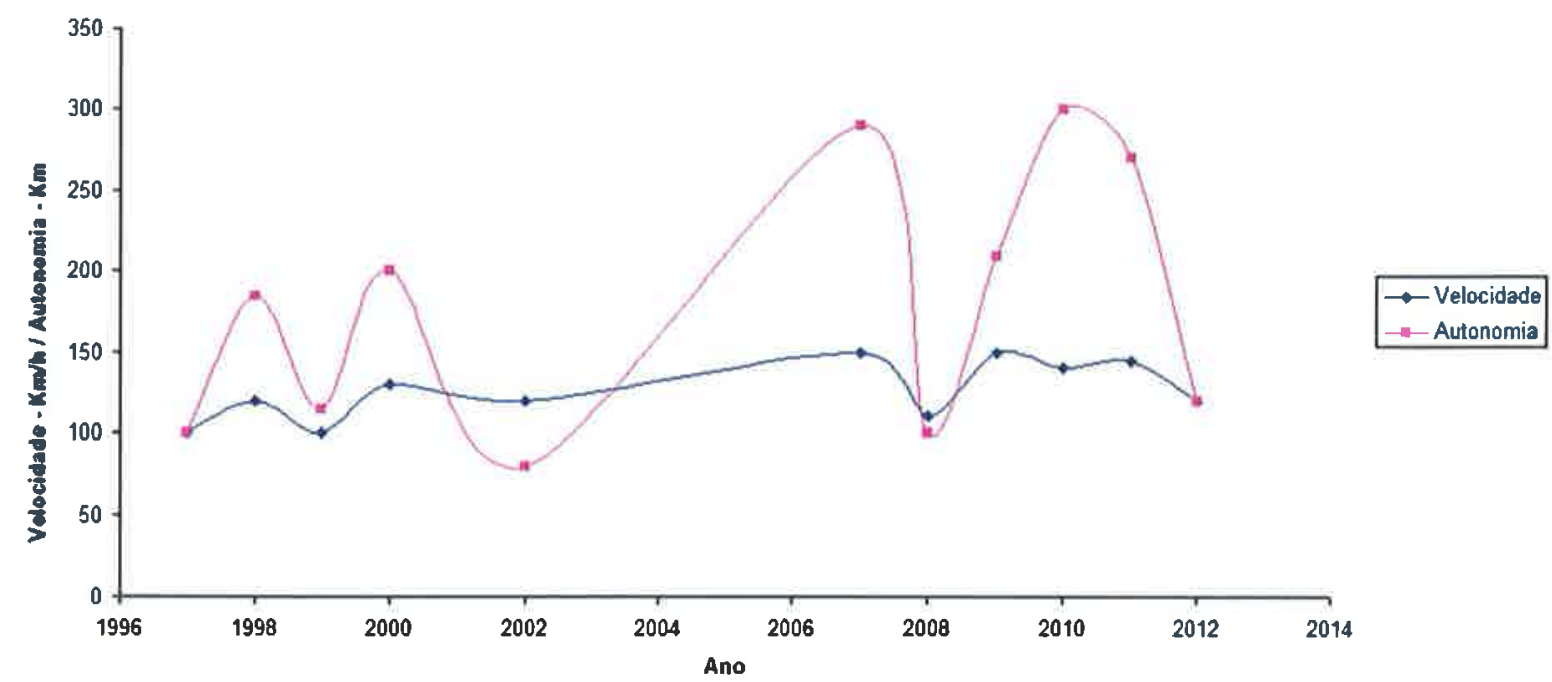

Gráfico 5 - $4^{\circ}$ Ciclo - Veículos Elétricos (1997 até os dias atuais)

Fonte: Elaboração própria

Uma solução para a inflexibilidade da autonomia das baterias foi apresentado por Andersen et al. (2009), que está sendo implementada em Israel. O cerne desta proposta é separação da propriedade do veículo da propriedade da bateria. Uma empresa seria responsável por assumir o risco de apropriação das baterias, que seriam alugadas. $\mathrm{O}$ consumidor seria cobrado pela energia que consumisse ao longo dos quilômetros viajados. Este modelo é análogo à cobrança de minutos utilizados por telefonia celular. Os consumidores teriam a disposição uma série de "pacotes", que irão depender do perfil de utilização da bateria.

Nessa vertente, os principais tipos de motores utilizados nos veículos elétricos são: Motor de Corrente Contínua (MCC), Motor de Indução ou Assíncrono (MI), Motor Síncrono de Imanes Permanentes (MIP) e o Motor de Relutância Comutado (MRC). Na Figura 7, pode-se verificar a avaliação qualitativa das diversas características dos motores, com o 
objetivo de se identificarem as tecnologias que poderão ter maior interesse/performance em aplicações de carros elétricos segundo Zeraoulia, Benbouzid, Diallo (2006).

\begin{tabular}{|c|c|c|c|c|c|}
\hline Caracteristicas & $\begin{array}{l}\text { (iin) है } \\
\text { MCC }\end{array}$ & $M$ & MP & MRC & $\begin{array}{l}5 \text { - Excelente } \\
4 \text { - Murito Bom } \\
\text { 3,5-Bom } \\
3 \text { - Suficiente } \\
\text { 2,5-Suficiente menos }\end{array}$ \\
\hline Densidade de potência & 2,5 & 3,5 & 5 & 3,5 & \\
\hline Eficiência & 2,5 & 3.5 & 5 & 3,5 & \\
\hline Controlabilidade & 5 & 5 & 4 & 3 & \\
\hline Fiabilidade & 3 & 5 & 4 & 5 & \\
\hline Maturidade Tecnológica & 5 & 5 & 4 & 4 & \\
\hline Custo & 4 & 5 & 3 & 4 & \\
\hline
\end{tabular}

Figura 7 - Electric Motor Drive Selection Issues for HEV Propulsion Systems: A Comparative Study

Fonte: Benbouzid; Diallo; Zeraoulia , (2005).

Assim, comparativamente os totais das classificações das características dos diferentes sistemas de propulsão referidos na Figura 7 , permitindo-nos indagar que o MI e o MIP são os mais indicados para os veículos elétricos. Assim, a partir do $4^{\circ}$ ciclo, o motor MIP torna- se mais requisitado nos modelos atuais perante aos ganhos em densidade, eficiência e custo.

No entanto, Zeraoulia, Benbouzid, Diallo (2006) elucidam que todos os motores da Figura 7 têm a capacidade de funcionarem como geradores aproveitando a energia da TR e da diminuição da velocidade para a transformarem em energia cinética em elétrica, que por sua vez será encaminhada para a bateria. 
Esse capítulo tem por finalidade apresentar um novo conceito para questões envolvendo o sistema de distribuição de cargas leves objetivando, sobretudo, a sustentabilidade dos transportes através da aplicabilidade do conceito de mobilidade elétrica. Serão apresentados propriamente topologias, características do Veículo Elétrico Urbano de Carga, assim como, a questão do carregamento realizado por intermédio das baterias.

\section{VEÍCULO ELÉTRICO: E SUAS CARACTERÍSTICAS}

\subsection{Tendências Atuais e Futuras}

A sociedade contemporânea está atravessando um período de grandes transformações sociais, econômicas, políticas e culturais. De acordo com Mitchell (2010), os números impressionam e assustam. A população do planeta está próxima dos 7 bilhões de habitantes. Ele reitera, que atualmente, 26 cidades ao redor do mundo são megalópoles com mais de 10 milhões de moradores - São Paulo está entre elas, estima-se que em 2030 cerca de $80 \%$ da riqueza mundial estará concentrada nas áreas urbanas. Para transportar tanta gente e suas mercadorias existem 850 milhões entre carros e caminhões movidos por trilhões de litros de combustíveis fósseis, que despejam na atmosfera quase 3 bilhões de toneladas de dióxido de carbono.

Sobretudo, o rápido crescimento da população e sua dispersão geográfica, a alta competitividade nos serviços de distribuição e a complexidade no sistema de trânsito têm gerado aumentos nos custos associados à operação dos veículos, principalmente em áreas urbanas. Pode-se observar, no entanto, que a economia de uma região está intrinsicamente ligada ao movimento de mercadorias. $O$ transporte de carga tem papel relevante na competitividade de uma área urbana e pode ser, em si mesmo, um elemento importante na economia de uma região.

Nesse sentido, várias cidades vêm adotando medidas restritivas, buscando minimizar os impactos negativos que de certa forma reduzem a acessibilidade e diminuem a eficiência logística do sistema de transporte urbano de pessoas e mercadorias. Isso acaba resultando em congestionamentos, no aumento dos tempos de viagem, baixa qualidade do serviço e, em alguns casos, maior número de veículos do que o necessário.

O termo transporte de carga (ou mercadorias), também chamado "urban goods movement" nos países de língua inglesa e "transport dês marchandises en ville" nos de língua 
francesa, pode ser definido como a organização do deslocamento de produtos dentro do território urbano (DABLANC, 1997). A movimentação da carga não é um fim em si mesmo, mas o reflexo físico de um processo econômico global, nacional e local (CZERNIAK, 2000).

Segundo Ogden (1992), está implícito que o sistema urbano de carga é apenas uma parte do processo administrativo no que diz respeito a transporte, armazenamento e manipulação de bens. Assim, o objetivo maior do transporte urbano de mercadoria, do ponto de vista da orientação política do planejamento, é o de minimizar os custos sociais totais. Dentro desse objetivo geral, Ogden (1992) sugere um conjunto de seis objetivos políticos específicos visto na Tabela 7 .

Tabela 7 - Conjunto de seis objetivos políticos específicos

\begin{tabular}{|c|c|}
\hline Objetivos & Descrições \\
\hline $\begin{array}{c}\text { Desempenho Macro Econômico do } \\
\text { Setor Público } \\
\end{array}$ & $\begin{array}{l}\text { Contribuir com o desempenho econômico dos mais variados } \\
\text { níveis (local, regional, nacional) }\end{array}$ \\
\hline $\begin{array}{l}\text { Custos e Qualidade dos Serviços de } \\
\text { Carga }\end{array}$ & $\begin{array}{l}\text { Aumentar a eficiência e produtividade da carga pela redução } \\
\text { dos custos operacionais dos transportes, especialmente, } \\
\text { àqueles associados ao congestionamento de tráfego }\end{array}$ \\
\hline Ambiental & $\begin{array}{l}\text { Minimizar os efeitos adversos das atividades de carga } \\
\text { (terminais e transportes), especialmente, ruído, emissões, } \\
\text { vibração e intrusão dentro das áreas residenciais }\end{array}$ \\
\hline Infra-Estrutura e Gerência & 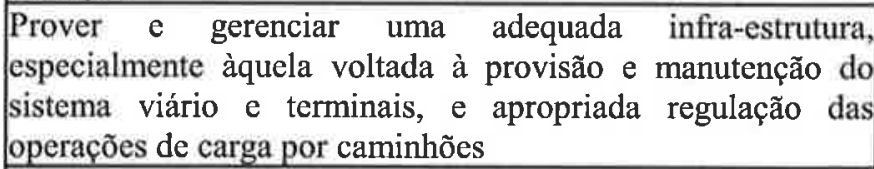 \\
\hline Segurança Viária & $\begin{array}{l}\text { Minimizar o número e a gravidade dos acidentes por } \\
\text { caminhões }\end{array}$ \\
\hline Estrutura Urbana & $\begin{array}{l}\text { Contribuir com a estrutura urbana "desejada", especialmente } \\
\text { na localização das atividades geradoras de carga e terminais }\end{array}$ \\
\hline
\end{tabular}

Fonte: OGDEN, (1992)

Neste contexto, como se constrói uma cidade sustentável? É possível harmonia entre os espaços públicos urbanos e as necessidades do mundo moderno? É viável criar políticas tendo como panorama qualidade de vida através de um desenvolvimento sustentável definido e planejado? Na Figura 8 percebemos resumidamente, os problemas decorrentes do transporte de carga. Como agentes influenciadores e responsáveis por mudanças no comportamento de cargas nas últimas décadas, pode-se citar, a globalização do mercado, a fillosofia JIT "Just in Time", estoque zero, o aumento da preocupação ambiental e o surgimento de novas tecnologias, como a B2C (Business to Consumer) e o comércio eletrônico (QUISPEL, 2002). Essas mudanças têm alterado o tamanho das entregas passando a menores e mais frequentes. 


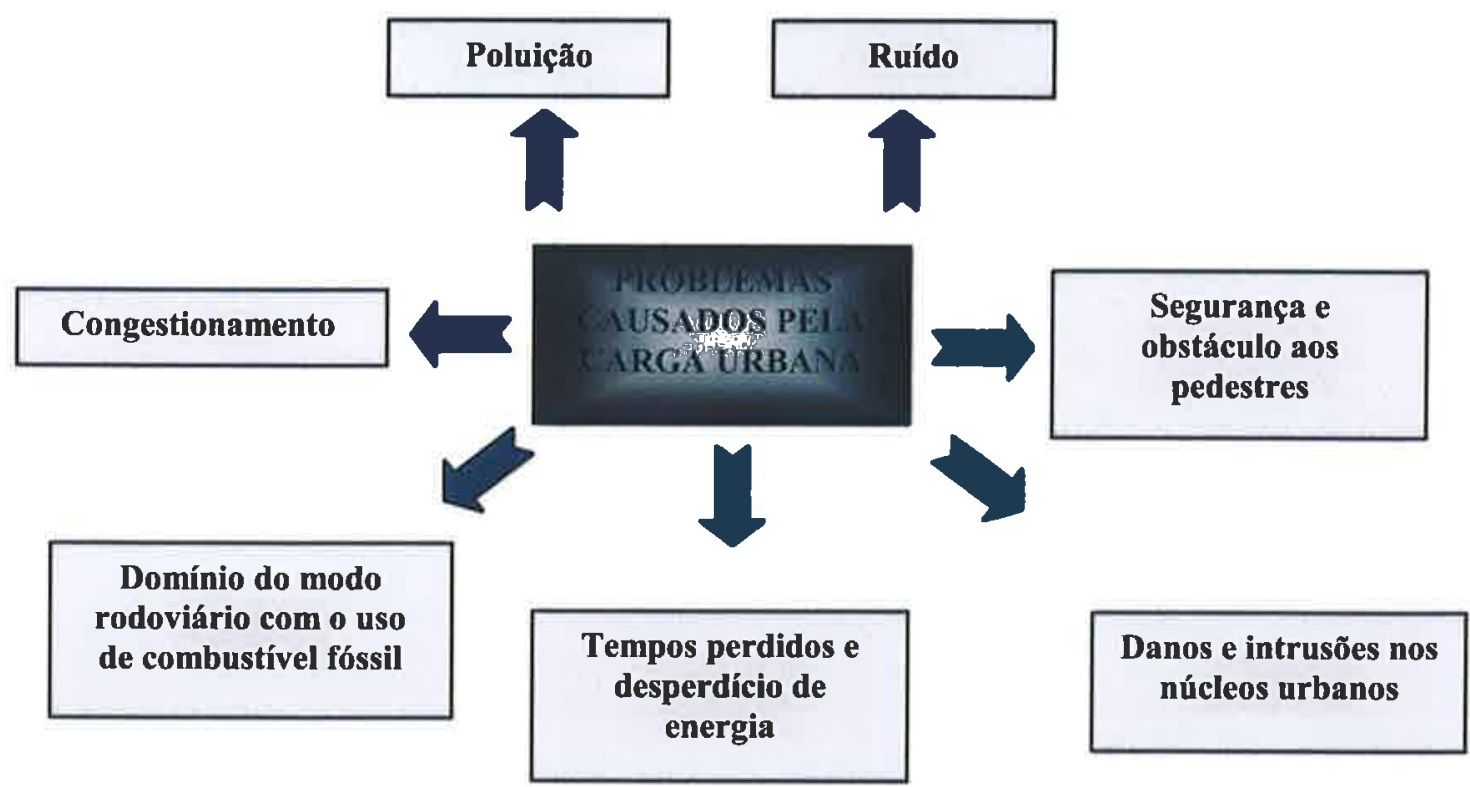

Figura 8 - Problemas no transporte urbano de cargas Fonte: QUISPEL, 2002. p. 2

Nesse aspecto, na Tabela 8 podemos visualizar conforme DENATRAN (2011), que o Brasil possui uma frota de 70,5 milhões de veículos entre automóveis, caminhões, ônibus, motos e carretas. O número evidencia aumento de $121 \%$ sobre os quase 32 milhões de veículos registrados em 2001.

Tabela 8 - Frota brasileira cresceu $121 \%$ nos últimos 10 anos

\begin{tabular}{|l|c|c|c|}
\hline \multicolumn{1}{|c|}{ Tipo } & $\mathbf{2 0 0 1}$ & $\mathbf{2 0 1 1}$ & Variação \\
\hline Automóveis & & & $88 \%$ \\
\hline Caminhões & 21.236 .011 & 39.832 .919 \\
\hline 1.650 .458 & 2.732 .901 & $66 \%$ \\
\hline Picapes & 3.318 .938 & 6.829 .326 & $106 \%$ \\
\hline Motocicletas & 4.535 .308 & 18.319 .502 \\
\hline Outros (ônibus, carretas) & 1.172 .288 & 2.828 .887 & $304 \%$ \\
\hline Total da frota brasileira & 31.913 .003 & 70.543 .535 \\
\hline
\end{tabular}

Fonte: Denatran, (2011)

Assim, o aumento da motorização, a tendência à formação de concentrações urbanas e o maior fluxo de cargas e pessoas fazem com que as áreas urbanas permaneçam fortemente congestionadas na maior parte do dia, com cada vez mais restrições para o planejamento e a geração de novas soluções de transporte, o que gera investimentos cada vez mais altos.

De acordo com Scaringella (2011), num periodo de cinco anos (entre 1992 e 1997), a média de quilômetros de congestionamento medidos pela CET no sistema viário principal da cidade passou de $40 \mathrm{~km}$, na hora de pico da tarde, para $120 \mathrm{~km}$. Hoje, conforme dados 
fornecidos pela CET (2011), há congestionamentos significativos em corredores da mais longínqua periferia e em todos os quadrantes. $\mathrm{O}$ grau de viscosidade urbana aumenta, e a problemática da mobilidade se agrava. Os deslocamentos ficam mais lentos e as áreas congestionadas crescem. No ano de 2011 houveram recordes de congestionamentos atingindo o pico de $220 \mathrm{~km}$ (CET, 2011).

A Secretaria do Estado de Transportes Metropolitanos (2010) estima que as perdas financeiras com acidentes de trânsito, poluição e engarrafamentos em São Paulo sejam de R\$ 4,1 bilhões por ano. Já o Instituto de Estudos Avançados da USP (2010) calcula perdas diárias de $\mathrm{R} \$ 11$ milhões com tempo e combustível nos congestionamentos. $\mathrm{O}$ estudo considerou a média de $80 \mathrm{Km}$ de lentidão por dia, com picos de $200 \mathrm{Km}$. No total, os custos anuais chegariam a R 3,3 bilhões. A soma do tempo perdido pelas pessoas no trânsito atinge média de 240.000 horas anuais. São desperdiçados cerca de 4 milhões de litros de diesel por ano em engarrafamentos na cidade.

A pergunta que se faz é: são traçadas diretrizes que envolvem a combinação das políticas de uso do solo, transporte e trânsito que devem compor a proposta de um modelo sistêmico visando propriamente o desenvolvimento sustentável de uma cidade? A amplitude e a complexidade do conceito de desenvolvimento sustentável permitem ainda que uma multiplicidade de dimensões ou potenciais dimensões sejam consideradas.

A questão das cidades, ou mais precisamente a questão urbana é, portanto, o ponto cerne para a promoção do desenvolvimento sustentável. Conforme Maclaren (2004), as expressões "sustentabilidade urbana" e "desenvolvimento urbano sustentável" possuem significados muito próximos e têm sido utilizadas indistintamente nos muitos trabalhos já publicados sobre o assunto.

Uma forma de distinguir estas duas expressões, entretanto, é considerar a sustentabilidade como um estado desejável ou um conjunto de condições que se mantém ao longo do tempo. Já a palavra "desenvolvimento" no termo "desenvolvimento urbano sustentável" implicaria no processo pelo qual a sustentabilidade pode ser alcançada. Algumas características-chaves relacionadas à sustentabilidade urbana são encontradas com freqüência na literatura incluindo (MACLAREN, 2004):

1. Equidade entre gerações;

2. Equidade intragerações, incluindo equidade social, geográfica (minimização das desigualdades entre diferentes comunidades) e governamental; 
3. Proteção ao meio ambiente natural e respeito aos seus limites;

4. Minimização do uso de recursos não-renováveis;

5. Vitalidade e diversidade econômica;

6. Autoconfiança por parte da comunidade;

7. Bem-estar individual;

8. Satisfação das necessidades básicas.

Logo, com o objetivo de determinar as medidas prioritárias voltadas à movimentação de cargas, em um ambiente com muitos envolvidos, Sinarimbo e Lidasan (2001) propuseram um modelo hierárquico. $\mathrm{O}$ diagrama hierárquico empregado é apresentado na Figura 9. Nesse estudo, o método se mostra eficiente ao que se propõe, chegando à obtenção de resultados que mostram a diversificação dos interesses entre os diversos participantes do movimento de carga.

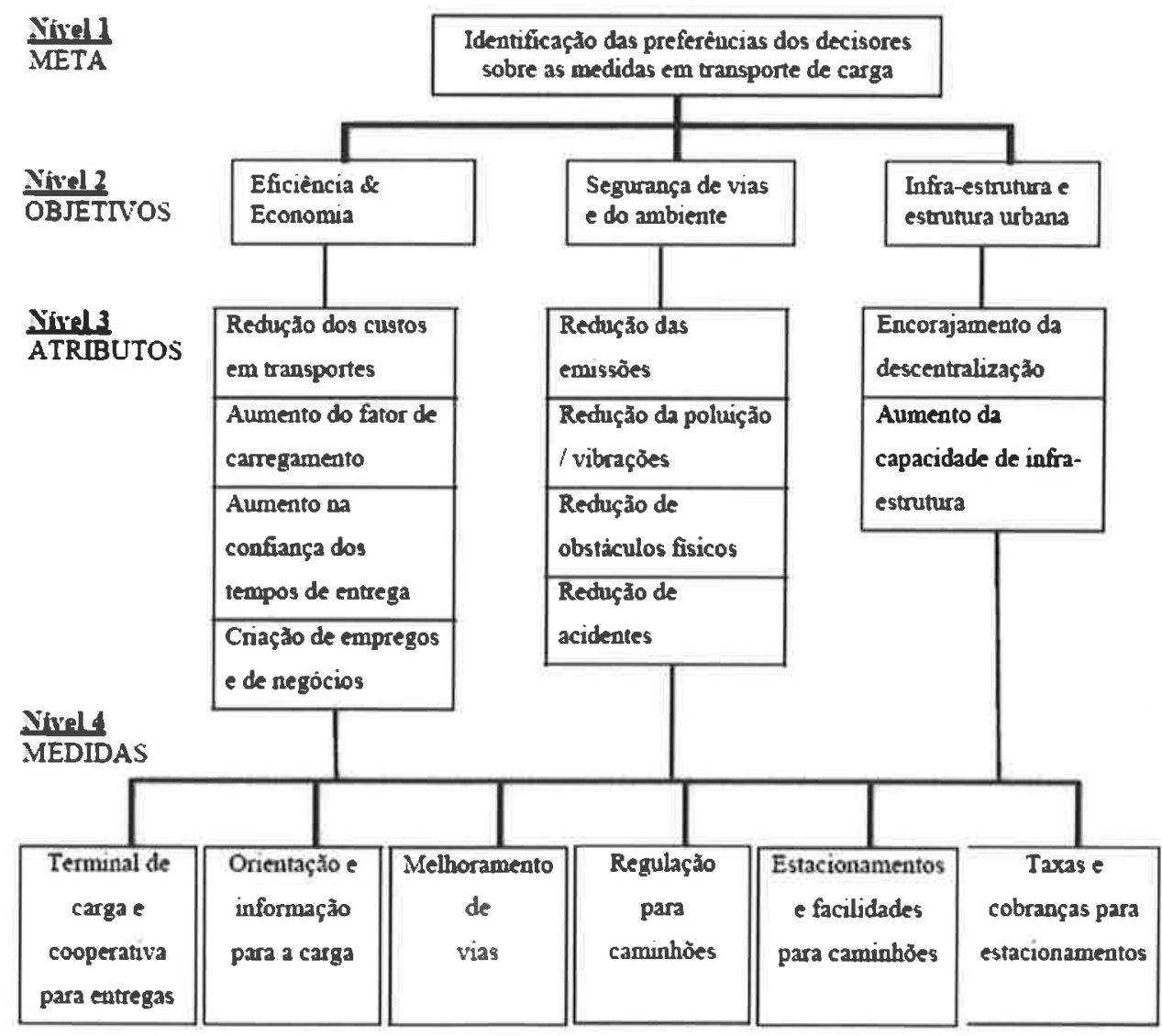

Figura 9 - Hierarquia das medidas

Fonte: SINARIMBO e LIDASAN (2001), p. 4. 
É factível que uma das formas de reduzir a dependência do setor de transportes e as emissões de poluentes locais e globais é derivada do uso de novas tecnologias que permitirão a interação do setor de transportes com o sistema elétrico. Dentre as opções, os veículos puramente elétricos possuem como única fonte de energia, a eletricidade, proveniente da rede, armazenada eletroquimicamente, enquanto que os veículos híbridos "plug-in" são automóveis híbridos elétricos (Hybrid Electric Vehicles - HEVs) que podem também extrair e armazenar energia, a partir de uma rede elétrica, para fornecer energia para a propulsão do veículo. Nos próximos itens serão contextualizados e detalhados os sistemas de propulsão elétrico e híbrido.

\subsection{Caracterizando os Veículos Elétricos}

Em um formato simplista, os veículos movidos à propulsão elétrica especificamente utilizam pelo menos um motor elétrico em sua tração, em que se associam a alta eficiência energética, o mínimo ruído e a reduzida ou nenhuma emissão de poluentes. Apresentam pouca complexidade na montagem propriamente na fabricação em comparação com os automóveis movidos a motor de combustão interna, sem a existência, de caixa de marchas, motor de arranque e de equipamentos do sistema de exaustão como o escapamento e catalisador, a até mesmo de sistema de arrefecimento como o radiador, bomba de água, entre outros elementos em se tratando do veículo movido à baterias. A Figura 10 engloba uma ampla gama de configurações com diferenciadas fontes de energia que encontram-se em estágios distintos de desenvolvimento. 


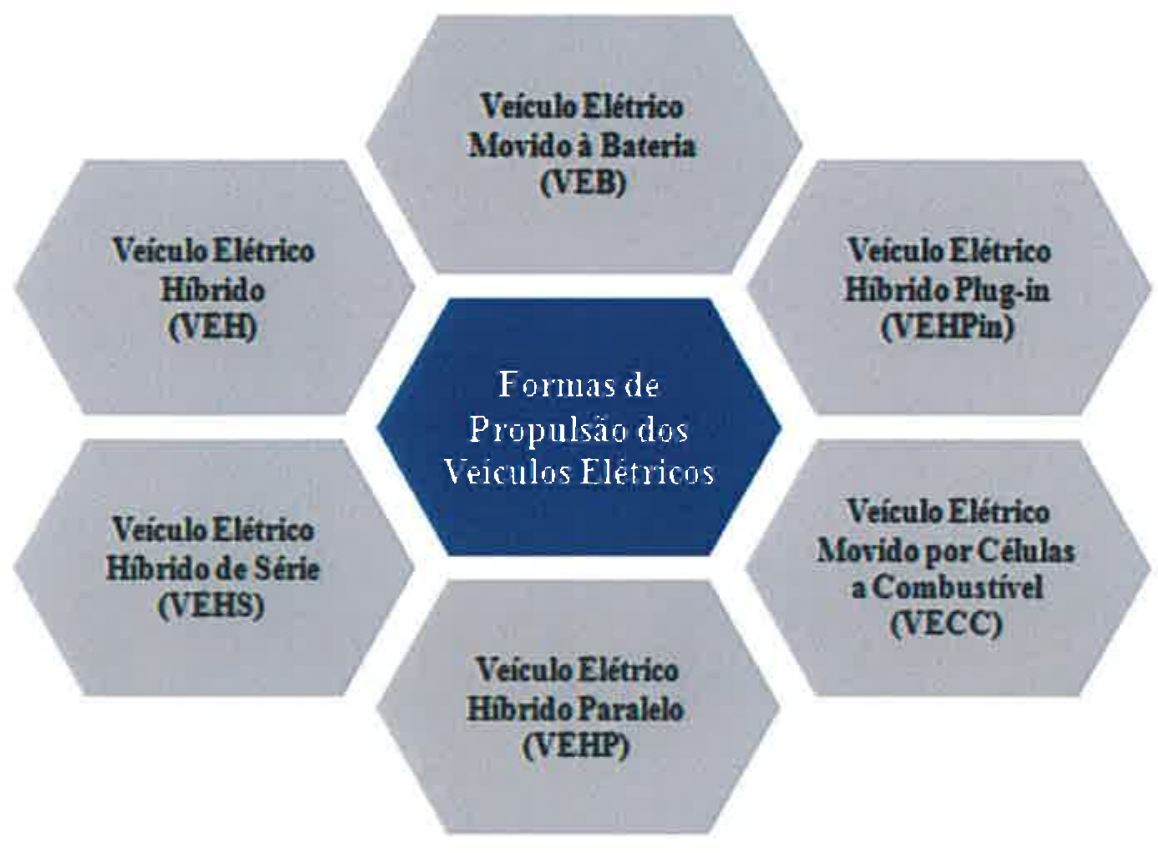

Figura 10 - Caracterização da propulsão elétrica em veículos

Fonte: Elaboração Própria

\subsubsection{Formas de Propulsão dos Veículos Elétricos}

Adiante, as configurações citadas no item acima poderão ser contextualizadas da seguinte forma:

- Veículo Elétrico Movido a Bateria (VEB): Do ponto de vista operacional é um automóvel que utiliza propriamente a energia elétrica proveniente da rede de distribuição pública, para recarregar a bateria instalada no interior do veículo (banco de baterias). A energia recebida é armazenada na bateria, em formato eletroquímico. Esta energia armazenada é convertida em energia elétrica, sendo esta transportada até ao Motor Elétrico (M/G) que fará a sua conversão em energia mecânica, proporcionando assim o movimento do veículo, sem a geração de emissões e sem ruído. Se no VEB estiver implementado seu sistema de Travagem Regenerativa (TR) é também possível armazenar a energia produzida em situações de travagem ou diminuição de velocidade, através da conversão da energia cinética em elétrica pelo $M / G$, a qual será armazenada na bateria. A configuração parcial dos componentes de um VEB está representada na Figura 11. 


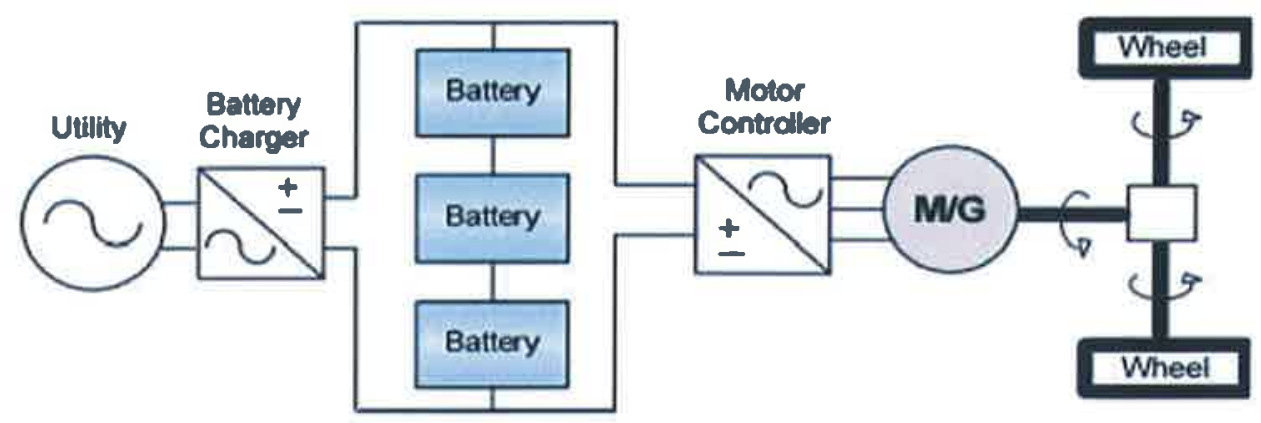

Figura 11 - Evolução das Baterias Fonte: Kramer, Kroposki (2009)

Já na Figura 12 os componentes são monstrados inseridos no veículo.

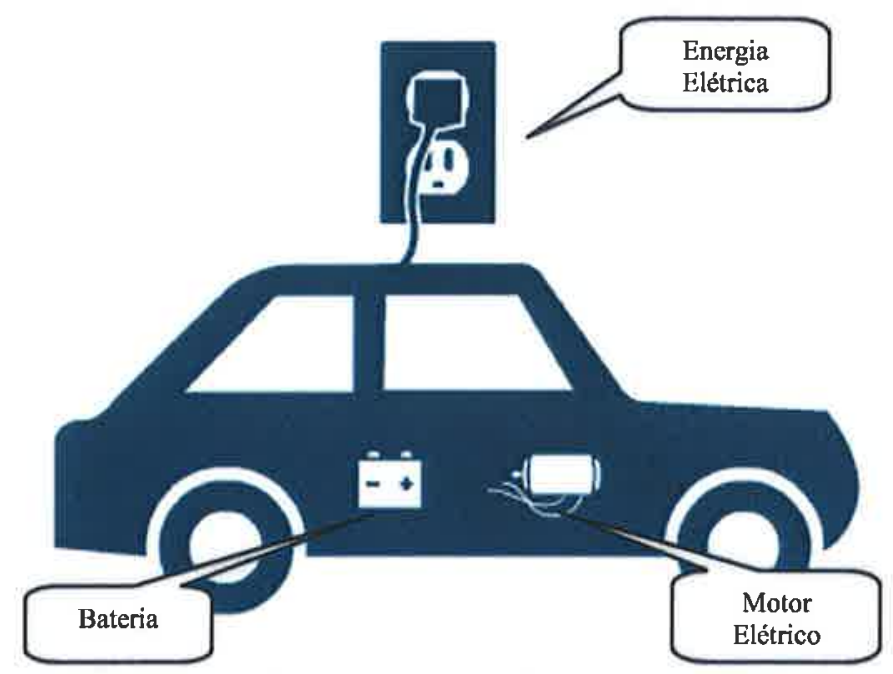

Figura 12 - Veículo movido a bateria Fonte: IEA

O alto rendimento do motor elétrico, em torno de $90 \%$, além da pouca vibração do automóvel é um destaque preeminente em comparação ao veículo movido à combustão. Vale ressaltar, que os ultra-capacitores auxiliam no sistema de regeneração (onde o motor elétrico passa a atuar como gerador elétrico nos momentos de frenagem e desaceleração) e são utilizados a fim de absorver a energia regenerada, já que nem sempre uma bateria consegue absorvê-la em curtos períodos de tempos de forma isolada. Os ultra-capacitores ainda podem disponibilizar a energia em formato maximizado auxiliando em uma rápida aceleração.

Fatores preponderantes a custos, à baixa autonomia, a morosidade para efetuar o carregamento são desvantagens verificadas. Para ampliar a autonomia do 
veículo é utilizado grandes bancos de baterias resultando em perda de espaço ocupado e excesso de peso. É producente observar também que um dos entraves na propagação dos veículos elétricos está ligado às tecnologias existentes para armazenagem de energia a bordo destes, as quais no caso dos acumuladores eletroquímicos, não alcançaram ainda níveis de performance que torne os veículos elétricos competitivos (KANARI, 2000).

Atualmente, já se encontram disponíveis veículos elétricos de diversos fabricantes e modelos, os quais visam atender a trajetos urbanos, ou para aplicações em fábricas, parques entre outras. O exemplo da Figura 13 mostra o"ECOTRAN" desenvolvido pela IVECO, como resposta às requisições do mercado para entregas urbanas (apud QUISPEL, 2002).

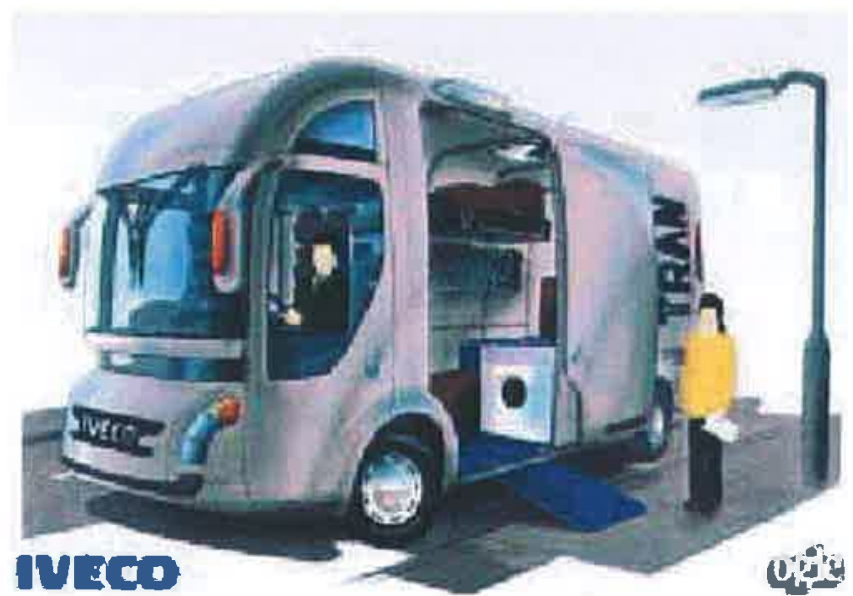

Figura 13 - "ECOTRAN", voltado à distribuição urbana Fonte: Quispel, 2002

Outro exemplo excelente é proveniente de duas fabricantes francesas, Goupil e Éco-Mobilité, em destaque a montadora Goupil, como mostra a Figura 14, é uma pequena empresa com cerca de 30 colaboradores na linha montagem, 10 na área técnica, além do pessoal administrativo e comercial. Atua desde $1996 \mathrm{e}$ fornece veículos elétricos movidos para prefeituras, indústrias e parques de entretenimento.

O conceito é fornecer uma opção em termos de menor volume, com um veículo que possa adentrar em locais em que caminhões não entram ou são proibidos de circular. Com dimensões aproximadas de 3,0 m (comprimento), $1,7 \mathrm{~m}$ (largura) e 1,5 m (altura) e que utiliza baterias de chumbo com até 1500 ciclos de recarga. Apresenta a capacidade de carregamento de 600 a $700 \mathrm{~kg}$ e 
uma autonomia que varia de 50 a 100 quilometros, de acordo com as cargas transportadas e baterias utilizadas.

Os custos operacionais são menores que um euro para cada 100 quilômetros percorridos. Tendo menor volume, a particularidade é a adoção de várias combinações com o mesmo chassi, o que permite a prática da modularidade de acordo com a função desejada (GOUPIL, 2011).

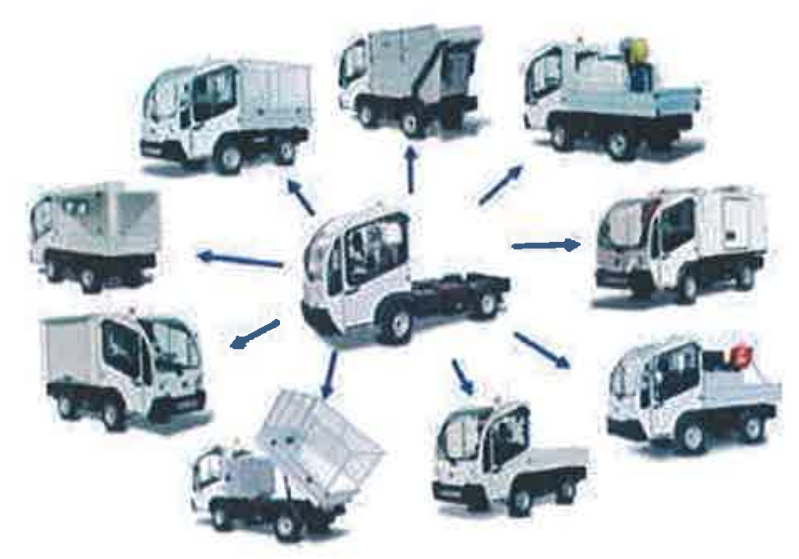

Figura 14- Veículos elétricos usados no transporte de cargas - containeres apoiados sobre o chassi

Fonte: Goupil, 2011

A Éco-Mobilité, uma empresa de origem mais recente, fabrica uma linha contendo vários produtos que associam a tração elétrica com características semelhantes ás do VEB fabricados pela Goupil. A Figura 15 traz exemplos de veículo elétricos Eco-Mobilité.
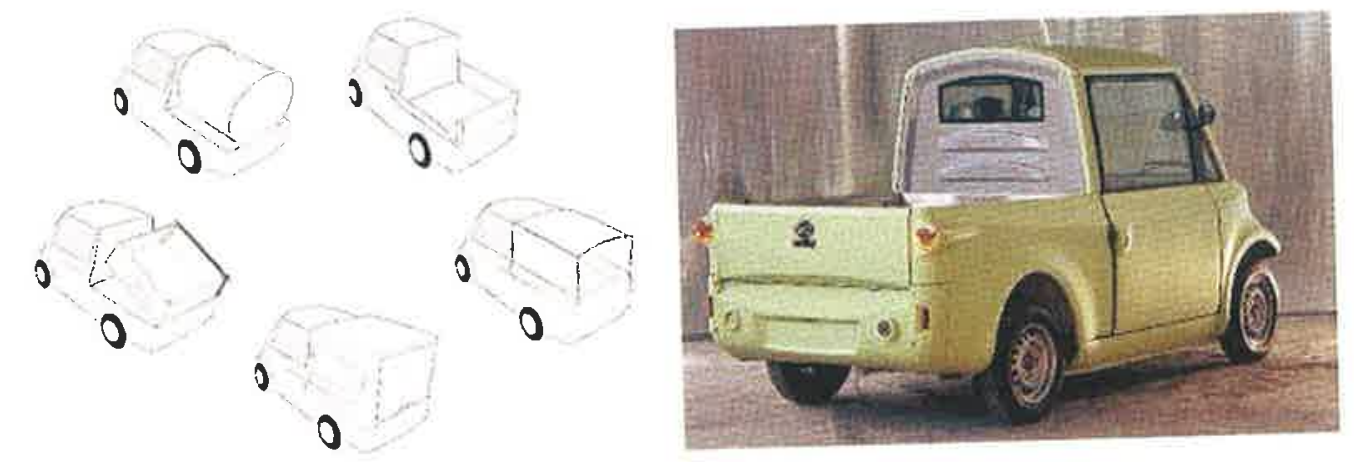

Figura 15 - "Éco-Mobilité", voltado à distribuição urbana Fonte: Éco-Mobilité, 2011 
Algumas cidades brasileiras começam a se movimentar no intuito de desenvolver projetos voltados à mobilidade como é o caso da parceria entre a Itaipu Binacional, Kraftwerke Oberhasli (KWO), controladora de hidrelétricas suíças, e a montadora FIAT, além de empresas de tecnologias, concessionárias de energia elétrica e instituições de pesquisa no Brasil que foram responsáveis pelo lançamento do primeiro caminhão elétrico no Brasil.

O Daily elétrico $55 \mathrm{C} / \mathrm{E}$, protótipo criado pela montadora Iveco, apresenta 6,9 metros de comprimento e nada mais que 5,5 toneladas de peso bruto, cerca de $450 \mathrm{~kg} \mathrm{a}$ mais do que a versão convencional. Buscando movimentar essa massa, a Iveco instalou sob o capô, um motor elétrico capaz de gerar $54 \mathrm{cv}$ de potência e 13,1 kgfm de torque, mas que pode atingir um pico de $108 \mathrm{cv}$ e 30,5 $\mathrm{kgfm}$. De qualquer forma, o desempenho permanece em torno, de $70 \mathrm{~km} / \mathrm{h}$ de velocidade máxima, que pode chegar a $85 \mathrm{~km} / \mathrm{h}$ no modo mais potente.

Esse motor foi projetado pela empresa suíça MES-DEA. Sua alimentação fica por conta de um conjunto de três baterias elétricas instaladas entre as longarinas do chassi, logo após o eixo traseiro. A energia contida nas baterias é repassada ao motor pelo regulador ligado a potenciômetros, dispositivos que determinam a potência a ser repassada de acordo com a necessidade.

A adaptação do Daily convencional à eletricidade é realizada dentro de um galpão da própria Usina de Itaipu, em Foz de Iguaçu, Paraná, com o auxílio da Isvor, empresa do grupo Fiat que trabalha com veículos elétricos.

A tração permanece no eixo traseiro, mas o câmbio manual dá lugar à uma caixa de transferência com apenas duas marchas, uma à frente e a outra a ré. As baterias são do tipo sódio, níquel e cádmio e pesam $165 \mathrm{~kg}$. A recarga completa leva mais ou menos 8 horas e as baterias podem ser recarregadas até mil vezes antes de serem trocadas. A autonomia é de aproximadamente $100 \mathrm{~km}$ no modo econômico, boa para um veículo que possui uma capacidade de carga de 2,5 toneladas.

Embora o modelo apresentado não guardasse diferenças visuais significativas em relação ao Daily movido à combustão, ao ligar o caminhão elétrico, elas ficam evidentes. Ao contrário de um turbodiesel, o motor elétrico não dá sinal de que está ligado. 
No entanto, ao acelerar, o Daily $55 \mathrm{C} / \mathrm{E}$ se move com suavidade, sem provocar outros ruídos além do contato dos pneus com o solo. O motor emite um leve sussurro apenas após desligar o modo Economy por meio de um botão no painel. Com isso, a potência máxima dobra de limitados $54 \mathrm{cv}$ para razoáveis $108 \mathrm{cv}$.

Com relação ao torque máximo, disponível de imediato com $30,5 \mathrm{kgfm}$ de força no modo mais forte, o Daily de 5,5 toneladas não se ressente da falta de força em rampas de até $18^{\circ}$ de inclinação.

Com uma boa calibração da direção eletrohidráulica, com a ausência de trancos e respostas adequadas do sistema de freios, cuja energia gerada em frenagens é armazenada nas baterias fazem deste veículo um transporte eficiente, sustentável e convidativo para sua utilização. A Figura 16 traz o modelo na versão elétrica do veículo Daily - IVECO.

\section{Informações Técnicas - Daily Elétrico - (protótipo)}

Modelo: 55C/E Cabine Dupla;

Sistema de Propulsão: motor elétrico MES-DEA de corrente alternada, tipo assíncrono, trifásico, controlado pelo inversor de potência e refrigerado a água.

Com $40 \mathrm{~kW}(54 \mathrm{cv})$ de potência nominal e torque de $129 \mathrm{Nm}$ a $2.950 \mathrm{rpm}$. Pico de potência a $80 \mathrm{~kW}(108 \mathrm{cv})$ e pico e torque de $300 \mathrm{Nm}$ a $2.950 \mathrm{rpm}$;

Velocidade máxima: $70 \mathrm{~km} / \mathrm{h}$ (carregado) a $85 \mathrm{~km} / \mathrm{h}$ (sem carga);

Comprimento: 6,9 metros;

Entre-Eixos: $3.750 \mathrm{~mm}$;

Peso Bruto Total: 5,5 toneladas;

Carga Útil: 2,5 toneladas;

Baterias: 3 baterias do tipo Zebra Z5;

Autonomia: $100 \mathrm{~km}$;

Recarga de Bateria: 8 horas (a partir da bateria totalmente descarregada). 


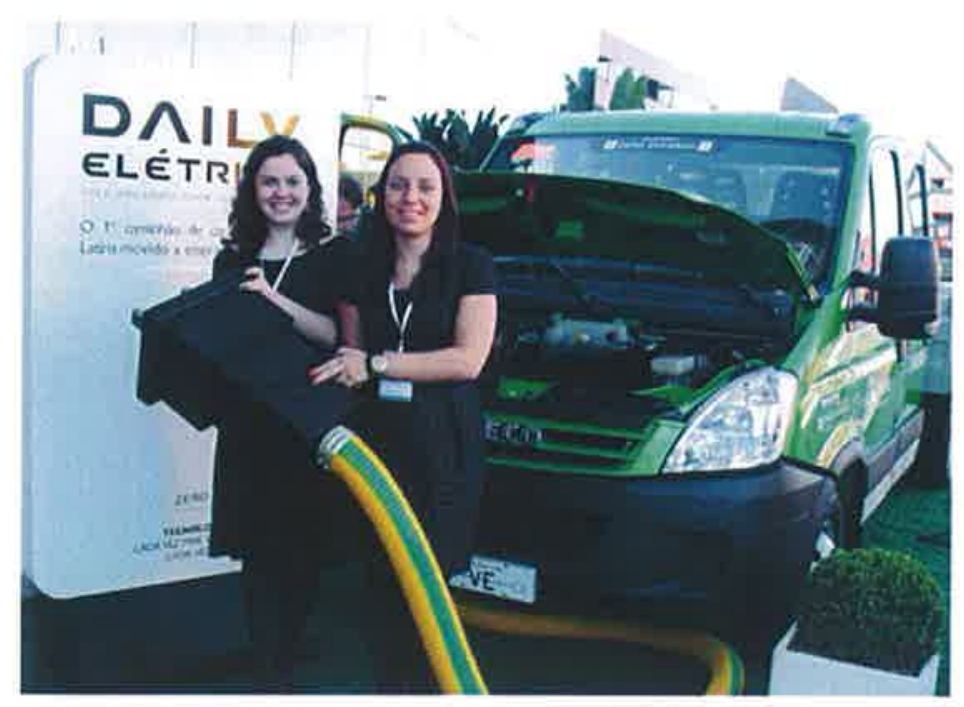

Figura 16 - Daily Elétrico

Fonte: Iveco, 2011

- Veículo Elétrico Híbrido (VEH): Veículo Elétrico Híbrido por definição caracteriza-se por possuir duas ou mais fontes de energia de propulsão, incorporando na sua estrutura um Motor a Combustão Interna (MCI) e um Motor Elétrico $\mathrm{M} / \mathrm{G}$ (que também funciona como gerador em caso de Travagem Regenerativa -TR) associado à uma bateria de pequena capacidade. A Figura 17 mostra os componentes alocados no veículo.

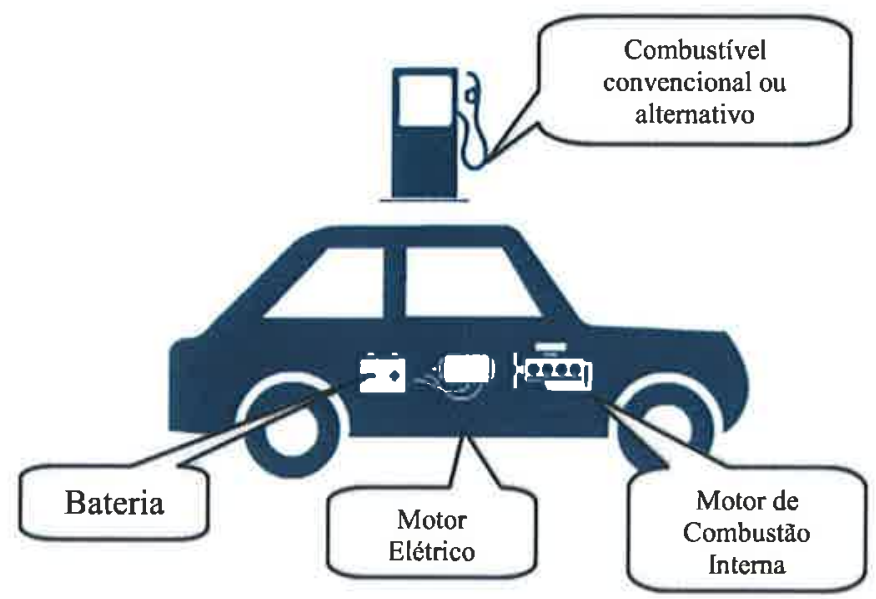

Figura 17 -Veículo elétrico híbrido

Fonte: IEA

Chau e Wong (2002) assinalam que qualquer veículo que tenha mais de uma fonte de propulsão pode ser classificado como um veículo elétrico híbrido, mas esse termo é mais freqüentemente utilizado para veículos que combinam motores elétricos com motores à combustão interna. 
Os veículos híbridos elétricos utilizam baterias ou supercapacitores especiais, como fontes de potência secundária, em adição à bateria principal. Essas fontes são responsáveis pelo fornecimento de alta potência em curtos períodos de tempo requeridos em pico de operação, como por exemplo, durante aceleração. Isto é preciso, pois algumas baterias com alta densidade de energia possuem baixa densidade de potência. Este tipo de veículo pode ter diferentes configurações de modo a serem atingidos vários objetivos como: diminuição do consumo de combustível, aumento de potência e diminuição das emissões de $\mathrm{CO}_{2}$, quer na cidade, quer em estrada, quando utilizados os dois tipos de motores.

A parte elétrica do veículo foi projetada para funcionar como motor ou gerador. No caso do funcionamento como motor, tenta-se trabalhar, sobretudo, nas baixas rotações, zona de funcionamento em que o motor de combustão interna com ciclo Otto tem baixo desempenho energético. No funcionamento como gerador, tenta-se aproveitar a energia cinética que o carro possui e seria desperdiçada em frenagens.

Vale ressaltar, que as exigências dos veículos elétricos híbridos com relação às baterias são menores do que em contrapartida nos veículos elétricos puros, onde elevada energia específica é necessária. Para os veículos elétricos híbridos o quesito fundamental é quanto à capacidade de potência.

A primazia dos veículos híbridos está associada ao fato do MCI operar na região ótima do motor, reduzindo o consumo energético do mesmo. $\mathrm{O}$ desenvolvimento e o progresso da eletro-eletrônica e áreas afins têm possibilitado o desenvolvimento de motores elétricos e sistemas de acionamento de alta eficiência, o que aliado à capacidade de regeneração de potência durante frenagens ou em descidas, tornam os veículos elétricos híbridos mais eficientes do que os veículos convencionais (JUNIOR, 2002).

Comparando a efíciência de veículos híbridos com os veículos à combustão, a partir do mapa de consumo específico de combustível ( $\mathrm{g} / \mathrm{kWh}$ ) do MCI a gasolina mapeado em um plano de velocidade ( $\mathrm{pm})$ e torque $(\mathrm{Nm})$. Cada região tem um contorno de consumo específico de combustível e o MCI tem regiões de eficiência delimitadas por fronteiras isoconsumo. Na Figura 18 observam-se os principais pontos de operação de um veículo convencional a gasolina, dentro de um mapa de consumo específico e de um MCI em um ciclo 
urbano de um veículo híbrido completo possuindo tipicamente um motor elétrico de cerca de $50 \mathrm{~kW}$ a 200-350 V. Apresentando o motor, gerador e o motor de combustão interna adotados em arquitetura série ou mista. Estes elementos em conjunto com os dispositivos restantes, incluindo a bateria, têm por objetivo achar o ponto ótimo de máxima eficiência energética e o mínimo de emissões de poluentes. Tipicamente na condução nas cidades consegue-se poupar $30 \%$ - $40 \%$ de energia, enquanto o preço do veículo aumenta $30 \%$ $40 \%$.
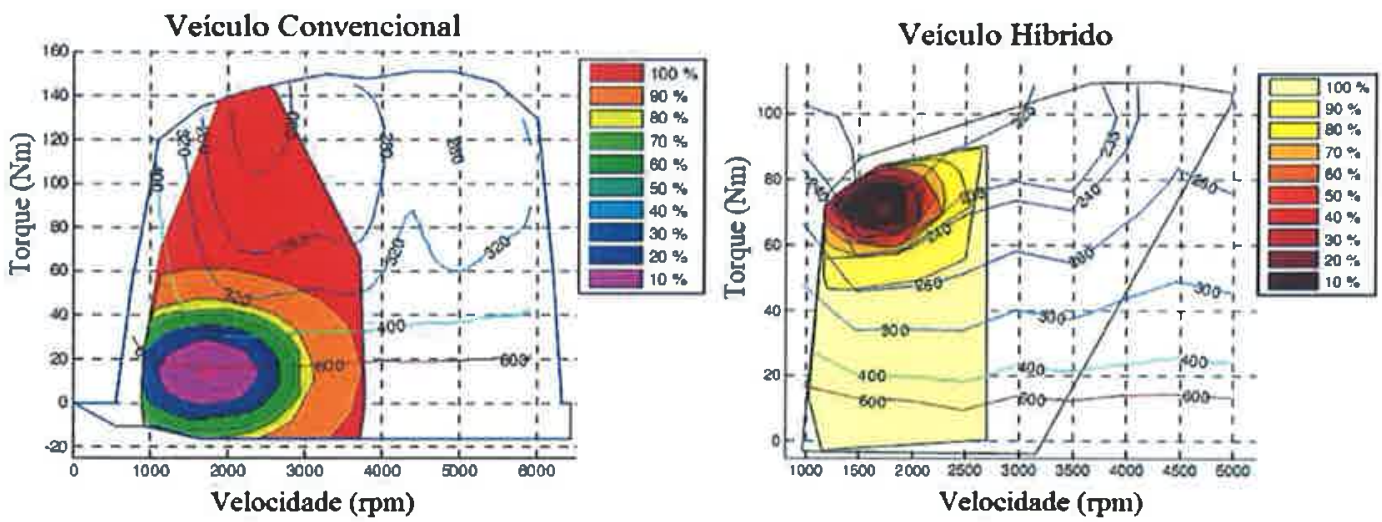

Figura 18 - Operação de um veículo MCI e um veículo híbrido no ciclo urbano Fonte: IEA,(2007)

É possível observar, que o MCI do veículo convencional permanece 50\% do tempo na faixa entre 1.000 e $2.500 \mathrm{rpm}$ e com torque entre -15 a $40 \mathrm{Nm}$. Em termos de eficiência, isso significa que o MCI operava em regiões de consumo específico $(\mathrm{g} / \mathrm{kWh})$ maior. No veículo híbrido completo, o sistema de gerenciamento de energia do veículo permite melhor o funcionamento do $\mathrm{MCI}$, fazendo-o trabalhar em regiões mais eficientes (torque mais elevado e velocidade variando entre 1.500 e $2.000 \mathrm{rpm}$ ) (SCHMITT, 2010).

Em contrapartida, a Figura 19 apresenta os principais pontos de operação de um motor movido à combustão convencional em um ciclo rodoviário e de um veículo elétrico híbrido completo dentro do mapa de consumo especifico. 

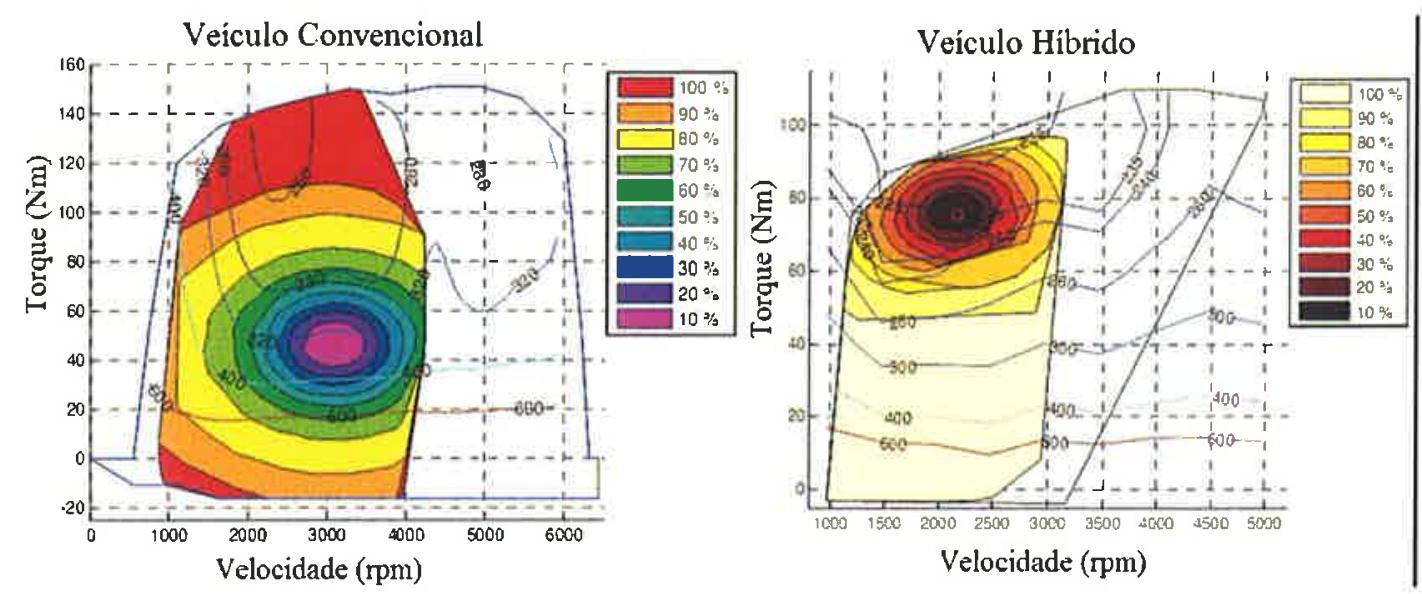

Figura 19 - Operação de um veículo MCI e um veículo VEH no ciclo rodoviário Fonte: IEA,(2007)

É considerável notar que os veículos híbridos não são tão benéficos nesta situação demonstrada acima. No ciclo rodoviário, o veículo convencional permanece $50 \%$ do tempo na faixa de 2.000 a $4.000 \mathrm{rpm}$ e torque de 20 a 60 $\mathrm{Nm}$, enquanto que o veículo híbrido permanece trabalhando na mesma região que no ciclo urbano.

Conforme o IEA (2007), o veículo elétrico híbrido completo apresenta uma redução de $40 \%$ em relação ao consumo de combustível comparando com o veículo convencional em condições urbanas. Em condições de auto-estrada a redução decai para $20 \%$.

- Veículo Híbrido Eletromecânico: De acordo, com Larminie e Lowry (2003), Shen e Veldpaus (2004) e Westbrook (2001), uma categoria adicional de veículo elétrico híbrido apresenta bateria assistida por um dispositivo acumulador de energia mecânico tal como um volante de inércia ou um acumulador hidráulico. $\mathrm{Na}$ Figura 20 é possível visualizar que o volante de inércia ou o acumulador hidráulico são conectados à linha de potência fornecida pela bateria e ao motor elétrico de tração através de um controlador central. O mesmo é responsável pelo funcionamento desejado do motor de tração elétrica, do volante de inércia ou do acumulador hidráulico propriamente, e pelo fluxo de potência da bateria. 


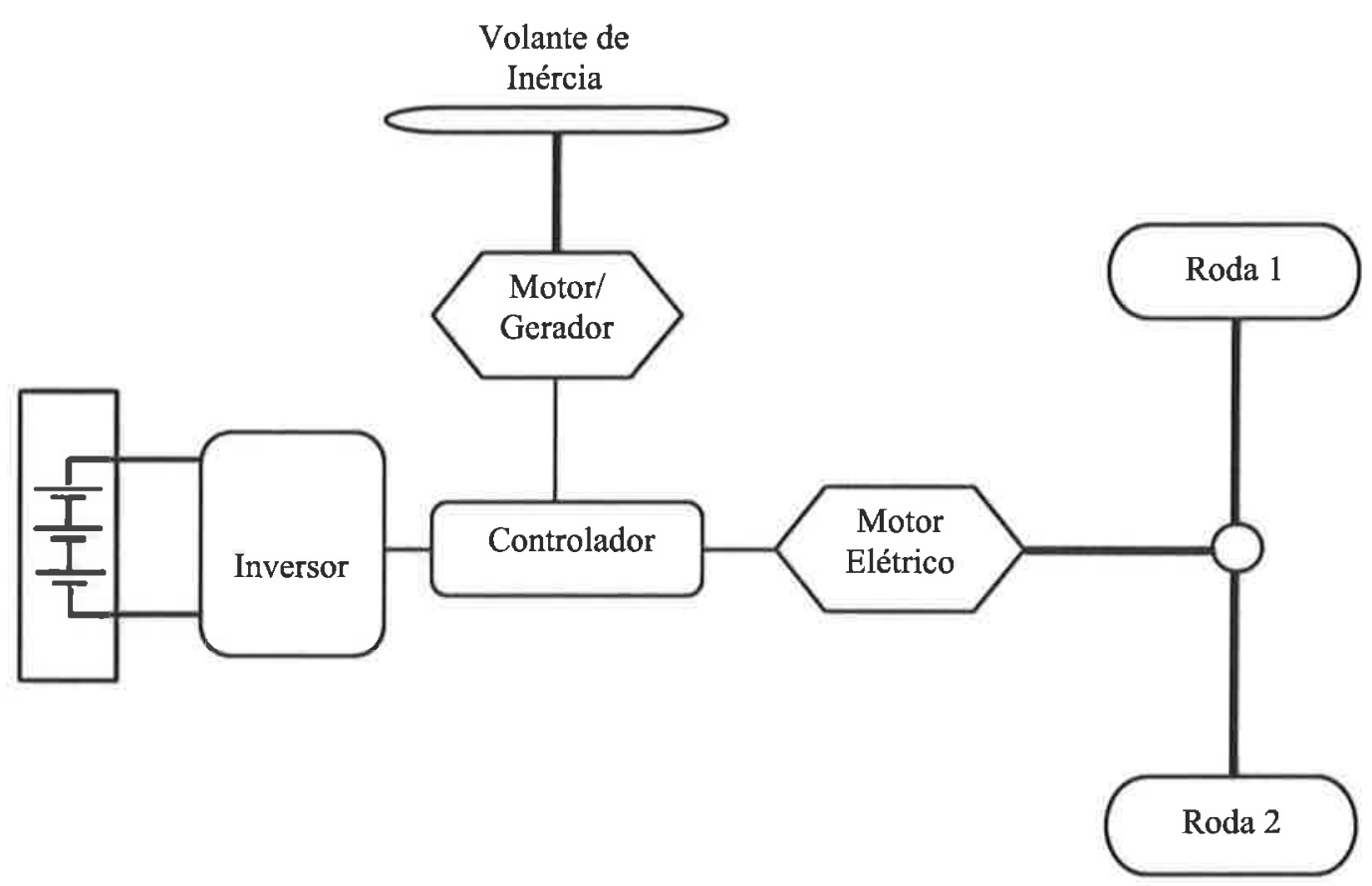

Figura 20 - Veículo Eletromecânico com volante de inércia Fonte: Adaptado de Shen e Veldpaus, (2004)

É coerente destacar que o controlador opera utilizando um algoritmo que utiliza o fluxo de energia para a máxima eficiência do sistema para que a potência requerida em velocidades constantes seja fornecida pela bateria. Entretanto, em situações de aceleração, a potência é solicitada a partir do volante de inércia ou do acumulador hidráulico.

Tanto o acumulador hidráulico quanto o volante de inércia são capazes de fornecer, ou absorver durante a regeneração. $\mathrm{Na}$ frenagem, a maquina elétrica de tração atua como gerador e a energia regenerada é usada para recarregar a bateria e manter o volante de inércia à alta velocidade ou o acumulador recarregado.

- Veículo Elétrico Híbrido de Série (VEHS) : O sistema híbrido em série apresenta uma topologia constituída pelo motor elétrico responsável pela tração do veículo, não havendo transmissão direta do motor a combustão interna para as rodas. Neste sistema, o motor à combustão interna gera a energia necessária para o funcionamento do motor elétrico. Ou seja, o motor à combustão interna aciona um gerador, cuja energia pode ser utilizada para carregar as baterias e/ou acionar o motor elétrico, como traz a Figura 21: 


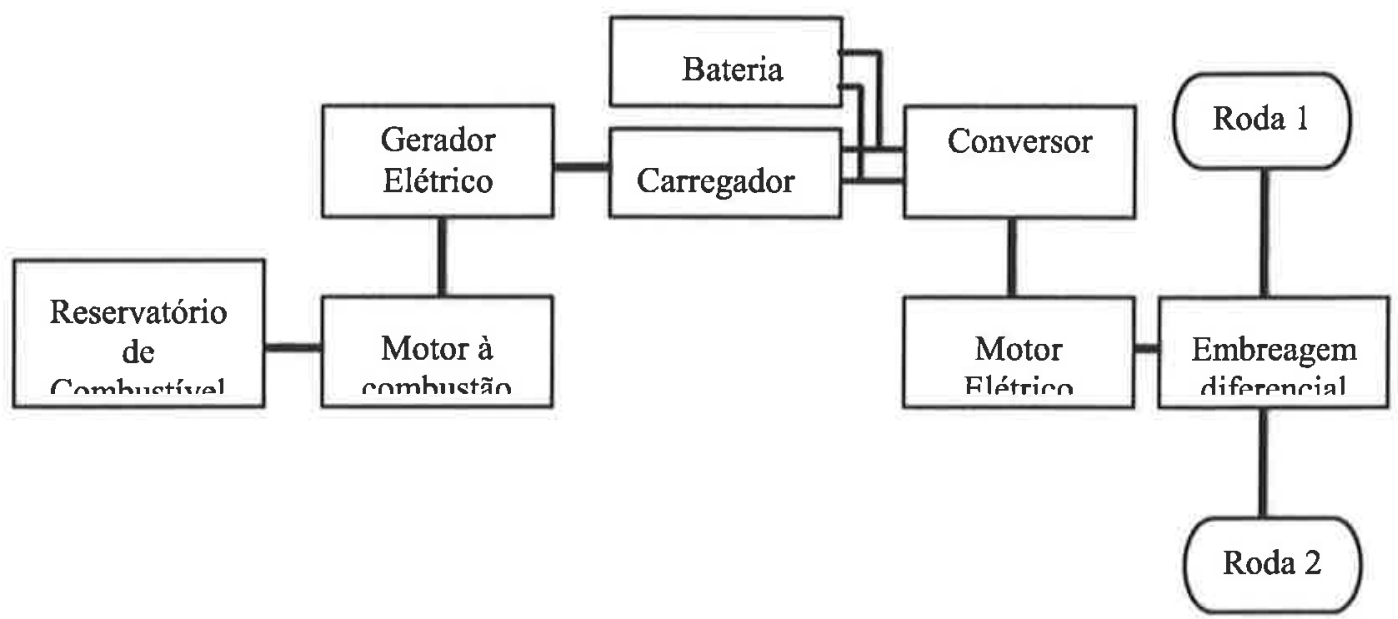

Figura 21 - Veículo Elétrico Híbrido de Série (topologia)

Fonte: Lebensztajn e Pellini, (2005)

Na Figura acima fica claro que existe uma combinação de fontes de energia. A tração do veículo é obtida a partir de um único motor elétrico. No entanto, a energia necessária para o acionamento deste motor resulta da combinação de duas ou mais fontes independentes. O reservatório de combustível utilizado tanto para gasolina quanto para diesel é utilizado para acionar um motor à combustão que aciona um gerador elétrico. A energia elétrica gerada por este gerador pode seguir dois caminhos. No primeiro, ela segue diretamente para alimentar o conversor eletrônico que aciona o motor elétrico. No segundo, esta energia pode alimentar o sistema de baterias a bordo.

Para elucidar, a Figura 22 ilustra um VEH na configuração série, onde a força de tração que chega as rodas é obtida através de um ou mais motores elétricos, alimentados pelas fontes de energia do veículo. Caso um motor de combustão interna seja uma das fontes do sistema, um gerador irá converter a energia do MCI em energia elétrica que será somada 'a energia proveniente das outras fontes e fornecida às rodas através dos motores elétricos. 


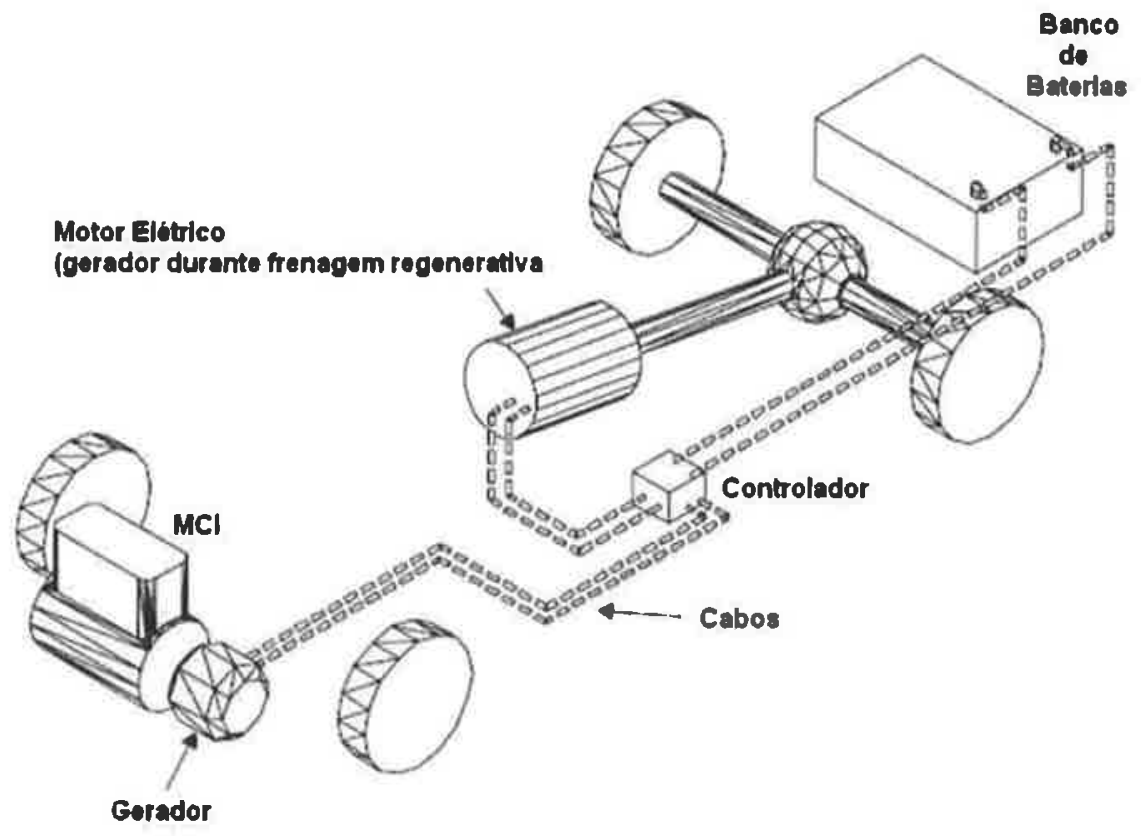

Figura 22 - Veículo Elétrico Híbrido de Série (configuração)

Fonte: Revoredo, (2007)

O fluxo de potência poderá escolher caminhos distintos dependendo do modo de operação do carro. Em uma situação onde seja necessário uma elevada potência de aceleração, tanto a bateria como o motor a combustão, fornecem energia para o motor elétrico. Durante os períodos de frenagem, o sistema de baterias irá receber energia do motor à combustão e ao mesmo tempo energia cinética do carro. Neste instante, o motor elétrico irá operar também como um gerador elétrico.

É valido ressaltar que neste veículo, é possível acionar o motor de combustão próximo à uma velocidade constante dividindo sua potência de saída tanto para carregar a bateria como para fornecer potência para tração das rodas do veículo. Como desvantagens podemos citar a ausência de um alternador/retificador. De acordo com Rizoulis, Burl e Beard (2001), a eficiência do sistema total é reduzida pela dupla conversão de potência mecânica para elétrica, armazenando parte dessa potência na bateria, e então convertendo essa energia novamente de elétrica para mecânica buscando mover o veículo.

- Veículo Elétrico Híbrido Paralelo (VEHP): É uma combinação de dois tipos de tração como consta na Figura 23. 


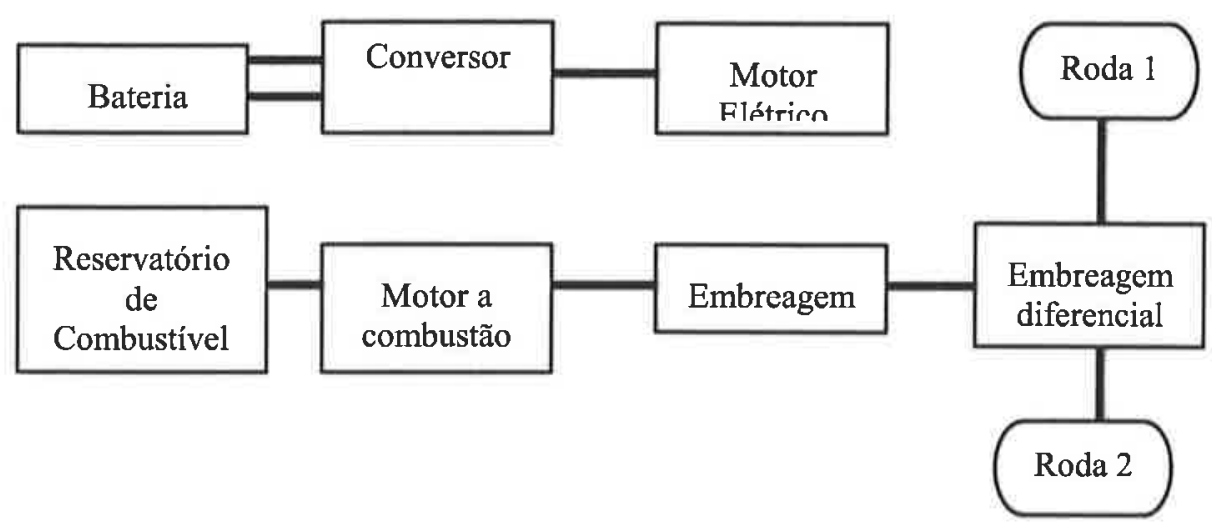

Figura 23 - Veículo Elétrico Híbrido Paralelo (topologia)

Fonte: Lebensztajn e Pellini, (2005)

Tanto o motor elétrico como o motor a combustão atuam de forma conjunta através de embreagens de modo a tracionar o veículo. Tanto um como o outro podem ser desconectados, o que torna possível tracionar usando apenas o motor a combustão ou apenas o motor elétrico.

A Figura 24 mostra o veículo sendo impulsionado diretamente pelo motor de combustão interna, através de um sistema de engrenagens que transmite a potência gerada pelo mesmo às rodas e/ou através de motores elétricos alimentados por outras fontes de energia, normalmente um banco de baterias.

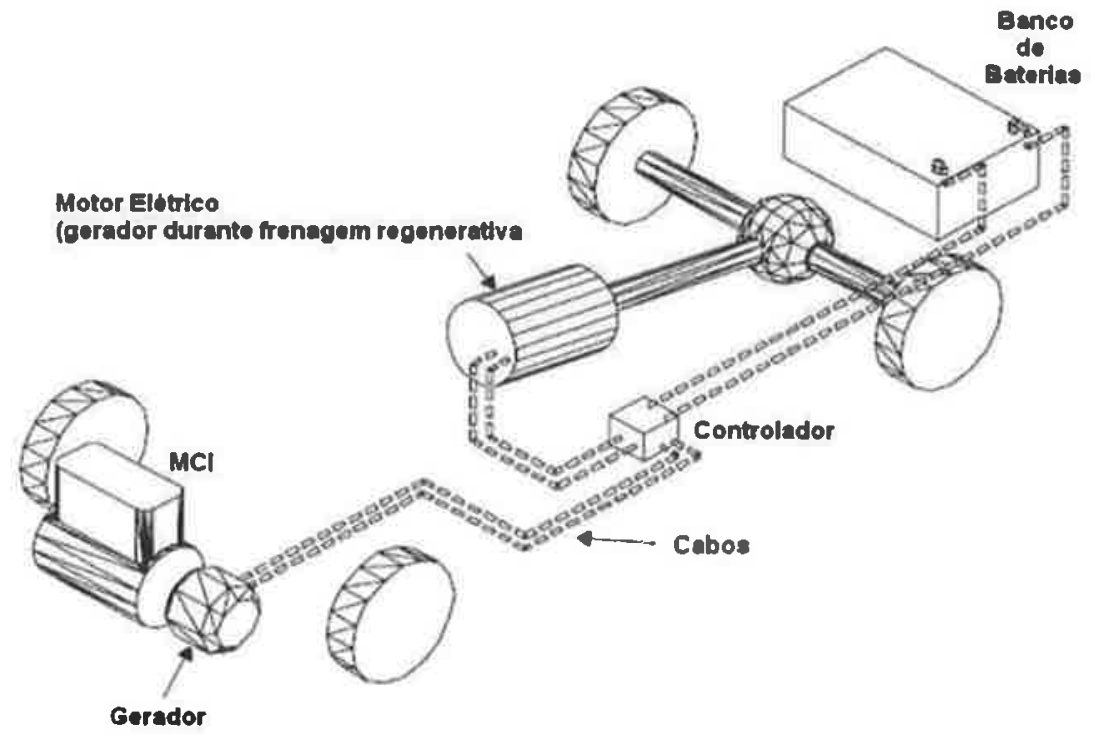

Figura 24 - Veículo Elétrico Híbrido Paralelo (configuração)

Fonte: Revoredo, (2007) 
No carro híbrido paralelo também é possível inverter o fluxo de potência fazendo com que o motor elétrico passe a operar como gerador. Deste modo, o sistema de baterias poderá ser carregado a partir do motor a combustão, e também, do excesso de energia cinética durante os intervalos de frenagem.

De acordo com o nível funcional e de potência do motor elétrico, os veículos híbridos podem ser classificados em três categorias (CHAN et al., 2007):

(a) Micro: Possui tipicamente um motor elétrico com cerca de $2,5 \mathrm{~kW}$ a $12 \mathrm{~V}$, é essencial para o arranque e funciona como alternador nos veículos convencionais de combustão. Consegue-se melhorar a eficiência energética entre $5 \%-10 \%$ em relação aos veículos convencionais em situações de trânsito. Em relação aos veículos convencionais, estes automóveis possuem um preço final ligeiramente mais elevado.

(b) Mediano: Possui tipicamente um motor elétrico com cerca de 15-20 kW a 120-160 V. Neste caso, o motor é incorporado diretamente na transmissão e é desenhado de forma a ter uma elevada inércia. Baseada na arquitetura em paralelo, esta categoria de hibridos consegue poupar cerca de $20 \%-30 \%$ de energia a custo do aumento de $20 \%-30 \%$ do preço final do veículo.

(c) Completo: Possui tipicamente um motor elétrico de cerca de $50 \mathrm{~kW}$ a 200$350 \mathrm{~V}$. Normalmente tem o motor, o gerador e o motor de combustão interna adotados em arquitetura em série ou mista. Estes elementos em conjunto com os dispositivos restantes, incluindo a bateria, têm por objetivo achar o ponto ótimo de máxima eficiência energética e o mínimo de emissões de poluentes. Tipicamente na condução nas cidades consegue-se poupar 30\%-40\% de energia, enquanto o preço do veículo aumenta $30 \%$ - $40 \%$.

- Veículo Híbrido Elétrico Plug-in (VEHP-in): apresenta uma bateria com maior capacidade de armazenamento que pode ser carregada diretamente da rede elétrica por meio de uma tomada (plug) . No entanto, os veículos híbridos plug-in diferem de um veículo elétrico puro, pois ele usa outras fontes de energia além de elétrica e a bateria normalmente tem uma capacidade menor em comparação com o veículo elétrico. 
A frenagem regenerativa também é usada e é acionada quando o freio é pressionado para reduzir a velocidade, transformando a energia cinética do veículo em elétrica que é armazenada na bateria.

Uma das principais vantagens deste veículo deriva do fato de que as concessionárias de energia elétrica operam na maior parte do tempo em um nível de subutilização, devido às características do sistema energético para atender uma expectativa de pico de demanda. Assim sendo, exceto por esses períodos de pico de uso, o sistema poderia gerar e fornecer uma quantidade substancial de energia necessária para abastecer os veículos que consomem eletricidade da rede a um baixo custo marginal de geração de energia (SOVACOOL e HIRSH 2009).

O gerenciamento de energia dos veículos plug-in determinam como o automóvel utilizará os combustíveis disponíveis a partir dos objetivos do usuário (maior eficiência, menor emissão, menor custo entre outros). Os modos de gerenciamento de energia dos (VEHP-in) mais relevantes são (BRADLEY e FRANK, 2009) :

(a) Modo Sustentação de Carga (Charge-Sustaining mode - CS): Neste modo o estado de carga da bateria (Battery State of Charge - SOC) é controlado para permanecer dentro de uma faixa estreita de funcionamento. Dependendo do tipo de bateria e do tipo de configuração do veículo, este valor oscila entre 30 e 45\% (SILVA et al., 2009). Este é o modo que os veículos híbridos elétricos convencionais operam na maior parte do tempo. Todavia, nos veículos híbridos convencionais, o SOC é mantido entre 65 e 75\% (EMADI et al., 2006). Dado que o estado de carga da bateria não altera significativamente com o tempo, o combustível líquido é a principal fonte de energia para o veículo;

(b) Modo Depleção de Carga (Charge-Depleting mode CD): o estado de carga da bateria é controlado para diminuir durante o funcionamento do veículo. Ou seja, a principal fonte energética para o veículo neste modo de operação é a eletricidade proveniente do sistema de armazenamento eletroquímico de energia; 
(c) Modo Veículo Elétrico única fonte de energia para o veículo é o sistema de armazenamento de energia eletroquímica. O VEHP-in opera como um veículo elétrico;

(d) Modo Motor de Combustão Interna: o sistema de tração elétrica não fornece potência para o veículo. O VEHP-in funciona como um veículo convencional.

A maioria dos protótipos VEHP-in contém uma bateria capaz de alimentar o veículo entre 30 e 100 quilômetros somente com eletricidade (SOVACOLL e HIRSH 2009).

Os modos de gerenciamento de energia podem ser alterados com base em parâmetros do veículo, como estado de carga da bateria, velocidade, torque, rotação do motor, temperatura ambiente, temperatura da bateria, etc, assim como, pode ser alterado manualmente pelo usuário do veículo (BRADLEY e FRANK, 2009).

Geralmente os VEHP-in são classificados de acordo com o modo de gerenciamento de energia da seguinte forma (BRADLEY e FRANK, 2009; SILVA et al., 2009):

(a) VEHP-in Extensor de Autonomia (Range extender PHEVs): Opera principalmente no Modo Veículo Elétrico e muda para o Modo Sustentação de Carga quando o estado de carga da bateria (SOC) fica reduzido;

(b) VEHP-in Misturado (PHEVs Blended): Opera no Modo Depleção de Carga e muda para o Modo Sustentação de Carga quando o SOC diminui;

(c) VEHP-in Zona Verde (Green Zone PHEVs): Opera no Modo Sustentação de Carga, mas pode ser controlado pelo usuário para operar no Modo Veículo Elétrico. Pode ser usado para operar em locais com restrição de emissões locais.

A freqüência .e o tempo de carga dos veículos plug-in dependem do comportamento do usuário e da disponibilidade de locais de recarga. $\mathrm{O}$ 
desempenho energético destes veículos é maximizado se cada viagem é iniciada com a bateria totalmente carregada, ou seja, quanto maior a frequência de carga da bateria, melhor o desempenho dos veículos (SILVA et al., 2009). Duas pesquisas realizadas no EUA indicam que os usuários dos VEHP-in podem preferir abastecer o veículo com energia elétrica ao invés de combustíveis líquidos. Os estudos feitos com pessoas que possuem veículos híbridos convertidos, indicaram que as principais vantagens associadas ao VEHP-in são a flexibilidade de recarga e o custo. Ou seja, a maioria das pessoas prefere abastecer o veículo nos locais que visita regularmente, como trabalho ou residência, ao invés de em postos de abastecimento. Os resultados sugerem que é mais provável que as pessoas utilizem o Modo Depleção de Carga no caso de menor preço da eletricidade em comparação com os combustíveis líquidos, e o Modo Sustentação de Carga, no caso do preço da eletricidade elevado (EPRI, 2001; KURANI et al. 2007).

O gerenciamento de energia do sistema de propulsão é um dos fatores determinantes para o consumo energético do veículo que está intrinsecamente relacionado com a preferência do consumidor, seja do ponto de vista econômico, ambiental ou de desempenho. A distância média percorrida em cada viagem também será responsável para determinar se o modo de operação do veículo será capaz de atender todo o percurso.

- Veículo Elétrico Movido por Células a Combustível (VECC): a energia elétrica é gerada a bordo por meio de processo eletroquímico em que a energia de um combustível (hidrogênio) é transformada diretamente em eletricidade. A utilização dessa classe de veículos automotores, como meio de transporte em âmbito global, vem ganhando notoriedade motivada por aspectos técnicos, econômicos e ambientais.

Esse veículos movidos à "células de combustível" são carros híbridos "em série" nos quais o grupo "reservatório de combustível, o motor à explosão e o gerador" são substituídos por um sistema que gera energia elétrica diretamente a partir do hidrogênio armazenado. Novamente, o excesso de energia será armazenado em um sistema de baterias. No caso extremo, o banco de baterias será eliminado passando a existir apenas o sistema de "células de combustível", como mostra a Figura 25. 


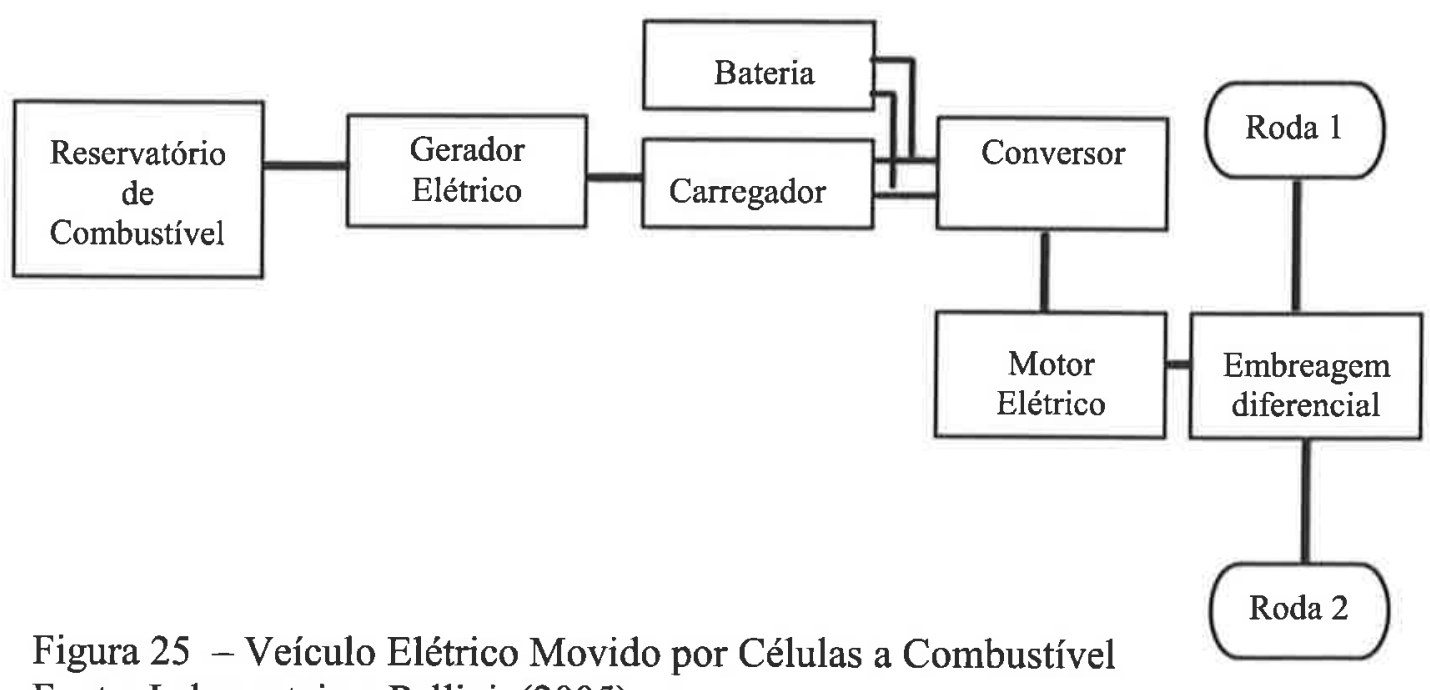

Fonte: Lebensztajn e Pellini, (2005)

\subsection{Componentes de um Veículo Elétrico: Motores e Baterias}

Nos próximos itens serão explanados os principais tipos de baterias e motores utilizados em veículos elétricos movidos à bateria.

\subsection{Motores Elétricos}

Larminie e Lowry (2003), ressaltam que até a década de 1960, os motores de corrente contínua (CC) foram largamente utilizados como sistemas de propulsão. Desde então, com o surgimento de dispositivos de chaveamento "power switching" eletrônicos, para altas correntes tornou-se possível a conversão direta da corrente da bateria para alternada (CA) de freqüência e amplitude variáveis. Neste sentido, com esses avanços, os motores de indução e motores síncronos puderam ser empregados como unidades propulsoras veiculares. $\mathrm{O}$ emprego destes tem mostrado considerável vantagem em custo, dimensão, peso e confiabilidade como sistemas de propulsão se comparados aos de CC.

Segundo CHAN, (1997) além das exigências gerais requeridas para o motor de um veículo elétrico, outras características relacionadas à arquitetura do motor são fundamentais, o que depende do modelo de veículo que se pretende construir. Os veículos elétricos podem ser projetados com diversas configurações no que tange ao seu sistema de tração. Eles podem ter motor elétrico acoplado à uma transmissão e diferencial, também podem ter dois motores elétricos e dois conjuntos de transmissão e diferencial. O sistema de tração poderá ainda ser 
projetado para que o motor fique interligado direto nas rodas; neste caso, em algumas situações, poderá haver transmissão com engrenagens ou não. Em muitos casos, para cada configuração da propulsão elétrica veicular haverá diferenças em relação aos motores e seus sistemas de controle.

De forma simplificada e redundante, para escolher um motor elétrico ideal em um sistema de propulsão veicular, é primordial que possua um elevado torque inicial e consiga desenvolver uma velocidade final condizente com as características definidas para o veículo.

A força de tração, fornecida pela equação (3.1), é a soma das forças para vencer a resistência ao rolamento, a resistência aerodinâmica, a resistência da inclinação do percurso e a resistência para vencer a inércia (LARMINIE E LOWRY, 2003).

$$
F_{T R}=F_{R A}+F_{A D}+F_{D}+F_{I}
$$

A força de resistência ao rolamento $F_{R \Omega}$ pode ser escrita de maneira simplificada através da equação (3.2):

$$
F_{R R}=K \cdot M_{\cdot} \cdot g
$$

Sendo:

$K$ - Coeficiente de resistência ao rolamento;

g- Aceleração da gravidade em $\mathrm{m} / \mathrm{s}^{2}$;

Me -Massa equivalente do veículo em $\mathrm{kg}$, incluindo a inércia rotacional que é aproximadamente igual a $1,03 W_{V}$, sendo $W_{V}$ a massa do veículo em $\mathrm{kg}$.

Para a força de resistência aerodinâmica $\boldsymbol{F}_{A D}$ a equação (3.3) fornece: 


$$
F_{A D}=\frac{1}{2} \cdot \rho \cdot A_{F} \cdot C_{d} \cdot v\left(t^{2}\right)
$$

Sendo:

p - densidade volumétrica do ar em $\mathrm{kg} / \mathrm{m}^{3}$;

$A F$ - Área frontal do veículo em $\mathrm{m}^{2}$;

$\boldsymbol{C}_{\boldsymbol{d}}$ - Coeficiente de arrasto;

$\mathbf{v}(\mathbf{t})$ - Velocidade de deslocamento do veículo em função do tempo $(t)$ em segundos em $\mathrm{m} / \mathrm{s}$.

A força para vencer a resistência da inclinação do percurso é dada pela equação (3.4):

$$
F_{D}=W_{v} \cdot g \cdot \operatorname{sen}(\theta(\mathrm{t}))
$$

Onde:

0 - ângulo da inclinação do percurso em graus

A Força Fı para vencer a inércia é indicada na equação 3.5:

$$
F_{I}=M_{e} \cdot a(t)
$$

Onde:

Me - Massa equivalente do veículo em $\mathrm{kg}$, incluindo a inércia rotacional $\left(M e=1,03 W_{V}\right)$; a - Aceleração do veículo em $\mathrm{m} / \mathrm{s}^{2}$.

Obtendo-se a Força de tração $F_{T R}$ determina-se o torque necessário nas rodas para movimentação do veículo utilizando a equação 3.6 descrita:

$$
T_{R}=F_{T R} \cdot \mathbf{r}
$$

Onde; 
$\boldsymbol{T}_{\boldsymbol{R}}$ - Torque nas rodas do veículo em $\mathrm{Nm}$;

$\mathbf{r}$ - Raio do pneu em $m$.

Definido o torque nas rodas é possível determinar o torque do motor elétrico, que depende da relação de transmissão do sistema, conforme indicado pela equação 3.7 .

$$
T_{m}=\frac{T_{i}}{n_{T} \cdot R_{T}}
$$

Onde:

$\boldsymbol{R}_{\mathbf{T}-\text { Relação de transmissão; }}$

$\mathbf{n}_{\mathbf{T}}$ - Rendimento da transmissão.

\subsubsection{Motores Elétricos de Corrente Contínua (Componentes)}

Ao mesmo tempo em que o motor de indução é o mais utilizado em comparação a todos os tipos de motores pelo custo reduzido, elevada versatilidade de adaptação às cargas dos mais diversos tipos e melhores rendimentos, os motores de corrente contínua apresentam em contrapartida, um custo mais elevado e, além disso, precisam de uma fonte de corrente contínua, ou de um dispositivo que converta a corrente alternada comum em contínua.

Larmini e Lowry e Kenjo e Nagamori (1985), dizem que um motor elétrico de CC pode ser facilmente controlado se a tensão de alimentação é reduzida, então o máximo torque decrescerá proporcionalmente. Isto significa que, qualquer torque e velocidade podem ser obtidos abaixo dos valores máximos pré-estabelecidos.

Dessa forma, reduzir ou aumentar a tensão de alimentação não é única forma utilizada para controlar um motor elétrico de CC. É possível obter um controle através da variação do fluxo magnético quando bobinas são utilizadas no fornecimento do campo no lugar de imãs permanentes. Entretanto, caso o fluxo magnético seja reduzido, o torque máximo cairá permitindo ao motor operar em uma larga faixa de valores de torque e velocidade. Esta metodologia de controle é aconselhável especialmente em regiões de operação do veículo de alta velocidade e baixo torque (LARMINIE E LOWRY, 2003). 
Segundo Fitzgerald, Kingsley e KusKo (1975) e Larmini e Lowry (2003), existem três tipos clássicos de motores elétricos de CC com campo de enrolamento em série (series) em derivação (shunt) e o com campo independente (separately excited) como apontado na Figura 26. Os motores em série e em derivação não possibilitam o controle adequado da velocidade do torque necessário em um veículo elétrico, porém o motor com campo independente desperta real interesse para essa aplicação.

a)

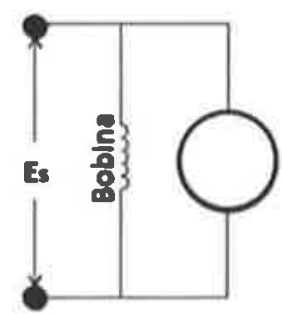

b)

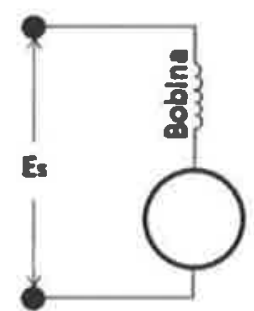

c)

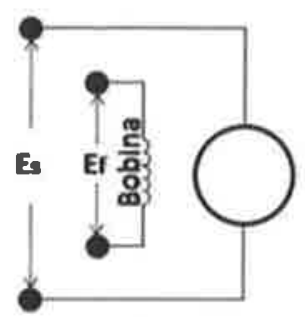

Figura 26 - Motores elétricos de CC com campo de enrolamento: (a) em série (series), (b) em derivação (shunt) e (c) com campo independente (separately excited)

Fonte: Fitzgerald, Kingsley e KusKo (1975) e Larmini e Lowry (2003)

\subsubsection{Motores Elétricos com Campo de Enrolamento em Série}

Como mencionado por Westbrook (2001), as características desse motor são particularmente favoráveis à aplicação em veículos elétricos, pois, fornecem excelente aceleração combinada com a redução controlada da velocidade em pavimento inclinado e com altas velocidades em pavimento plano. Somada à estas vantagens, está a utilização de controladores de tensão e resistividade relativamente simples, logo, pode-se concluir que este tipo de motor tem sido largamente utilizado em veículos elétricos desde os primeiros protótipos até os dias atuais.

\subsubsection{Motores Elétricos com Campo de Enrolamento em Derivação}

Westbrook (2001) relata a dificuldade em manter o controle deste tipo de motor, desde que controladores eletrônicos começaram a ser utilizados, melhorando a sua eficiência e controlabilidade, seu uso tem ganhado espaço em alguns veículos elétricos de baixo custo.

\subsubsection{Motores Elétricos em Campo Independente}


Larminie e Lowry (2003) e Westbrook (2001), ao considerar em longo prazo, a tecnologia dos motores de corrente alternada (CA) tem muito mais a oferecer em eficiência, confiabilidade, peso e tamanho em comparação aos de corrente contínua (CC).

Cabe aqui ressaltar, que com esse motor é possível obter qualquer combinação entre os tipos de motores descritos acima. Diante isso, o motor com campo independente é utilizado como motor de tração. Em torno da simplicidade e baixo custo de sistemas de controle e a maturidade da tecnologia, esses motores irão permanecer em serviço por algum tempo.

\subsubsection{Motores Elétricos de Corrente Alternada}

Ainda segundo Westbrook (2001), motores de corrente alternada são apropriados para o uso em veículos de tração elétrica sendo os mais utilizados, pois a distribuição de energia elétrica é feita normalmente em corrente alternada. Os motores podem ser classificados em três categorias:

1. Motores de Indução (trifásico e monofásico);

2. Motores síncronos;

3. Motores de relutância variável.

Motores síncronos e de indução vem sendo utilizados a vários anos em diversas aplicações industriais e seu uso em veículos elétricos só foi possível com a geração de inversores de alta potência, alta eficiência e freqüência variável. Já os motores de relutância variável exigem sofisticados controladores eletrônicos e seu uso e utilidade em veículos elétricos encontra-se em processo de investigação. Motores que apresentam rotores permanentemente magnetizados, tais como motor síncrono conhecido como "motor CC sem escovas"(brushless DC motor) tem despertado considerável interesse para aplicações veiculares e alguns veículos utilizando estas máquinas já foram construídos (Westbrook 2001),

\subsubsection{Motores Elétricos de Indução (Trifásico e Monofásico)}

O princípio de funcionamento do motor de indução trifásico (MIT) é semelhante a todos os motores elétricos, ou seja, baseia-se na iteração do fluxo magnético com uma 
corrente em um condutor, gerando uma força no condutor. Esta força é proporcional às intensidades de fluxo e de corrente. Atualmente é possível controlar a velocidade dos motores de indução com auxílio de inversores de freqüência.

Dentre varias funções, estes motores apresentam o menor custo comparado ao motor de corrente contínua (CC) de mesma potência; uma reduzida manutenção devido à ausência de escovas e de um comutador e um consumo de energia menor nos processos de aceleração e frenagem, podendo-se obter velocidades maiores, o que implica em potências maiores.

Concretamente, a dependência entre fluxo e a tensão do estator, o que não ocorre nos motores de CC com excitação independente, pode ser considerada uma grande desvantagem. Este fato limita a faixa de variação de velocidade do motor, quando controlado por variação da tensão do estator. A Figura 27 apresenta um motor de indução trifásico composto fundamentalmente de duas partes: estator e o rotor.

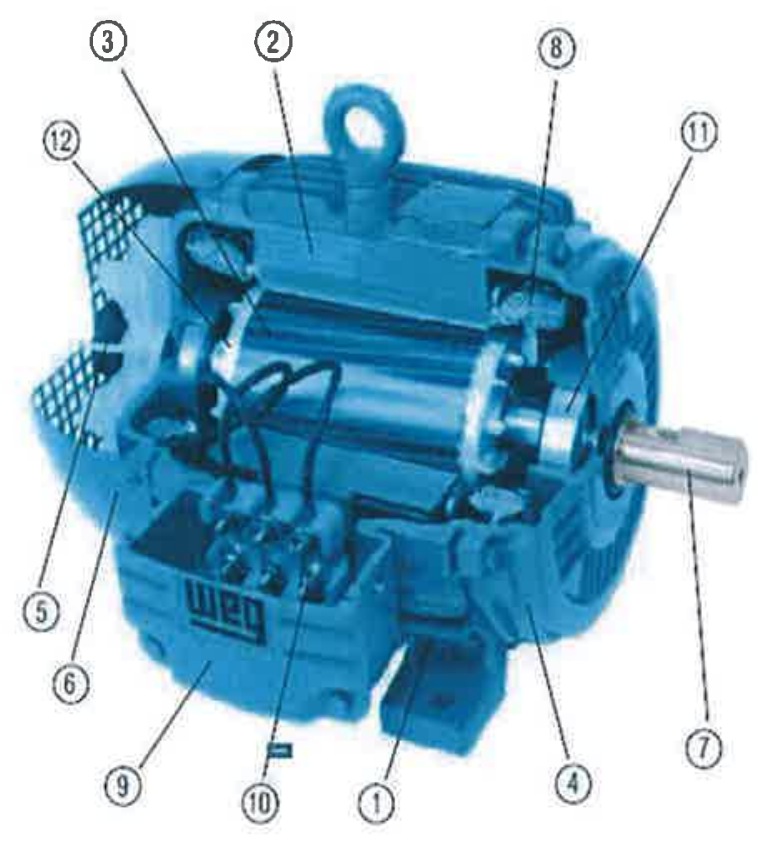

Estator

1. Carcaça (1) é a estrutura do conjunto de construção robusta em ferro fundido, aço ou alumínio injetado resistente à corrosão ;

2. Núcleo de chapas (2) as chapas são de aço magnético, tratadas termicamente para reduzir ao mínimo as perdas no ferro;

3. Enrolamento trifásico (8) três conjuntos iguais de bobinas uma para cada fase, formando um sistema trifásico ligado à rede trifásica de alimentação;

4.

Rotor

- Eixo (7) transmite a potência mecânica desenvolvida pelo motor. E tratado termicamente para evitar problemas como empenamento e fadiga;

- Núcleo de chapas (3) as chapas possuem as mesmas características das chapas do estator;

- Barras e anéis de curto circuito (12) são de alumínio injetado sob pressão numa única peça;

Outras partes do motor de indução trifásico

- Tampa (4)

- Ventilador (5)

- Tampa defletora (6)

- Terminais (10)

- Rolamentos (11)

Figura 27- Motor de indução trifásico

Fonte: Weg, (2010)

Assim, recentemente com a expansão dos sistemas eletrônicos que fundamentalmente permitem o controle do motor por variação simultânea da tensão e freqüência do estator, faz com que esta desvantagem desapareça. 
Em contrapartida, já o motor de indução monofásico possui um único enrolamento no estator que acaba gerando um campo que se alterna ao longo do eixo do enrolamento.

Quando o rotor está parado, o campo do estator, induz correntes no rotor. O campo gerado no rotor tem polaridade oposta ao do estator (Lei de Lenz). A oposição dos campos determina o aparecimento de forças que atuam sobre a parte superior e a inferior do rotor, com a tendência de girá-lo 180 graus a partir da posição inicial. A ação de forças é igual em ambos os sentidos, pois elas atuam através do centro do rotor (regra da mão esquerda). $\mathrm{O}$ resultado é que o rotor continua parado.

Entretanto, se o rotor estiver girando ao se ligar o motor, ele continuará em movimento no sentido inicial, pois a ação das forças será ajudada pela inércia do rotor.

Como o campo criado pela tensão monofásica aplicada ao enrolamento do estator é pulsativo, os motores de indução monofásicos desenvolvem um torque pulsativo. Portanto, eles são menos eficientes do que os motores trifásicos cujos torques são mais uniformes.

\subsubsection{Motores Elétricos Síncronos}

É inquestionável a importância dos motores síncronos com rotor cilíndrico (wound rotor) que apresentam uma saída na faixa que se estende entre os poucos quilowatts a muitos megawatts, no entanto motores com imãs permanentes são limitados à uma faixa de operação entre $100 \mathrm{~W}$ a $100 \mathrm{KW}$. Visto que os veículos elétricos necessitam de motores que estejam na faixa de 5 a $50 \mathrm{KW}$, motores de imãs permanentes são indicados para tal aplicação e oferecem alta eficiência, pois não é requerida potência durante o funcionamento do motor para indução de corrente no rotor.

Neste sentido, os motores síncronos são considerados menores em contrapartida aos motores de indução e motores com a razão potência / peso acima de $3,0 \mathrm{KW} / \mathrm{kg}$ têm sido projetados para o uso em veículos elétricos. Entretanto, o custo dos imãs de terra rara e a complexidade eletrônica dos controladores / inversores dos quais esses motores necessitam têm restringido sua utilização como sistemas de tração. Westbrook (2001) ressalta que os motores de imãs permanentes de neodímio-ferro-boro $(\mathrm{NdFeB})$ são empregados na produção dos veículos elétricos, híbridos fabricados pela montadora Toyota, Honda e Nissan. Além do mais funcionam com velocidade fixa, utilizado somente para grandes potências (devido ao seu alto custo em tamanhos menores) ou quando se necessita de velocidade invariável. 


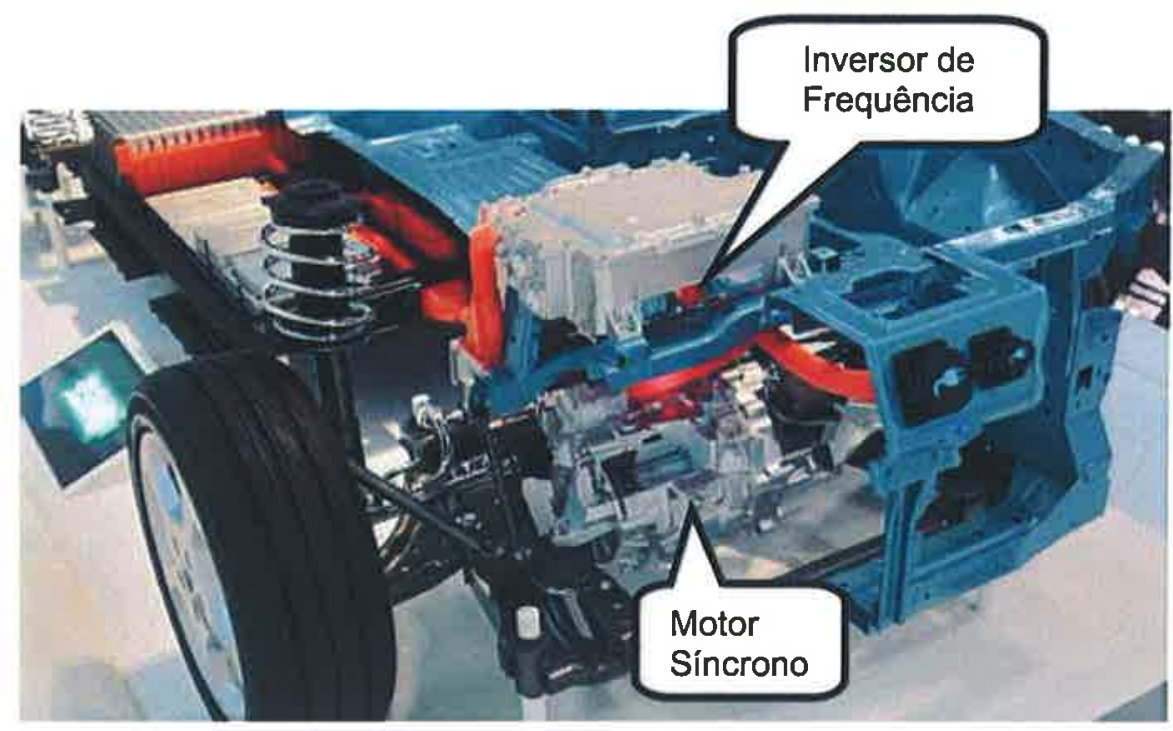

Figura 28- Motor Síncrono de Imã Permanente (Nissan) Fonte: Reanult, (2011)

A Figura 28 mostra um exemplo, de Motor Síncrono de Imã Permanente Interior, modelo Nissan. As principais especificações deste motor inclui a geração de um torque máximo de $280 \mathrm{Nm}$, uma potência máxima de $80 \mathrm{~kW}$, uma velocidade de acionamento máxima de $10.390 \mathrm{rpm}$, pesando apenas $58 \mathrm{~kg}$. Ao contrário de um motor de combustão interna convencional, o motor deste modelo puramente elétrico é operado por um Inversor de Freqüência que possibilita oferecer um torque máximo desde velocidade zero, proporcionando aceleração consistente, eliminando solavancos ou queima de friç̧ão.

\subsubsection{Motores Elétricos CC sem Escovas}

Nessa mesma vertente, uma versão diferenciada dos motores síncronos é chamada de motor de imã permanente auto-síncrono com inversor, também conhecido como motor CC sem escovas. As vantagens atribuídas para estes motores estão relacionadas na alta eficiência e rotor de simples construção. Entretanto, a necessidade de imãs permanentes eleva o custo de forma considerável. Embora, a corrente através das bobinas do motor alternar, deve existir uma fonte de corrente contínua (sendo este o motivo pelo qual esses motores são freqüentemente classificados como $\mathrm{CC}$ ). É utilizado em equipamentos computacionais, em aplicações de alta potência como os veículos elétricos. Nesse sentido, precisam de controladores mais sofisticados que possam variar a corrente da bobina (e o torque) para produzir um sistema de acionamento bastante flexível. 


\subsubsection{Motores Elétricos de Relutância Variável}

Categoricamente, os motores de relutância variável são considerados como um tipo especial de motor síncrono com potencial aplicação para propulsão de veículos elétricos $\mathrm{e}$ híbridos. Neste motor, o rotor pode ser simplesmente formado por ferro magnetizado reduzindo potencialmente seu custo. Mediante à simplicidade do rotor e à eficiência de todo o princípio de relutância variável, este motor poderá oferecer melhorias na potência por unidade de massa, volume, confiabilidade e flexibilidade no uso. Dessa forma, desde que o rotor não é de imã permanente, não existe força contra-eletromotriz, implicando no alcance de altas velocidades. Embora o pico de eficiência desses motores esteja ligeiramente abaixo do motor CC sem escovas, os motores de relutância variável mantêm seu nível de eficiência acima do range de velocidade e torque alcançados por qualquer outro motor.

Sem dúvida, desde que o rotor não é de imã permanente, não existe força contraeletromotriz, implicando no alcance de altas velocidades. Embora o pico de eficiência desses motores esteja ligeiramente abaixo do motor $\mathrm{CC}$ sem escovas, os motores de relutância variável mantêm seu nível de eficiência acima do range de velocidade e torque alcançados por qualquer motor.

Todos os motores citados são capazes de operar em uma faixa de potência entre 5 e 50 $\mathrm{KW}$ requerida por carros elétricos. A escolha do tipo de motor elétrico do sistema de propulsão deve estar em consonância com as características como eficiência, peso, volume e custo do sistema de propulsão completo incluindo controladores, motores e transmissão mecânica.

Como apresentado, os tipos de motores descritos são capazes de operar como geradores se os circuitos de controle forem devidamente projetados, e portanto, podem ser utilizados na frenagem regenerativa. Particularmente, para ser efetiva, a frenagem regenerativa deve ser aplicada sobre todo ciclo de operação do veículo e os freios dinâmicos somente usados como um dispositivo de segurança.

\subsubsection{Panorama atual - Motores Elétricos}

Não se pode esquecer que para veículos de pequeno porte, não rodoviários, a tendência atual é utilizar motores com comutadores e baterias chumbo-ácidas, visto que as velocidades de funcionamento são baixas, permitindo um projeto satisfatório inclusive quanto 
à autonomia. Para veículos de grande porte, a tendência recente é empregar motores sem comutadores, como os motores de indução com baterias avançadas (CHAU; WANG, 2005).

Assim, vários tipos de motores $\mathrm{CC}$ (corrente contínua), excitação série, excitação independente e excitação a ímã permanente têm sido amplamente aplicados em diversos veículos elétricos de pequeno porte e empilhadeiras.

Porém, os motores de indução, por serem muito utilizados e em conseqüência propiciarem um elevado volume de produção, têm um custo competitivo com os seus homólogos de CC. Assim, os motores de indução CA se tornam atrativos, porém, os motores de indução com controles convencionais, tais como aqueles com tensão-variável e frequênciavariável, não oferecem a performance desejada aos veículos elétricos. Uma das principais razões é a não linearidade deste modelo dinâmico. Com o advento da era dos microcontroladores, os motores de indução se tornam viáveis através do controle vetorial exercido pelos inversores (CHAU; WANG, 2005).

Nesse sentido, substituindo-se o enrolamento do induzido por ímãs permanentes de alta capacidade, os motores síncronos podem eliminar escovas convencionais, anéisdeslizantes e perdas nas bobinas de cobre. Um número de topologias de motores com alta densidade e alta efíciência recentemente tem sido desenvolvido. Como são essencialmente motores CA síncronos tradicionais com enrolamento senoidal-distribuído, podem ser controlados através da modulação de largura de pulso conhecida na literatura técnica como PWM (Pulse Width Modulation), de forma semelhante aos motores de indução. A mais óbvia vantagem destes motores é a remoção das escovas, além de produzir um grande torque. A Tabela 9 adaptada de Chau (CHAU; WANG, 2005) apresenta um quadro comparativo relacionado à tecnologia de motores para veículos elétricos.

Tabela 9 - Comparativo relacionado à tecnologia de motores para veículos elétricos

\begin{tabular}{|l|c|c|c|c|}
\hline $\begin{array}{c}\text { Elementos } \\
\text { de } \\
\text { Comparação }\end{array}$ & $\begin{array}{c}\text { Motor } \\
\text { CC }\end{array}$ & $\begin{array}{c}\text { Motor } \\
\text { de } \\
\text { Indução }\end{array}$ & $\begin{array}{c}\text { Motor a imã } \\
\text { permanente sem } \\
\text { escovas }\end{array}$ & $\begin{array}{c}\text { Motor } \\
\text { a } \\
\text { relutância }\end{array}$ \\
\hline Eficiência & 2 & 3 & 5 & 3 \\
\hline Controlabilidade & 5 & 3 & 4 & 3 \\
\hline Confiabilidade & 3 & 5 & 4 & 5 \\
\hline Maturidade & 5 & 5 & 4 & 3 \\
\hline Custo & 4 & 5 & 2 & 4 \\
\hline Total & $\mathbf{2 1}$ & $\mathbf{2 4}$ & $\mathbf{2 4}$ & $\mathbf{2 1}$ \\
\hline
\end{tabular}

Fonte: adaptada de Chau; Wang, 2005 
Já na tabela acima o autor apresenta esquematicamente, uma graduação em pontos de zero a 5, que consiste, em ordem de valores, em comparar as seis principais características dos motores aplicados em veículos elétricos. A Tabela 9 indica a evolução dos motores de indução que são aceitáveis. Em relação a custo e maturidade, os motores de ímãs permanentes sem escovas, incluindo motores $\mathrm{CA}$ ou $\mathrm{CC}$, necessitam de melhorias significativas, no entanto, se tornam atrativos se forem consideradas as demais características. Os motores convencionais de $\mathrm{CC}$ perderam a sua competitividade em relação aos motores à relutância $\mathrm{e}$ aos motores de ímãs permanentes híbridos. Ainda com relação ao custo e a disponibilidade no Brasil, os motores de indução se mostram interessantes para conversão.

São vários os elementos que compõem a evolução das topologias dos inversores de potência que se deve principalmente ao avanço dos componentes eletrônicos que se desenvolveram, atingindo atualmente, elevada densidade de potência, alta efíciência e alta controlabilidade. Os critérios de seleção das unidades motoras para os VEs (incluindo os motores e seus conversores de energia) podem ser divididos em dois requisitos: os essenciais, sem os quais o projeto do veículo não se viabiliza, e os desejáveis. Os essenciais são aqueles que o motor do veículo pode oferecer; o primeiro é a relação torque-velocidade, que é determinada pelo perfil de operação do veículo elétrico, e o segundo, é a capacidade de fluxo de potência bidirecional para recuperar a energia de frenagem regenerativa. Em geral, motores de CC ou CA podem oferecer uma boa relação torque-velocidade. As exigências na unidade motora dos veículos elétricos são: baixo custo, alta eficiência, alta densidade de potência, controlabilidade e baixa de manutenção. Estes requisitos para serem obtidos dependem da adequação dos diversos dispositivos que fazem parte do sistema de propulsão.

\subsubsection{Comparativo entre os motores}

De um ponto de vista mais operacional, os motores de combustão interna possuem características diferenciadas comparadas aos motores elétricos. No entanto, nos motores a Diesel, o torque em baixa rotação é alto quando comparado ao motor Otto (gasolina), e com o aumento da rotação não há grandes quedas. A curva de torque em relação à rotação se mantém aproximadamente constante, o mesmo ocorrendo com a potência.

O motor Diesel possui um regime de rotação inferior ao Otto. Por este motivo, motores Diesel são mais indicados para trabalhos que exigem maior torque. Os Gráfícos 6 e 7, conforme Carvalho (CARVALHO, 2007), apresentam as curvas de torque e potência de um 
motor Diesel e de um motor Otto, onde se observa que, após atingirem um valor máximo, há um decréscimo apreciável do torque e da potência.

\section{Curvas do um motor Diesol}

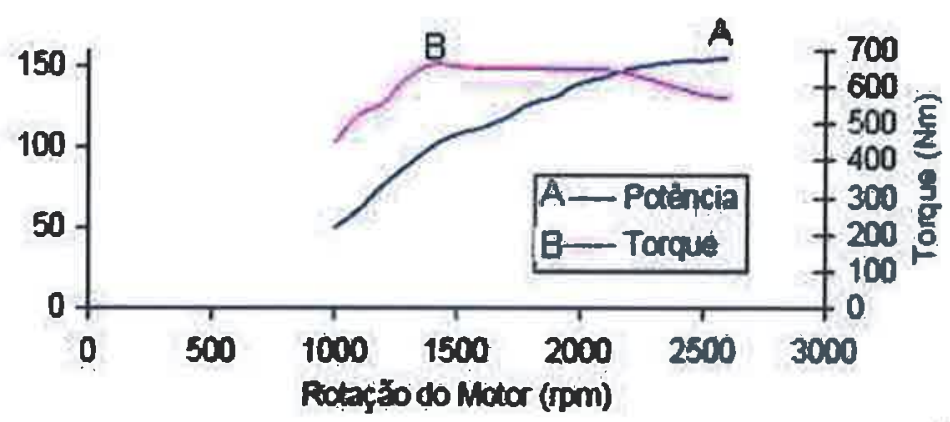

Gráfico 6 - Curvas do motor Diesel

Fonte: Carvalho, (2004)

\section{Curvas de um motor Clclo Ono}

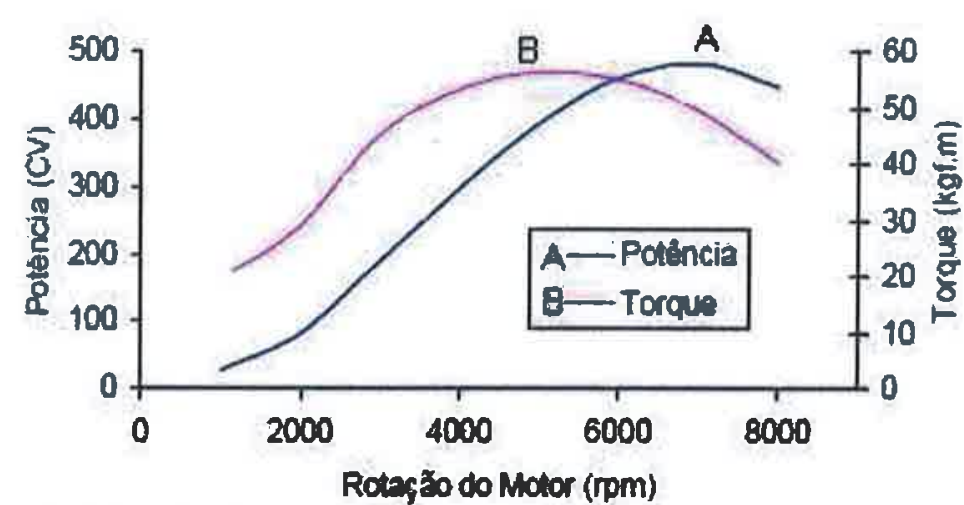

Gráfico 7- Curvas de um motor Ciclo Otto

Fonte: Carvalho, (2007)

Vale ressaltar que, com relação aos motores elétricos em baixas rotações, dependendo do tipo considerado, este pode possuir torque elevado, como é o caso do motor série de corrente contínua, que durante muito tempo foi utilizado de forma preferencial para tração elétrica. Já o Gráfico 8 apresenta graficamente a variação do torque com a velocidade, para um motor de indução típico. 


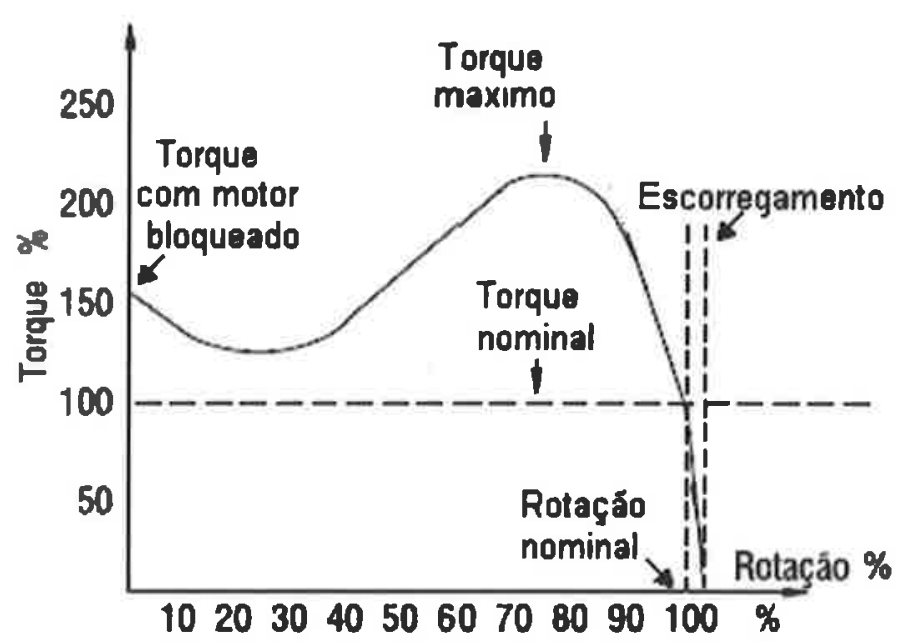

Gráfico 8- Variação do torque com a velocidade para um motor de indução Fonte: Carvalho, (2007)

Do exposto, pode-se concluir que se deve chegar ao consenso fazendo uma comparação entre os motores de combustão interna e os motores elétricos. A partir dos gráficos apresentados, pode-se observar que já nas velocidades iniciais de partida de um motor elétrico de indução, o torque pode chegar a um valor $60 \%$ superior ao torque nominal, enquanto os motores de combustão interna só começam a produzir torque mais elevado para o sistema de propulsão quando o mesmo atinge rotações elevadas. Além disso, os motores elétricos apresentam valor de potência e torque de curta duração que podem chegar a valores muito superiores aos das condições normais, o que possibilita uma enorme flexibilidade em condições de acelerações bruscas.

\subsection{Acumulador Eletroquímico - Bateria}

O acumulador eletroquímico (bateria) consiste em um dispositivo que armazena energia através de um processo eletroquímico, provisionando a energia para uso através de eletricidade. Os principais atributos de uma bateria são: a energia específica mássica, a potência específica mássica e o tempo de vida útil. A energia específica mássica consiste na quantidade de energia armazenada pela bateria por unidade de massa, a potência específica mássica é a potência fornecida por unidade de massa, o tempo de vida útil corresponde ao número de ciclos de carga/descarga a que pode ser sujeita.

As exigências técnicas solicitadas para cada bateria são diferenciadas para cada tipo de veículo. No entanto, os veículos elétricos puros necessitam de baterias com maiores densidades de 
energia, limitando-as devido às massas e volumes associados, o que contribui para uma baixa autonomia destes tipos de veículos.

Sendo assim, as baterias constituem a única fonte de energia a bordo, estas sofrem descargas mais profundas, exigindo-se baterias mais robustas, com tempo de vida longo e aceitação de um número elevado de ciclos de carga e recarga para os veículos movidos à bateria.

Há basicamente duas categorias de baterias. As baterias primárias são aquelas que não são recarregadas. Fornecem a sua energia a partir de uma reação eletroquímica, geralmente irreversível, o que as inutiliza. As baterias secundárias são aquelas recarregadas por uma fonte de alimentação externa. Uma bateria secundária pode ser carregada e descarregada muitas vezes.

As principais tecnologias de baterias recarregáveis resumem-se a baterias de chumboácido $(\mathrm{Pb})$, níquel-cádmio (Ni-Cd), hidreto metálico de níquel (Ni-Mh) e íon de lítio (Li-ion). As características destes tipos de baterias são apresentadas na Tabela 10 e no Gráfico 9.

Tabela 10 - Características dos Principais tipos de baterias

\begin{tabular}{|c|c|c|c|c|}
\hline & Pb & Ni-Cd & Ni-Mh & Li-ion \\
\hline Custo & Baixo & Médio & Alto & Muito Alto \\
\hline Energia Específica Mássica (Wh/kg) & $30-50$ & $50-80$ & $40-100$ & 160 \\
\hline Tensão por célula (V) & 2,00 & 1,25 & 1,25 & 3,60 \\
\hline Corrente de Carga & Baixa & Muito Baixa & Moderada & Alta \\
\hline Número de Ciclos (carga/descarga) & $200-500$ & 1.000 & 1.000 & 1.200 \\
\hline Autodescarga por Mês (\% do total) & $\begin{array}{c}\text { Baixa } \\
(5 \%)\end{array}$ & $\begin{array}{c}\text { Moderada } \\
(20 \%)\end{array}$ & $\begin{array}{c}\text { Alta } \\
(30 \%)\end{array}$ & $\begin{array}{c}\text { Baixa } \\
(10 \%)\end{array}$ \\
\hline Tempo Mínimo para Carga (h) & $8-16$ & $1-1,5$ & $2-4$ & $2-4$ \\
\hline
\end{tabular}

Fonte: Valsera-Naranjo et al. (2009) 


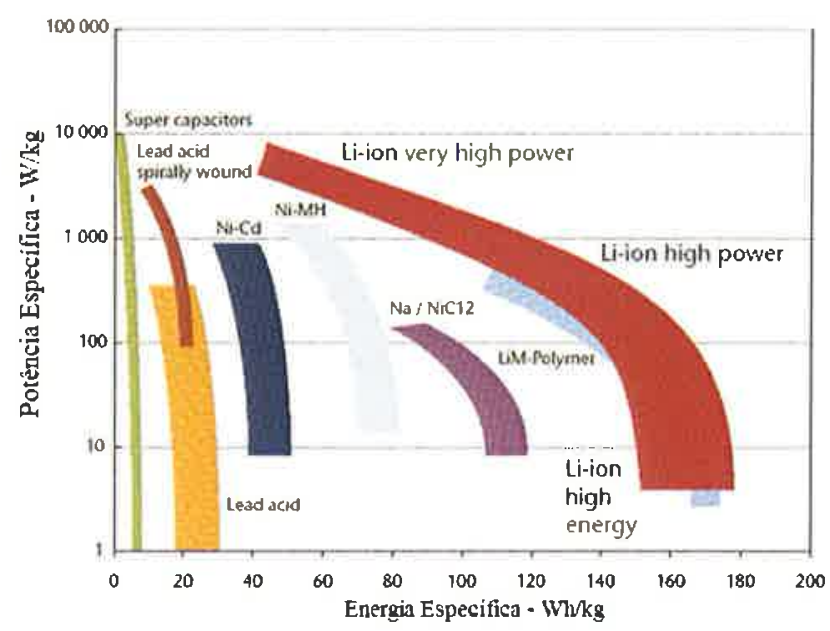

Gráfico 9- Energia Específica e Potência Específica das Principais Baterias Fonte: IEA, (2011)

As baterias de chumbo-ácido $\left(\mathrm{PbSO}_{4}\right)$ apresentam reduzidas energia e potência específicas, $40 \mathrm{Wh} / \mathrm{kg}$ e $350 \mathrm{~W} / \mathrm{kg}$, respectivamente. O tempo médio de vida útil destas baterias é um dos seus limitantes, cerca de 500 ciclos carga/descarga. Esses acumuladores químicos apresentam um custo reduzido requerendo pouca manutenção.

As baterias níquel-cádmio (Ni-Cd) apresentam energias e potências específicas superiores às das baterias chumbo-ácidas. A energia específica das baterias níquel-cádmio permanece em torno de $60 \mathrm{Wh} / \mathrm{kg}$ enquanto a potência específica pode ir até aos $500 \mathrm{~W} / \mathrm{kg}$. O ciclo de vida destas baterias é relativamente longo, cerca de 1.000 ciclos. No entanto, devido ao cádmio ser uma substância potencialmente cancerígena, a produção e aplicação destas baterias não é atrativa para o uso automotivo (VALSERA-NARANJO et al, 2009).

As baterias de Niquel Cloreto de Sódio ( $\mathrm{NaNiCl})$ são conhecidas por Zebra, têm alta potência porque as pilhas que a constituem têm grande capacidade, normalmente é utilizada para baterias de grande energia específica, superior a $20 \mathrm{kWh}$. Este tipo de bateria, está vocacionada para a tração elétrica, podendo ser utilizada em veículos movidos à bateria. As vantagens da sua utilização são: serem projetadas para veículos elétricos urbanos, terem ciclos de carga até aos 3500 ciclos, podendo operar em ambientes de temperatura elevada, entre $270^{\circ}$ a $350^{\circ}$ e, em termos ambientais, todos os materiais são recicláveis e de baixo custo. Uma das desvantagens inerentes à estas baterias é o fato de ser necessário um período longo de aquecimento, cerca de 24 horas, caso se deixe que as baterias arrefeçam totalmente (DUSTMANN, 2003).

Outro tipo de bateria é o hidreto metálico de níquel (Ni-Mh). Nestas baterias, o Cádmio foi substituído por uma liga metálica com Hidrogênio. As baterias Ni-Mh têm sido 
usadas nos veículos híbridos comerciais devido às suas características e à maturação em relação às outras. As baterias $N i-M h$ apresentam energia específica que pode ir até os 100 $\mathrm{Wh} / \mathrm{kg}$, e a potência especifica pode atingir os $1.500 \mathrm{~W} / \mathrm{kg}$. A vida útil destas baterias é de cerca de 1.000 ciclos. Entretanto, como desvantagem, seu preço é um dos mais elevados, sendo o dobro do valor cobrado pelas baterias de níquel-cádmio.

O modelo de bateria mais promissor apresentado nos últimos anos foi o de íon de lítio (Li-Ion). Estas baterias apresentam energias específicas de mais de $150 \mathrm{Wh} / \mathrm{kg}$ e potências específicas que podem ir até aos $2.000 \mathrm{~W} / \mathrm{kg}$. A sua vida útil é de cerca de 1.200 ciclos carga/descarga.

As vantagens da sua utilização são: fornecem uma elevada densidade de energia, baixa resistência interna, ciclos de vida grandes, superiores a quinhentos, não têm o efeito de memória, admitem maiores valores de temperatura, têm poucos impactos em termos ambientais e menores custos de produção em comparação com os outros tipos de baterias (FAIA, 2006).

As desvantagens deste tipo de baterias derivam do fato de necessitarem de um sistema de carga preciso, devido à sua reduzida tolerância a picos de potência e de serem ainda relativamente caras para veículos elétricos puros (FAIA, 2006).

Contudo, mesmo para as baterias de íon de lítio, que possuem maior energia específica entre as baterias atualmente disponíveis, a sua energia específica mássica é duas ordens de grandeza inferior a de combustíveis líquidos. Os motores elétricos apresentando uma eficiência maior de conversão de energia e menor massa do que os motores de combustão podem fornecer uma maior energia específica mecânica do que os motores de combustão interna para a maioria das aplicações de transporte. Fischer et al. (2009) propõem uma nova metodologia de energia específica, denominada energia específica efetiva $\left(\rho_{\Xi}\right)$ conforme a Equação 3.9:

$$
\rho_{\varepsilon}=\frac{\boldsymbol{n}_{\varepsilon c}}{\boldsymbol{m}_{c}+\boldsymbol{m}_{d}}
$$

Onde:

Ec - Representa a energia armazenada no combustível (poder calorífico inferior do combustível líquido ou energia contida na bateria);

$\boldsymbol{n}$ - É a eficiência de conversão da energia em trabalho mecânico, incluindo contribuições de frenagem regenerativa, assim como perdas na transmissão; 
$\boldsymbol{m}_{\boldsymbol{c}}$ - Massa do combustível;

$\boldsymbol{m}_{\boldsymbol{d}}$ - É a massa do motor e partes associadas,como transmissão e conversores.

Todavia, a energia específica efetiva depende intrinsecamente da quantidade de energia armazenada no combustível/bateria, que irá determinar a autonomia do veículo. Para aumentar a autonomia de veículos com motor à combustão interna basta aumentar o tanque de combustível. Em contrapartida, para aumentar a autonomia de veículos elétricos requer a inserção de baterias maiores, o que resulta na elevação da massa do veículo (FISCHER et al. 2009). Inversamente, reduzir a autonomia de veículos elétricos permite ter uma maior eficiência energética efetiva em relação aos veículos à combustão interna, como mostra o Gráfico 10.

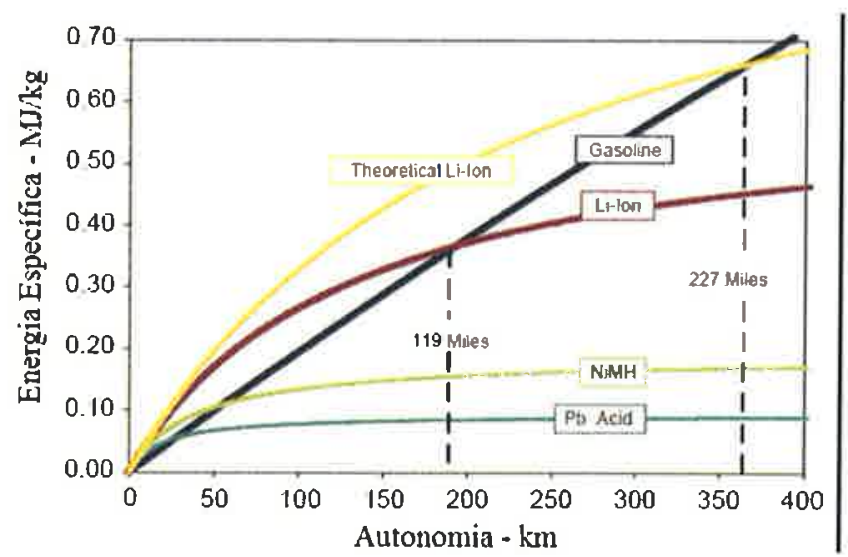

Gráfico 10- Energia Específica de Veículos Esportivos a Bateria / Gasolina Fonte: Fischer et al. (2009)

De acordo com Borba (2008), os veículos no Brasil rodam diariamente, em média, entre 25 e $50 \mathrm{~km}$. Reduzir significativamente o tamanho da bateria dos veículos elétricos pode impactar significativamente a potência disponível do veículo, tendo em vista que a potência específica das baterias, no caso das baterias de íons de lítio, é de cerca de 1 a $2 \mathrm{~kW} / \mathrm{kg}$. Além disso, a bateria de pequeno porte implica em operação com baixo estado de carga (SOC), ponto onde a bateria apresenta avanços de degradação sob carga de potência máxima (Fischer et al., 2009).

Um solução para a inflexibilidade da autonomia das baterias foi apresentado por Andersen et al. (2009), que está sendo implementada em Israel. O ápice desta proposta é separação da propriedade do automóvel da propriedade da bateria. Uma empresa seria responsável por assumir o risco de apropriação das baterias, que seriam alugadas. $\mathrm{O}$ 
consumidor seria cobrado pela energia que consumisse ao longo dos quilômetros viajados. Este modelo é equiparável à cobrança de minutos utilizados por telefonia celular. Os consumidores teriam à disposição uma série de "pacotes", que irão depender do perfil de utilização da bateria.

O Gráfico 11 e a Tabela 11 mostram uma previsão da evolução das baterias de Lítio para o ano 2020 com base em alguns pressupostos enumerados a seguir, com o objetivo de atingir o raio de alcance de aproximadamente $400 \mathrm{~km}$ em 2020, de acordo com estudo realizado por Rbschat (2009).
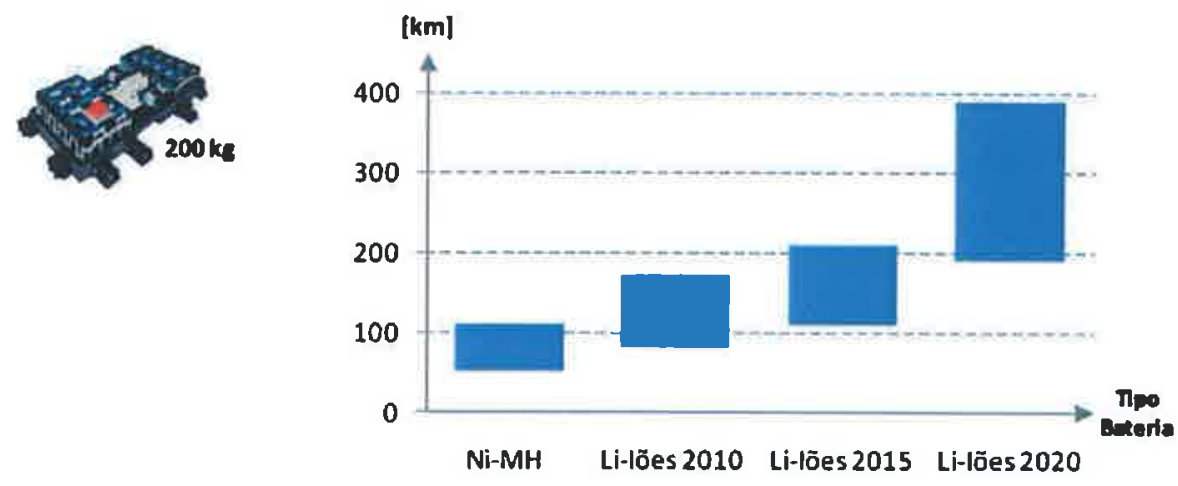

Gráfico 11- Raio de alcance da tecnologia de Íons de Lítio até 2020 Fonte: Rbschat (2009).

- Consumo de $12,5 \mathrm{~kW}$ para realizar $100 \mathrm{~km}$;

- A Bateria em 2020 será de $36 \mathrm{kWh}$;

- Considerou-se que o peso da bateria será sempre $200 \mathrm{~kg}$, ao longo de todos os anos.

Tabela 11 - Principais tipos de baterias

\begin{tabular}{|c|c|c|c|c|}
\cline { 2 - 5 } \multicolumn{1}{c|}{} & Ni-MH & Li-íons / 2010 & Li-íons / 2015 & Li-íons / 2020 \\
\hline Energia específica [W.h/kg] & 60 & 100 & 125 & 180 \\
\hline Capacidade da bateria [kW.h] & 12 & 20 & 25 & 36 \\
\hline
\end{tabular}

Fonte: Adaptado pelo autor de Rbschat (2009).

\subsection{Formas de Carregamento e sua Infra-estrutura}

A principio, os veículos convencionais movidos à combustão exigiram primeiramente a criação de uma extensa infra-estrutura para a distribuição e a venda de combustível em postos convenientemente localizados (só nos Estados Unidos existem cerca de 170.000). 
Apesar disso, o mesmo precisa ser projetado e posto em prática com relação aos automóveis elétricos que demandam de uma infra-estrutura de recarregamento.

Para se tornarem atrativos e numerosos os veículos elétricos exigem uma infraestrutura adequável que justifique esse investimento. Felizmente, segundo Hughes (2009), já existem nas cidades modernas, o núcleo do sistema de distribuição obrigatório : a rede elétrica, que foi desenvolvida há mais de um século e hoje se encontra em todo lugar. Com algum esforço e planejamento, ela poderá ser adaptada e ampliada vislumbrando recarregar os veículos elétricos.

Com avanços tecnológicos, econômicos e de "design", mas especificamente de aerodinâmica, questiona-se qual a melhor forma de transferir a eletricidade da rede para os veículos elétricos. Ao comparar com a distribuição de gasolina ou diesel, há passos diferenciados onde, por questões de segurança e economia, o combustível deve ser armazenado em elevada quantidade em poucos locais da cidade, para que consequentemente, sejam transportados por intermédios dos caminhões-tanque. Partindo desse pressuposto, bombas especiais transferem esse combustível para o tanque encontrado nos veículos.

No tocante, às tomadas elétricas, as mesmas podem ser encontradas e conectadas em todo a parte de uma cidade ou País em questão, sendo necessário apenas cabos, e não caminhões-tanque. A transferência de pequenas quantidades de eletricidade é econômica, portanto torna-se fácil criar um sistema de distribuição mais refinado.

O reabastecimento do tanque de um veículo movido à combustão através da bomba localizada nos postos demora apenas alguns minutos. Isso significa, que os trajetos realizados poderão ser interrompidos para rápidos reabastecimentos ao longo do caminho. No caso da bateria leva-se um tempo maior, em geral algumas horas em decorrências às limitações da parte química e dos equipamentos de carregamento que leva a eletricidade da rede até as baterias.

Essa mesma bateria é projetada para fornecer um número limitado de recarregamento antes de ser reciclada e substituída. Isso quer dizer que o manuseio deste acumulador eletroquímico é parte pertinente para os usuários de veículos elétricos. Na Figura 29 é possível visualizar as divergências citadas entre o abastecimento realizado por combustível versus eletricidade. 


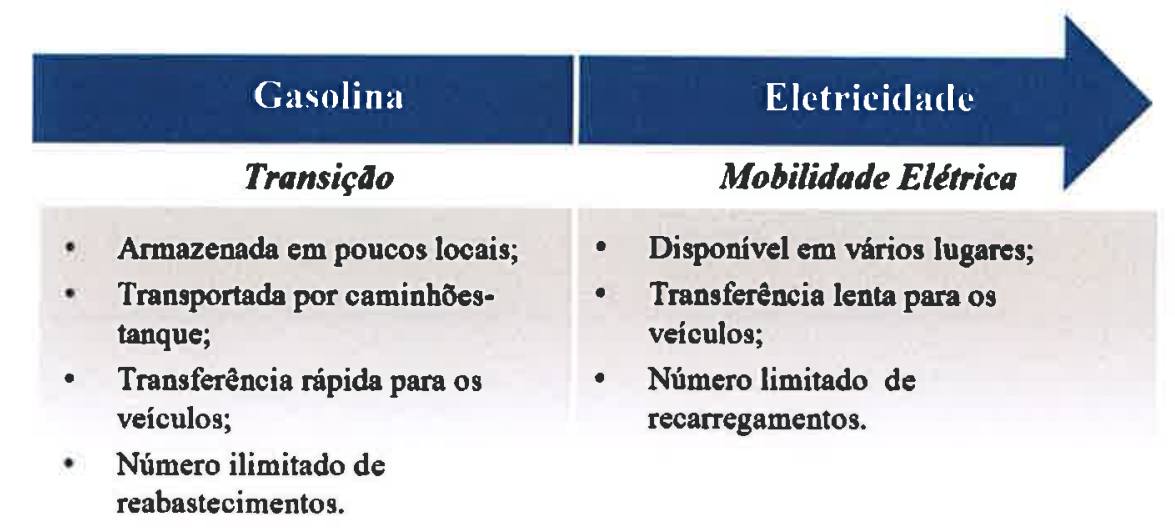

Figura 29 - Reabastecimento - Carregamento

Fonte: Elaboração Própria

Muitos fatores irão influenciar a popularização dos veículos elétricos como o meio de transporte ideal, dentre eles, disponibilidade energética, política ambiental, custo, disponibilidade de metais, conscientização da população, entre outros fatores (BOTTURA, 1986).

Os veículos, por exemplo, como o trólebus, metrôs e trens possuem muitos periféricos e elementos de controle formado por subsistemas instalados previamente para possibilitar sua utilização inicial, portanto, elevando o custo da implementação destes sistemas. Podemos destacar nestas interfaces ainda segundo Bottura, 1986:

I. Sistemas de trilhos ou linhas aéreas;

II. Sistemas especiais para abastecimento da energia elétrica ao veículo, formados por transformadores ou retificadores.

Já na questão que envolve o reabastecimento do veículo elétrico é preciso adotar e definir uma logística equiparada aos postos de serviços existentes aos usuários que utilizam o veículo movido à combustão (BOTTURA, 1986).

\subsubsection{Requisitos para construção da logística de carregamento}

Quando se trata do emprego dos veículos elétricos alguns fatores devem ser apreciados como por exemplo: 
- A distância a ser percorrida pelos veículos elétricos antes mesmo que os acumuladores eletroquímicos descarreguem;

- Se a autonomia for menor, os eletropostos devem ser mais próximos;

- Se os postos de recarga tiverem uma elevada autonomia eles poderão ficar mais dispersos.

Ao planejar e organizar a infra-estrutura de recarregamento de uma cidade sem percalços, imune da distância entre os pontos de recarregamento, alguma empresa sem definição precisará encontrar e comprar o terreno necessário fornecendo conexões à rede com os equipamentos necessários, uma vez que as mesmas deverão respeitar as políticas difundidas para a utilização dos espaços públicos e privados nas cidades, para que os construtores dos eletropostos possam instalar os postos utilizando como métrica a normativa SAE J1772, que já é utilizada por fabricantes europeus.

Román et al (2011) diz que o importante antes da construção em maior escala de pontos de recarga dos veículos é a padronização dos conectores, assim como, os protocolos de comunicação entre os veículos e a infra-estrutura de recarga. A Figura 30 mostra o progresso e o investimento de algumas nações competitivas que investem em políticas de mobilidade elétrica através da aplicabilidade e da padronização de normativas. Duas normas definem atualmente, os padrões dos carregadores, o que indica que a infra-estrutura de recarga deverá ser diferenciada em certos países. A SAE J1772 é uma norma da América do Norte mantida pela SAE (Society of Automotive Engineers) e está sendo utilizada pelos EUA e Japão, enquanto que a norma IEC 62196 é norma internacional desenvolvida pela International Electrotechnical Commission (IEC) e vem sendo a mais utilizada pela Europa (BOHN, 2011). 


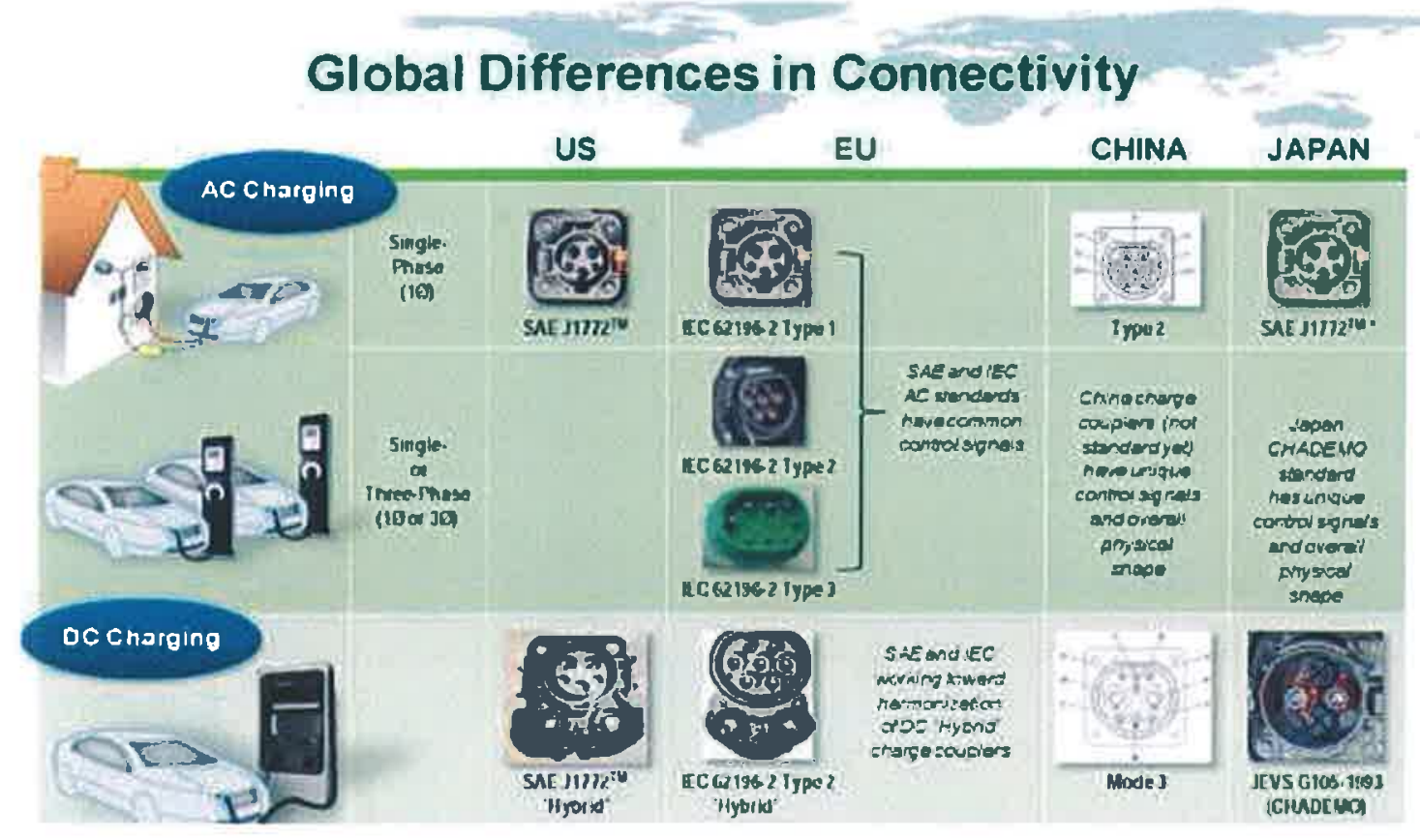

Figura 30 - Padronização de normativas em alguns países Fonte: IEA, (2012)

Essas normas definem possíveis níveis de recarga dos veículos (TAYLOR et al. 2009). Em termos gerais, divide-se a recarga em três níveis diferentes:

Nível 1 - utiliza tomada elétrica residencial padrão. No Brasil há dois padrões de tensão para a distribuição secundária de corrente alternada trifásica em redes públicas: 380/220 e 220/127 V (BRASIL, 1988). Os valores padrões de disjuntores utilizados para tomadas de uso geral são de 10 a 20 A. A maior quantidade de energia demandada pelos veículos elétricos puros provavelmente, irão necessitar de formas de recargas com maiores potências;

Nível 2 - de recarga admite a ligação fase-fase de $220 \mathrm{~V}$. Neste nível, pode-se dividir as formas de recarga em dois sub-níveis: baixo, com corrente entre 10 e $20 \mathrm{~A}$, e alto, com correntes mais elevadas. A recarga no nível 2 pode ocorrer tanto nas residências como em estações públicas de recarga. Nesta forma de recarga há a necessidade de pequenas mudanças na infra-estrutura, principalmente com correntes mais elevadas, como mudanças de cabos, disjuntores e aterramento;

Nível 3 - que compreende as recargas rápidas, feitas exclusivamente em postos públicos de recarga. O nível 3 admite tensão próxima a $600 \mathrm{~V}$ (em CA ou CC) com potência que pode chegar a $240 \mathrm{~kW}$. A alta potência envolvida neste nível está além da capacidade dos transformadores que alimentam regiões residenciais e até mesmo alguns que servem à áreas 
comerciais, necessitando modificações e reforços na rede elétrica da região. A Tabela 12 exibe as formas de recargas possíveis, considerando os diferentes níveis de recarga.

Tabela 12 - Modos de Recarga

\begin{tabular}{|c|c|c|c|}
\hline Modelo & Tensão (V) & Corrente (A) & Potência (KW) \\
\hline Nível 1 & $127(\mathrm{CA})$ & $10-20$ & $1,2-2,5$ \\
\hline Nível 2 (baixo) & $220(\mathrm{CA})$ & $10-20$ & $2,2-4,4$ \\
\hline Nível 2 (alto) & $220(\mathrm{CA})$ & $<80$ & $<18$ \\
\hline Nível 3 (CA) & $<600$ trifásico & & $15-96$ \\
\hline Nível 2 (CC) & $600 \mathrm{CC}$ & & $<240$ \\
\hline
\end{tabular}

Fonte: Adaptado pelo autor de BOHN, (2011)

Diversas residências em vários países já possuem locais de estacionamento com acesso à tomadas elétricas. Para outras regiões, no entanto, esse acesso vai exigir novos investimentos e modificações nos sistemas elétricos. Esta situação envolve o caso do Brasil, em que os grandes centros urbanos apresentam uma maior concentração de prédios que, em geral, possuem apenas algumas tomadas de acesso público aos moradores do prédio. Mais grave ainda é o caso das residências que não possuem um espaço de estacionamento dedicado. Nesta situação, a recarga durante a noite será mais complicada (EC, 2009).

Seguindo esses pré-requisitos apontados anteriormente onde poderia ser alocados os eletropostos? Certamente, essa nova estrutura deveria ser instalada aonde os veículos passam parte do tempo estacionados, pois assim, teriam mais oportunidades de adquirir a energia que precisam. Podemos observar abaixo uma análise dos dados da National Household Travel Survey-NHTS (2009) indicando os lugares mais comuns freqüentados por americanos, entre eles, podemos citar: casa, trabalho, shopping centers (são aqueles em que a capacidade de recarregamento seria mais apropriada) como mostra a Figura 31, as linhas representam o lugar onde os veículos iniciam as viagens; as colunas, o lugar onde terminam; e as cores, a freqüência com que são feitas. O trajeto exposto de casa até o trabalho apresenta a cor escura porque é uma viagem comum. Outros percursos recentes são as visitas a amigos e as idas e vindas de casa às lojas. 


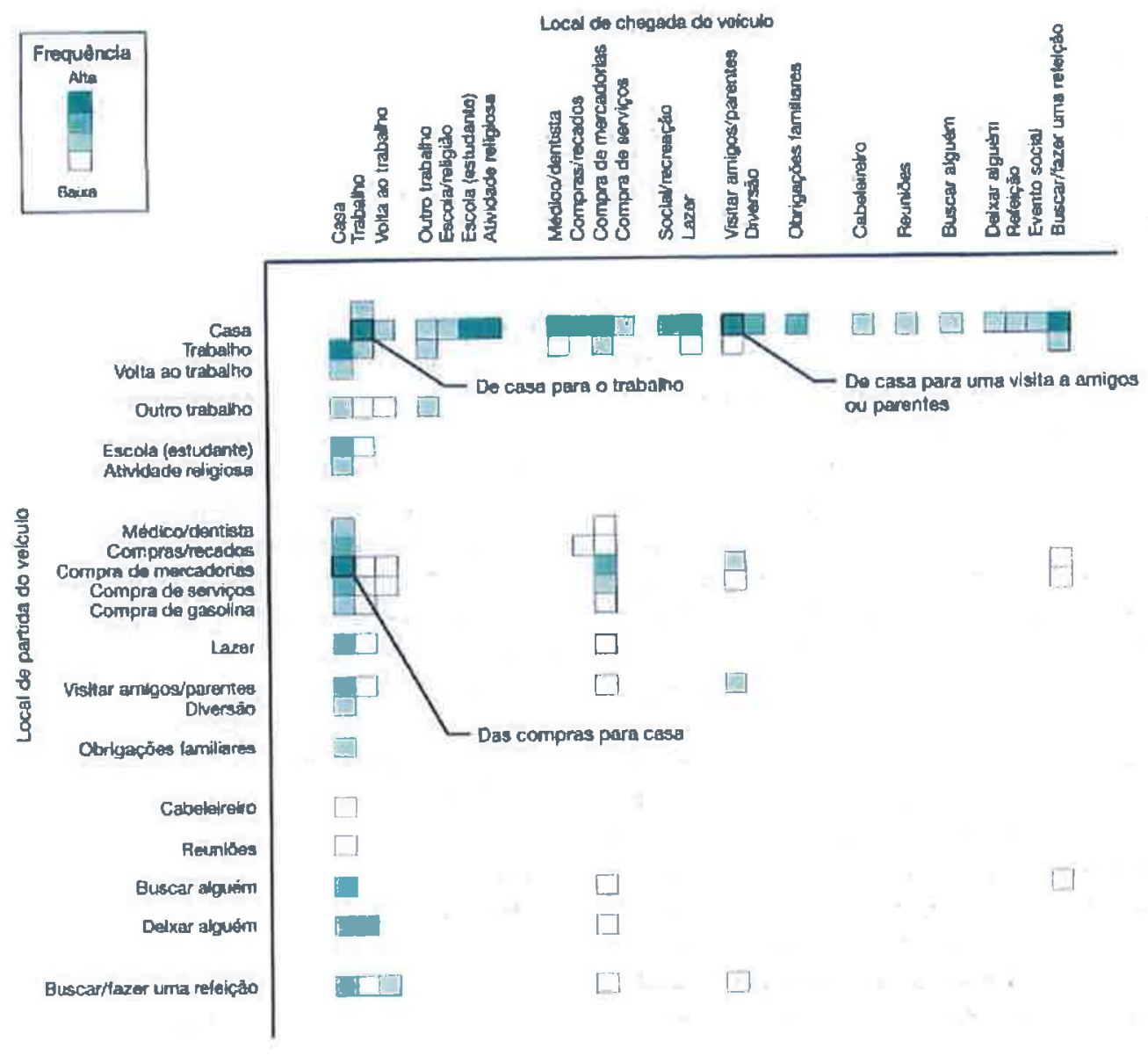

Figura 31 - Locais onde as pessoas deixam os veículos por pelo menos 30 minutos Fonte: NHTS, (2009)

Ao interpretar os dados deve-se atentar que as atividades urbanas e os padrões de utilização do solo evoluem intrinsecamente com os sistemas de mobilidade. Em áreas que mesclam moradia, comércio com rede de transporte público, cada vez mais usuários deixam seus veículos estacionados próximos a terminais de ônibus e mêtro. Nesses locais, o veículo passa mais tempo parado nos pontos de embarque e desembarque do que na residência.

Um outro ponto a ser abordado é o tempo da recarga. Um carregamento lento perdura a noite toda exigindo que os eletropostos estejam localizados onde os veículos ficam estacionados por longos períodos, enquanto os carregamentos rápidos ocorrem em menos tempo por volta de 30 minutos. Seja, qual for a estratégia de recarregamento, deve-se projetar a instalação de eletropostos com recarregamento rápido facilitando o usuário quando perceber que a bateria aponta para carga baixa. 


\subsubsection{Infra- Estrutura do carregamento e à rede elétrica}

Preliminarmente, a infra-estrutura de carregamento precisa estar de acordo com a capacidade da rede elétrica. As tomadas utilizadas para os carregamentos noturnos como a de 110 V não deverão representar um problema na maior parte dos casos. Já a utilização de voltagens mais altas para os recarregamentos rápidos poderá causar conseqüências para a subestação elétrica pela ausência de planejamento.

O impacto dos veículos elétricos na rede elétrica está intimamente associado ao momento da recarga. Segundo Kiviluoma e Meibom (2011) e Hadley e Tsvetkova (2008), com a recarga da bateria sem qualquer controle, é provável que o pico de energia elétrica da noite seja aumentado, e, consequentemente, a utilização de unidades geradoras para atender à demanda de pico irá aumentar.

A recarga sendo realizada no horário de pico contendo uma maior penetração dos veículos resulta no aumento da carga dos transformadores, perdas no sistema de distribuição, desvios de tensão e aumento da corrente de falta (Green II et al., 2011; Lin et al., 2010; Papadopoulos et al., 2010; Clement-Nynset al., 2010; Shao et al., 2009).

Localmente, a infra-estrutura elétrica das casas deverá estar preparada para recarregar os veículos elétricos simultaneamente com outros aparelhos elétricos. Estacionamentos também precisarão estar preparados para recarregar grandes quantidades de veículos e, finalmente, a rede de energia elétrica nacional deverá estar disponível para recarga simultânea de uma frota de veículos elétricos e híbridos plug-in. A demanda de energia da rede elétrica para abastecer os veículos elétricos é função da voltagem e amperagem da conexão à rede. A capacidade da bateria a ser recarregada irá determinar o tempo de recarga.

Um teste-piloto realizado pelo Laboratório Nacional de Idaho (Idaho National Laboratory - INL, 2009), confirma em grande parte, a noção de que, na ausência de infraestrutura pública para recarga, o proprietário do veículo tende a carregá-lo entre $18 \mathrm{~h}$ e $22 \mathrm{~h}$. O Gráfico 12 exibe o padrão de direção e de recarga para uma frota de veículos elétricos em cinco estados americanos no período de janeiro e fevereiro de 2008 . O resultado confirma que enquanto a condução se concentra ao longo do dia, a carga é realizada no período da noite. 


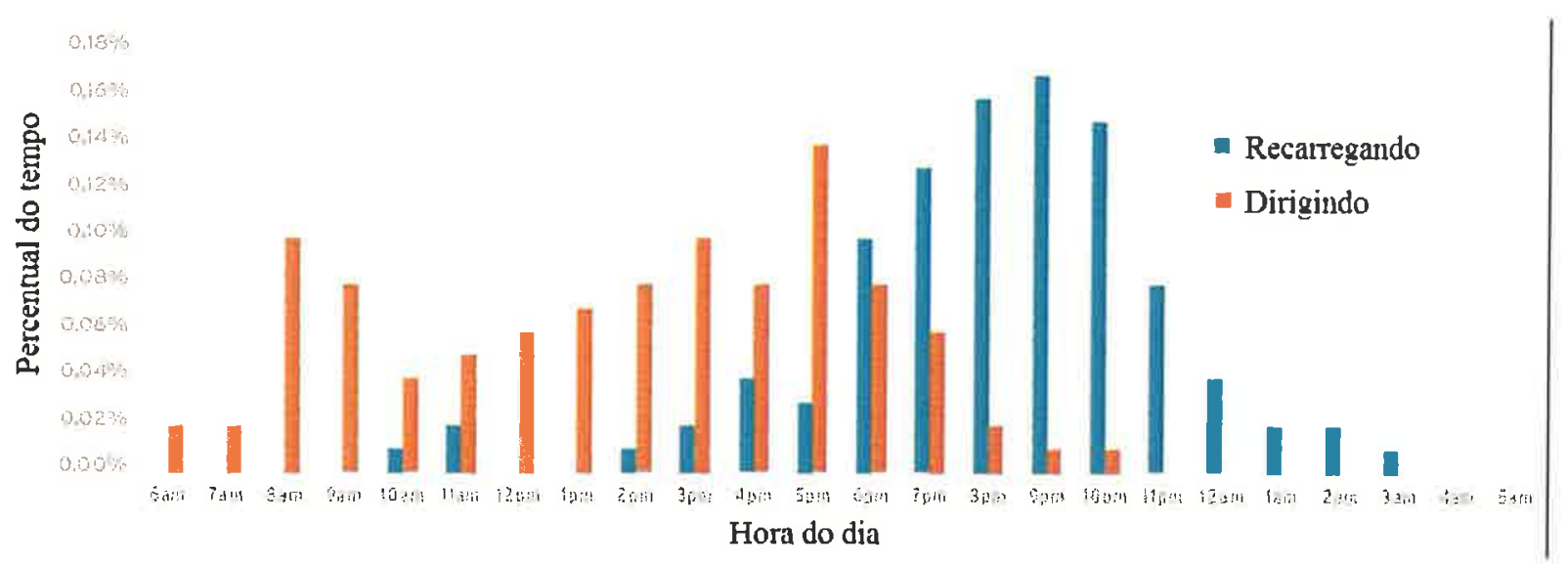

Gráfico 12 - Utilização e Recarga dos Veículos Elétricos

Fonte: INL (2008) apud EC (2009)

É necessário considerar a comercialização da eletricidade juntamente com o equilíbrio da carga. Os usuários poderão abastecer seus veículos injetando eletricidade da rede, como também armazená-la, em alguns casos vendê-la .

O tempo no qual esse veículo permanecer conectado, a distribuição desse tempo irá afetar a capacidade de comercializar a eletricidade - de comprá-la, armazená-la e vendê-la em um formato vantajoso, de acordo com a flutuação dos preços que serão cobrados. Isso pode ser um fator primordial na busca da minimização do custo da eletricidade para os usuários, para a utilização de fontes de energia renovável, porém intermitentes, como as turbinas do vento e os painéis solares e para manter a operação da rede elétrica equilibrada vislumbrando a utilização das fontes de energia renovável citada anteriormente.

\subsubsection{Troca de Bateria}

A troca de baterias refere-se à possibilidade da construção de estações de serviço que ofereceriam aos proprietários dos veículos a oportunidade de trocar a bateria, quando esta estivesse deplecionada, por uma bateria carregada. Este modelo foi desenvolvido pela empresa Better Place, que atualmente possui compromisso com diversos países e parceria com a Renault-Nissan, cujos modelos recentes de veículos elétricos movidos a bateria estão sendo adaptados para o sistema de troca automatizada de baterias em estações fixas (BROWN et al., 2010). 
I. Troca do conjunto de baterias descarregadas por outra carregada; este método dependerá de postos de serviços com vários conjuntos de baterias, bem como, da padronização das baterias, além de depender do desenvolvimento de um método adequado para substituição rápida de todas as baterias. A Figura 32 ilustra com propriedade, o formato de troca de baterias.

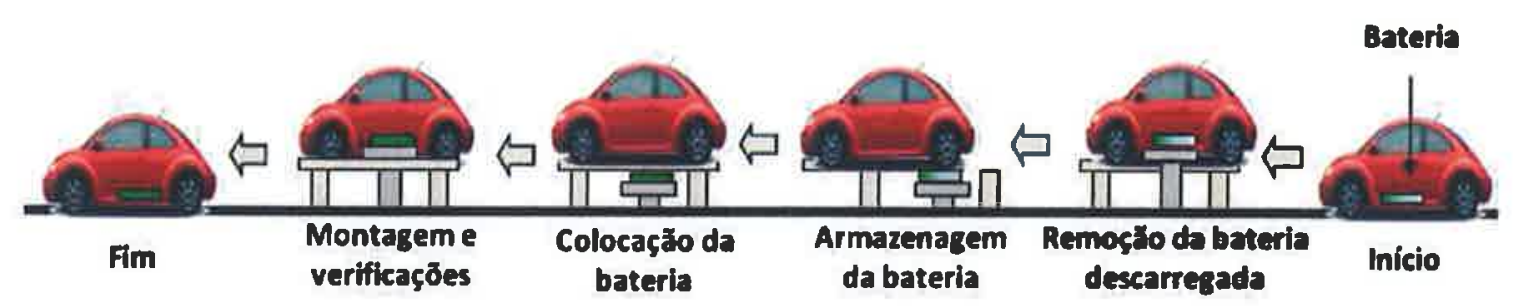

Figura 32- Troca de baterias

Fonte: B. Place ("Better Place, is a global provider of EV networks and services, accelerating the transition to sustainable transportation)

II. Desenvolvimento de um método rápido para o carregamento das baterias, o que obrigaria instalações especiais por parte das concessionárias de energia, pois para carregar um conjunto de baterias com uma tensão de 100 Volts (V) de 50000 Wh em uma hora precisaríamos de uma corrente de 500 Ampère (A).

\subsubsection{Carga lenta}

Atualmente, os utilizadores de veículos elétricos terão a sua disposição no mercado, diferentes tipologias de infra-estruturas de carregamento, que irão diferir em função das distâncias que o veículo elétrico necessitará percorrer.

Em situações em que o utilizador faz pequenos deslocamentos, o tipo de carga aconselhável é uma carga normal. Em um deslocamento médio que tenha uma variação de $120 \mathrm{~km}$ percorridos, o tipo de carga poderá ser normal ou rápida, por fim, para trajetos longos, o tipo de carga pode ser normal, rápida ou efetuar o modo de troca rápida de bateria conforme apontado por Agassi, 2009. Botsford e Szczepanek, 2009 ilustram com veemência, o apontamento acima, ressaltando que a carga normal pode ser feita numa tomada normal de 230 Volts (V) de 10 a 20 Ampère (A), permitindo recarregar o veículo elétrico entre 4 a 8 horas. Este modo de abastecimento é adaptado para automóveis elétricos estacionados durante a noite em parques privados e durante o dia de trabalho em estacionamentos coletivos preparados para tal. Na Figura 33 podemos observar o tipo de cabo de ligação oriundo do 
posto de carregamento próprios para veículos elétricos que está sendo desenvolvido para os fabricantes de automóveis europeus, que permite carregar com uma fase ou com as três.
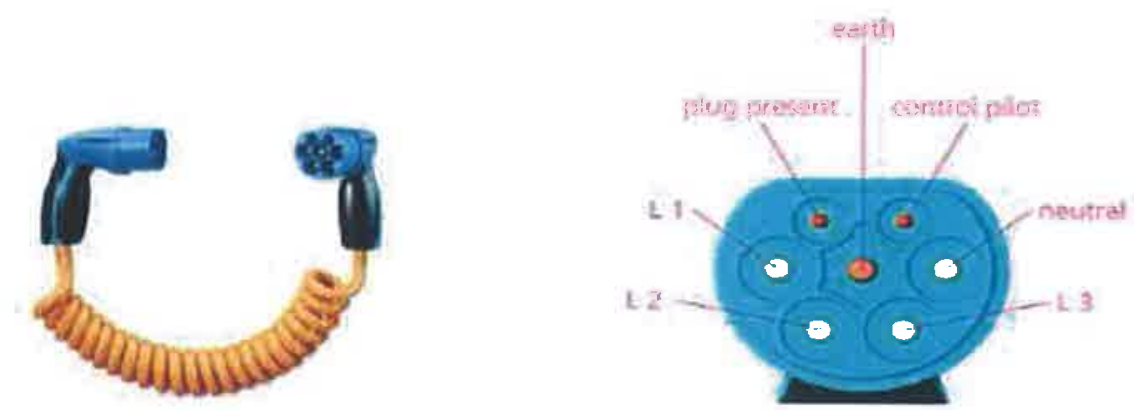

Figura 33- Cabo de Carregamento Fonte: Mennekes, 2009

A escolha, a principio do modelo inicial na busca da transferência de energia deverá ser preferencialmente lento, com recarregamentos durante a noite, na residência do proprietário, nas empresas ou durante o dia no local de estacionamento. O que diferencia os carregadores rápidos dos lentos é o custo tanto da instalação quanto dos carregadores e da rede adicional necessaária. Randazzo (2009) ressalta que para realizar um carregamento completo de meia hora ou o complemento de carga em dez minutos, em locais públicos, o valor dos carregadores atingem um valor de US\$15.000,00 doláres.

O custo de infra-estrutura, de acordo com Schroeder e Traber (2012), para instalação do nível 2 nas residências, é da ordem de mil Euros, como apresentado na Tabela 13, podendo chegar a quase 100 mil euros no caso de um sistema de recarga rápida. No entanto, os governos e a indústria automobilística precisam determinar quem vai pagar por estes custos, e em que ponto durante a expansão dos veículos elétricos os diferentes investimentos deverão ser feitos. 
Tabela 13 - Custo de Infra-Estrutura do Eletroposto

\begin{tabular}{|l|c|c|c|c|c|}
\cline { 2 - 6 } \multicolumn{1}{c|}{} & Nível 3 (CC) & Nível 3 (CA) & Nível 2 (alto) & Nível 2 (baixo) & Nível 2 (baixo) \\
\hline Material (EURO) & Público & Público & Público & Público & Residência \\
\hline Reforço do Grid (EURO) & $\begin{array}{c}40.000 \\
(40.000-75.000)\end{array}$ & $\begin{array}{c}40.000 \\
(40.000-75.000)\end{array}$ & $\begin{array}{c}4.000 \\
(4.000-7.500)\end{array}$ & 2.000 & 500 \\
\hline Transformador (EURO) & $0-35.000$ & 10.000 & 2.000 & 1.000 & 0 \\
\hline Total CAPEX (EURO) & $\mathbf{5 5 . 0 0 0}$ & $\mathbf{5 0 . 0 0 0}$ & $\mathbf{6 . 0 0 0}$ & $\mathbf{3 . 0 0 0}$ & $\mathbf{5 0 0}$ \\
\hline $\begin{array}{l}\text { Manutenção (EURO/ano) } \\
\text { (10\% OPEX) }\end{array}$ & 4.000 & 4.000 & 400 & 200 & 50 \\
\hline Total OPEX (EURO) & $\mathbf{4 0 . 0 0 0}$ & $\mathbf{4 0 . 0 0 0}$ & $\mathbf{4 . 0 0 0}$ & $\mathbf{2 . 0 0 0}$ & $\mathbf{5 0 0}$ \\
\hline INVESTIMENTO (EURO) & $\mathbf{9 5 . 0 0 0}$ & $\mathbf{9 0 . 0 0 0}$ & $\mathbf{1 0 . 0 0 0}$ & $\mathbf{5 . 0 0 0}$ & $\mathbf{1 . 0 0 0}$ \\
\hline
\end{tabular}

Fonte: Schroeder e Traber, (2012)

Soble (2008) descreve que no Japão existem projetos cujo tema principal é a busca do desenvolvimento de centenas de eletropostos "expressos". A empresa Tokyo Electric Power (Tepco) busca fornecer equipamentos de US\$ 36.500,00, capazes de carregar em cinco minutos a bateria de um pequeno elétrico com autonomia de $40 \mathrm{Km}$, e em dez minutos para uma autonomia de $60 \mathrm{Km}$. Contudo, é quantificado o custo dos recursos adicionais da rede afim de suportar esses carregadores, totalizando em uma elevação do custo final.

Uma comparação entre os custos de alocação dos tanques subterrâneos das bombas de um posto de gasolina e dos equipamentos de recarregamento se chega a conclusão que o custo torna-se compatível, sendo similar ao dos postos atuais (SOBLE, 2008).

\subsubsection{Carga rápida}

A carga rápida pode ser feita em uma infra-estrutura, com uma potência disponível de 22 a $44 \mathrm{~kW}$, fornecendo uma gama de correntes entre 30 a $63 \mathrm{~A}$, em modo trifásico, permitindo recarregar $80 \%$ da bateria entre 20 a 30 minutos (BOTSFORD E SZCZEPANEK, 2009).

Do exposto, pode-se concluir que para introduzir os veículos elétricos como meios de transportes em um formato confiável que resulte em vantagem competitiva sustentável são necessários a elaboração de projetos específicos para baterias, motores e acionamento.

Neste sentido, segundo Valle Real e Balassiano (2002), basicamente, existem dois caminhos a serem tomados. O primeiro deles seria tornar os veículos mais eficientes do ponto de vista do consumo energético (bem como para a quantidade de emissões) e, em segundo 
lugar, por meio de restrições e adoção de taxas específicas, levar o usuário a diminuir o uso do automóvel particular e demais veículos automotores.

De forma geral, a recarga dos veículos elétricos pode ser feita de forma condutiva ou indutiva. A recarga condutiva representa a transferência de energia elétrica por meio de contato físico através de um meio condutor, enquanto que a recarga indutiva é feita por indução eletromagnética: a variação do campo magnético gerado por um fluxo de corrente em um material condutor (usualmente uma bobina) enlaça outro material condutor (que também pode ser uma bobina), induzindo tensão nas extremidades do material (IEA, 2011). De acordo com Bossche (2010), a recarga condutiva é a mais amplamente utilizada para os veículos elétricos.

A vantagem associada à recarga indutiva está relacionada à segurança, pois não existem contatos elétricos expostos. Todavia, para a recarga condutiva há maior praticidade. Se os dispositivos eletrônicos para converter a corrente alternada da rede elétrica em corrente contínua (em uma tensão apropriada) para alimentar as baterias dos veículos estiverem localizados no veículo, a recarga da bateria de forma condutiva pode ser feita em qualquer tomada padrão (IEA, 2011). Neste caso, entretanto, há a desvantagem do custo adicional do veículo envolvendo não apenas a bateria, como também o carregador.

\subsubsection{Infra-estrutura para carregamento planejado em Québec (Canadá)}

Para realizar recarga durante o dia em locais públicos, há a necessidade de construção de infra-estrutura adequada, que inclui locais públicos de recarga (por exemplo, em escritórios, centros comerciais e estacionamento de rua). Este tipo de infra-estrutura torna-se fundamental para incentivar a utilização em larga escala dos veículos elétricos movidos à bateria, principalmente quando o sistema de recarga nas residências for limitado, como discutido anteriormente. Atualmente, a infra-estrutura pública para recarregar veículos elétricos é muito limitada ou inexistente na maioria das cidades, embora algumas delas já possuam infra-estrutura instalada como parte de projetos-piloto e outros programas (IEA, 2011).

O circuito elétrico (Hydro -Québec) é um passo importante na implantação da infraestrutura de carregamento necessário para suportar a chegada de veículos elétricos recarregáveis em Québec, no Canadá. Com políticas engajadas na Mobilidade Elétrica, a esfera governamental deliberou que fossem alocados 30 eletropostos em 2012 e 150, no fim de janeiro de 2013. As estações de carregamento de $240 \mathrm{~V}$ podem ser localizadas em lojas, mercearias, estacionamentos, no Mêtro St-Hubert em Québec entre outros. 
De acordo com um estudo realizado pela Hydro-Québec (2009), empresa responsável por este projeto - $94 \%$ das famílias em Québec possuem ou pretendem adquirir um veículo já possuindo vagas de estacionamento em casa, e $89 \%$ dessas famílias já têm acesso à uma tomada padrão (120 volts, a carga de nível 1) nos própios estacionamentos. A Figura 34 revela os resultados da pesquisa.

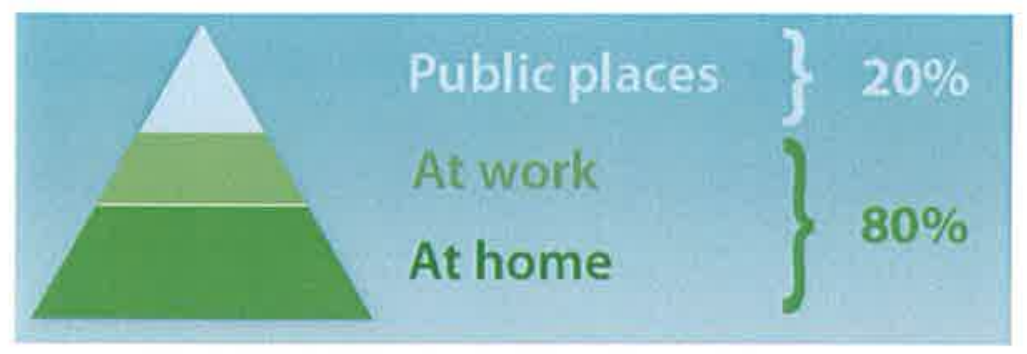

Figura 34- Relação de carregamentos a serem realizados em Québec Fonte: Hydro-Québec, (2012)

Os carregamentos em questão serão feitos em casa, no trabalho ou em um estacionamento usado no trabalho. Isso deve nos permitir atender mais de $80 \%$ das nossas necessidades de carregamento. A substituição de um milhão de automóveis, o que corresponde a $25 \%$ da frota atual pelos veículos elétricos iria reduzir as emissões de gases de efeito estufa em 3,4 milhões de toneladas (HYDRO-QUÉBEC, 2009). A Tabela 14 mostra a economicidade em utilizar o veículo elétrico

Tabela 14- Vantagem ao utilizar os veículos elétricos

\begin{tabular}{|l||c|}
\hline \multicolumn{1}{|c|}{ Tipo de Veículo } & $\begin{array}{c}\text { Consumo } \\
\mathbf{1 0 0} \mathbf{~ K m}\end{array}$ \\
\hline Veículo Elétrico & $15 \mathrm{KWh}$ \\
\hline Veículo movido à gasolina & 8.2 litros \\
\hline
\end{tabular}

\begin{tabular}{|c|c|}
\hline $\begin{array}{c}\text { Custo eletricidade } \\
\text { gasolina } \\
\text { USS }\end{array}$ & $\begin{array}{c}\text { Custo Final } \\
\text { USS }\end{array}$ \\
\hline & 1.17 \\
\hline $0.0777 / \mathrm{KWh}$ & 11.48 \\
\hline $1.40 /$ litro \\
\hline
\end{tabular}

Fonte: Elaboração própria

o usuário que adquirir um veículo elétrico em Québec poderá carregar seu automóvel nos eletropostos localizados nas principais vias da cidade. A figura 35 demonstra a facilidade para efetuar o carregamento do veículo em locais públicos. 


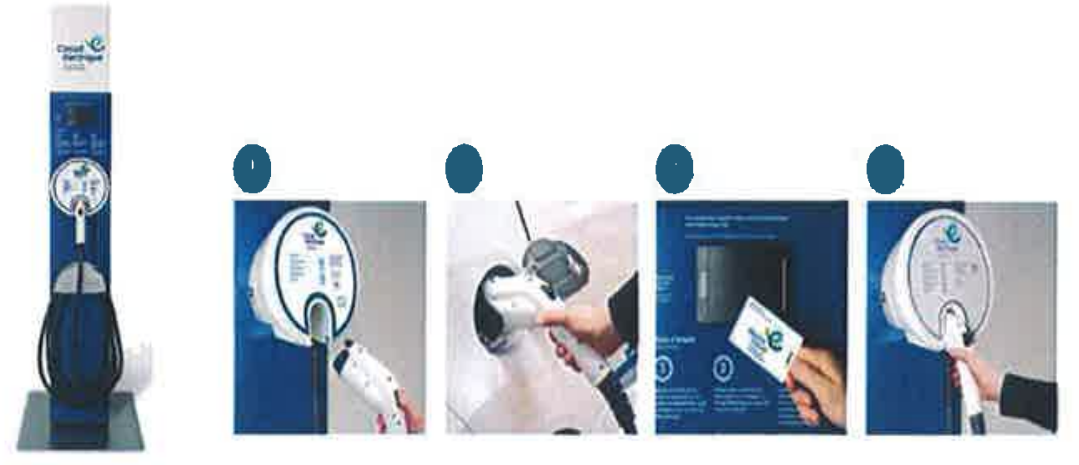

Figura 35- Eletroposto - HYDRO-QUÉBEC Fonte: HYDRO-QUÉBEC (2012)

1- Pressione o botão de liberação para desconectar o conector da estação de carregamento;

2- Ligue o conector na tomada do seu veículo;

3- Segure o cartão "circuito elétrico" na frente do leitor. O carregamento inicia quando uma luz verde se acende no visor;

4- Ao terminar o carregamento, ligar o conector de volta para a estação de carregamento para finalizar a transação.

A Figura 36 traz um mapa mostrando a versatlidade de postos de recarga em Québec, para encontrar o mais próximo é só digitar o endereço e verificar se está diponível.

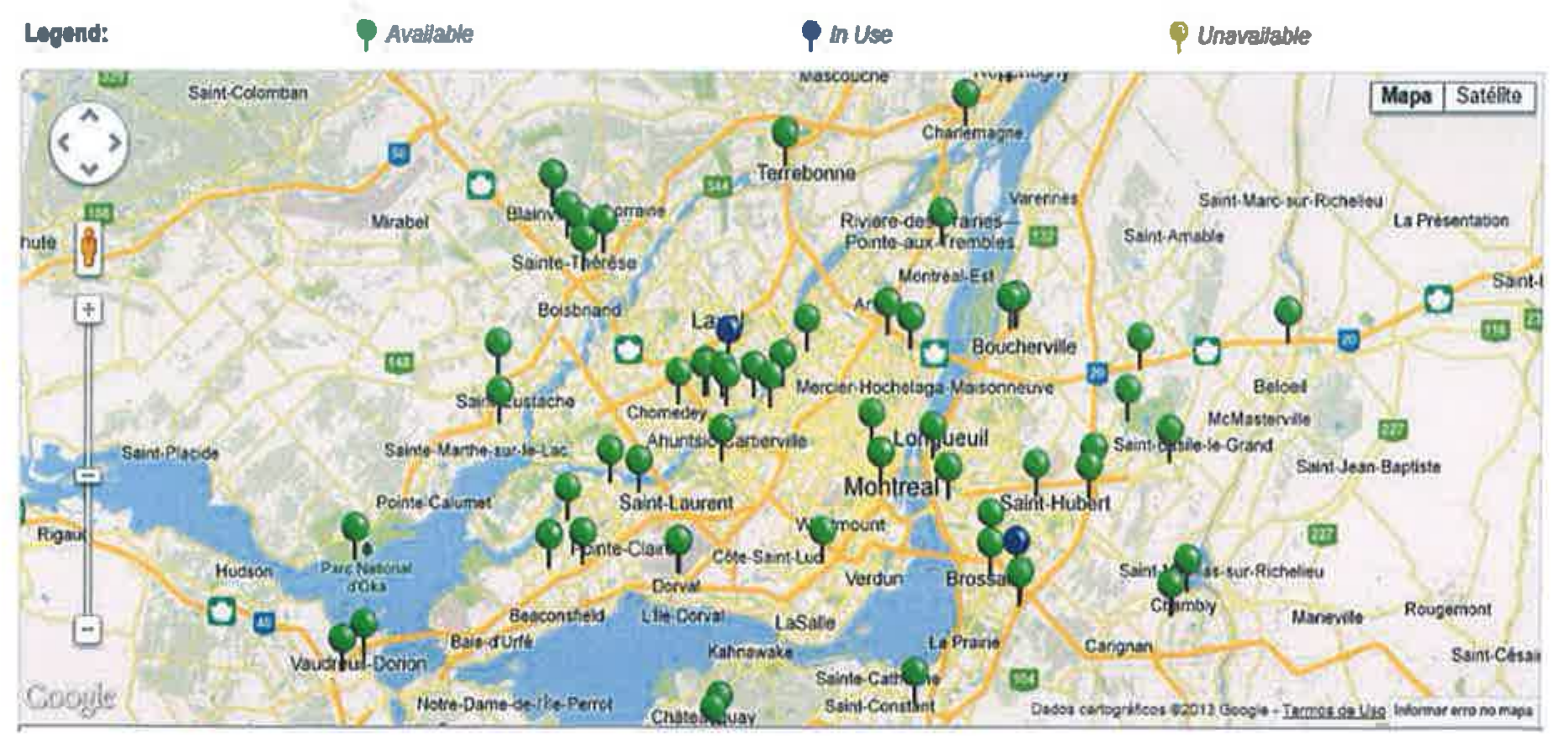

Figura 36- Mapa de localização dos eletropostos

Fonte: HYDRO-QUÉBEC (2012) 
Esse capítulo apresenta a problemática de distribuição de mercadorias atrelado a um novo conceito para mobilidade e sustentabilidade através da utilização dos veículos elétricos urbanos de carga. Pretende-se com isso, apresentar uma nova política de geração de eletricidade a partir da utilização de fontes renováveis, mostrando possíveis soluções encontradas e definidas por outros países.

\section{INTRODUÇÃO DA MOBILIDADE ELÉTRICA ATRAVÉS DA ANÁLISE DO CONSUMO DE ENERGIA NO SETOR DOS TRANSPORTES}

\subsection{Mobilidade no Transporte}

O EUROFORUM (2007) define mobilidade para as pessoas como a capacidade de participar de diferentes atividades em diferentes lugares e, para bens, a possibilidade de acesso às atividades relacionadas à sua produção e comercialização, as quais ocorrem freqüentemente em diferentes lugares. Para o transporte de passageiros as suas atividades representam o ir e vir à residência, ao trabalho, aos centros educacionais e comerciais, ao lazer, entre outros. Para o transporte de cargas, as atividades representam a extração de matéria-prima, o processamento, a estocagem, a venda, a reciclagem, etc. O EUROFORUM (2007) destaca ainda que as cidades necessitam dar suporte à mobilidade de forma a cumprir sua função social e proporcionar crescimento econômico, ao mesmo tempo em que devem buscar limitar o crescimento do tráfego motorizado e seus impactos negativos sobre as pessoas e sobre o meio ambiente.

Segundo Macário (2005), influenciam a mobilidade fatores como as dimensões do espaço urbano, a complexidade das atividades nele desenvolvidas, a disponibilidade de serviços de transporte e as características da população, especialmente no que diz respeito às questões como renda, faixa etária e gênero. Do mesmo modo, as condições de mobilidade afetam diretamente o desenvolvimento econômico das cidades, a interação social e o bemestar de seus habitantes.

Já Bertolini (2008), diz que o aumento da mobilidade é resultado do incremento dos fluxos de pessoas e bens, tem implicado em impactos negativos sobre o ambiente local e global, sobre a qualidade de vida e sobre o desempenho econômico das cidades. Estes impactos incluem congestionamentos, emissão de poluentes, ruído, fragmentação de 
comunidades, acidentes, uso de energia não renovável. As medidas mitigadoras destes impactos têm implicado no aumento dos custos para a expansão da infra-estrutura urbana.

Uma economia ambientalmente sustentável - uma ecoeconomia - requer que os princípios da ecologia estabeleçam o arcabouço para a formulação de políticas econômicas e que economistas e ecólogos trabalhem, em conjunto, para modelar a nova economia (BROWN, 2003).

$\mathrm{O}$ aumento das atividades conduz aos crescimentos espacial e econômico dos centros urbanos. Dessa forma, a Organização das Nações Unidas (ONU) projeta que, até 2050, mais de dois terços da humanidade estará habitando as cidades (apud BROWN, 2003). Segundo o documento que deu origem à $1^{\text {a }}$ Conferência das Cidades, além de $80 \%$ da população, se concentram nas áreas urbanas, a produção industrial e a comercialização de bens e serviços, que provocam elevados ônus ambientais e a evolução das cidades está ligada aos avanços nos transportes (é consenso que os meios de transportes e as infra-estruturas correlatas são responsáveis diretos na modificação de estilos e padrões das atividades urbanas).

O comércio internacional jamais teria se expandido sem a mobilidade. Também é importante reconhecer que sistemas de transporte de cargas de alta qualidade e eficiência favorecem o desenvolvimento sustentável (WBCSD, 2001).

Assim, torna-se inquestionável a importância que tem um sistema de transportes eficiente, eficaz e flexível à atividade econômica e à qualidade de vida. Porém, um sistema de transportes que atenda às necessidades de deslocamento de uma população, dando-lhe mobilidade, por si só representa uma grande ameaça ao ambiente e à saúde humana ("demasiado tráfego destrói o tráfego"). Logo, a chave para encontrar a solução de equilíbrio entre essas "forças" está, então, no encontro de políticas que integrem considerações ambientais e de sustentabilidade na tomada de decisões sobre transportes e políticas afins. São vários os grupos que têm papel a desempenhar no processo de integração: decisores em todos os níveis nas áreas de transportes, ambiente, economia, desenvolvimento regional e ordenamento do território, bem como, as indústrias, os operadores de transportes e usuários (TERM, 2000).

\subsubsection{Mobilidade Sustentável}

Sustentabilidade é um termo que vem sendo muito aplicado às questões ligadas ao transporte. Segundo Ferreira (1999), o termo vem da qualidade de sustentável, que significa: 
que se pode sustentar e capaz de se manter mais ou menos constante, ou estável, por longo período.

A Comissão Mundial de Meio Ambiente e Desenvolvimento (World Commission on Environment and Development - WCED ou "Brundtland Commission"), em 1987, definiu desenvolvimento sustentável como sendo "o desenvolvimento que vai ao encontro das necessidades do presente sem comprometer a capacidade de resolução das mesmas às futuras gerações" (CENTRE FOR SUSTAINABLE TRANSPORTATION, 2001).

“Mobilidade sustentável” é um vocábulo de diferentes conotações. Segundo o WBCSD6 (Conselho Empresarial Internacional para o Desenvolvimento Sustentável) significa "a capacidade de atender às necessidades da sociedade em deslocar-se livremente, em ganhar acesso, em comunicar-se, em comercializar e em estabelecer relações sem sacrificar outros valores fundamentais humanos ou ecológicos hoje ou futuramente (conceituação mais voltada para o social)". Para outros, no entanto, o termo reflete preocupações mais plausíveis (operacionais), como saber se os sistemas de transporte, no futuro, ainda conseguirão atender às nossas necessidades.

Em outras palavras, para se conseguir uma mobilidade urbana sustentável, é necessário definir objetivos e indicadores de sustentabilidade, estabelecer metas e controles que estejam a par de políticas tendentes a melhorar não só as condições de mobilidade, mas também a acessibilidade. A conciliação da acessibilidade, do desenvolvimento econômico e dos aspectos ambientais deverá ser o objetivo principal da política de transportes urbanos. É necessário um sistema de transporte urbano multimodal e integrado, que promova modos de transporte complementares em vez de concorrentes (PORTAL VERDE, 2003).

Segundo o WBCSD (2001), a análise de mobilidade deverá avaliar a eficiência da acessibilidade e os efeitos por ela gerados.

O diagrama mostrado na Figura 37 traz, de forma simplificada, as diferenças básicas entre alguns termos que se costumam confundir. 


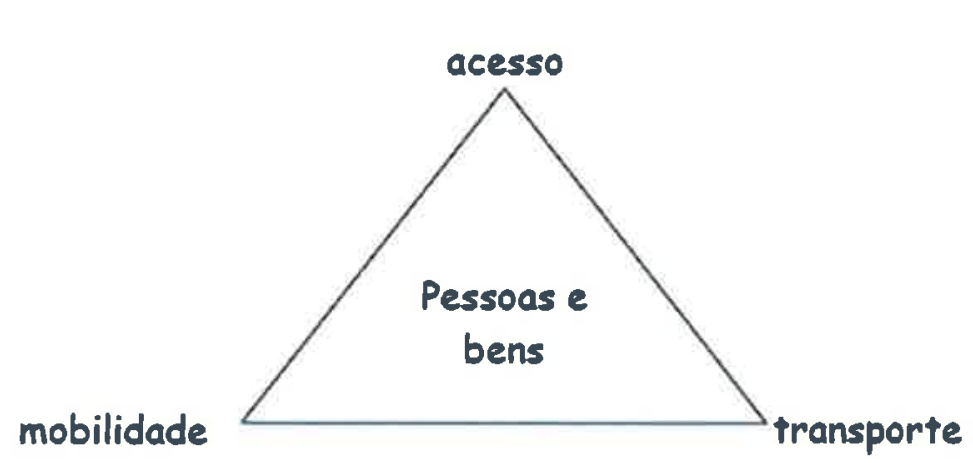

Qual a difarenga entre os trîs

vintices?

- Acesso é a chave para o movimento (posso ter um visto?).

- Mobilidade é a necessidade de se mover (posso viajar?).

- Transporte significa o meio pelo qual cada um se move (como vou?).

Figura 37 - Mobilidade, acessibilidade e os efeitos por ela gerados Fonte: WBCSD (2001)

Uma outra questão importante, e que tem clara vinculação com a sustentabilidade, é a igualdade da mobilidade, ou seja, a oferta dos serviços de transporte às pessoas de baixa renda. Fica a questão: será a mobilidade considerada um direito de cidadania ou um bem de consumo? Além disso, a sustentabilidade é tremendamente afetada pela capacidade institucional na regulamentação do meio ambiente e da segurança. Para os países em desenvolvimento, essa capacidade institucional ainda é mais importante, dadas às desvantagens e atrasos (em relação aos países em desenvolvimento) e o crescimento desordenado das cidades (WBCSD, 2001).

Segundo Gudmundsson (2004), no que diz respeito à mobilidade, há diversas fontes para a definiç̧ão de transporte sustentável, impedindo o estabelecimento de uma definição única. A dificuldade em se obter um conceito único está associada, entre outros fatores:

- A idéia de transporte sustentável em si mesma é contestada, uma vez que há um amplo conjunto de metodologias sendo aplicadas para medir vários aspectos do conceito;

- $\quad$ o setor de transportes consiste em uma série de subsistemas técnicos e sociais interagindo para produzir benefícios sociais, ao mesmo tempo em que provocam impactos negativos ao meio ambiente;

- $\mathrm{O}$ transporte não pode ser visto de forma isolada do resto da sociedade, o que significa que a sustentabilidade dos sistemas de transportes deve ser de fato considerada como parte das mudanças em todo o sistema socioeconômico. 
Desta forma, ainda que não seja possível identificar uma definição única para transporte sustentável já bastante aceita e difundida sobre o tema, um primeiro conceito trabalhado pela OECD (Organization for Economic Cooperation and Development), posteriormente complementado pelo Grupo de Especialistas em Transportes e Meio Ambiente da Comissão Européia e aceito como referência pelo Conselho Europeu de Ministros de Transportes, define como um transporte sustentável aquele que contribui para o bem-estar econômico e social, sem prejudicar a saúde humana e o meio ambiente. Integrando as dimensões sociais, econômicas e ambientais, podendo ser definido como aquele que:

- Permite a satisfação das necessidades básicas de acesso e mobilidade de pessoas empresas e sociedade, de forma compatível com a saúde humana e o equilíbrio do ecossistema, promovendo igualdade dentro das gerações e entre as mesmas;

- Possui custos aceitáveis, funciona eficientemente, oferece a possibilidade de escolha do modo de transporte e apoia uma economia dinâmica e o desenvolvimento regional;

- Limita as emissões e os resíduos em função da capacidade da Terra para absorvê-los, utiliza recursos renováveis a um ritmo inferior ou igual a sua renovação, utiliza os recursos não renováveis a um ritmo inferior ou igual ao desenvolvimento de substitutos renováveis e reduz o uso do solo e a emissão de ruído (OECD,2000, apud Moruelo, 2002; TRB, 2008).

Gudmundsson (2004) ressalta ao mesmo tempo em que emergem diferentes definições para mobilidade sustentável, inúmeros aspectos têm sido destacados nas iniciativas em se promover o conceito. Algumas questões incorporadas na definição de transporte dizem respeito a:

- Maior integração entre as questões econômicas e ambientais na tomada de decisão e a necessidade de maior participação e engajamento dos cidadãos nos processos políticos;

- Mudanças para novas tecnologias e energias alternativas;

- Otimização da logística e fluxos de transportes;

- Mitigação dos congestionamentos urbanos, poluição do ar e ruído;

- Conservação de recursos e eficiência econômica dos transportes. 
Atualmente, também se observa que as cidades mais dependentes do automóvel têm mais congestionamento e menos mobilidade do que aquelas que oferecem outras opções de translado. "O próprio veículo, cuja grande promessa era a mobilidade, está, na realidade, imobilizando populações. Assim, quanto pior o congestionamento, maior o estilo sedentário de vida da população" (BROWN, 2003).

É fato de que não se pode viver sem mobilidade. Mas, serão suas consequências suportáveis? A população disporá de mobilidade no futuro? Seus custos econômicos, ambientais e sociais serão toleráveis? Para que se tenha verdadeiramente a mobilidade sustentável é preciso que a resposta às três perguntas seja positiva (WBCSD, 2001).

$\mathrm{O}$ aumento de infra-estrutura, adequando-a à exigência do uso, deveria então, ser capaz de solucionar esse mal-estar. Nesse sentido, vale acrescentar a observação feita por Richard Moe, Diretor do National Trust for Historic Preservation, "construir mais vias para facilitar o tráfego é como tentar curar a obesidade afrouxando o cinto" (apud BROWN, 2003).

Além do aumento em infra-estrutura, a melhoria nos combustíveis também deveria ser substancialmente significativa. É importante, mas também não resolve. Segundo o Transport and Environment Reporting Mechanism (TERM4), o que se vem observando nos últimos tempos é que, mesmo se tendo melhorado a qualidade dos combustiveis e se tendo diminuído as emissões por veículo, os benefícios têm sido superados pelo crescente aumento do volume de transportes e pela utilização de veículos mais pesados e potentes.

\subsection{Geração de Eletricidade Através de Fontes Renováveis}

Ao mesmo tempo que o recurso energético, constituído pelos combustíveis fósseis, em especial o petróleo, é finito e que sua utilização é feita de forma maciça, mostra-se plenamente exequível à dependência energética do mesmo, podendo esgotar-se nas próximas décadas.

Nesse sentido, será primordial buscar alternativas a fim de proporcionar sustentabilidade no setor de transportes. A Figura 38 mostra que praticamente $81 \%$ das reservas mundiais de petróleo estão sob controle dos países da Organização dos Países Exportadores de Petróleo (OPEP). Entre os 12 países membros da OPEP, sete são árabes onde eles são detentores de $66 \%$ das reservas. 


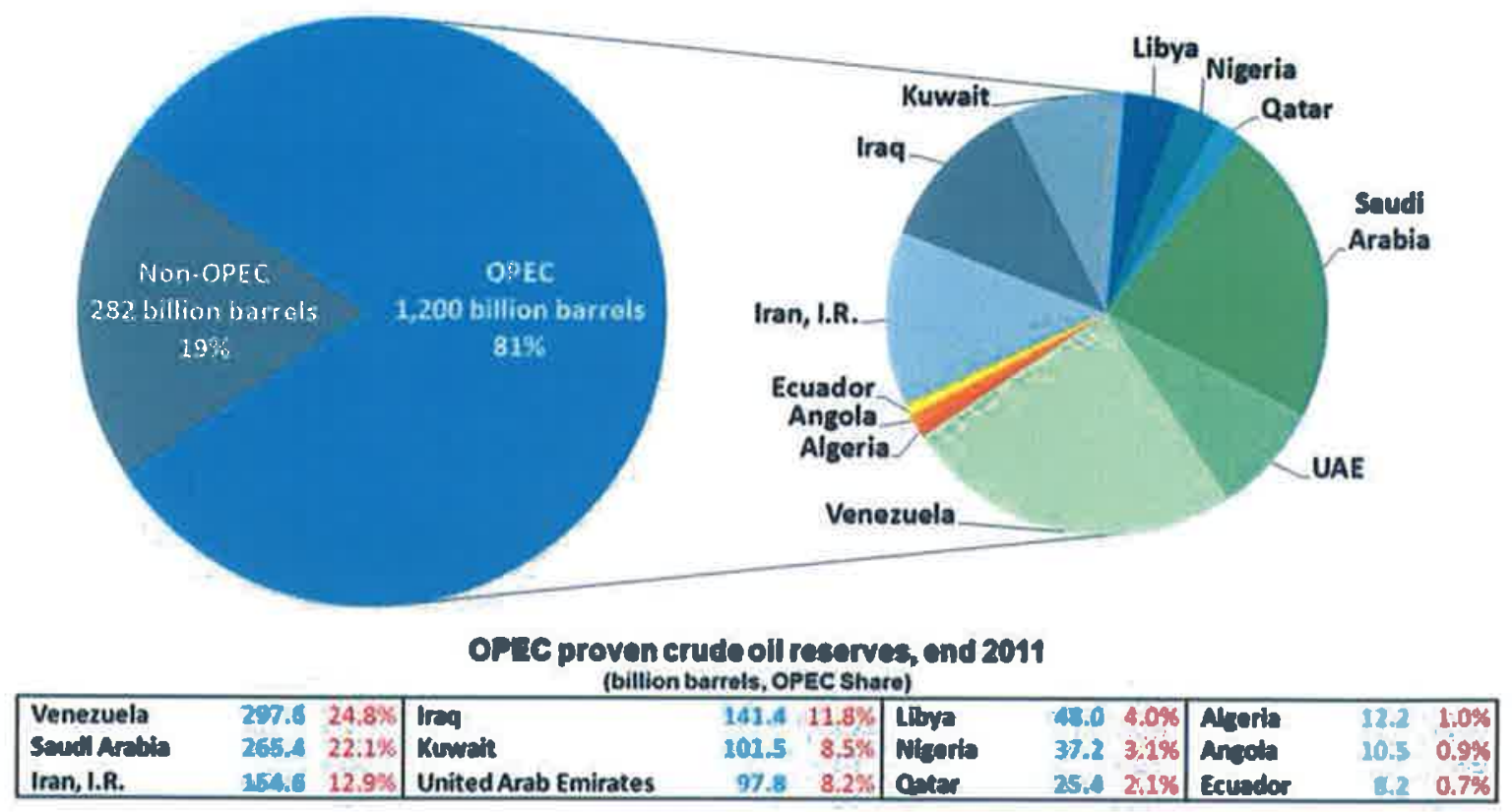

Figura 38 - Membros da OPEP

Fonte: OPEP, 2012

Em contrapartida, o Gráfico 13 traz um comparativo entre a produção mundial de combustíveis líquidos, o consumo e as retiradas. Entre as variáveis produção e consumo é notório observar uma elevação do consumo global (listado em azul) de combustíveis líquidos principalmente nos meses de novembro e dezembro de 2012 atingindo a média de 90,2 milhões bbl/d. Explicações para essas elevações do lado da demanda corresponde ao período de inverno nos Estados Unidos nos meses apontados acima, mesmo ocorrendo a interrupção no fornecimento de produtos petrolíferos causadas pelo furacão Sandy não foi possivel mitigar o consumo. A China também foi uma das responsavéis pela elevação do consumo no ano de 2012 fundamentalmente ocasionado pelo seu crescimento econômico (EIA, 2012). 


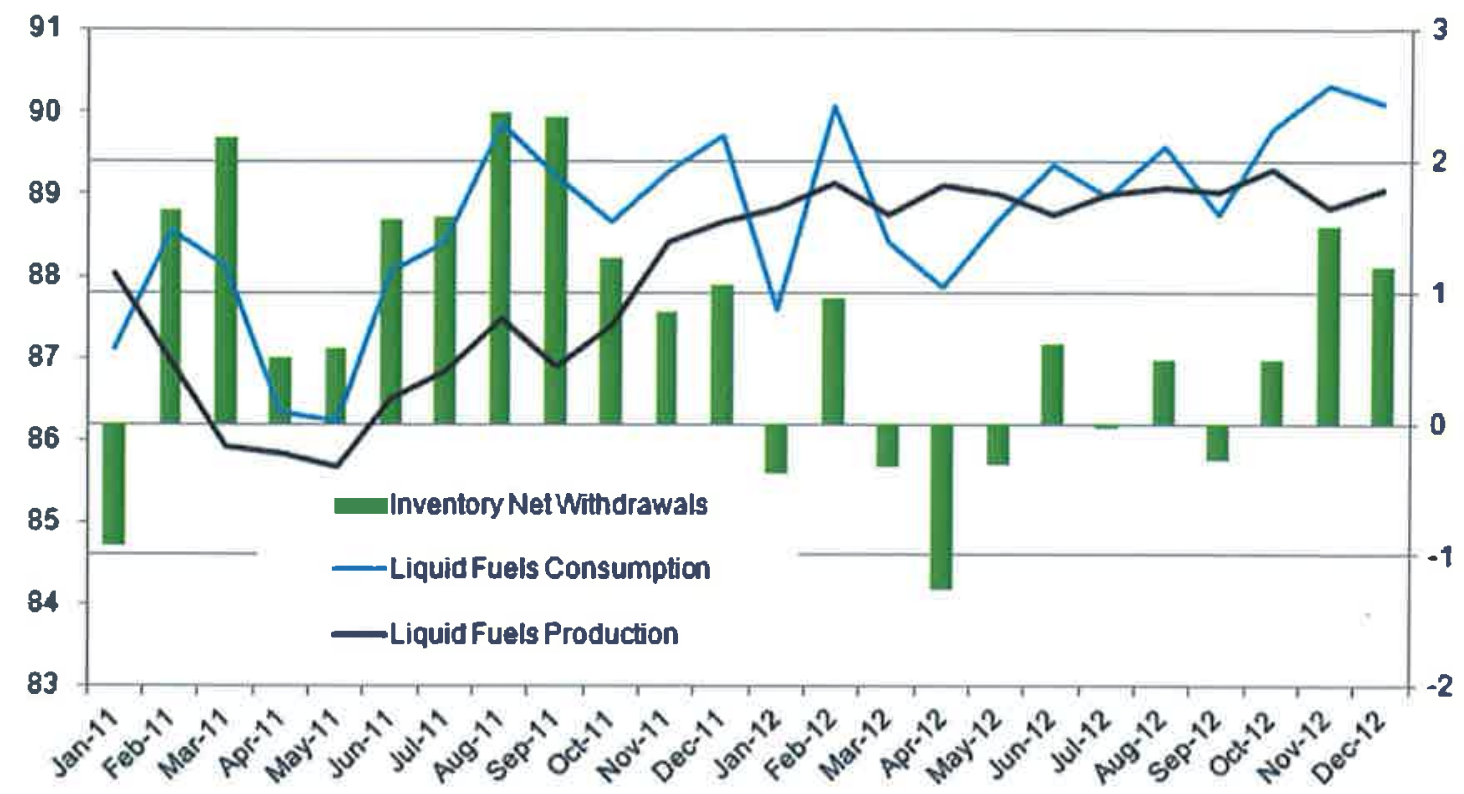

Gráfico 13 - Produção e consumo de petróleo

Fonte: EIA, (2012)

Todavia, segundo as previsões da Agência Internacional de Energia - IEA (2011), a participação dos combustíveis fósseis em relação ao consumo global de energia primária sofrerá sensíveis quedas até o ano de 2035 passando de $81 \%$ em 2010 para uma projeção de $75 \%$ em 2035. Metade dessa nova capacidade instalada do setor elétrico será decorrente do uso de fontes renováveis, de acordo com as características de cada país. A Tabela 15 mostra o consumo de petróleo no período demarcado e a participação em relação ao consumo global desmembrado por países. Destaque para os países grifados em vermelho que iniciaram a adoção de políticas sustentáveis priorizando a mobilidade elétrica sustentável.

Tabela 15- Os quinze países que mais consumiram petróleo em 2011

\begin{tabular}{|c|c|c|c|c|}
\hline País & $\begin{array}{c}\text { Consumo de petróleo } \\
\text { (2011/ milhōes de } \\
\text { barris dia) }\end{array}$ & \begin{tabular}{|c|} 
Consumo de petróleo \\
(2010/ milhões de \\
barris dia)
\end{tabular} & \begin{tabular}{|l} 
Participação em \\
relação ao consumo \\
global de petróleo
\end{tabular} & Variação \\
\hline Estados Unidos & 18,8 & 19,1 & $20,5 \%$ & $-1,9 \%$ \\
\hline China & 9,75 & 9,25 & $11,4 \%$ & $5,5 \%$ \\
\hline Índia & 3,47 & 3,32 & $4,0 \%$ & $3,9 \%$ \\
\hline Rússia & 2,9 & 2,8 & $3,4 \%$ & $5,5 \%$ \\
\hline Arábia Saudita & 2,8 & 2,7 & $3,7 \%$ & $3,1 \%$ \\
\hline
\end{tabular}




\begin{tabular}{|l|}
\hline Brasil \\
\hline Alemanha \\
\hline Coréia do Sul \\
\hline Canadá \\
\hline México \\
\hline Irãa \\
\hline França \\
\hline Reino Unido \\
\hline Itália \\
\hline
\end{tabular}

\begin{tabular}{|c|}
\hline 2,65 \\
\hline 2,36 \\
\hline 2,3 \\
\hline 2,2 \\
\hline 2 \\
\hline 1,82 \\
\hline 1,72 \\
\hline 1,54 \\
\hline 1,48 \\
\hline
\end{tabular}

\begin{tabular}{|c|}
\hline 2,63 \\
\hline 2,44 \\
\hline 2,3 \\
\hline 2,2 \\
\hline 2 \\
\hline 1,88 \\
\hline 1,76 \\
\hline 1,59 \\
\hline 1,53 \\
\hline
\end{tabular}

\begin{tabular}{|c|}
\hline $3,0 \%$ \\
\hline $2,7 \%$ \\
\hline $2,6 \%$ \\
\hline $2,5 \%$ \\
\hline $2,2 \%$ \\
\hline $2,1 \%$ \\
\hline $2,0 \%$ \\
\hline $1,8 \%$ \\
\hline $1,8 \%$ \\
\hline
\end{tabular}

\begin{tabular}{|c|}
\hline $2,3 \%$ \\
\hline$-3,3 \%$ \\
\hline- \\
\hline- \\
\hline- \\
\hline$-3,1 \%$ \\
\hline$-2,6 \%$ \\
\hline$-2,7 \%$ \\
\hline
\end{tabular}

Fonte: Adaptado de BP Energy, 2012

Algumas das principais fontes renováveis apresentadas na Tabela 16 geram energia elétrica de forma variável, devido a dependerem do fluxo de energia cuja previsibilidade é estocástica. Assim, torna-se dificultoso ajustar a produção de energia com a demanda, o que pode ocasionar em excesso de produção de energia, em especial em sistemas inflexíveis, ou não atendimento da carga (DENHOLM e HAND, 2011; WILSON et al., 2011; DE JONGHE et al., 2011).

Desta forma, os impactos elétricos envolvendo o uso dos veículos movidos a bateria, podem ser positivos, se bem administrada, a frota de veículos pode ser usada para auxiliar na operação e despacho de fontes renováveis de geração de eletricidade.

A operação conjunta dos veículos elétricos atrelado às fontes renováveis poderá ser vantajosa para o sistema elétrico, pois as baterias dos veículos poderão operar como uma fonte de armazenamento, absorvendo excessos de energia elétrica em momentos de alta produção e baixa demanda. Isto pode ser importante para praticamente todas as fontes renováveis de energia intermitente como usinas eólicas, fotovoltaicas e concentradores solares sem armazenamento térmico.

Tabela 16 - Dez potências mundiais em energia renovável

\begin{tabular}{|c|c|c|c|}
\hline País & $\begin{array}{c}\text { Capacidade instalada } \\
\text { de fontes renováveis em } \\
\text { GW }\end{array}$ \\
\hline China & 133 \\
\hline 93 & $\begin{array}{c}\text { Investimento } \\
\text { em 2011 (bilhðes / } \\
\text { US\$) }\end{array}$ \\
\hline & 45,5 \\
\hline \\
\hline
\end{tabular}

\begin{tabular}{|l|}
\hline \multicolumn{1}{|c|}{$\begin{array}{c}\text { Potencial e investimentos (US\$) } \\
\text { em fontes renováveis }\end{array}$} \\
\hline $\begin{array}{l}\text { Eólica (gasto em } 29 \text { bilhões nos parques eólicos que somam em } 64 \\
\text { GW em capacidade instalada) }\end{array}$ \\
\hline $\begin{array}{l}\text { Eólica (47 GW), pequenas centrais hidroelétricas }(25,3 \mathrm{GW}) \\
\text { biomassa e geração de energia a partir de resíduos }(13 \mathrm{GW}), \text { solar } \\
(4,6 \mathrm{GW}), \text { geotérmica }(3,3 \mathrm{GW})\end{array}$ \\
\hline
\end{tabular}




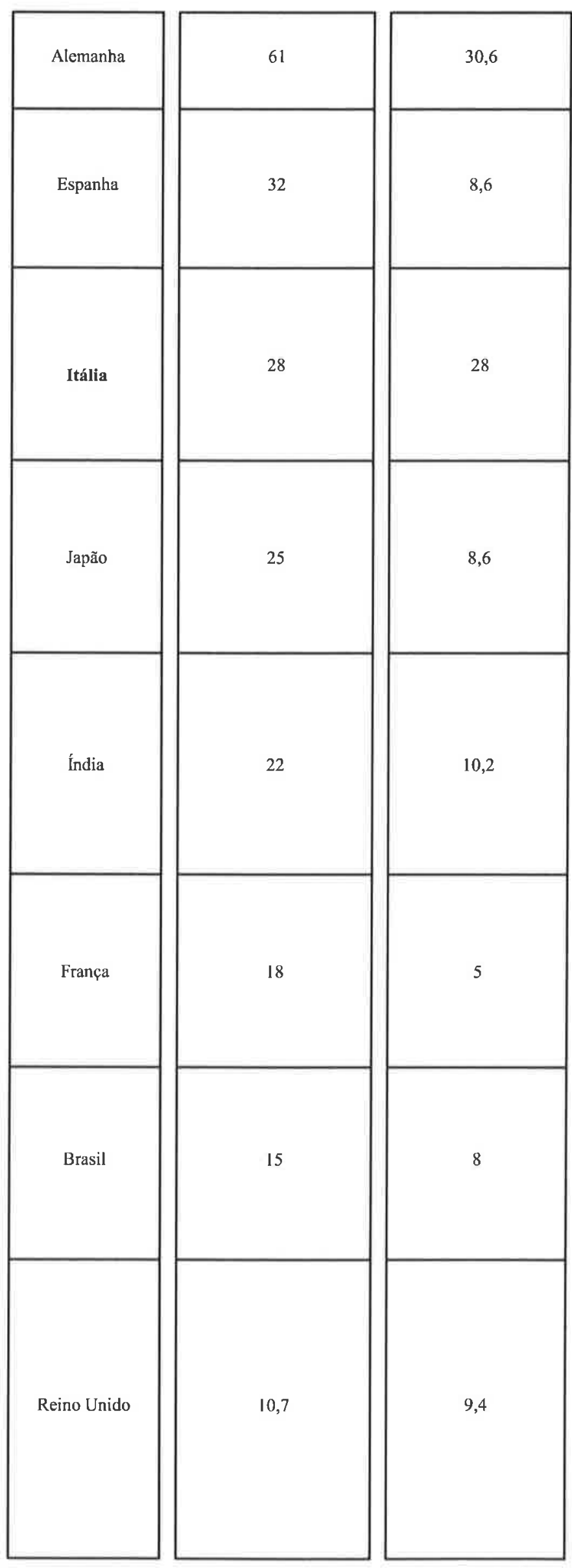

$65 \%$ dos investimentos foram para energia Solar com $25 \mathrm{GW}$ outros $29 \%(8,5$ bilhões de dólares) foram investidos em projetos élicos que já somam $29 \mathrm{GW}$ em capacidade instalada.

7,6 bilhões foram direcionados para energia solar, que ganhou mais $700 \mathrm{MW}$ em capacidade no período. A energia eólica lidera $\mathrm{cm}$ capacidade instalada total, com $22 \mathrm{GW}$, seguida da solar $5.3 \mathrm{GW}$, pequenas centrais hidroelétricas $4,4 \mathrm{GW}$ e, por fim, biomassa resíduos $0.9 \mathrm{GW}$.

Expandiu sua capacidade instalada ( $8 \mathrm{GW}$ ), atraindo 28 bilhões de dólares em investimentos. A maior parte disso foi para projetos dc energia solar, que dobrou em capacidade chegando a 12,4 GW Também foi instalado mais $1 \mathrm{GW}$ de eólica, segundo maior setor de renováveis do país, com $6,7 \mathrm{GW}$.

Os investimentos em energia renovável aumentaram 23\% em 2011. chegando a 8,6 bilhões de dólares. A maior parte dessc investimento (94\%) foi para a energia solar, que ganhou mais $\mathrm{I}, \mathrm{I}$ GW, juntamente com o setor eólico, que ganhou mais $150 \mathrm{MW}$.

Os investimentos cresceram $54 \%$, atingindo pouco mais de 10 bilhões. A maior parte dos recursos foram para o setor eólico, que possui $15,7 \mathrm{GW}$, o maior desempenho entre as renováveis na matriz energética indiana. Focado em sua "Missão Solar Nacional", que prevê a implantação de $20 \mathrm{GW}$ até 2020 , o país prevê aumentar em sete vezes sua capacidade de geração solar, hoje uma das mais baixas, com apenas $0,4 \mathrm{GW}$.

Os projetos solares foram os que mais se beneficiaram, com ur incremento de $145 \%$ em capacidade total instalada, somando 1,6 GW. O setor atraiu mais de $80 \%$ dos investimentos (4,4 bilhões). O país também acrescentou $700 \mathrm{MW}$ de energia élica e agora conta com um total de $6,3 \mathrm{GW}$.

p investimento em energia renovável no Brasil aumentou $15 \%$ thegando aos 8 bilhøes. O país apresentou um progresso claro no setor de fontes renováveis que responde pelo terceiro maior rescimento de capacidade instalada nos úitimos cinco anos. $O$ país. Iltrapassou $1 \mathrm{GW}$ de capacidade eólica instalada e ganhou mais 1,9GW de biomassa, totalizando em $8,7 \mathrm{GW}$.

Os investimentos totais no Reino Unido forem da ordern dos;

9,4 bilhoos. Mais de motade dos recursos form para onergia solar (4,8 bilhöes) - 25\% (2,3 bilnzes) para energia ab́lice. Lider mundial em projetos ofl-shore (protundidede) de ólica, o pois acrescentou mais 800MW em capacidade de peraçlo. O objetivo do Reino Unido chegar a $2020 \mathrm{com}$ 

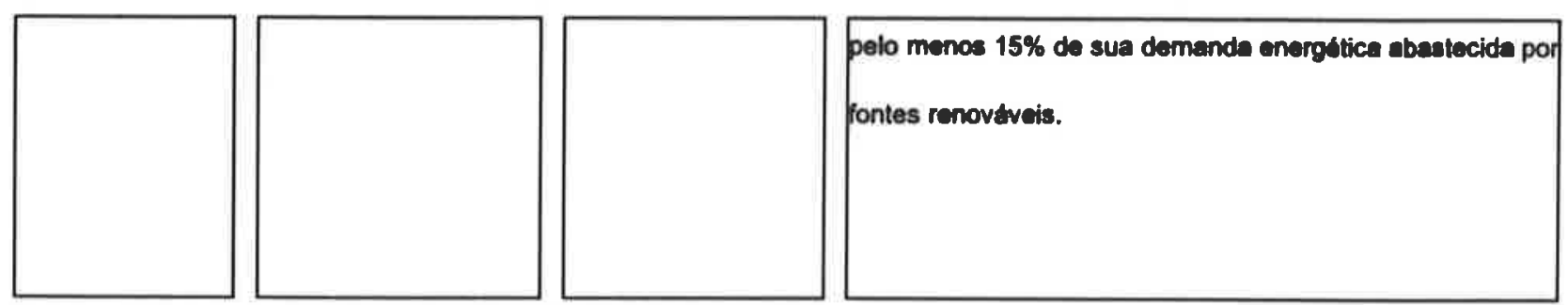

Fonte: Adaptado de Pew Environment Group, 2012

$\mathrm{Na}$ Tabela 16 é possível observar avanços tecnológicos, incentivos governamentais e a perspectiva de contribuir para reduções significativas das emissões de gases de efeito estufa. A utilização de energia eólica para a produção de energia elétrica, tanto em nível mundial quanto brasileiro, está planejada em busca da redução dos seus custos, devido, sobretudo, a avanços tecnológicos estimulados pelos programas de incentivo implantados em países desenvolvidos o que proporciona incentivos aos fabricantes e empreendedores dos parques eólicos (VEIGA, 2012).

O mercado global proveniente da energia eólica vem se expandindo rapidamente, tendo saltado de uma capacidade instalada de 6,1 GW, em 1996, para quase $200 \mathrm{GW}$, ao final de 2010, o que se aproxima de uma taxa anual de crescimento de quase $30 \%$, a despeito de um pequeno decréscimo em 2010, devido à crise financeira internacional, quando, ainda assim, foram adicionados $38,2 \mathrm{GW}$, equivalentes aproximadamente a um terço de toda a capacidade instalada do sistema elétrico brasileiro. Os Estados Unidos e a China totalizam $43 \%$ da capacidade instalada global, enquanto a China foi a responsável por $50 \%$ do crescimento obtido em 2010 (VEIGA,2012).

No tocante ao Brasil, apesar do atraso para a iniciação das instalações, a capacidade instalada passou de pouco menos de $30 \mathrm{MW}$ em 2005, para mais de $1 \mathrm{GW}$ em meados de 2011. É dada uma atenção especial para o caso dos sistemas eólicos devido ao otimismo em torno da expansão de geração eólica, em especial no Nordeste do país que concentra $53 \%$ do potencial brasileiro particularmente na região central da Bahia e nos litorais do Rio Grande do Norte e no Ceará. A Região Sudeste permanece com $20 \%$, com destaque para a região norte de Minas Gerais, e, finalmente a região Sul com 15\% chamando atenção para o litoral sul do Rio Grande do Sul e o oeste de Santa Catarina. A região Norte apresenta um potencial mais inexpressivo.

A Figura 39 ilustra visualmente o potencial eólico brasileiro. A expectativa é de que, até 2013, sejam adicionados quase $4 \mathrm{GW}$ de geração eólica, principalmente no Nordeste (EPE, 2011). 


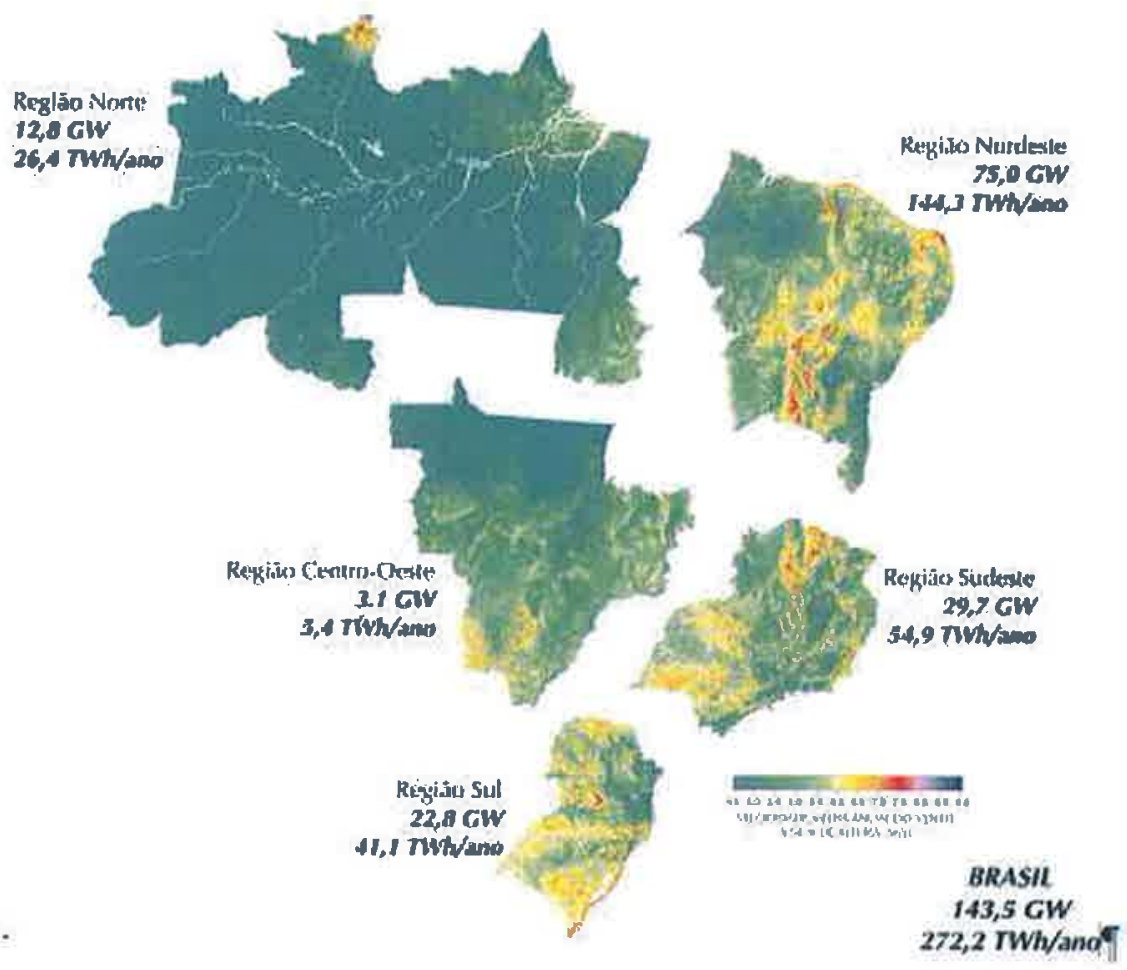

Figura 39 - Potencial Eólico Brasileiro

Fonte: MME , Eletrobras \& Cepel, (2011)

Conforme Denholm e Hand (2011) e Strbac et al. (2007), este quadro indica a necessidade de modelar adequadamente o sistema elétrico, visando integrar nele fontes renováveis de eletricidade. A participação de fontes renováveis de produção de eletricidade ampliou-se em 2,5 pontos percentuais na matriz elétrica brasileira no ano de 2011, chegando a 88,8\%, de acordo com os dados preliminares do Balanço Energético Nacional - BEN, (2012).

O Gráfico 14 mostra os valores decorrentes a 2010 e 2011 comparando com a matriz elétrica mundial. 


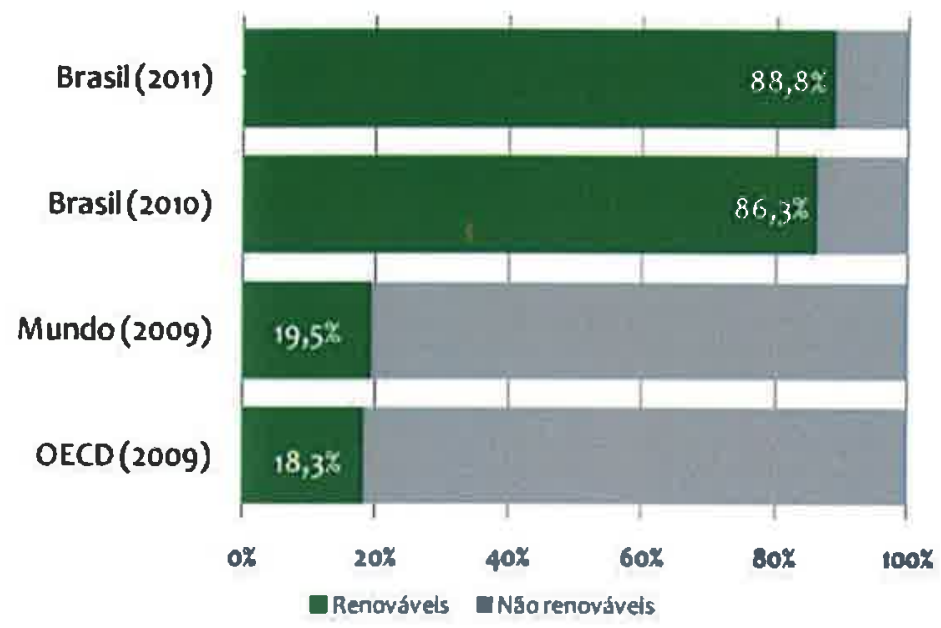

Gráfico 14 - Brasil e Mundo. Participação de Renováveis na Matriz Elétrica Fonte: EPE, EIA, (2012)

O Gráfico 14 aponta para um crescimento contínuo perante à participação de fontes renováveis na matriz elétrica nacional em 2011, o Brasil amplia ainda mais sua posição de liderança em geração de energia renovável se comparado ao conjunto das demais nações do mundo e aos países membros da OCDE (Organização para a Cooperação e Desenvolvimento Econômico), majoritariamente desenvolvidos (EPE, 2012).

Um dos destaques da atual matriz brasileira de eletricidade é a fonte eólica, cuja geração totalizou cerca de 2,7 mil gigawatts-hora (GWh) em 2011, na comparação com 2010, a expansão da produção através dos ventos alcançou $24,2 \%$,como mostra a Tabela 17 . 0 elevado percentual de crescimento prenuncia o que deve ocorrer de forma ainda mais expressiva nos próximos quatro anos, quando novos parques, já em construção, entrarão em operação (EPE,2012).

Ao longo da última década, a geração de energia eólica apresentou expressivo crescimento nas matrizes mundiais de geração elétrica como consequência de sua renovabilidade, da redução de seus custos de geração ao longo do tempo e de sua não geração de poluição local e global (SOVACOOL, 2008). Vale resaltar que as emissões diretas da produção de eletricidade a partir de energia eólica são nulas. No entanto, existem emissões indiretas, ou seja, associadas ao ciclo de vida dos materiais: produção das pás da turbina, da nacele, da torre, assim como do transporte dos equipamentos. 
Tabela 17 - Participação de Fontes Renováveis de Produção de Eletricidade

\begin{tabular}{|c|c|c|c|}
\hline FONTLS & 2011 & 2010 & $\Delta 11 / 10$ \\
\hline OPLRTA TOTAL [owh] & 571.302 & 531.704 & $3,0 \%$ \\
\hline ENLROM MOZO RENOVAVEL & c4.18 & 73.320 & $-14,0 \%$ \\
\hline Gás Natural & 26.242 & 36.475 & $-28,1 \%$ \\
\hline Derivados de Petróleo & 14.401 & 16.065 & $-10,4 \%$ \\
\hline Nuclear & 15.659 & 14.523 & $7,8 \%$ \\
\hline Carvĩo e Derivados 1 & 7.883 & 8.256 & $-4,5 \%$ \\
\hline ENERCIA RENOVÁVEL & 507.116 & 476.304 & $6,5 \%$ \\
\hline Hidráuliea & 428.570 & 403.290 & $6,3 \%$ \\
\hline Importação 2 & 38.430 & 35.906 & $7,0 \%$ \\
\hline Biomasea 3 & 37.411 & 34.940 & $7,1 \%$ \\
\hline Eóliea & 2.704 & 2.177 & $24,2 \%$ \\
\hline
\end{tabular}

Fonte: EPE, 2012

Contudo, a interação diferenciada de usinas eólicas com o sistema elétrico pode causar impactos locais, devendo exigir novas abordagens e novas soluções. No entanto, existem significativas diferenças entre as centrais eólicas e os geradores síncronos convencionais. Por exemplo, as turbinas eólicas empregam diferentes sistemas de geração elétrica (muitas vezes baseados em eletrônica de potência) comparativamente com os usados nas centrais convencionais; a energia primária, o vento, não é controlável e varia estocasticamente; e o tamanho individual típico de geradores eólicos é muito menor do que o de um gerador síncrono convencional (SLOOTWEG, 2003).

Estas divergências não representaram um eminente desafio para a expansão do uso da energia eólica até o dado momento, porquanto a participação desta nos sistemas energéticos mundiais é ainda relativamente baixa, à exceção de em algumas regiões, como no oeste da Dinamarca, no norte da Alemanha e Galícia na Espanha (SAHEB-KOUSSA et al., 2010). Assim, o crescimento do uso desta fonte renovável de geração elétrica pode mudar este quadro (WILSON et al., 2011).

Anaya-Lara et al., (2009), Manwell et al., (2002), Burton et al., (2001) revelam que os possíveis impactos locais de sistemas eólicos no sistema elétrico são os que ocorrem na proximidade das turbinas e/ou parques eólicos. Os principais impactos se dão na redução do controle de tensão, alteração na corrente de curto-circuito e alteração na qualidade da energia, como geração de harmônicos e cintilação. Independentemente do nível de penetração de energia eólica no sistema elétrico, esses efeitos ocorrem e são influenciados pelo tipo de tecnologia utilizada para geração eólica (SLOOTWEG, 2003). 
O desequilíbrio entre carga e geração ocasionado no sistema elétrico está vigorosamente relacionado com o nível de penetração desta tecnologia no sistema, enquanto que o nível de disseminação geográfica dos aerogeradores e o tipo de turbina eólica aplicada são menos importantes. De fato, conforme Ackermann e Söder (2005), a penetração em larga escala de usinas eólicas (acima de 30\% em energia) em grandes sistemas elétricos interconectados pode exigir uma reestruturação, passo-a-passo, das abordagens de operação dos sistemas elétricos existentes.

Outro fator considerável é o efeito da minimização da variação temporal do vento e a redução do erro de previsão que a distribuição geográfica das turbinas eólicas pode ocasionar. Segundo Harvey (2010), com o aumento da distribuição geográfica e do número de aerogeradores reduz-se a volatilidade temporal do vento, uma vez que oscilações menores de vento não afetarão todas as turbinas simultaneamente.

No caso de um sistema elétrico relativamente inflexível, com grande participação de geradores com restrições operativas para carga parcial, ou para serem ligados e desligados com frequência, como plantas nucleares, térmicas a carvão ou até mesmo hidroelétricas com baixa capacidade de acumulação de energia (usinas a fio d'água), a entrada de usinas eólicas pode levar a um desequilíbrio entre geração e demanda. Mais do que isso, a flexibilidade operacional do sistema, medida em aumento de potência por tempo, também é afetada.

Denholm e Hand (2011), Castro et al., (2008) e Strbac et al., (2007) definem medidas que podem ser adotadas a fim de reduzir ou eliminar este problema, que vão desde modificações na própria usina eólica a adequações do sistema energético, como a complementação de geração eólica com outras fontes convencionais de energia que possuam maior flexibilidade e controlabilidade (com tempo reduzido de resposta ao aumento/redução da carga/geração), e/ou ampliação do sistema de transmissão para melhor integração da malha elétrica e/ou o uso de armazenamento de energia.

As baterias elétricas apresentam um papel considerável dentre as formas de armazenamento. Isso devido à possibilidade de rápido armazenamento e descarga de potência ativa. Assim, um sistema de armazenamento com baterias pode melhorar a confiabilidade do fornecimento de energia durante períodos de pico e absorver excessos de geração de energia eólica. Ademais, baterias podem auxiliar em serviços ancilares do sistema elétrico, como controle de frequência, nivelamento de carga, reserva girante, regulação da área, estabilização de linha de transmissão e correção do fator de potência (ADITYA e DAS, 2001).

Neste sentido, a possível eletrificação do setor de transporte pode representar uma alternativa para maior integração de fontes renováveis à rede elétrica. Os veículos elétricos se 
prestariam a armazenagem de energia onde poderiam ser utilizados como cargas elétricas inteligentes consumindo energia elétrica em casos de excesso de geração elétrica variável. Os veículos poderiam também funcionar como um grande armazenador de energia, sendo abastecidos na base e fornecendo parte da energia no pico do sistema. A Figura 40 exibe uma associação eficiente entre fontes renováveis intermitentes atrelada ao armazenamento de energia nas baterias.

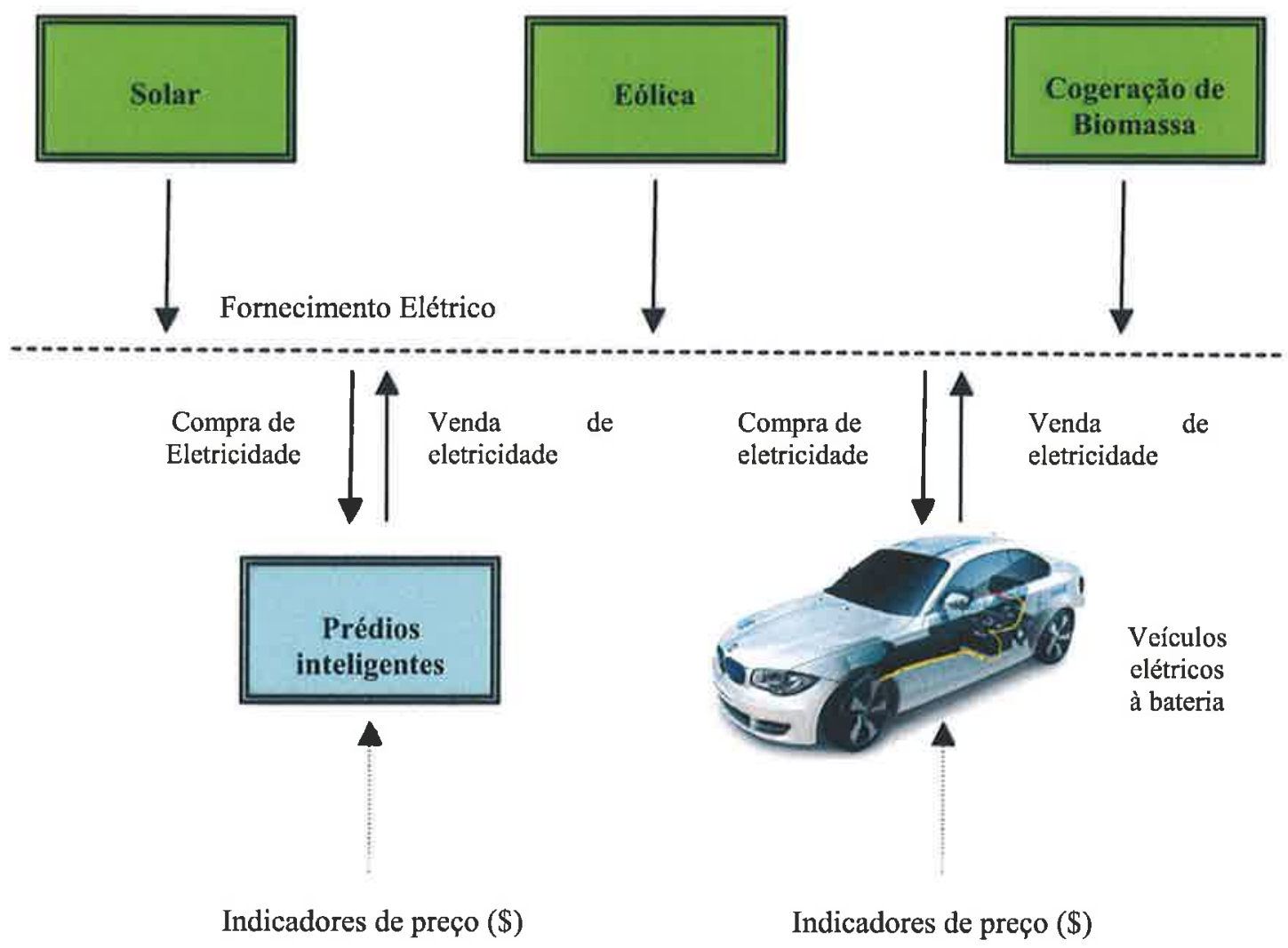

Figura 40 - Associação entre energias renováveis e veículos elétricos Fonte: Mitchell, 2011

A progressiva transição para as fontes renováveis é uma opção desejável em toda a cadeia de abastecimento de energia para os veículos como mostra a Figura 40. A quantidade de energia renovável presente em áreas urbanas é expressiva, mas a relutância permanece em coletá-la. A eficiência perante os equipamentos de captação disponíveis é limitada, em particular nos centros urbanos, que geram sombra sobre os painéis fotovoltaicos seguidas de turbulências nocivas às turbinas eólicas. Em conseqüência, a quantidade de eletricidade por quilômetro quadrado gerada por essas fontes é limitada, onde seu custo no entorno da cadeia costuma ser elevado. Com o avanço tecnológico, as 
fontes renováveis coletadas localmente terão um papel de extrema relevância no abastecimento energético da mobilidade urbana.

Uma única desvantagem dos painéis solares e das turbinas eólicas é que sua atividade é intermitente e não permanente. Não temos incidências solares a todo o momento e a intensidade dos ventos varia no decorrer do dia. $\mathrm{O}$ efeito resultante a essa intermitência é na elevação dos custos nesta cadeia com reserva operacional que são os geradores que permanecem parados fora de horários de pico.

Nesse sentido, com o armazenamento de energia da bateria e a capacidade de nivelar a carga dos sistemas de mobilidade urbana, a energia eólica e a solar tornam-se vantajosas em relação ao custo final. No início da tarde com incidências de raios solares, os painéis fotovoltaicos fornecem o máximo rendimento, podendo ser atrativos para o carregamento das baterias realizado ao longo do dia. O fator resultante da intermitência não é preponderante quando a rede apresenta um sistema de armazenamento de eletricidade com vantagens competitivas, com custo-benefício em escala suficiente.

A vantagem competitiva sustentável ocasionada pela utilização de fontes renováveis é possível pela integração dos veículos elétricos com a rede de energia. Além de utilizarem fontes renováveis ao invés de combustível fóssil podem fornecer o armazenamento de energia em formato gratuito por intermédio das baterias atenuando os efeitos de intermitência no fornecimento proporcionando uma versatilidade na rede.

\subsection{Consumo de Energia Elétrica no Setor de Transportes de Carga}

Orientar-se procurando racionalizar o uso dos combustíveis de origem fóssil, é fator prioritário perante políticas adotadas pelas nações. As exigências referentes ao controle de emissões, alem da demanda crescente por energia, tanto nos países industrializados como nos países em desenvolvimento, tem exigido o desenvolvimento de combustíveis alternativos para uso em motores diesel.

Ainda assim, o Brasil é um dos maiores mercados consumidores de combustíveis, sendo o sétimo maior consumidor de petróleo no mundo, estando na frente de paises como Alemanha, Coréia do Sul e Canadá (ANP,2012).

Os setores de energia e dos transportes constituem um importante suporte ao desenvolvimento econômico e social de qualquer território. É válido realçar a importância que a disponibilidade de energia desempenha nos diferentes setores de atividade econômica, 
rememorando que as formas convencionais de produção e distribuição de energia, bem como, o seu consumo final no setor de transportes, são um dos responsáveis pela degradação da qualidade do ambiente, nomeadamente através da emissão de gases como $\mathrm{CO} 2$, devido à sua dependência na utilização de combustíveis fósseis conforme explicitado anteriormente. $\mathrm{O}$ Gráfico 15 revela o consumo de energia no segmento de transportes no ano de 2011 . O consumo referente à gasolina elevou-se pela queda no consumo do etanol hidratado em $24,4 \%$, já o etanol anidro teve uma similaridade com o acréscimo no consumo de gasolina fechando com 18,9\% (ANFAVEA, 2012). O consumo de energia nos transportes em comparação com o ano de 2010 ascendeu 6,6 \% em 2011 passando de 69,6 Mtep para 74,2 Mtep (EPE, 2012).

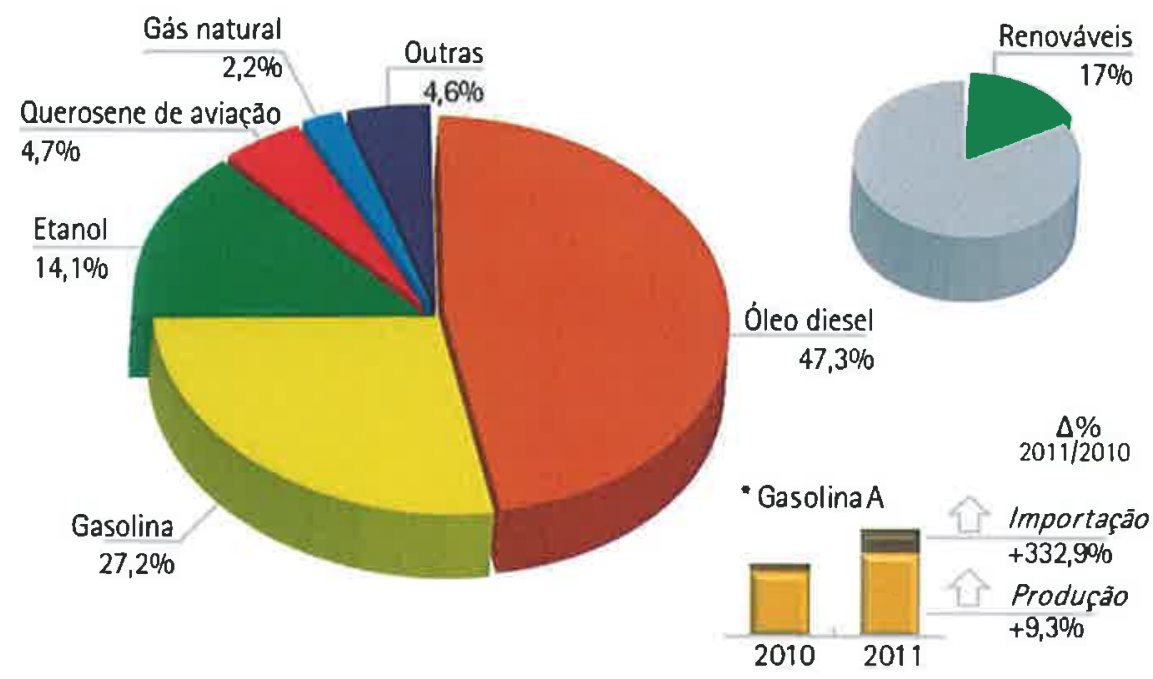

Gráfico 15 - Consumo de Energia nos Transportes Fonte: Anfavea, SECEX/MDIC,EPE, 2012

Embora, a sua matriz elétrica, em 2011, tenha sido constituída dominantemente por energia de origem renovável como mostra o Gráfico 14, os combustíveis fósseis ainda constam como a base da matriz energética brasileira como traz o Gráfico 16. 


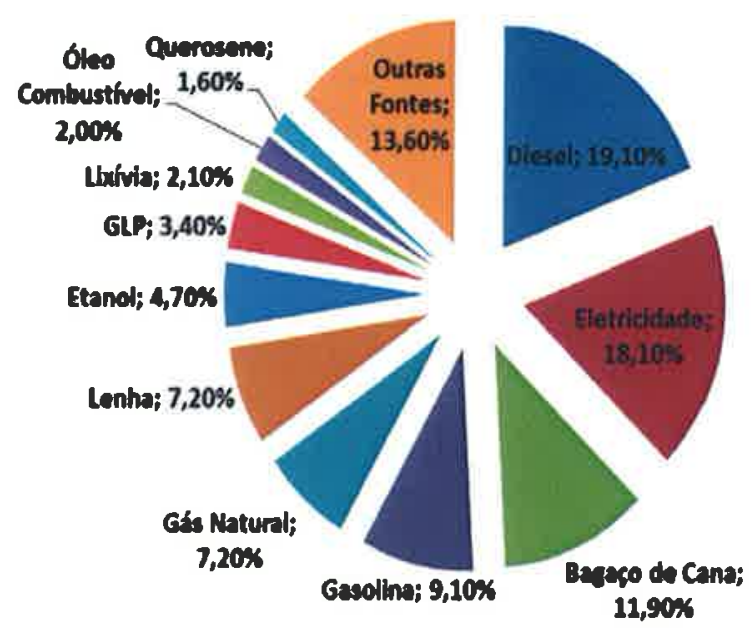

Gráfico 16 - Matriz energética Brasileira, (2011)

Fonte: (MME, 2012)

É valido salientar que na Figura 40, observa-se um grande consumo de diesel, mas devemos atentar ao percentual de biodiesel que é adicionado àquele, correspondente a um percentual de $5 \%$ em massa.

Com relação, aos 18,10 \% de eletricidade, a matriz elétrica nacional em 2011, encontra-se disposta na Tabela 17, e no Gráfico 14 observa-se que a maior parte da energia elétrica nacional é de origem hidráulica, seguida da biomassa, que inclui bagaço de cana, lixivia, lenha, dentre outras. Aproximadamente $2,5 \%$ da matriz elétrica é de origem fóssil, sendo o óleo diesel o que mais se destaca.

\subsection{1 Óleo Diesel}

Brandão (2012),ressalta que o óleo diesel é um combustível proveniente do petróleo (fonte não-renovável) e é constituído basicamente por hidrocarbonetos cujas cadeias contêm de 12 até 20 átomos de carbono, predominando parafínicos, olefínicos, aromáticos e em menor quantidade, por substâncias com átomos de enxofre, nitrogênio, metais, oxigênio e outros.

O diesel é obtido do refino do petróleo por destilação em outras frações denominada de diesel leve e pesado. Ao diesel são agregados produtos como nafta, querosene ou gasóleo leve de vácuo como ilustra a Figura 41. A proporção desses componentes permite enquadrar o produto final em especificações previamente definidas, a fim de favorecer o bom desempenho do produto, minimizando o desgaste prematuro dos motores, e manter a emissão de poluentes, gerados na queima do produto, em níveis aceitáveis. 


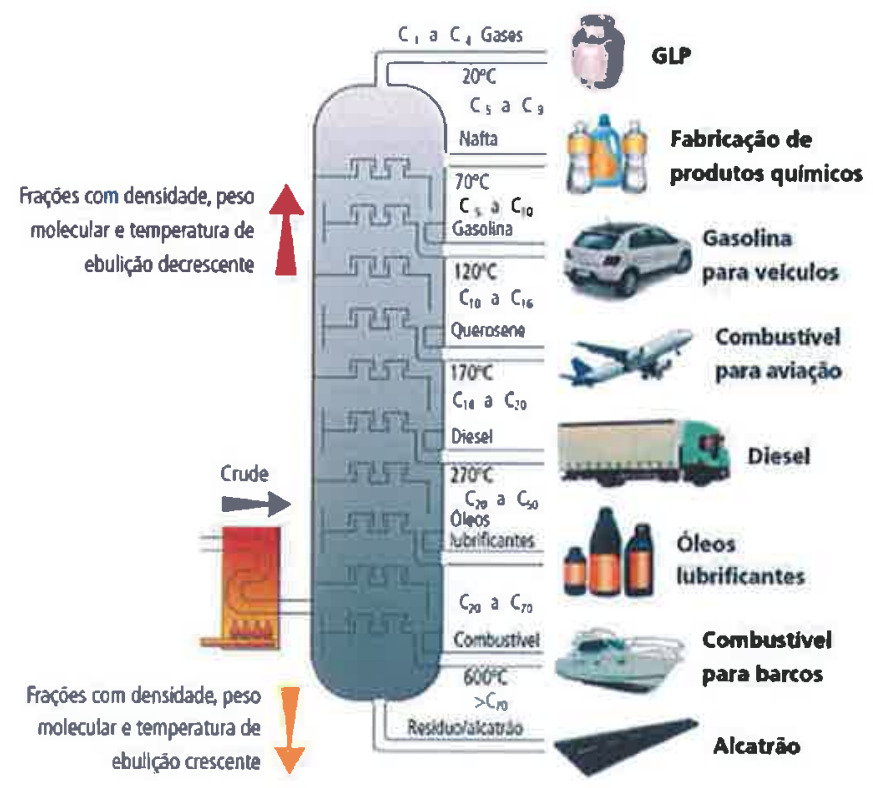

Figura 41 - Refino do petróleo - óleo diesel

Fonte: CNT, 2012

Apresentando uma característica que depende da presença de aromáticos que varia de 20 a $35 \%$ do seu peso específico, o Brasil comercializa três tipos de diesel: metropolitano, interior e marítimo. O metropolitano, produzido com menor teor de enxofre e particulados, é consumido em regiões que necessitam de uma menor emissão de poluentes, enquanto o diesel interior é consumido nas demais regiões do país. O diesel marítimo, com ponto de fulgor de $60{ }^{\circ} \mathrm{C}$ e teor de enxofre por volta de $10.000 \mathrm{ppm}$, é usado em embarcações. $\mathrm{O}$ diesel metropolitano e interior possui ainda uma subdivisão: Diesel Aditivado e Diesel Inverno. O diesel aditivado possui composto que melhoram o sistema de alimentação de combustivel e injetores, enquanto o diesel de inverno apresenta o grau de desempenho necessário nas regiões do país com temperaturas ambientes de até $-5^{\circ} \mathrm{C}$.

As perdas significativas nos motores alternativos são as perdas de calor nos gases de escape, as perdas no óleo lubrificante, água ou ar de arrefecimento e as perdas de calor através da superfície do motor. Em geral, as perdas de calor pelas paredes do motor são maiores nos motores diesel que nos motores ciclo Otto, porém as perdas nos gases de escape são menores. Como conseqüência, o rendimento global de um motor de ciclo Otto está compreendido entre 27 e $30 \%$, enquanto que o rendimento global de um motor diesel está entre 36 e $45 \%$. (PORTE, 2008) 
No motor diesel, apenas o ar entra no cilindro, através de um coletor. Este ar é comprimido em altas temperaturas e pressão, sendo logo após, inserido o combustível, vaporizado e pulverizado em alta velocidade no ar. Quando entra em contato com o ar em temperaturas elevadas, o combustível vaporiza-se rapidamente e, ao misturar-se com o ar, provoca reações químicas espontâneas que resultam na ignição espontânea ou auto-ignição. Neste tipo de motor não há a necessidade da utilização de velas, porém alguns dispõem de velas aquecedoras, que proporcionam melhores partidas em baixas temperaturas. Sua potência é controlada pela variação da quantidade de combustível injetada no interior do cilindro, não havendo a necessidade de acelerador (BUENO, 2006).

O rendimento de um motor é dado pela função do rendimento termodinâmico teórico, das perdas e do rendimento mecânico. O rendimento termodinâmico aumenta com a relação de pressão, que apresenta valores da ordem de 10 para os motores ciclo Otto devido à detonação da mistura entre ar e combustivel e de 20 e 30, para motores ciclo diesel. Desta forma, este último tipo de motor apresenta um rendimento mais favorável.

No entanto, as diferenças básicas entre o motor diesel e o de Otto estão na forma de misturar o ar com o combustível e no processo para a ignição do motor. No diesel, a ignição se dá por compressão e no Otto por centelha elétrica.

Silva (2005), realça que dependendo da quantidade indesejável de enxofre, este, além de ser prejudicial ao funcionamento do motor é também um poluente atmosférico.

Em contato com o ar, submetido a altas temperaturas, contido no cilindro do coletor de admissão, o diesel vaporiza-se, originando as reações químicas espontâneas que resultam na auto-ignição. Uma das peculiaridades primordiais deste combustível é a ignição medida por meio do teste do número de cetano $(\mathrm{NC})$.

Através da normativa ASTM-S613 (Standard Test Mehtod for Cetane Number of Diesel Fuel OiI) pode-se estimar, em formato experimental, o número de cetano de um combustível. Um teste é realizado comparando a tendência de auto-ignição de uma amostra de combustivel com misturas formadas por dois combustiveis de referência, o cetano (hexadecano) e o heptametilnonano. Mínimos retardamentos de ignição ocorrerá com altos NC já que pequenas quantidades de combustível permanecerá na fase de combustão em prémistura, devido ao pequeno tempo para o preparo efetivo do combustível para combustão (SILVA,2005).

Um combustível com um baixo NC promove um funcionamento ineficiente do motor ciclo Diesel, enquanto um combustível cujo NC é próximo de 100 é o ideal para o bom funcionamento do mencionado motor (RACHE, 2004). 
Uma série de variáveis afeta a composição do combustível, o valor do seu poder calorífico inferior será variável e dependerá da refinaria na qual é produzido, da época do ano e da fonte de petróleo utilizada como matéria-prima. A energia contida no diesel não é um fator controlado durante a sua obtenção. Óleo diesel com altas porcentagens de aromáticos tendem a ter altos conteúdos de energia por litro, ainda que os aromáticos tenham baixos poderes caloríficos por quilograma. A alta densidade compensa o seu baixo conteúdo energético quando se sobrepõe a massa do combustível. Isso dando enfoque para os motores diesel ,pois o combustível é fornecido volumetricamente para o motor.

Categoricamente, se o combustível tiver enxofre, este será oxidado, transformando-se em dióxido e trioxido de enxofre. Estes óxidos de enxofre certamente, irão reagir com o vapor de água, formando ácido sulfúrico e outros componentes sulfatados que poderão ser o indício da formação de partículas na exaustão elevando a concentração de particulados.

A Agência Americana de Proteção Ambiental (EPA) até meados dos anos 90, estabeleceu que o diesel americano poderia conter no máximo 500 ppm de enxofre. Isso ocasionou uma redução de dez vezes o teor da mencionada substância, atenuando as partículas na exaustão. Em 2006, foi estabelecido uma nova redução de do teor de enxofre atingindo $15 \mathrm{ppm}$, o que resultou no decréscimo do mesmo como componente fornecedor de particulados na exaustão, permitindo a introdução de tratamento catalíticos de gases e controlando as emissões geradas pelos motores.

De acordo com Agência Nacional de Petróleo a ANP (2012), a produção do diesel de petróleo tem aumentado exacerbadamente nos últimos anos, com retração em 2010, sendo este um reflexo da crise econômica ocorrida durante os anos de 2008 e 2009, voltando a crescer em 2011. O gráfico 17 exibe a produção do diesel no Brasil entre 2000 e 2011. 


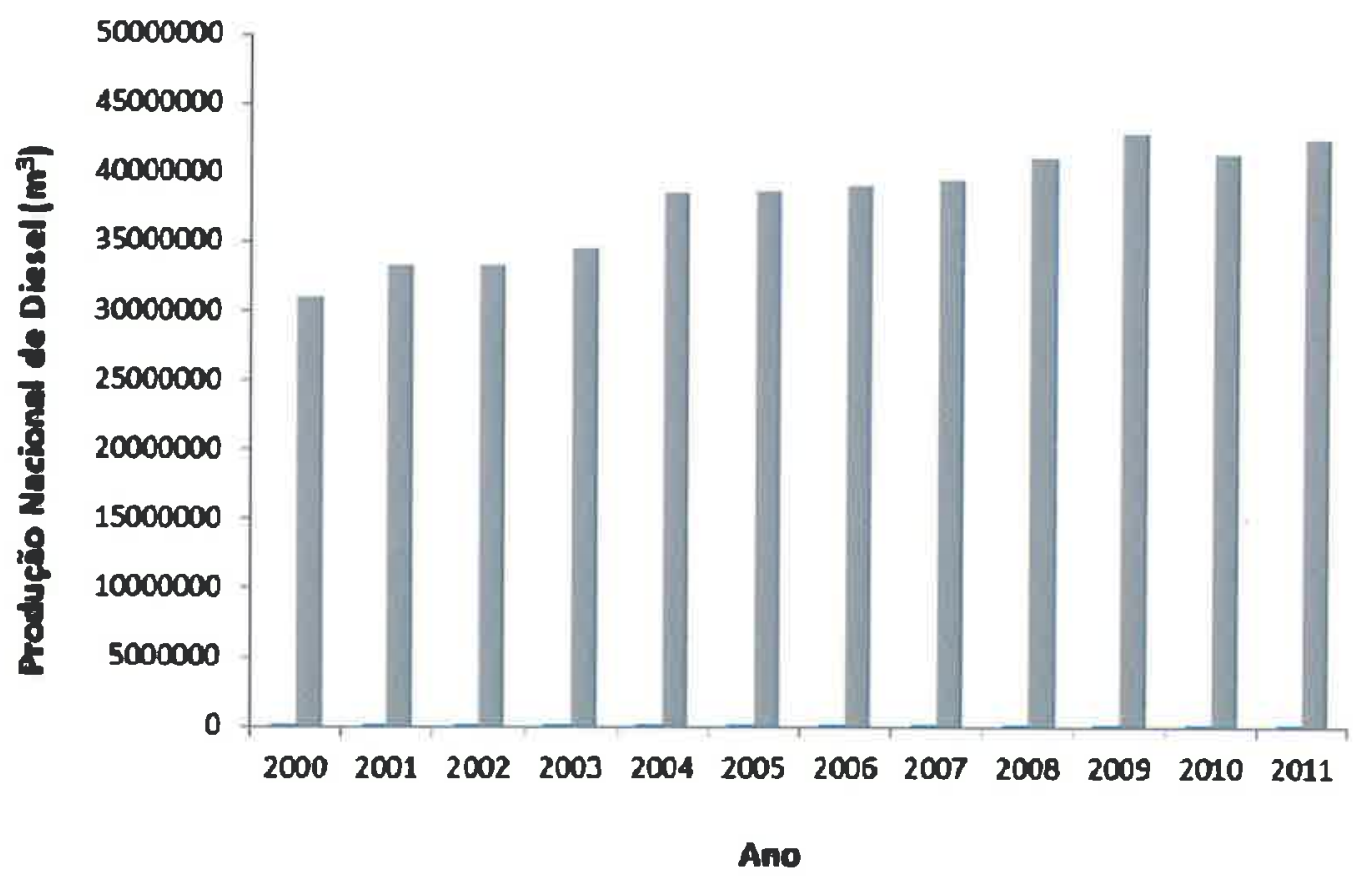

Gráfico 17 - Produção de diesel no Brasil Fonte: ANP, 2012

O incremento na produção de diesel é reflexo do aumento do seu consumo, que se elevou com o passar dos anos, com uma diminuição em 2009, voltando a crescer entre 2010 e 2011, conforme se vê no Gráfico 18.

Elevações consideráveis na produção e no consumo do diesel nos últimos anos tornase uma questão preocupante, dentre outros fatores, pelo teor de enxofre apresentado. $O$ enxofre é um elemento químico extremamente indesejável para o meio ambiente e também para os motores a diesel, pois durante a combustão, o trióxido de enxofre ao reagir com a água forma o ácido sulfúrico, que corrói partes metálicas do motor. Se a concentração desse elemento for elevada, as emissões de material particulado serão elevadas, assim como as emissões de poluentes primários como $\mathrm{SO} 2$ e SO3, acarretando grandes prejuízos à saúde humana e ao meio ambiente através da formação de chuvas ácidas (DESPOLUIR, 2010).

Com o progresso da indústria automobilística brasileira, com a melhora da produção e venda de equipamentos com motores ciclo diesel, o Brasil torna-se tradicionalmente importador de óleo diesel, pois sua demanda se mostra, consistentemente maior que sua produção apesar, de conquistar em 2006, a auto-suficiência na produção de petróleo e derivados. 


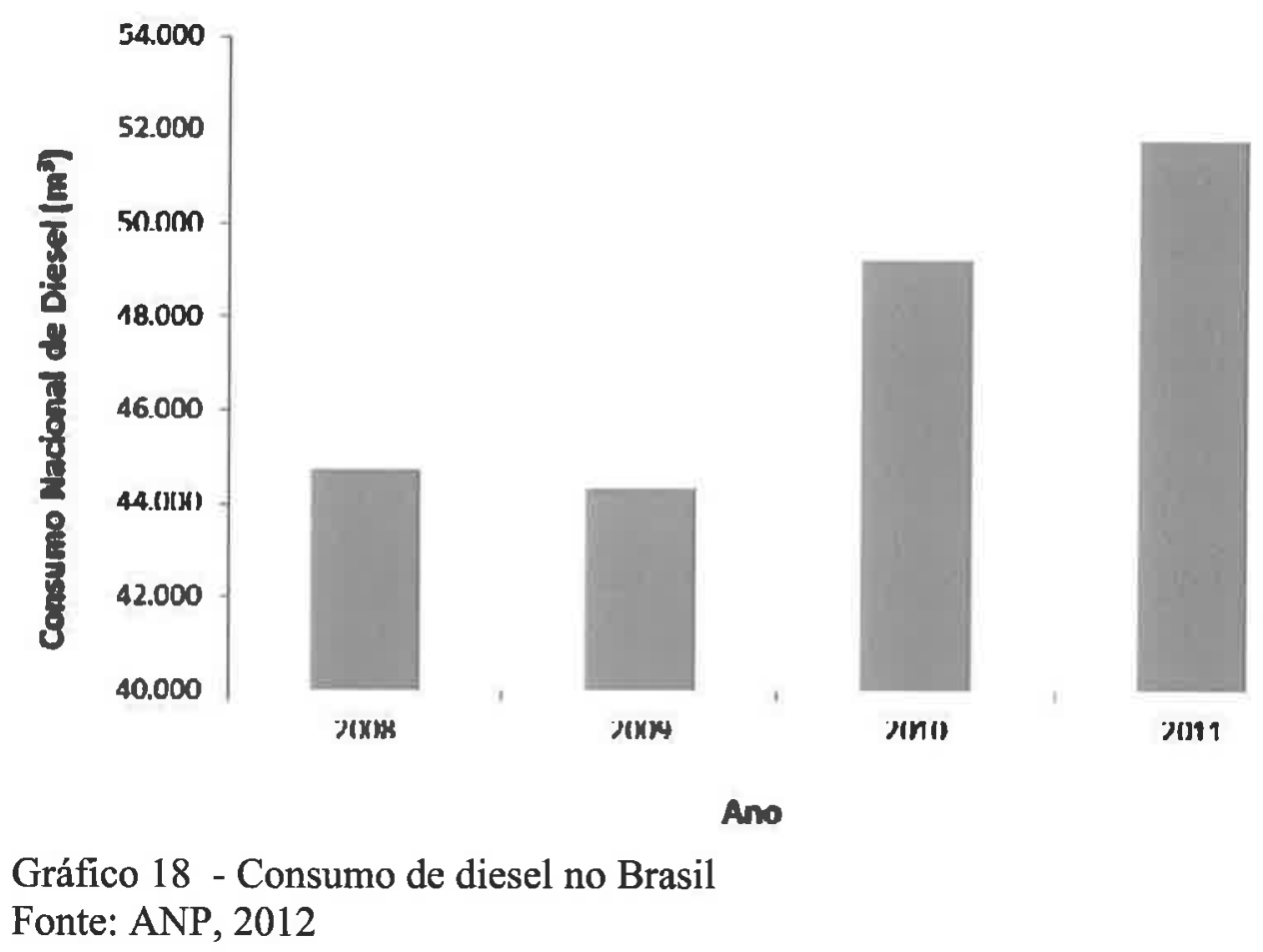

No entanto, novos limites de emissões para veículos pesados e leves foram exigidos em forma de medidas pela entidade reguladora ANP, que estipulou regras a serem seguidas pelas montadoras de veículos no processo de fabricação e pelos refinadores de petróleo. Está norma entrou em vigência em 2012 sendo corroborativa, para atender os requisitos ambientais que incluam, no mínimo, a redução dos teor de enxofre de $50 \mathrm{ppm}$ (partes por milhão) em 2010, para 10 ppm em 2013.

Todavia, a adição de biodiesel, ou outros biocombustiveis, ao diesel tem sido uma das medidas tomadas, uma vez que esse biocombustível não apresenta enxofre em sua composição, ao mesmo tempo em que reduz as emissões de gases tóxicos e materiais particulados que são lançados na atmosfera.

A eficiência do diesel como combustível e a inferioridade do seu custo final em relação aos demais, reflete na enorme utilização em caminhões e ônibus urbanos, mesmo diante ao maléfico problema com a sua composição e seu teor elevado de enxofre, e ainda, com os níveis de poluentes sob regulamentação contidos na mesma. A Empresa de Pesquisa Energética (EPE, 2011) prevê uma elevação do consumo de energia preponderantemente ocasionado pelo setor de transportes que terá sua participação incrementada em $4 \%$ ao ano até 2030 . 


\subsubsection{Diesel Metropolitano}

No Brasil, propriamente nos anos 80 , quando não havia regulamentação definida pela entidade governamental, os veículos munidos a motor diesel utilizavam um combustível com $13.000 \mathrm{mg} / \mathrm{kg}$ de enxofre. A partir de 1994, passaram a existir dois tipos de óleo diesel comercializados, segundo a região de consumo do combustível e a concentração de enxofre: o diesel metropolitano, fornecido com menor teor de enxofre nas regiões metropolitanas, com grande concentração de pessoas e veículos e maiores problemas de poluição atmosférica; e o diesel interior, utilizado no interior do país, com concentração mais alta de enxofre.

Em 2009, o diesel comercializado no interior passou a ter $1.800 \mathrm{mg} / \mathrm{kg}$ (S1800) e o metropolitano, no máximo, $500 \mathrm{mg} / \mathrm{kg}$ (S500). Em algumas regiões metropolitanas, existe a oferta do diesel com $50 \mathrm{mg} / \mathrm{kg}$ (S50), disponível à população ou, em certos casos, apenas às frotas de ônibus urbanos.

De acordo com a Resolução $n^{\circ}$. 403, de novembro de 2008, promulgada pelo Conselho Nacional do Meio Ambiente (CONAMA), a partir de janeiro de 2012, ficaram estabelecidos novos limites máximos de emissões de poluentes para os motores do ciclo diesel destinados a veículos automotores pesados novos, nacionais e importados, denominada Fase P7 do Programa de Controle da Poluição do Ar por Veículos Automotores - Proconve.

Para atender a nova frota com tecnologia da fase P7, que corresponde a fase Euro 5 dos países da União Européia, o óleo diesel com baixo teor de enxofre, deverá ser comercializado em todo país. Atualmente, é comercializado o $\mathrm{S} 50$ e, em janeiro de 2013, o S10 substituirá o S50. Este combustível associado à nova tecnologia permite uma redução drástica na emissão de poluentes atmosféricos. Comparando os limites de emissões estipulados nas fases $\mathrm{P} 2$, a primeira a ser compulsória, e P7, nota-se redução de $81 \%$ nos limites de hidrocarbonetos (HC), 86\% de óxidos de nitrogênio (NOx) e 87\% de monóxido de carbono (CO). Destaca-se ainda a redução de $95 \%$ nos limites de material particulado em relação à fase P3, a primeira a ter limites compulsórios para emissão deste poluente (CNT, 2012).

Em virtude dessa resolução ampliou-se o número de cidades que passaram a comercializar o S50, conforme as Resoluções $n^{\circ} .63$ e a nº. 65 de dezembro de 2011, da ANP. Reitera-se, que a partir de 2013, o óleo diesel S50 será substituído integralmente pelo S10 e, em 2014, para uso rodoviário, o S500 substituirá o óleo diesel S1800 conforme mostra a Figura 42. Desta forma, a partir de 2014, o Brasil usará apenas S10 e S500 para uso rodoviário, conforme cenário estipulado pela Petrobrás. O diesel metropolitano apresenta um 
custo elevado em comparação ao interiorano, devido ao processo de dessulfurização que sofre antes da comercialização (SILVA, 2005).

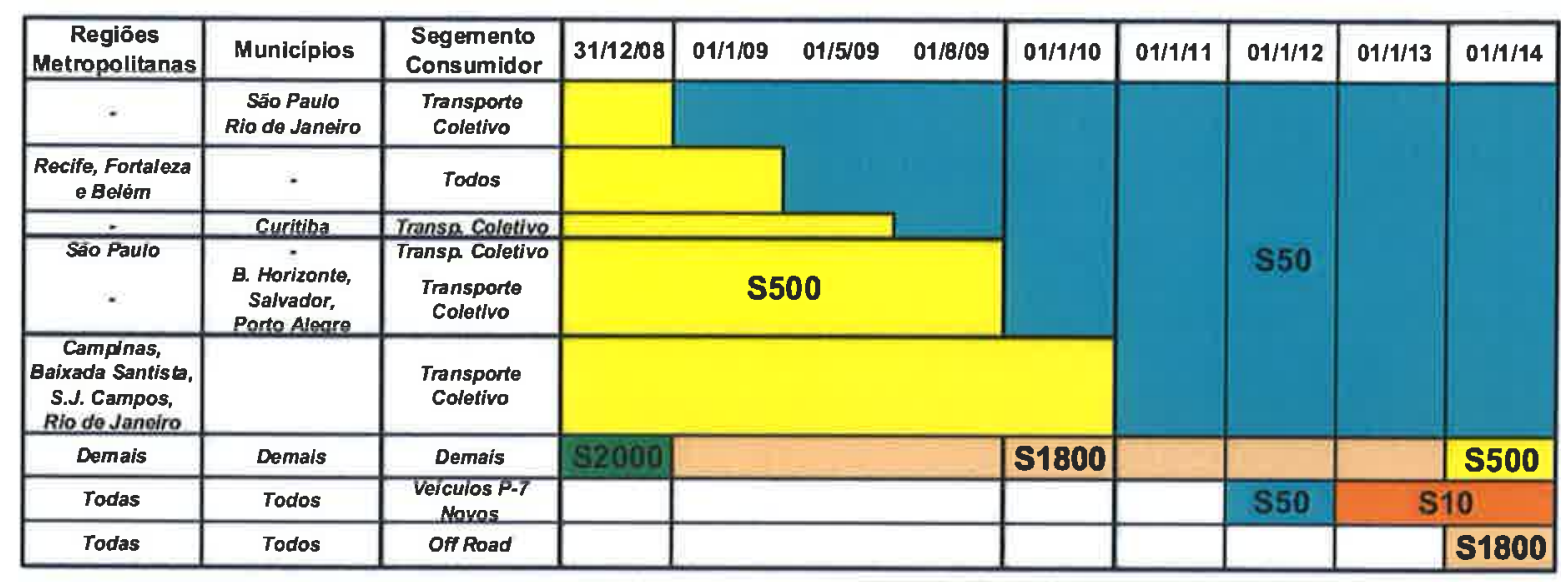

Figura 42 - Evolução do Abastecimento do Diesel Automotivo Fonte: ANP, 2012

O processo básico para a dessulfurização na maioria das refinarias consiste em provocar uma reação entre a corrente de óleo e o hidrogênio na presença de catalisadores em reatores especiais. $\mathrm{O}$ hidrogênio combina com o enxofre para formar gás sulfúrico $\left(H_{2} \mathrm{~S}\right)$ que é removido. $\mathrm{O}$ enxofre é recuperado e qualquer quantidade de $\mathrm{H}_{2}$ recuperada é reencaminhada ao reator como suprimento de $\mathrm{H}_{2}$.

Enquanto a introdução de um combustível com $50 \mathrm{mg} / \mathrm{kg}$ de enxofre pode ser considerada um avanço no Brasil, observa-se ao redor do mundo medidas arrojadas que priorizam a redução do teor de enxofre no diesel, como é o caso do México, que utiliza um diesel com $15 \mathrm{mg} / \mathrm{kg}$ de enxofre, desde 2009 (CNT, 2012).

Como é possível notar, a redução do enxofre no combustível propicia benefícios ambientais, mas a tecnologia aplicada aos motores continua sendo o fator determinante do grau em que as emissões são reduzidas.

\subsubsection{O Uso Eficaz dos Combustíveis não Renováveis}

As fontes de energia utilizadas para a produção de eletricidade são usualmente classificadas em dois grupos: fontes renováveis e não renováveis. Esta classificação relacionase com a limitação da sua existência na natureza. Um recurso que geralmente, não é reposto 
ao longo do tempo considera-se como uma fonte não renovável, enquanto um recurso que não tem uma existência limitada, ou seja, que é reposto ao longo da vida do ser humano, diz-se renovável. Respectivamente, as fontes de energia são também classificadas pela capacidade de armazenamento, ou seja, se são fontes de energia armazenáveis ou não armazenáveis.

As principais fontes de energia não renováveis (ou armazenáveis) são o carvão, o petróleo, o gás natural e a energia nuclear, enquanto as fontes de energia renováveis utilizadas são as eólica, solar, geotérmica, biomassa e hídricas. No contexto atual, vários países produzem a eletricidade mediante a queima dos combustíveis fósseis como o carvão, petróleo, gás natural em espaçosas termelétricas. Esse processo além de gerar uma parcela de emissões de carbono é particularmente nefasto onde a produção de eletricidade depende de fontes não renováveis. Sobretudo, cria-se uma complexidade maior, controlar as emissões geradas nos escapamentos dos veículos movidos à combustão, do que em contrapartida, controlar as emissões formadas em locais propícios às queimas de carvão, por exemplo.

Contudo, medidas vêm sendo adotadas em todo os países vislumbrando alterações na matriz energética. A Figura 43 traz uma alternativa contundente através do princípio de cogeração aplicado pelo aquecimento solar em escala doméstica, com sistema de refrigeração (MITCHELL, 2010). 


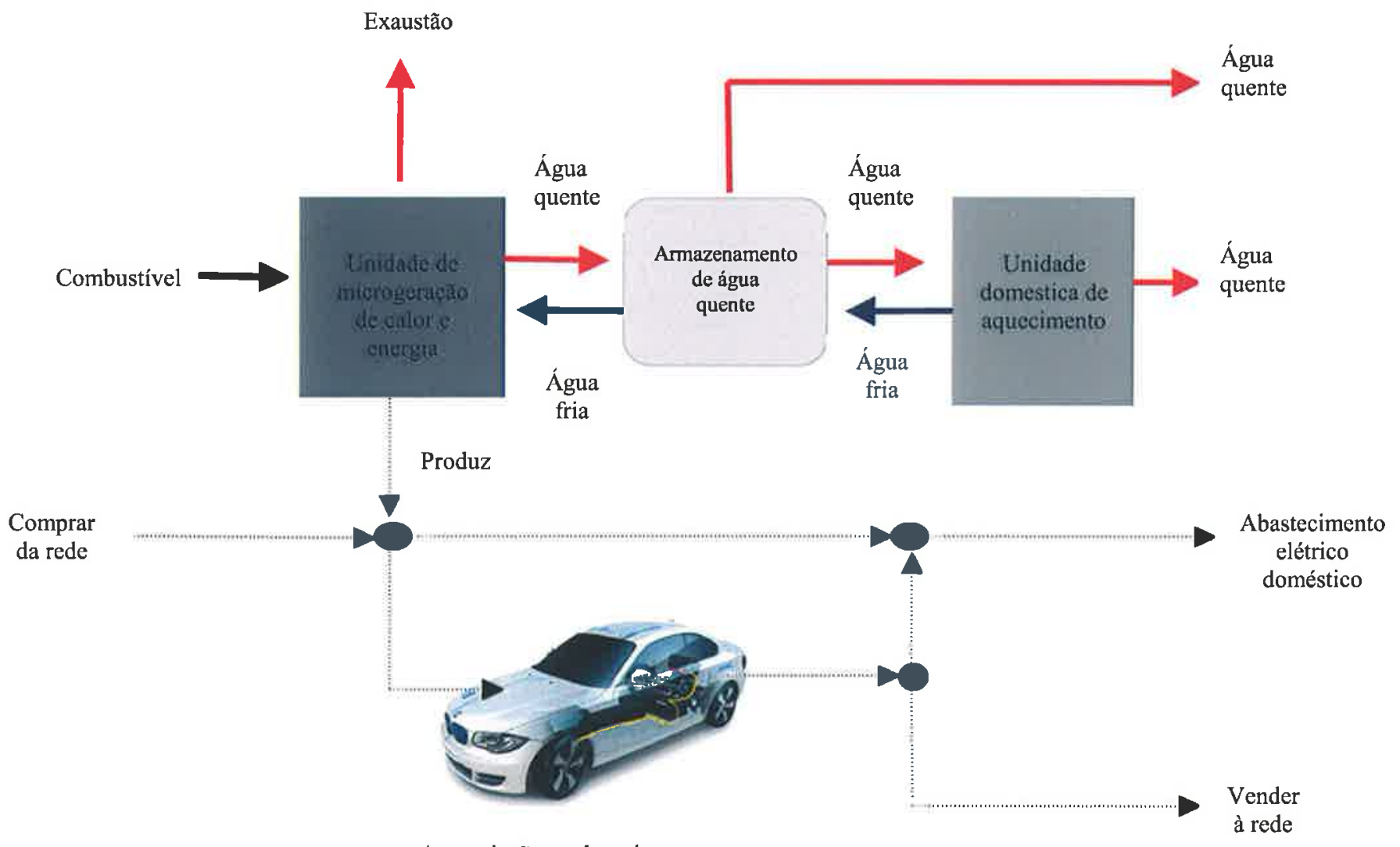

Acumulação em baterias

Figura 43 - Cogeração aplicado a aquecimento solar em escala doméstica Fonte: Mitchell, 2011

Na Figura 43 consta o desenvolvimento de uma tecnologia denominada cogeração, que pode ser compreendida como um processo de produção e utilização combinada de calor e eletricidade proveniente dos combustíveis. Esses sistemas além de gerar o calor que será usado para aquecer a água e os ambientes, fornecem também resfriamento de ambientes, podendo ser instalados em prédios. Essa eletricidade produzida pode ser utilizada para recarregar os veículos estacionados nas garagens. Carnot em seu artigo escrito em 1824 enfatiza esse processo sugerindo que:

[...] a produção de calor exclusivamente não é suficiente para gerar potência propulsora: é necessário que também exista o frio; sem isso, o calor seria inútil. E de fato, se encontrássemos ao nosso redor somente corpos tão quentes como nossas fornalhas, como poderíamos condensar o vapor? $O$ que poderíamos fazer com ele, uma vez produzido? Não podemos presumir que poderíamos descarregar na atmosfera, como ocorre em alguns motores; a atmosfera não iria recebê-lo. Ela o recebe nas circunstâncias atuais das coisas, somente porque cumpre o papel de um enorme condensador, porque tem uma menor temperatura. 
Esse processo de conversão torna-se eficiente já que grande parcela do calor gerado é utilizado de forma adequável. Essas unidades de microgeração de calor e energia são projetadas para funcionar em residências e pequenos edifícios comerciais e subvertem o enfoque, pois servem primeiro para aquecer os ambientes seguido da água que será destinada para gerar a eletricidade. Em geral, a eletricidade excedente pode ser usada para carregar os veículos alocados nas garagens. A Figura 44 exibe um exemplo prático de microgeração de energia utilizada por uma montadora e uma empresa do ramo de energia. $\mathrm{Na}$ imagem nos deparamos com uma estação de abastecimento solar projetada por uma montadora japonesa. O sistema é constituído por um conjunto de módulos fotovoltaicos para produção de energia elétrica, um inversor para transformação de energia DC (Corrente Contínua) para AC (Corrente Alternada), um contador de energia, um quadro de ligação à rede e cabos de ligação.

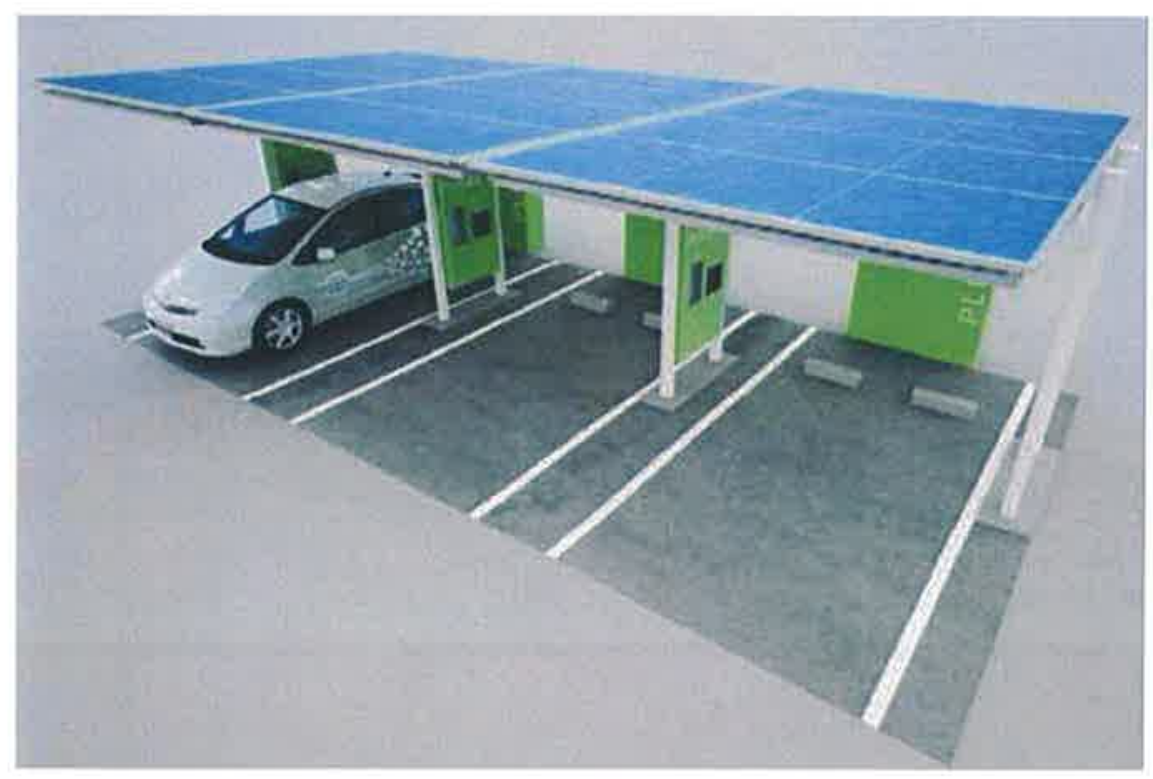

Figura 44- Estação de abastecimento solar Fonte: Toyota, (2011)

\subsection{Mobilidade Elétrica}

A mobilidade elétrica surge como uma mudança de paradigma associada aos novos modelos de sustentabilidade energética e ambiental representando categoricamente uma oportunidade de desenvolvimento econômico e social que resulte de propostas viárias de setores relacionados ao dos transportes, na primeira década do século XXI. 
A mobilidade elétrica não constitui uma invenção do novo milênio, mas um regresso aos primórdios da indústria automotiva que falharam perante os desafios tecnológicos da sua eletrificação, nomeadamente ao nível dos mecanismos de armazenamento de energia. Ainda assim, o paradigma elétrico permeia grande parte dos transportes públicos terrestres, nomeadamente no setor ferroviário. A revolução que se antecipa reside então na massificação do veículo elétrico ao nível da mobilidade individual dos cidadãos, segundo Dias e Pereira (2011).

Obviamente, a mobilidade elétrica serve como uma resposta plausível na redução da dependência do setor de transportes em relação aos combustíveis fósseis vislumbrando a redução de emissões de gases com o efeito estufa e da redução dos níveis de ruído, contribuindo na melhora da qualidade do ar e do ambiente nas cidades.

\subsection{1 "Redes Inteligentes" (Smart Grid)}

Praticamente, os sistemas elétricos de potência, exclusivamente os sistemas de distribuição, estão rompendo paradigmas em seu conceito. A busca incansável pela redução do uso de fontes de energia muito poluentes, a tentativa de alcançar uma maior eficiência energética tornou-se prioridade.

Imbuído propriamente na utilização de geração distribuída, cientistas e pesquisadores almejam que esta camada de informação possa prover à rede de distribuição funcionalidades que auxiliem no gerenciamento do sistema em si, tornando-o mais confiável e transparente para os operadores, além de permitir que o próprio sistema execute tarefas tais como reconfiguração, acompanhamento pormenorizado da demanda e do consumo, redução das perdas, entre outras. Seriam estes os smart grids - as "redes inteligentes" (SARAIVA, 2012).

Estudos de uma proposta para a nova geração de sistemas elétricos de potência, que interage avanços tecnológicos em diversas áreas como computação, telecomunicações, sistemas distribuídos, e inteligência artificial às etapas de geração, transmissão, e distribuição de energia elétrica são o ponto cerne de uma combinação de tecnologias com o potencial para prover uma camada de comunicação às redes elétricas, permitindo a troca de informações sobre o estado da rede entre equipamentos alocados ao sistema: 
Conforme Brown (2008); Wei; Yu-Hui; Jie-Li (2009), esta nova geração de sistemas elétricos de potência transformaria os sistemas elétricos convencionais em um grande "sistema de informação" computacional, onde as características já mencionadas de controle distribuído e conhecimento do estado da rede possibilitariam interessantes funcionalidades. Entre estas, destacam-se.

- Auto-recuperação do sistema;

- Alta qualidade da energia entregue;

- Resistência à ataques cibernéticos;

- Possibilidade de utilização em larga escala de geração distribuída;

- Acomodação de equipamentos para estoque de energia;

- Controle e acompanhamento pormenorizado do consumo por parte do usuário;

- Maior acompanhamento da demanda dos usuários pelas empresas de distribuição;

- Reconfiguração do sistema de distribuição a partir de medições observadas "on-line";

- Minimização dos custos de operação e manutenção.

Wei; Yu-Hui; Jie-Li (2009) ressaltam que o esforço empreendido no desenvolvimento desta tecnologia é motivado por dois movimentos que ganharam visibilidade na última década entre os atores do mercado global de energia, a crescente desregulação deste mercado e a busca pela eficiência energética a partir de preceitos da responsabilidade ambiental.

Tende-se utilizar e manusear fontes de energia como a energia solar que são muito dependentes de condições climáticas/ambientais bastantes inconstantes como a força dos ventos. A utilização destes tipos de fontes de energia demandaria um sistema de transmissão ou distribuição que conseguisse gerenciar o fluxo de energia dessas fontes a partir da disponibilidade de geração das mesmas em determinado tempo.

Rodrigues; Borges; Falcão (2007) explicam que para potencializar a adoção deste tipo de fonte de energia, seria interessante utilizá-las de forma distribuída em um dado espaço geográfico. Por exemplo, pequenas turbinas eólicas e placas fotovoltaicas em coberturas de edifícios de uma metrópole, responsáveis pela geração de energia e posterior injeção da mesma na rede de distribuição. Essa forma de obtenção de energia chama-se geração distribuída.

Na Figura 45 apresentam-se duas imagens que ilustram as diferenças conceituais entre geração tradicional-centralizada e a geração distribuída. À esquerda, um único gerador e as 
linhas de distribuição em sentido único, alimentando indústria, área residencial e comércio. No lado direito, a outra figura apresenta um grande gerador central e vários pequenos geradores. Percebe-se que os fluxos representados pelos arcos chegam de várias direções a um mesmo lugar (no comércio, por exemplo) ou mesmo chegam a sair de convencionais consumidores de energia (indústria, no exemplo). Isso exemplifica a possibilidade de geração de energia também por parte de alguns consumidores, através do uso de painéis fotovoltaicos ou pequenas turbinas de energia eólica.

Para o caso das cidades, o modelo convencional de redes de distribuição que existe e é trabalhado pela engenharia elétrica não comporta este tipo de gerenciamento em formato simples.

Assim, a geração distribuída em muitos casos, pode afetar o sistema de distribuição ou transmissão como um todo a partir de uma ocasional diferença de tensão, como exemplo. Dessa forma, como a rede não tem automação para executar ações corretivas, torna-se muito complicado ou mesmo impraticável, o uso deste tipo de geração (WEI; YU-HUI; JIE-LI, 2009).
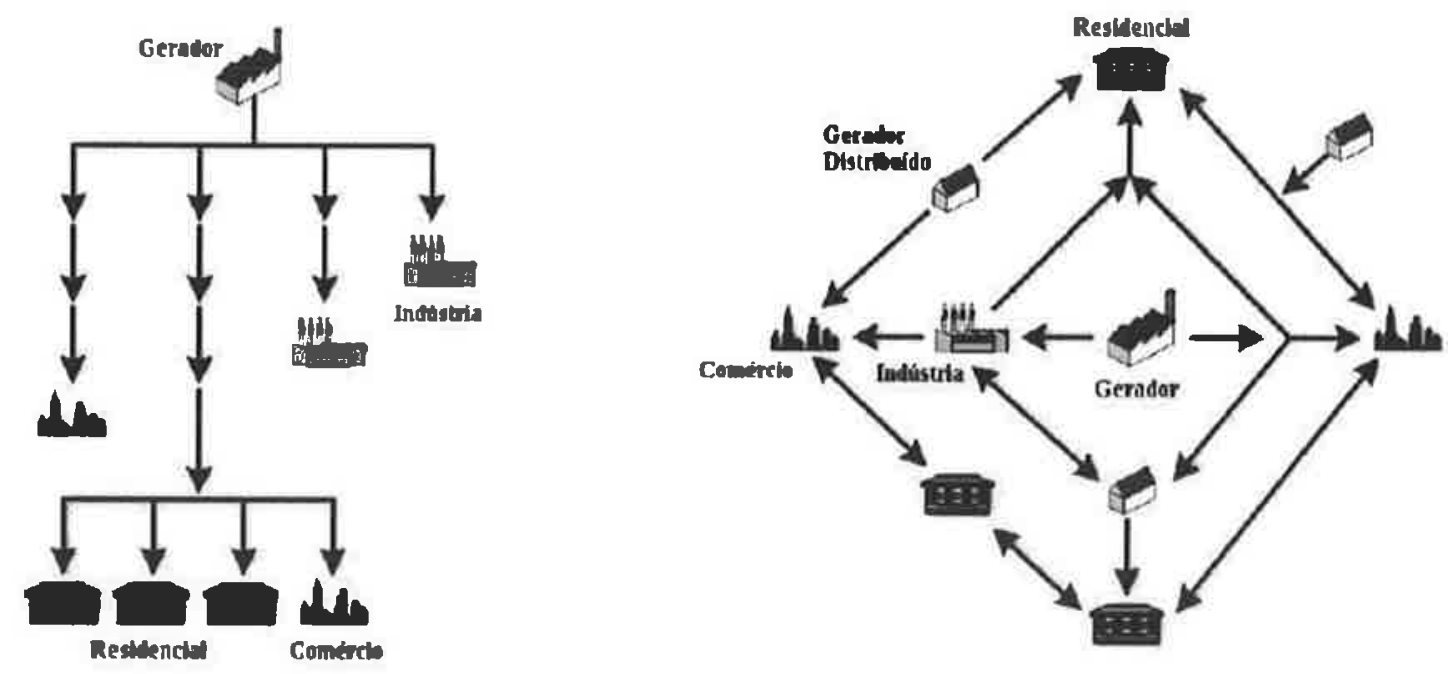

Figura 45- Sistema de Distribuição com Geração Centralizada x Geração Distribuída Fonte: Wei; Yu-Hui; Jie-Li, 2009

Como observa Brown (2008), o desenvolvimento da tecnologia de smart grids e suas funcionalidades impactará no planejamento dos futuros sistemas de distribuição. Se hoje temos sistemas prioritariamente radiais e sem (ou com pouca) automação, no futuro o controle 
distribuído da rede permitirá que a mesma tenha uma topologia malhada, permitindo uma maior flexibilidade para reconfiguração do sistema.

Nesse sentido, um sistema de controle e avaliação distribuído ao longo da rede poderia gerenciar estas múltiplas fontes de energia sem desestabilizar o sistema de distribuição ou transmissão, utilizando a geração distribuída a partir do acompanhamento temporal da disponibilidade de geração das fontes, injetando energia no sistema sempre que isso não incorrer em problemas técnicos para a estrutura ou para o provimento de seus respectivos serviços (BROWN, 2008).

\subsubsection{Países que aplicam projetos para Smart Grids}

A União Européia iniciou ainda em 2005, o seu projeto de estudo e desenvolvimento de redes inteligentes, chamado ETP Smart Grids - European Tecnology Platform Smart Grids ${ }^{1}$ (COMISSION, 2006).

$\mathrm{O}$ aspecto relevante recorrido pelo bloco de países para suas redes de energia são flexibilidade quanto reconfiguração, expansão de acessibilidade ao sistema para usuários, uso prioritário de fontes de energia renováveis e busca pelo gerenciamento eficiente de energia (JIANG et al., 2009).

O Departamento Americano de Energia (U.S. Department of Energy) iniciou o projeto Grid Wise, que tem como objetivo modernizar a infra-estrutura e operação das redes de distribuição, adicionando um fluxo de mão-dupla de eletricidade quanto de informação entre consumidores e subestações (BROWN, 2008). Este projeto acabou gerando subprojetos complementares GridApps e o GridWorks, ambos patrocinados pelo Departamento Americano de Energia.

O projeto GridApps é um consórcio de empresas de tecnologia que trabalha focado em fornecer aplicações que visam modernizar a operação dos sistemas elétricos de transmissão e distribuição. Já o GridWorks busca fortalecer a confiabilidade dos sistemas elétricos através da modernização de cabos, condutores, subestações e sistemas de proteção, utilizando principalmente a eletrônica de potência.

Nos Estados Unidos, o projeto DV2010 (Distribution Vision 2010) tem como objetivo, criar uma rede de distribuição virtualmente "à prova de falhas" através da combinação de

\footnotetext{
' A União Européia mantém um site específico sobre seu projeto ETP SmartGrids, com vários documentos acessíveis para leitura. http://www.smartgrids.eu/ (acessado no dia 18 de abril de 2012)
} 
redes de comunicação de alta velocidade, dispositivos de chaveamento de redes e controladores inteligentes.

O centro de pesquisa californiano chamado EPRI (Electric Power Research Institute), iniciou em 2001 o projeto IntelliGrid, com o objetivo de criar uma nova infra-estrutura de distribuição de energia integrando avanços na comunicação, computação e eletrônica ${ }^{2}$.

Esta iniciativa propõe o desenvolvimento, a integração através da aplicação destas tecnologias a fim de tornar a infra-estrutura dos sistemas de distribuição mais eficientes, com alta qualidade, segurança e robustez. Este projeto angariou novos objetivos sendo alicerce do ADA (Advanced Distribution Automation) que é responsável pela criação de sistemas de distribuição do futuro, onde a infra-estrutura será totalmente automatizada através de uma arquitetura de operação flexível, gerenciada por sistemas de controle que se comunicam através de um protocolo aberto (BROWN, 2008).

Iniciativas de desenvolvimento de smart grids em países do continente asiático são projetadas. A China é um dos países que mais se expande economicamente mundo afora.

Com o crescimento da economia eleva-se a demanda por energia. Estima-se que atualmente o país conta com uma capacidade de geração instalada de $792 \mathrm{GW}$ e deverá necessariamente dobrá-la até meados de 2020 (BI et al., 2010).

O governo local na China aposta na geração distribuída a partir de fontes renováveis de energia como forma de complementar os esforços para suprir sua demanda energética neste espaço de tempo. Além desses países, vários outros investem na tecnologia de "smart grids", a partir de um plano político próprio para os sistemas elétricos.

\footnotetext{
${ }^{2}$ A ERPI mantém um site específico para o projeto IntelliGrid, com muitas informações e artigos. http://intelligrid.epri.com/ (acessado dia 18 de abril de 2012)
} 
Esse capítulo tem o propósito de apresentar as análises ambiental, social, econômica e política priorizando a gestão da mobilidade como um todo. Dessa forma, serão abordadas as dificuldades na distribuição de cargas e a elevação da circulação de mercadorias. Pretende-se, com isso, apresentar possíveis soluções encontradas na literatura para essa problemática.

\section{GESTÃO DA MOBILIDADE ATRAVÉS DAS ANÁLISES AMBIENTAL, SOCIAL, ECONÔMICA E POLÍTICA}

\subsection{Algumas Considerações}

Uma vez especificado o conceito de mobilidade urbana sustentável, mover-se dos objetivos mais abrangentes para os mais específicos é condição para a definição de indicadores ambientais, sociais e econômicos. Esta etapa desempenha um importante papel no processo de efetivação do conceito de mobilidade urbana sustentável, de forma a torná-lo um conceito manipulável e mensurável e a prover informação para a tomada de decisão (BLACK et al. 2002, GUDMUNDSSON, 2004).

No entanto, a abordagem mais difundida para operacionalização do conceito de transporte sustentável é simplesmente listar os principais problemas ou questões que devem ser incluídas na análise. Isto tipicamente abrange problemas ambientais (como ruído, poluição, aquecimento global), questões econômicas (investimentos em infra-estrutura de transportes) e questões sociais (como acessibilidade para todos, na área da saúde, educação e cidadania).

Contudo, pode-se dizer, em contrapartida, que o desenvolvimento sustentável compreende também dois objetivos similares (gerais):

- Minimizar os impactos ambientais;

- Fazer o melhor e mais equilibrado uso dos recursos;

Assim, para o desenvolvimento sustentável, a harmonia entre três outros objetivos específicos se faz necessária:

- Assegurar altos padrões de qualidade de vida por meio do desenvolvimento econômico;

- Proteger e melhorar o ambiente; 
- Assegurar uma distribuição eqüitativa dos benefícios entre as gerações atual e futura.

- O termo mobilidade sustentável defende processos e caminhos a serem seguidos muito mais do que, simplesmente, a representação de uma visão do futuro. Para tanto, as metas a serem seguidas devem (EXTRA, 2001):

- Prover acesso a bens, recursos e serviços reduzindo a necessidade de deslocamentos, de tal forma que a economia, as necessidades ambientais e sociais possam ser eficientemente postas, e de maneira integrada;

- Assegurar que a infra-estrutura de transporte e os movimentos não excedam a capacidade do meio ambiente;

- Assegurar que os usuários paguem os custos sociais e ambientais de suas opções em transporte, sem tornar a indústria não competitiva ou impedir aqueles de baixa renda de atingir ou satisfazer suas necessidades de transporte;

- Reduzir o crescimento do tráfego de carga e caminhões a níveis sustentáveis;

- Assegurar que os investimentos em infra-estrutura de transporte levem em conta os aspectos ambientais;

- Aumentar a escolha e estimular o uso de modos de transportes mais eficientes do ponto de vista econômico, ambiental e social;

- Proteger o capital natural e físico;

- Encontrar padrões de qualidade ambientais, observando-se os limites críticos e ecológicos e a saúde pública;

- Assegurar que os recursos naturais não renováveis sejam usados levando-se em conta as necessidades futuras e a disponibilidade de recursos alternativos;

- Assegurar segurança e saúde pública, reduzindo acidentes e aumentando a segurança;

- Aumentar a aceitabilidade econômica e social de novas medidas.

Nesse contexto, tomando por base as metas acima, pode-se definir, em termos práticos, mobilidade sustentável como sendo (EXTRA, 2001, Relatório 1/10, p.7):

"Um sistema e padrões de transporte que possam prover meios e oportunidades em direção às necessidades econômicas, ambientais e sociais (de maneira justa e eficiente), ao mesmo 
tempo em que se minimizam os impactos adversos e seus custos associados em escalas relevantes de espaço e tempo".

Proeminentemente, na busca do desenvolvimento sustentável, o desafio é reconciliar o crescimento econômico e a demanda social por mobilidade com os custos ambientais e outros causados pelo movimento de tráfego. A solução, então, está na aproximação integrada, que combine:

- Mudança de comportamento das pessoas em relação ao transporte e em suas formas de vida (afetando demanda por movimentos, padrões de uso do solo, etc.);

- Melhorias na tecnologia para aumentar a eficiência, reduzindo ao mesmo tempo, os impactos ambientais e aumentando a segurança;

- Um regime de preços que incorpore os custos reais de transporte na tomada de decisão e, por meio disso, influencie todo o consumo dos serviços de transporte, promovendo o mínimo de danos ao modo de transporte.

\subsection{Inter-Relacionamento de Dados Ambientais e de Saúde no Setor de Transportes}

O meio ambiente é fonte de recursos naturais imprescindíveis para a sobrevivência do homem e seu desenvolvimento. As atividades humanas causam impactos nesses recursos, os quais, pela sua classificação, podem representar maiores ou menores riscos na sua renovação (BARBIERI, 2006).

O termo impacto ambiental é definido como toda alteração das propriedades físicas, químicas e biológicas do meio ambiente, causada por qualquer forma de matéria ou energia resultante das atividades humanas que, direta ou indiretamente, afetam: I - a saúde, a segurança e o bem-estar da população; II - as atividades sociais e econômicas; III - a biota; IV - as condições estéticas e sanitárias do meio ambiente; V - a qualidade dos recursos ambientais (CONAMA, 2007).

Os problemas ao meio ambiente e à saúde da população de forma geral, variam de acordo com a expansão econômica, padrões de consumo, modelo de transporte, entre outros fatores adotados por uma sociedade (CASTRO et al., 2003). 
Nesse sentido, a poluição pode assumir características diversas, levando como fator determinante, a fonte que contribuirá para a sua existência (viária, industrial, agrícola) (MAISONET et al., 2004; RITZ; WIHELM, 2008).

Por outro lado, a eficiência e a integração entre os diversos modos de transportes são fatores fundamentais para o crescimento econômico de uma nação, pois permitem o deslocamento das pessoas, a acessibilidade à educação, a informação, a saúde, a comercialização de bens, a integração social e a criação de pólos comerciais, industriais e de lazer. Além de representar um fator positivo para a vida econômica dos países, a existência de um sistema de transporte efetivo contribui para o bem-estar dos cidadãos (FOGLIATTI et al.; 2004).

Entretanto, enquanto os sistemas de transporte são essenciais à sociedade moderna, com benefícios econômicos significativos para esta, eles também trazem impactos negativos ao meio ambiente (FOGLIATTI et al., 2004). Segundo Vasconcellos (2008), esses impactos podem inicialmente ser divididos em dois grandes grupos: os que implicam em consumo de recursos naturais e os que afetam a vida das pessoas. Portanto, quando da avaliação de um modo de transporte, devem-se considerar, além das questões de cunho econômico-financeiro, as de cunho socioambiental, que muitas vezes são ignoradas nas tomadas de decisão.

A exposição humana consiste no contato entre um contaminante e o indivíduo (via inalação, ingestão, contato dérmico), em um intervalo específico de tempo e em diferentes cenários ambientais (ar, água e solo). Essa interação envolve três aspectos em formato simplista (ZOU et al., 2009):

- concentração- abundância de um poluente no meio ambiente, definida como massa ou fração do material por volume ou área;

- exposição humana- concentração, conjunto ou intensidade de um agente ambiental que alcança a população-alvo, organismo ou tecido em um dado tempo/espaço;

- dose- conjunto de poluentes que foi ingerido ou absorvido por um organismo e, assim, associado com efeitos adversos à saúde.

Pode-se afirmar, em termos gerais, que nos grandes centros populacionais, os veículos automotores, fonte significativa de emissões contaminadoras do ar, contribuem, muitas vezes, com cerca de $100 \%$ dos poluentes emitidos para a atmosfera (CAMPI et al, 2004). 
No fim da década de 70, no Brasil surgiu a necessidade de se criar um programa que contemplasse as emissões atmosféricas de origem veicular. A motivação foi dada pela constatação de que a maléfica poluição ambiental, verificada nos grandes centros urbanos, era causada, predominantemente, pelos poluentes atmosféricos gerados na queima de combustíveis dos autos (IBAMA, 2012).

Nos anos 90, o Tratado de Kyoto, proposto no Japão em 1997, objetivava o compromisso das nações para com a diminuição do número de emissões. Segundo o pacto, países desenvolvidos se comprometeriam a diminuir a emissão de gases que provocam o efeito estufa em 5,2\%, em média, dos níveis de 1990 até o ano de 2012. Os EUA e a China, considerados entre os maiores emissores de gases causadores do chamado efeito estufa, negavam-se a atender as proporções determinadas pelo protocolo. Em contrapartida, o protocolo entrou em vigor em 2005, com as metas a serem observadas em 2012 . $^{2}$

Já o Conselho Nacional de Meio Ambiente (CONAMA), ligado ao Ministério do Meio Ambiente, criou em 1986, um programa de controle de emissões veiculares, que fosse tecnicamente exeqüível, bem como, viável do ponto de vista econômico para a realidade brasileira, chamado Programa de Controle da Poluição do Ar por Veículos Automotores (PROCONVE). O site do IBAMA (http://www.ibama.gov.br), além dessas e outras informações ligadas às emissões ambientais, traz as leis que regem cada um dos programas (IBAMA,2012).

Em termos gerais, o PROCONVE tem como objetivo proporcionar a redução dos níveis de emissão de poluentes nos veículos automotores incentivando o desenvolvimento tecnológico nacional (tanto em níveis de engenharia automotiva, como em métodos e equipamentos para a realização de ensaios e medições de poluentes). Os limites máximos de emissão de poluentes foram fixados, com um cronograma específico, para três categorias distintas de veículos (IBAMA, 2012):

- Veículo Leve de Passageiros (automóveis);

- Veículo Leve Comercial (pick-up, van, utilitários etc.);

- Veículo Pesado (ônibus e caminhões).

A Tabela 18, a seguir, mostra a evolução dos limites de emissões ao longo das fases do PROCONVE para veículos pesados. O Gráfico 19 mostra a redução das emissões ao longo das fases do PROCONVE para veículos pesados. 
Tabela 18 - Limites das emissões perante às fases do PROCONVE para veículos pesados

\begin{tabular}{|c|c|c|c|c|c|c|}
\hline PROCONVE & EURO & $\underset{(\mathrm{g} / \mathrm{KW} \cdot \mathrm{h})}{\mathbf{C O}}$ & $\begin{array}{c}\text { HC } \\
(\mathrm{g} / \mathbf{K W} \cdot \mathbf{h})\end{array}$ & $\begin{array}{c}\text { NOx } \\
(\mathrm{g} / \mathbf{K W} \cdot \mathbf{h})\end{array}$ & $\underset{(g / \mathbf{K W} \cdot h)}{\mathbf{M P}}$ & $\begin{array}{c}\text { Teor de } \\
\text { enxofre (S) }\end{array}$ \\
\hline FASE P1 & & 14,00 & 3,50 & 18,00 & - & . \\
\hline Fase P2 & Euro 0 & 11,20 & 2,45 & 14,40 & 0,60 & $\begin{array}{c}3.000 \mathrm{a} \\
10.000 \mathrm{ppm}\end{array}$ \\
\hline Fase P3 & Euro 1 & 4,90 & 1,23 & 9,00 & 0,40 ou 0,70 & $\begin{array}{c}3.000 \mathrm{a} \\
10.000 \mathrm{ppm}\end{array}$ \\
\hline Fase P4 & Euro 2 & 4,00 & 1,10 & 7,00 & 0,15 & $\begin{array}{c}3.000 \mathrm{a} \\
10.000 \mathrm{ppm}\end{array}$ \\
\hline Fase P5 & Euro 3 & 2,10 & 0,66 & 5,00 & 0,10 ou 0,13 & $\begin{array}{c}500 \mathrm{a} \\
2.000 \mathrm{ppm}\end{array}$ \\
\hline Fase P6 & Euro 4 & 1,50 & 0,46 & 3,50 & 0,02 & $50 \mathrm{ppm}$ \\
\hline Fase P7 & Euro 5 & 1,50 & 0,46 & 2,00 & 0,02 & $10 \mathrm{ppm}$ \\
\hline
\end{tabular}

Nota: CO (Monóxido de Carbono), HC (Hidrocarbonetos), NOx (Óxidos de Nitrogênio) MP (Material Particulado), S(Enxofre )

Fonte: Adaptado de IBAMA, (2012).
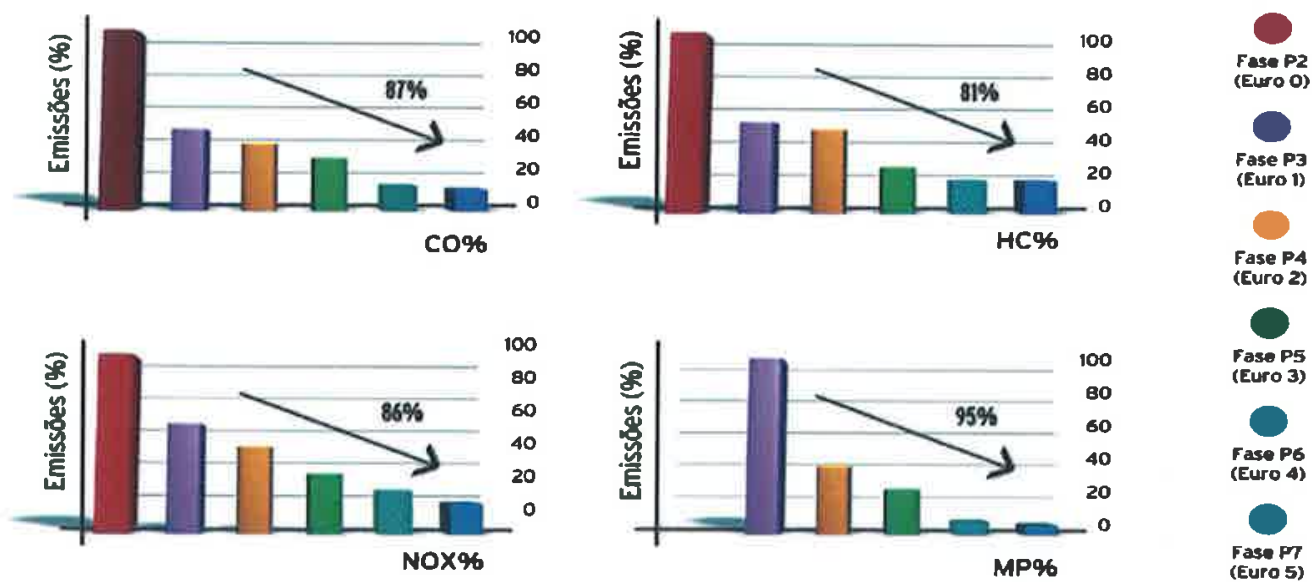

Gráfico 19 - Emissões ao longo das fases do PROCONVE para veículos pesados Fonte: CNT DESPOLUIR, (2012)

As emissões oriundas de um veículo podem ocorrer pelo escapamento (emissões diretas) ou podem ser de natureza evaporativa do combustível, aparecendo durante o uso e o repouso do veículo. São influenciadas por vários fatores, dentre os quais podemos destacar: tecnologia do motor, porte e tipo de uso do veículo, idade do veículo, projeto e materiais do sistema de alimentação de combustível, tipo e qualidade do combustível (pressão de vapor),

\footnotetext{
${ }^{2}$ Maiores informações sobre o protocolo de Kyoto podem ser encontradas em www.mma.gov.br
} 
condições de manutenção e condução, além de fatores meteorológicos (pressão e temperatura ambientes) (MMA, 2011).

As emissões de escapamento decorrem da queima dos combustíveis pelo motor, compreendendo uma série de substâncias como monóxido de carbono (CO), dióxido de carbono $\left(\mathrm{CO}_{2}\right)$, hidrocarbonetos $(\mathrm{HC})$, aldeídos $(\mathrm{RCHO})$, óxidos de nitrogênio $(\mathrm{NOx})$ e material particulado (MP).

As emissões evaporativas são constituídas pelos hidrocarbonetos (HC) que evaporam do sistema de alimentação de combustível do veículo. Tais emissões ocorrem pelos seguintes processos:

- Emissões diurnas - são as geradas no sistema de combustível com o veículo em repouso, devido às mudanças de temperatura ambiente ao longo das 24 horas do dia. Conforme a temperatura se eleva, aumenta o escape de vapores de combustível pelo sistema de alimentação, quer pela permeabilidade inerente aos materiais empregados, quer pela estanqueidade imperfeita de conexões;

- Perdas em movimento - são as emissões de vapores de combustível que ocorrem enquanto o veículo está em circulação pelo sistema de alimentação. Também se devem ao aumento da pressão e da temperatura do combustível durante o funcionamento do automóvel.

- Emissões evaporativas - do veículo em repouso; com o motor quente- emissões de vapores de combustível que ocorrem após o uso do veículo, caracterizam-se pelo fato do combustível estar parado e despressurizado, porém ainda aquecido devido à circulação no período em que o veículo estava em funcionamento e ao calor residual desprendido do motor.

Vale destacar que, o transporte rodoviário de carga é responsável por cerca de $60 \%$ da movimentação nacional de mercadorias (ROCHA; ARRUDA; ROCHA, 2009). Em números, isso corresponde a uma frota nacional de caminhões de 2.732 .901 unidades (ANFAVEA; DENATRAN, 2011).

A maior parte da frota pertence aos transportadores autônomos (55,6\%). Os caminhões de autônomos são mais antigos, apresentando em média, 23 anos de uso gerando ineficiência econômica (baixa produtividade), insegurança nas estradas e ruas das cidades, sem falar na poluição atmosférica (ARRUDA, 2010). O Gráfico 20 realça que $85 \%$ dos caminhões com mais de 20 anos de uso pertencem aos transportadores autônomos. 


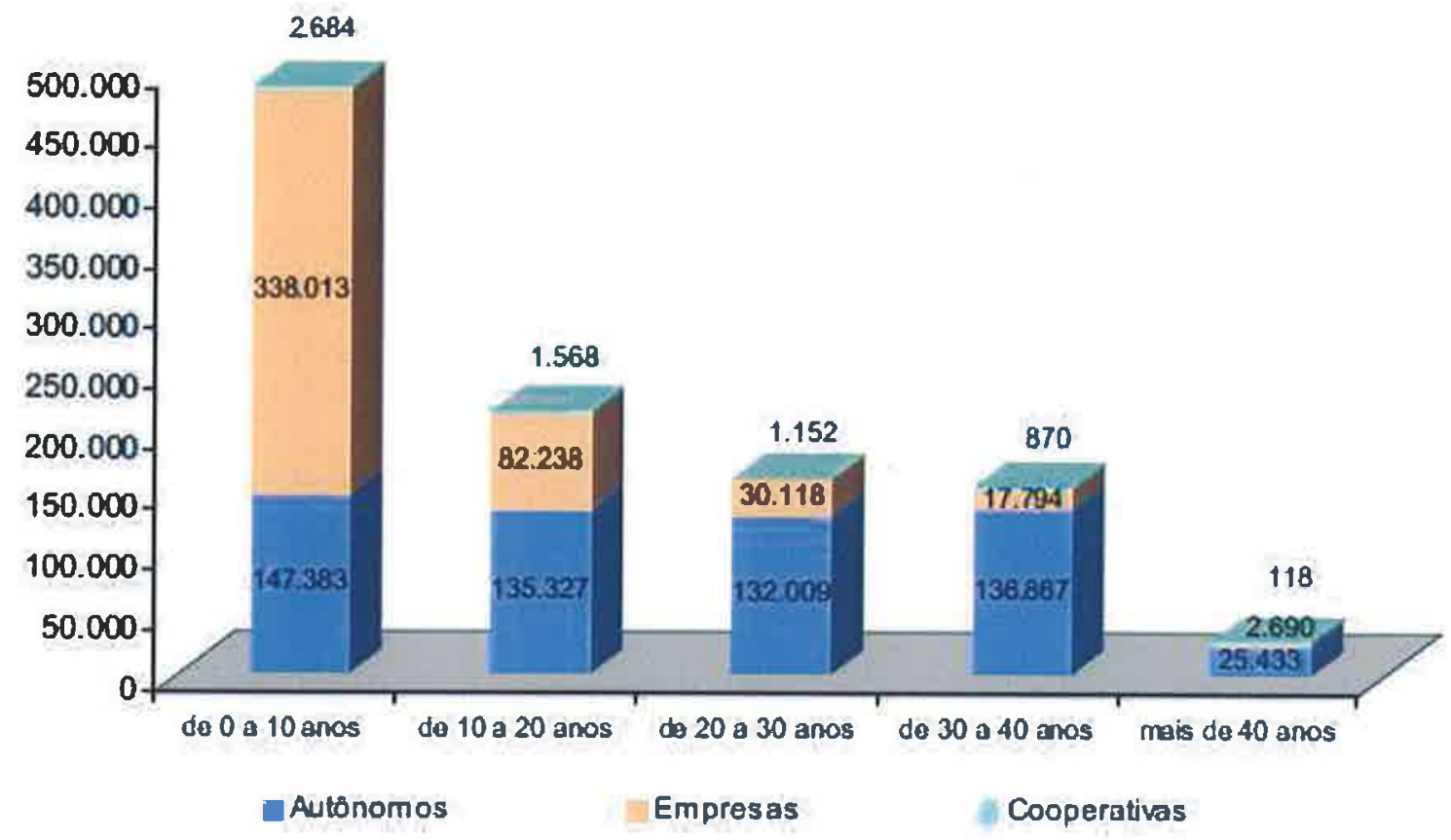

Gráfico 20 - Idade da frota e a propriedade dos veículos Fonte: ANTT, (2011)

Essa frota antiga produz externalidades negativas para a sociedade, como o aumento da poluição atmosférica, dos custos operacionais e dos gastos sociais com os acidentes, além de redução da arrecadação governamental, devido à isenção de pagamento do IPVA (ARRUDA, 2010; ROCHA; ARRUDA; ROCHA, 2009). Pode-se dizer que grande parte da externalidade subjacente à atual frota autônoma de caminhões toma a forma de bem público, pois envolve bens de propriedade comum sem direitos de propriedade definidos, como o ar, o sistema público de saúde, o sistema público de seguridade social, entre outros. O Gráfico 21 exibe as fases do PROCONVE atrelado à propriedade de veículos. Fica evidenciado que $40 \%$ da frota circulante possui motores adequáveis à Fase $\mathrm{P} 1$ ou a anterior. Esses veículos, além de disporem de tecnologias obsoletas, apresentam deformidades mecânicas proporcionalmente ao tempo de uso necessitando de maior manutenção. Com a produtividade em menor escala, emite poluentes atmosféricos, além de ocasionar congestionamentos, acidentes, elevando o consumo de combustível resultando em impactos sociais, ambientais e econômicos. A Figura 46 expõe o cenário atual, dividido por região, quantificando as unidades de caminhões com mais de 20 anos de uso existentes. 


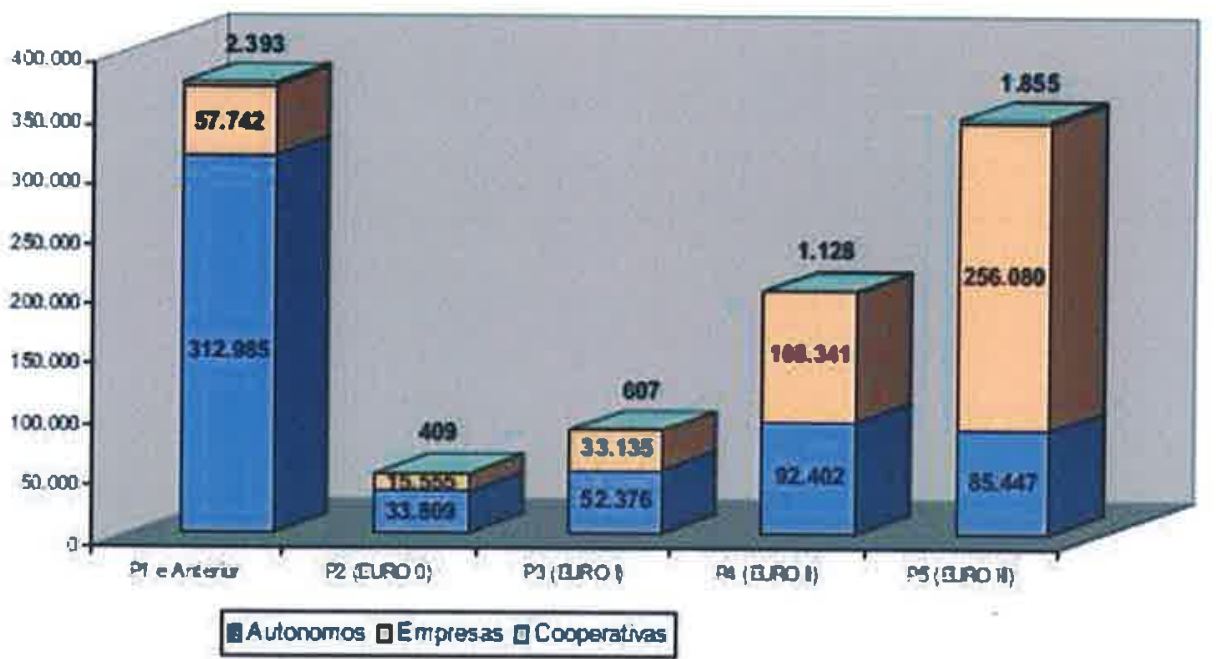

Gráfico 21- Fases do Proconve e a propriedade dos veículos Fonte: ANTT, (2011)

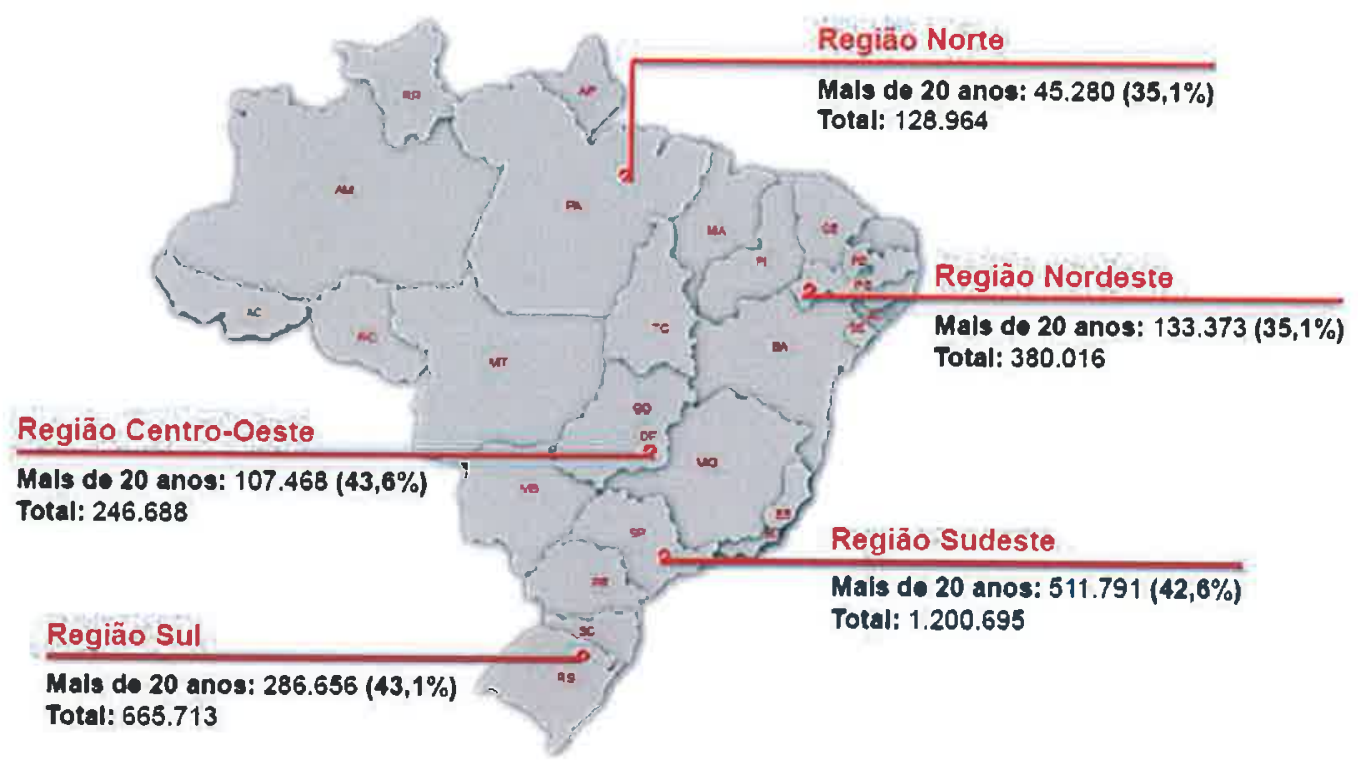

Figura 46- Unidades de caminhões com mais de 20 anos quantificado por região Fonte: ANFAVEA e DENATRAN, (2011)

\subsubsection{Poluentes Atmosféricos}

Os poluentes atmosféricos podem ser categorizados como primários e secundários. Os primários são aqueles emitidos diretamente pela fonte geradora e os secundários são formados na atmosfera, a partir de reações fotoquímicas dos poluentes primários. Os principais 
poluentes primários emitidos da queima de combustíveis fósseis são materiais particulados (MPs), o dióxido de enxofre ( $\mathrm{SO}_{2}$ ), os óxidos de nitrogênio (NOx) e o monóxido de carbono (CO). Da mesma forma, poluentes secundários como ozônio ( $\left.\mathrm{O}_{3}\right)$, ácido nítrico (HNO3), ácido sulfúrico $\left(\mathrm{H}_{2} \mathrm{SO}\right.$ 4) e diversos nitratos também são encontrados nas áreas urbanas (PAHO, 2005). Segundo a CETESB, as características principais dos poluentes atmosféricos encontrados na região urbana podem ser observados na Tabela 19.

\begin{tabular}{|c|c|c|}
\hline Poluentes & Características & Fontes Principais \\
\hline $\begin{array}{c}\text { Partículas Inaláveis }\left(\boldsymbol{M P} \mathbf{P}_{10}\right) \mathrm{e} \\
\text { fumaça. }\end{array}$ & $\begin{array}{c}\text { Partículas de material sólido ou liquido } \\
\text { que ficam suspensos no ar, na forma de } \\
\text { poeira, neblina, aerosol, fumaça, fuligem } \\
\text { etc. Faixa de tamanho < que } 10 \text { micra. } \\
\text { Gás incolor, com forte odor, semelhante } \\
\text { ao gás produzido na queima de palitos de } \\
\text { fósforo. }\end{array}$ & $\begin{array}{l}\text { Processos de combustão (indústria } \\
\text { e veículos automotores), aerosol } \\
\text { secundário (formação na } \\
\text { atmosfera). }\end{array}$ \\
\hline Dióxido de Enxofre $\left(\mathrm{SO}_{2}\right)$ & \begin{tabular}{|} 
Pode ser transformado em $\mathrm{So}_{3}$, que na \\
presença de vapor de água, passa \\
rapidamente a $\boldsymbol{H}_{2} \mathrm{SO}$. É um importante \\
precursor dos sulfatos, um dos principais \\
componentes das partículas inaláveis..
\end{tabular} & \begin{tabular}{|c|} 
Processos que utilizam queima de \\
óleo combustível, refinaria de \\
petróleo, veículos a diesel, polpa \\
papel.
\end{tabular} \\
\hline Dióxido de nitrogênio ( $\mathrm{Na}_{2}$ ) & $\begin{array}{l}\text { Gás marrom avermelhado, com odor } \\
\text { forte e muito irritante, pode levar a } \\
\text { formação de ácido nítrico, nitratos (os } \\
\text { quais contribuem para o aumento das } \\
\text { partículas inaláveis na atmosfera) e } \\
\text { compostos orgânicos tóxicos }\end{array}$ & \begin{tabular}{|c|} 
Processos de combustão \\
envolvendo veículos automotores, \\
processos industriais, usinas \\
térmicas que utilizam óleo ou gás, \\
incinerações. \\
\end{tabular} \\
\hline Monóxido de carbono ( $\mathrm{CO}$ ) & Gás incolor, inodoro e insípido. & $\begin{array}{l}\text { Combustão incompleta em } \\
\text { veículos automotores. }\end{array}$ \\
\hline Ozônio ( & $\begin{array}{c}\text { Gás incolor e inodoro nas concentrações } \\
\text { ambientais e o principal componente da } \\
\text { névoa fotoquímica. }\end{array}$ & $\begin{array}{c}\text { Não é emitido diretamente a } \\
\text { atmosfera. É produzido } \\
\text { fotoquimicamente pela radiação } \\
\text { solar sobre os óxidos de } \\
\text { nitrogênio e compostos orgânicos } \\
\text { voláteis. }\end{array}$ \\
\hline
\end{tabular}

Fonte: Adaptado de CETESB, (2011)

Devido aos poluentes ambientais, a poluição atmosférica é a que acarreta maiores riscos à saúde, atribuindo-se a ela, milhões de mortes e anos de vida perdidos (ARNENBERG et al.,2010). Crianças, idosos e pessoas com problemas cardiorespiratórios permanecem entre os mais prejudicados e vulneráveis aos efeitos deletérios desses poluentes. Estima-se que, anualmente, $4,9 \%$ e $5,5 \%$ do total de óbitos, derivados de causas respiratórias entre idosos e crianças, são atribuídos à poluição atmosférica, respectivamente, nas principais capitais brasileiras como São Paulo e Rio de Janeiro (MARCILIO; GOUVEIA, 2007). 
Sabe-se que o transporte de pessoas e mercadorias é de suma importância para o desenvolvimento econômico e para o fácil acesso das pessoas aos locais de trabalho ou lazer, porém estão atrelados a ele, problemas ambientais, ocasionados pelo modal rodoviário que acaba gerando contaminantes da combustão dos motores, dos componentes veiculares (pastilhas de freio e embreagem, pneus e tanques de combustível) e do uso das vias (WHO,2005).

Fatores como tráfego elevado e congestionado, adensamento populacional das áreas urbanas e a limitada dispersão de poluentes (corredores de prédios, inversões térmicas) potencializam os riscos à saúde da exposição aos poluentes atmosféricos, pois aumentam a emissão e concentração desses poluentes e o número de pessoas expostas a eles.

Mundialmente, essa problemática afeta várias cidades, e tem levado a esfera governamental, em diferentes níveis (local ou federal), a adotarem medidas restritivas, por meio de programas de controle de emissões de motores de veículos novos e inspeções veiculares naqueles já em circulação, bem como, a restrição dos veículos em determinados locais e/ou dias da semana. Desse modo, a minimização das emissões e do volume do tráfego beneficia a qualidade de vida da população, reduz os impactos à saúde diminuindo a perturbação causada pela poluição sonora e a emissão de gases geradores de efeito estufa (WHO, 2005).

Em âmbito nacional, segundo estudo publicado por Saldiva (2011), a captação de partículas varia ao longo da árvore brônquica e tecido pulmonar humano, causando colapso alveolar, inflamação e estresse oxidativo.

Essas partículas provenientes da poluição atmosférica são indutoras de exacerbação das doenças respiratórias crônicas, mesmo em doses baixas (BRAGA, 2009).

A existência de comorbidades, como diabetes tipo 2 e sua associação com exposição à poluição atmosférica albergam um aumento de visitas a setores de emergência hospitalar, e consequentemente, um aumento de doenças cardiovasculares associado ao problema de base (PEREIRA, 2008).

Os efeitos da poluição atmosférica também foram demonstrados no que diz respeito à instabilidade do filme lacrimal e na sintomatologia do desconforto ocular (NOVAES et al., 2010).

Igualmente, a função reprodutiva tem sido alvo de estudos que comprovaram os efeitos nocivos sobre a fertilidade e saúde fetal, evidenciando que a exposição aos poluentes atmosféricos está associada com o baixo peso ao nascer, retardo de crescimento intra-uterino, prematuridade, morte neonatal e redução da fertilidade masculina e feminina (VERAS et al., 2009). 
A Tabela 20 apresenta os tipos de emissões advindas dos transportes e seus respectivos danos ambientais.

Tabela 20 - Parâmetros ambientais utilizados como base para definir "transporte ambientalmente sustentável"

\begin{tabular}{|c|c|}
\hline Impactos ambientais & Contribuição do setor de transportes \\
\hline Diminuição da camada de ozônio & ODS (ozone depleting substances) \\
\hline Acidificaçāo & SOx, NOx \\
\hline $\begin{array}{c}\text { Eutroficaçào (aumento excessivo de nutrientes da água, } \\
\text { geralmente, fosfato e nitrato) }\end{array}$ & $\mathrm{NO}, \mathrm{NH}^{3}$ \\
\hline Aumento do nível de ozônio & NOx \\
\hline $\begin{array}{c}\text { Poluição do ar em áreas urbanas, causando impactos negativos naa } \\
\text { saúde (cânceres, doenças respiratórias, } \\
\text { entre outros) }\end{array}$ & NO2, MP, benzeno, entre outros \\
\hline Ruído & Niveis equivalentes e máximo de ruídos \\
\hline
\end{tabular}

Fonte: Adaptado de Box 1, WORKING GROUP I (2000)

Nos EUA, as iniciativas de medições das taxas de emissão datam do final dos anos 70 , como resposta às discrepâncias entre as emissões de veículos novos, apresentadas nos certificados e as emissões dos veículos em uso. Porém, apenas em 1990, passou-se a desenvolver um programa de I/M (Inspeção e Manutenção de Veículos em Uso) mais eficiente do que os que vinham sendo implementados, sendo obrigatório em todas as áreas metropolitanas com problemas de poluição atmosférica relacionados às emissões veiculares (MMA, 2006).

Já, em diversos países da União Européia existem os testes de emissão veicular há, aproximadamente, 27 anos. Entretanto, originalmente, apenas incluía caminhões, ônibus, táxis e ambulâncias. Eram estabelecidos os itens a serem inspecionados (como freios e emissões), mas não eram determinados padrões a serem seguidos, critérios e métodos de testes, o que só foi feito posteriormente, sofrendo os programas $\mathrm{L} / \mathrm{M}$, diversas modificações desde 1977. Atualmente, incluem também, automóveis e vans leves, além de um maior detalhamento nos testes de emissões e na padronização. 


\subsubsection{Material Particulado}

Defini-se material particulado (MP) como uma mistura complexa de componentes com diversas características físicas e químicas. As partículas são classificadas pelas suas propriedades aerodinâmicas, porque estas determinam os locais de sua deposição no aparelho respiratório.

Nos grandes centros urbanos, a poluição do ar é composta por diversas substâncias tóxicas, entre elas, gases, tais como ozônio $\left(\mathrm{O}_{3}\right)$, óxidos de nitrogênio $(\mathrm{NO} x)$, monóxido de carbono (CO) e partículas derivadas principalmente da queima de combustíveis fósseis. Contudo, o material particulado tem sido apontado como o principal causador de efeito nocivos à saúde (EPA, 2009).

Em termos gerais, o material particulado (MP) se deposita no aparelho respiratório por meio de impactos inertes, sedimentação, difusão, intercepção e precipitação eletrostática, o que se verifica em razão da mudança súbita na direção da corrente aérea e sua velocidade. Assim, não só a sedimentação mas também a impactação podem influenciar na deposição de partículas dentro da mesma faixa de tamanho. A precipitação eletrostática é a deposição relacionada à carga da partícula. A quantidade de material depositado é diretamente relacionada aos efeitos na saúde humana. Assim, dependendo da origem, da composição química e do tamanho da partícula, o efeito do material particulado é diferente. As partículas maiores ( 5 a $30 \mu \mathrm{m}$ de diâmetro) depositam-se, pelo impacto da turbulência do ar, no nariz, na boca, na faringe e na traquéia. Partículas de 1 a $5 \mu \mathrm{m}$, geralmente depositam-se por sedimentação na traquéia, nos brônquios e nos bronquíolos. Partículas com menos de $1 \mu \mathrm{m}$ de diâmetro, em geral depositam-se por difusão nos pequenos bronquíolos e alvéolos. As partículas que se dissolvem no catarro são eliminadas por expectoração, ou depois de engolidas, eliminadas pelo sistema digestivo. Já nos alvéolos, as partículas podem se dispersar no sistema linfático ou sanguíneo. O MP pode causar aumento de sintomas respiratórios e diminuição da função pulmonar em crianças, aumento da mortalidade em pacientes com doenças cardiovasculares e pulmonares, aumento e piora das crises de asma e aumento de neoplasias (EPA, 2009).

Por ser uma mistura complexa, o potencial do material particulado para causar dano varia de acordo com tamanho, características físicas, composição química e fonte emissora (BAIRD, 2002), além disso, seu potencial tóxico pode estar ligado à capacidade das partículas ativarem fontes endógenas de estresse oxidativo dentro do tecido pulmonar, ao contrário de partículas inertes como o carbono elementar (WHO, 2005). 
A classificação do material particulado é realizada pelo tamanho da partícula, que é expresso por seu diâmetro aerodinâmico. Os tamanhos se estendem de agrupamentos moleculares com nanômetros de diâmetro, as partículas ultrafinas, menores do que $0,1 \mu \mathrm{m}$; as partículas finas, menores do que 2,5 $\mu \mathrm{m}(\mathrm{MP} 2,5)$ e partículas grossas, de 2,5 a $10 \mu \mathrm{m}(\mathrm{MP} 10)$ (EPA, 2009). A Figura 47 traz particularidades referentes ao material particulado como tamanho, fonte e composição.

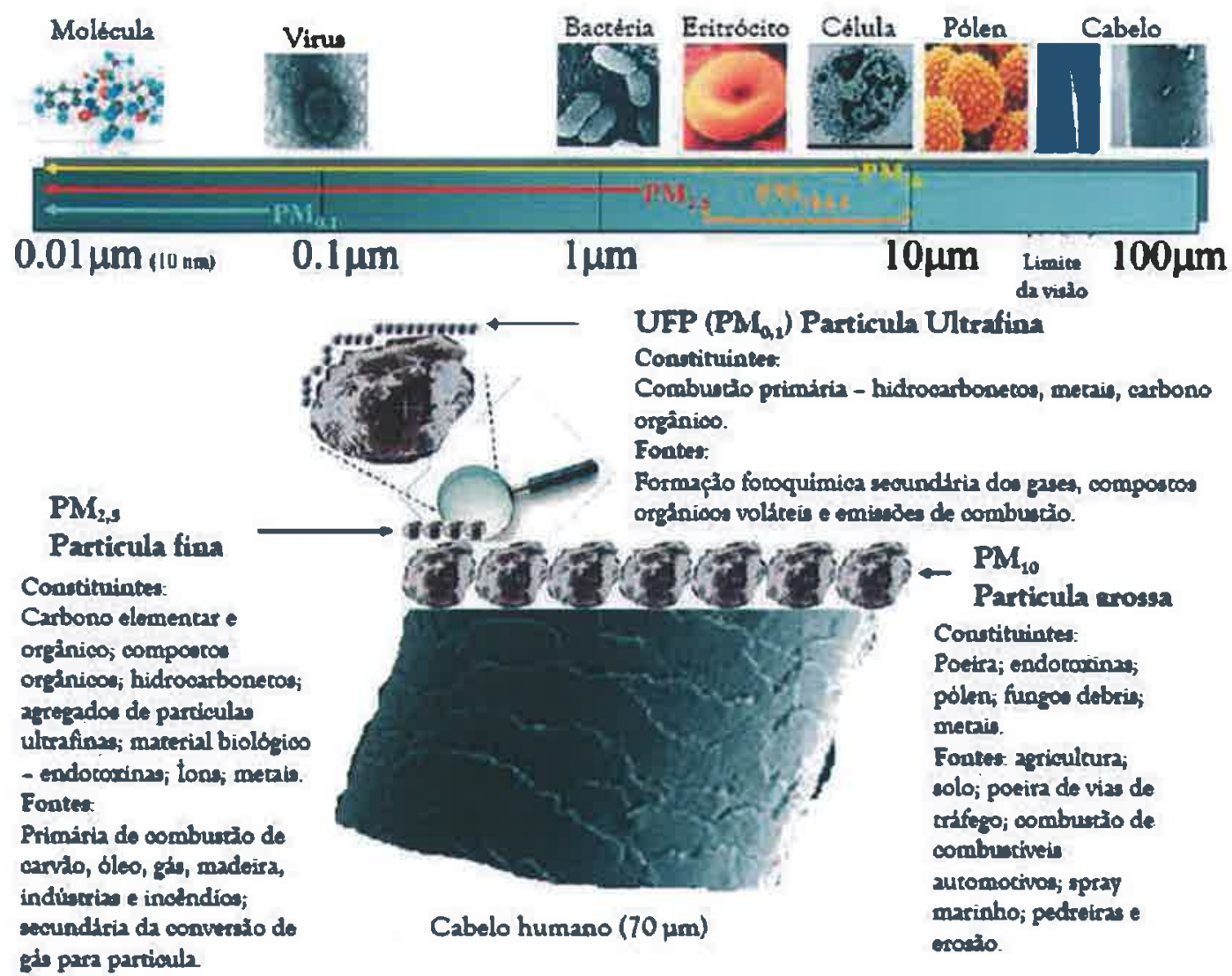

Figura 47 - Tamanho, Fonte e Composição do material particulado Fonte: Brook, (2008)

O MPı é considerado a fração inalável das partículas por ser suficientemente pequeno para entrar nas vias aéreas, já o MP2,5 pode se depositar nas vias aéreas inferiores e alvéolos conforme visto anteriormente (BAIRD, 2002; WHO, 2005).

Essas frações de material particulado diferem em sua contribuição para a massa total de partículas do ar, origem, características físicas e composição química (WHO, 2005b).

Embora tenha havido declínio nos níveis de concentração do MP, eles ainda são considerados elevados, quando se consideram seus efeitos à saúde da população. De acordo com a CETESB, em 2011 foram emitidas 6.057 toneladas na atmosfera no Estado de São 
Paulo. O segmento de caminhões pesados se destaca pela grande participação nas emissões de MP, causadas tanto pelos fatores de emissão como pela maior intensidade de uso desses veículos, como é demonstrado no Gráfico 22.

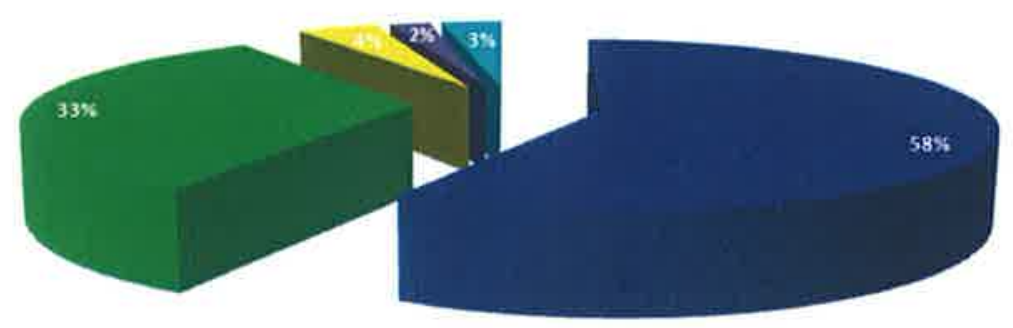

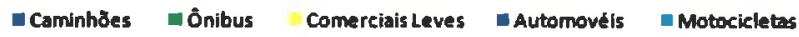

Gráfico 22 - Contribuição das categorias de veículos na emissão de material particulado no Estado de São Paulo em 2011

Fonte: CETESB, (2011)

No inverno, a ocorrência mais frequente de inversões térmicas e o ventos fracos na superfície produzem condições desfavoráveis à dispersão de poluentes como o $\mathrm{MP}, \mathrm{CO}$ e $\mathrm{SO} 2$ (CETESB, 2011). No Gráfico 23, observa-se um aumento das concentrações de MP10 nesse período, com máximas em junho, julho e agosto.

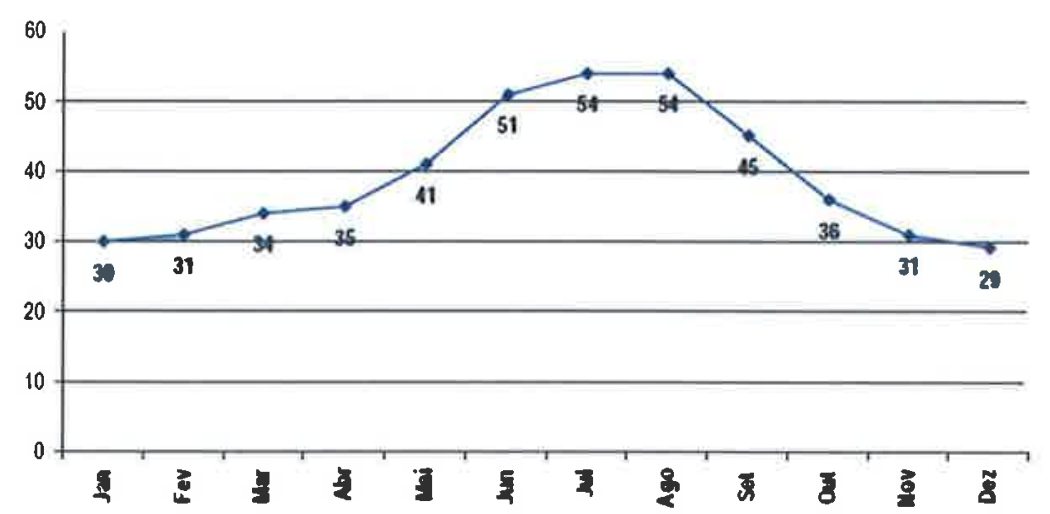

Gráfico 23 - Concentrações médias mensais (2005-2010) de MPı $\left(\mu \mathrm{g} / \mathrm{m}^{3}\right)$ das estações da RMSP

Fonte: Adaptado de CETESB (2011) 


\subsubsection{Dióxido de Enxofre ( $\left.\mathrm{SO}_{2}\right)$}

O dióxido de enxofre, conhecido como anidrido sulfuroso, é um composto químico constituído por dois átomos de oxigénio e um de enxofre, cuja fórmula quimica é SO2. É um gás denso, incolor, não-inflamável e altamente tóxico e a sua inalação pode ser fortemente irritante. Resulta, principalmente, da queima de combustíveis que contém enxofre, como óleo diesel, óleo combustível industrial e gasolina, sendo um dos principais formadores da chuva ácida. Ainda, pode reagir com outras subastâncias presentes no ar, formando partículas de sulfato, que são responsáveis pela redução da visibilidade na atmsofera (CETESB,2011).

Quando a concentração desse poluente é alta, há um aumento no número de internações hospitalares e mortalidade para doenças cardiorrespiratórias (WHO,2006).

Em Londres, em 1952, cerca de 4.000 mortes em relação à média de óbitos ocorreu após exposição à elevadas concentrações de dióxido de enxofre $\left(\mathrm{SO}_{2}\right)$ e particulados em suspensão durante episódio de inversão térmica que impediu a dispersão dos poluentes (AMDUR et al., 1991; MAZUMDAR et al., 1982; WHO, 1979, apud ATSDR, 1998).

As evidências disponíveis sugerem que o excesso de mortalidade pode ocorrer a concentrações de dióxido de enxofre maior ou igual a $500 \mu \mathrm{g} / \mathrm{m} 3(0,2 \mathrm{ppm}$, média de concentração - 24 horas) em combinação com elevado nível de concentração de material particulado. A elevação da mortalidade foi atribuída à bronquite e a outros problemas respiratórios, tendo ocorrido principalmente entre idosos e indivíduos com condições cardiacas ou respiratórias pré-existentes (WHO, 1979 apud ATSDR, 1998).

Elevada mortalidade por doença cardiovascular também tem sido relatada. No município de São Paulo, Sharovsky (2004) encontrou associação significativa entre infarto agudo do miocárdio e concentração atmosférica de $\mathrm{SO}$, aumentando-se o risco deste agravo em 3,4\% para cada elevação de $10 \mu \mathrm{g} / \mathrm{m} 3$. De acordo, com Gouveia et al. (2006), ocorre associação significativa entre o incremento de $10 \mu \mathrm{g} / \mathrm{m} 3$ de $\mathrm{SO}_{2}$ e o risco de internação de idosos e crianças em São Paulo por doenças respiratórias e cardiovasculares.

Em função disso, foram implementadas medidas efetivas de controle sobre as emissões de $\mathrm{SO}_{2}$, e atualmente, todas as áreas atendem o padrão de qualidade do ar, respeitando a rigorosa aplicação da legislação existente, além da monitoração contínua das emissões (CETESB, 2011).

Conforme a CETESB, em 2011 foram emitidas 8.889 toneladas métricas na atmosfera no Estado de São Paulo. O Gráfico 24 traz a contribuição das categorias de veículos na emissão de dióxido de enxofre no Estado de São Paulo. 


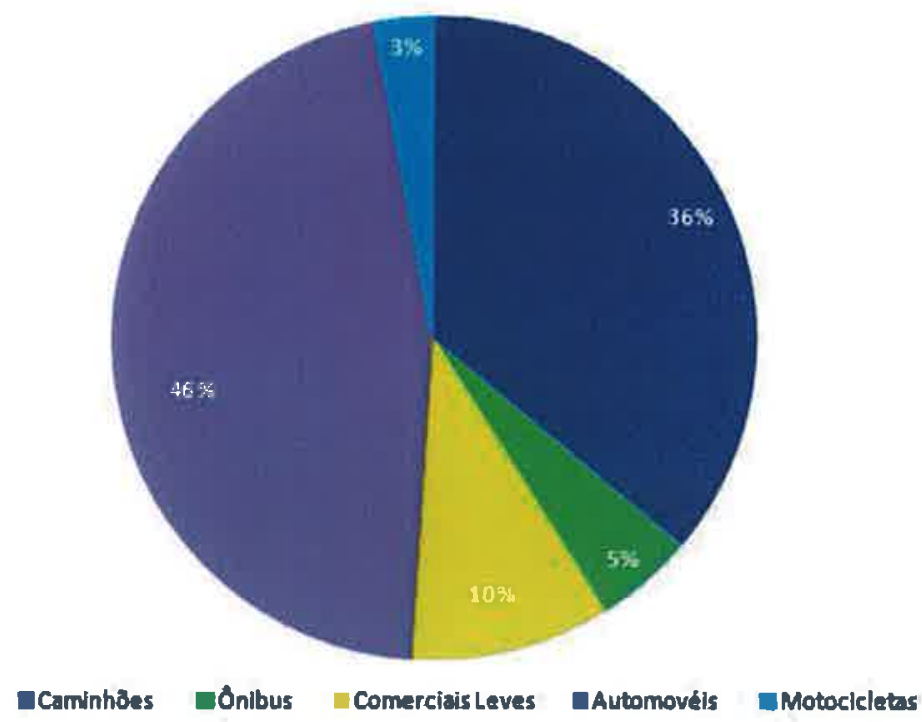

Gráfico 24 - Contribuição das categorias de veículos na emissão de $\mathrm{SO}$, Estado de São Paulo em 2011

Fonte: CETESB, (2011)

\subsection{4 Óxidos de Nitrogênio (NOx)}

Estão inclusos no grupo dos óxidos de nitrogênio: o dióxido de nitrogênio (NO2), o óxido nítrico (NO), o ácido nítrico (NHOs) e os nitratos (CASTRO et al., 2003), que são gases altamente reativos, compostos por Nitrogênio $(\mathrm{N})$ e Oxigênio $(\mathrm{O})$. Em quantidades variadas, também são formados pela reação de gás oxigênio $\left(\mathrm{O}_{2}\right)$ e gás nitrogênio $(\mathrm{N} 2)$ presentes no ar, sob condições de alta temperatura e elevada pressão. Juntamente aos hidrocarbonetos (HC) e aldeídos (RCHO), também são precursores na formação de O3 (BRASL, 2011).

Esses gases formam-se a partir da combustão da gasolina, carbono e petróleo (CASTRO et al., 2003), portanto, a principal fonte desse poluente é o tráfego veicular, servindo, frequentemente, de estimativa para avaliar todos os poluentes gerados por fontes móveis (BRUNEKREEF; HOLGATE, 2002).

No Brasil, $88 \%$ dos óxidos de nitrogênio emitidos pelo modal rodoviário correspondem aos veículos a diesel, enquanto $8 \%$, aos veículos movidos à gasolina. Cabe informar que houve um crescimento das emissões entre 1985 e 1998, atingindo um pico de 
1,2 milhões de toneladas no final dos anos 90, resultante do crescimento da frota veicular, principalmente dos veículos movidos a diesel. No início do ano 2000 , verificou-se uma redução (MMA, 2011).

No entanto, níveis altos de NO2, combinado com partículas ultrafinas e outros oxidantes, tornaram-se adversidades, contribuindo para a elevação da poluição atmosférica em áreas urbanas.

A intensidade de seus efeitos depende dos tipos de poluentes emitidos e das condições climáticas locais para a dispersão dos mesmos. Os principais tipos de problemas ambientais locais associados às mudanças climáticas são os atmosféricos denominados smogs. Ambos podem ocorrer simultânea ou separadamente, sendo difícil distinguir qual é predominante. (BRAGA, B. et AL, 2005)

Os principais gases originários da queima incompleta de combustíveis fósseis como os óxidos de nitrogênio, o monóxido de carbono $(\mathrm{CO})$ e os hidrocarbonetos são um dos principais componentes da mistura de poluentes denominada smog fotoquímico que é característico em dias quentes e secos, com elevada emissão de gases por veículos. É muito comum nas grandes cidades, como São Paulo, cidade do México e Los Angeles, onde a frota de veículos é elevada, com fluxo intenso, resultando em congestionamentos. Estes elementos reagem na atmosfera sob a ação da radiação solar, formando novos poluentes como óxidos de nitrogênio, ozônio e aldeídos. Este smog é caracterizado por uma cor avermelhada ou marrom.

O NO2 é objeto de transformações atmosféricas, que levam à formação de oxidantes resultantes na composição do $\mathrm{NHO}_{3}$ e $\mathrm{SO}_{2}$ gerando $\mathrm{H}_{2} \mathrm{SO}_{4}$. Reações fotoquímicas levam à ativação de novos poluentes, que são fontes de partículas orgânicas, nitratos e sulfatos, componentes do material particulado MP10 e MP2,5.

No ambiente, os óxidos de nitrogênio encontram-se no formato gasoso, assim, a rota de exposição para os seres humanos é a inalação. Nesse contexto, o $\mathrm{NO}_{2}$ é um radical livre que tem o potencial de exaurir a defesa dos tecidos e, como resultado, causar lesões e inflamações. A exposição em longo prazo deste poluente pode desencadear sintomas de bronquite em crianças asmáticas (WHO, 2005).

Há uma correlação entre poluentes gasosos, como os óxidos de nitrogênio, e o aumento no número de internações hospitalares, consultas médicas e encaminhamentos de emergência para doença isquêmica do coração, infarto do miocárdio e angina (MAITRE et al., 2006). Nesse sentido, Roselund et al. (2008) indicou o risco para eventos coronarianos, por aumento de $10 \mu \mathrm{g} / \mathrm{m} 3$ de $\mathrm{NO}_{2}$. 
Conforme a CETESB, em 2011 foram emitidas 237.395 toneladas de NOx no Estado de São Paulo. O Gráfico 25 traz a contribuição das categorias de veículos na emissão de dióxido de enxofre no Estado de São Paulo. Não houve variação significativa nas emissões de NOx no período, mesmo com o aumento importante da frota de veículos pesados, fonte principal desse poluente. Ainda que a evolução tecnológica deva impactar positivamente, nos casos dos veículos pesados, o ganho demora a ser percebido. A frota de veículos pesados tem idade média maior, conforme observado anteriormente, demora mais a ser sucateada e a redução mais significativa do fator de emissão do NOx será obtida com o advento da Fase P7 do PROCONVE, comercializada a partir de 2012.

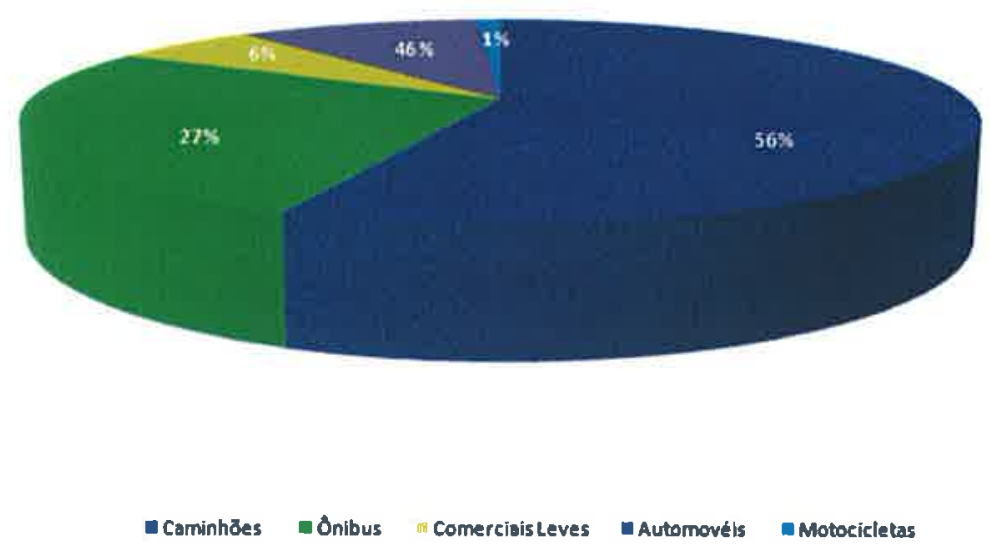

Gráfico 25 - Contribuição das categorias de veículos na emissão de óxidos de nitrogênio no Estado de São Paulo em 2011

Fonte: CETESB, (2011)

\subsubsection{Monóxido de Carbono (CO)}

Corresponde à um gás tóxico, inodoro, incolor e fruto da combustão incompleta do Carbono (C) contido em combustível (CASTRO et al., 2003). No Brasil, as emissões de CO são oriundas dos veículos leves em uma projeção de 90\%. A partir de 1991, houve uma redução significativa passando de cerca de 5,6 milhões de toneladas emitidas para 1,9 milhões em 2009. Isso ocorreu devido à implantação de programas de melhoria no fator de emissão de motores (MMA, 2011).

Os efeitos maléficos do CO são sentidos por pessoas sadias, e de maneira mais acentuada, por cardiopatas, idosos e crianças. Dentre os efeitos do CO no organismo humano podemos citar: problemas de visão, redução da capacidade cognitiva, redução da destreza manual, dificuldade de realizar tarefas complexas, problemas respiratórios e até a morte (CASTRO et al., 2003). 
Conforme a CETESB, em 2011 foram emitidas 355.933 toneladas de CO no Estado de São Paulo. O Gráfico 26 expõe a contribuição das categorias de veículos na emissão de monóxido de carbono no Estado de São Paulo

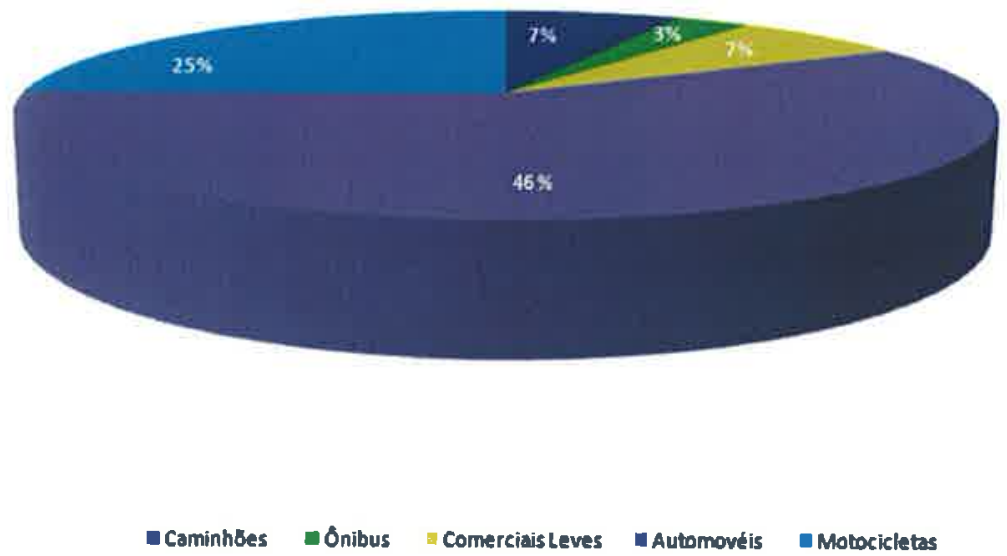

Gráfico 26 - Contribuição das categorias de veículos na emissão de monóxido de carbono no Estado de São Paulo em 2011

Fonte: CETESB, (2011)

\subsubsection{Emissão de Gases de Efeito Estufa}

Os problemas ambientais globais são aqueles que exigem uma ação conjunta de todas as nações para buscar soluções que eliminem seus impactos. Nesta escala, os problemas mais graves enfrentados atualmente pela humanidade são o aquecimento global, a depleção da camada de ozônio estratosférico e as emissões resultantes da utilização de combustíveis fósseis. Nesses casos, as ações antrópicas estão causando alterações profundas no equilíbrio dos sistemas naturais da Terra, afetando o balanço energético do planeta e a proteção contra os raios ultravioleta emitidos pelo sol, respectivamente. No primeiro caso, os efeitos são percebidos por alterações no sistema climático do planeta e perturbações em todos os seus subsistemas. Já no caso da camada de ozônio, os monitoramentos da estratosfera indicam a presença de buracos que apresentam riscos iminentes para a saúde dos organismos vivos.

Denomina-se efeito estufa, o processo de acúmulo de gases e nuvens na atmosfera, reduzindo a reflexão de calor da superfície da Terra para o espaço exterior, o que aumenta a temperatura média do planeta (Ribeiro et al, 2000). Este processo é causado pela energia solar incidente sobre o planeta sob a forma de radiação infravermelha, que é naturalmente refletida 
em parte pelas nuvens, atmosfera e superfície da Terra. A parte não refletida é absorvida pela superfície da Terra, aquecendo-a. O calor irradiado pela Terra é parcialmente absorvido pelos gases do efeito estufa (GEE), resultando num aquecimento da atmosfera e da superfície da Terra.

A camada da atmosfera conhecida como Troposfera, que vai do nível do mar até uma faixa de 10 a $16 \mathrm{~km}$ de altitude, concentra os fenômenos meteorológicos e os principais gases envolvidos no efeito estufa, e que também existem naturalmente. São eles o $\mathrm{CO}_{2}, \circ \mathrm{CH}_{4}$, o $\mathrm{N}_{2} \mathrm{O}$ e o $\mathrm{O}_{3}$. A camada seguinte da atmosfera é a Estratosfera, que vai até $50 \mathrm{Km}$ de altitude e onde fica a camada de ozônio. Nesta altitude, a temperatura média é de $56^{\circ} \mathrm{C}$ negativos e a reação do $\mathrm{O}_{2}$ com a radiação ultravioleta gera oxigênio molecular e oxigênio livre que formam o ozônio, quando combinado com $\mathrm{O}_{2}$, conforme pode ser visto na Figura 48.

O CO2 é emitido pela queima direta do diesel, o combustível mais utilizado para os transportes de carga. Os gases de efeito estufa não necessariamente são classificados como poluentes, visto que em alguns casos fazem parte de processos naturais, como é o caso do vapor de água e do dióxido de carbono.

O setor de transportes é, entre as fontes de emissão de gases de efeito estufa, o que cresce mais rapidamente (MATTOS, 2001). No que diz respeito à emissão de gases que contribuem para o efeito estufa, cada modo de transporte de carga tem a sua intensidade e representatividade.

As soluções para mitigação dos efeitos do aquecimento global dependem primordialmente de uma ação política coordenada mundialmente para implementar projetos em todos os âmbitos, reduzindo as emissões de gases do efeito estufa.

Além da eficiência energética, o tema da poluição atmosférica e dos respectivos impactos causados, seja referente aos Gases de Efeito de Estufa (GEE) ou a outros poluentes, é frequentemente um tema central na agenda política de vários países e objeto de debate em inúmeras conferências mundiais. Como tal, apesar da relação direta entre o consumo de combustível no veículo e a emissão de dióxido de carbono $\left(\mathrm{CO}_{2}\right)$, estão também estabelecidas metas de redução das emissões deste gás, que vão limitar a sua libertação em $130 \mathrm{~g} / \mathrm{km}$, para os veículos produzidos em 2015, e em $95 \mathrm{~g} / \mathrm{km}$ para os produzidos em 2020 na União Europeia (PARLAMENTO E CONSELHO EUROPEU, 2009a). 


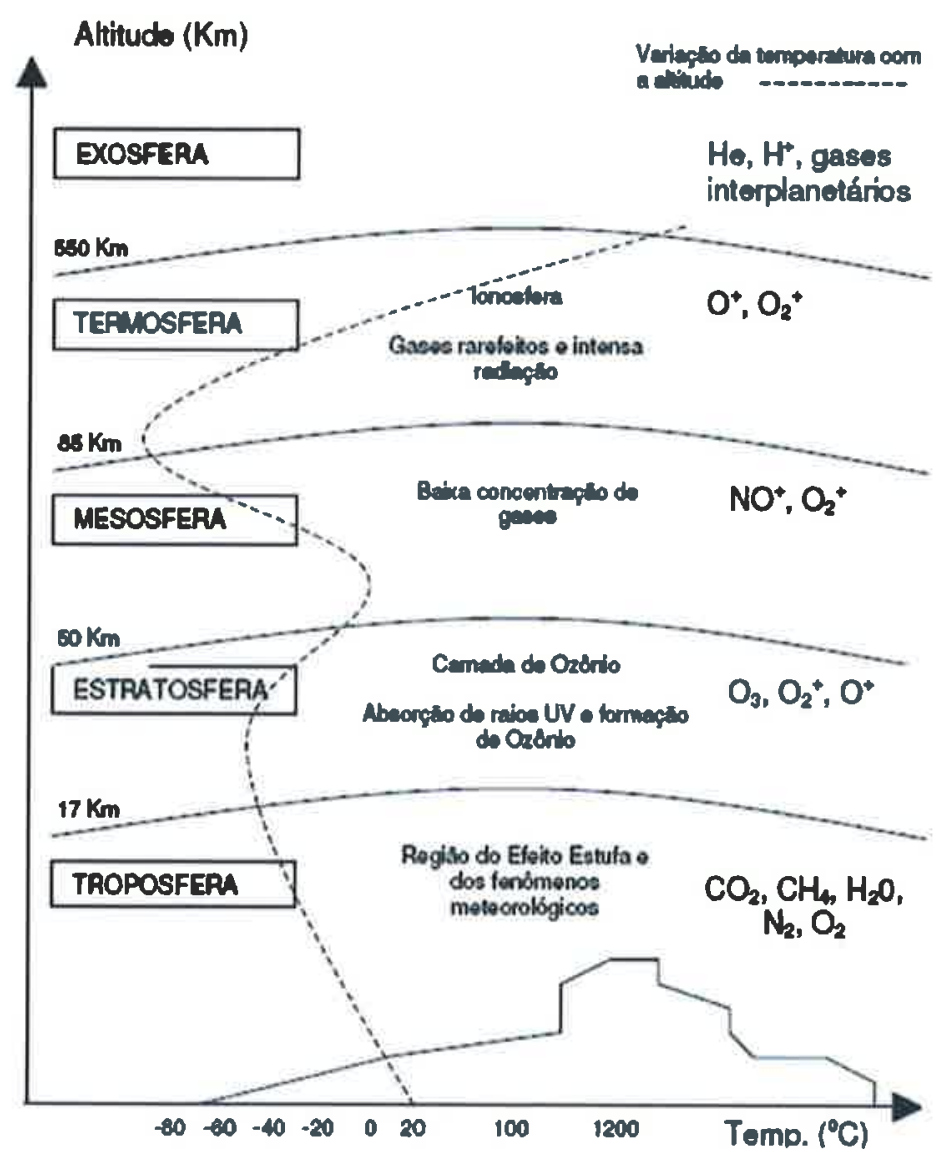

Figura 48 - Camada da Atmosfera

Fonte: RIBEIRO, S.K., et al, (2000)

Conforme a CETESB, em 2011 foram emitidas 51.360 mil toneladas de $\mathrm{CO}_{2}$ no Estado de São Paulo. O Gráfico 27 expõe a contribuição das categorias de veículos na emissão de $\mathrm{CO}_{2}$ no Estado de São Paulo.

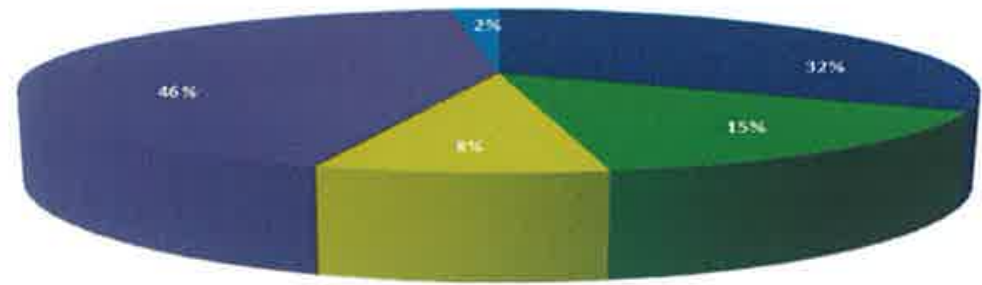

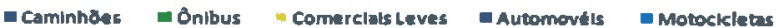

Gráfico 27- Contribuição das categorias de veículos na emissão de $\mathrm{CO}_{2}$ no Estado de São Paulo em 2011

Fonte: CETESB, (2011) 
Com relação aos veículos elétricos movidos à bateria, as emissões de $\mathrm{CO} 2$ associadas ao seu uso são relacionadas com o processo de geração de energia elétrica. Ou seja, em outras palavras, as emissões diretas dos veículos elétricos são nulas. Isso quer dizer que, desconsiderando as emissões dos processos de fabricação dos produtos que compõem o veículo, as emissões ao longo da cadeia da utilização dos veículos elétricos dependerá da fonte de energia utilizada para a geração de energia elétrica. Cumpre mencionar que as emissões ao longo da cadeia considerando a produção de energia elétrica por fontes renováveis são nulas.

No caso dos veículos híbridos plug-in, como há o motor de combustão interna, a emissão direta do veículo dependerá da forma de gerenciamento de energia empregada. No caso de uma direção focada mais no modo depleção de carga (CD), a fonte de energia principal será a energia elétrica e as emissões estarão associadas ao processo de geração de energia elétrica, de forma similar ao veículo movido à bateria. No caso da utilização do modo sustentação de carga (CS), a fonte de energia será o combustível líquido. Assumindo que os veículos híbridos plug-in cheguem ao Brasil com motores flexíveis, a emissão de $\mathrm{CO} 2$ também será em função da relação álcool etílico/gasolina utilizada na hora do abastecimento.

Para melhor entendimento, são calculadas as emissões dos respectivos veículos elétricos utilizando o WTW (Well to Wheel), nome de uma metodologia que foi desenvolvida especificamente para analisar os impactos ambientais do setor dos transportes, podendo ser aplicada a qualquer produto ou serviço sob diferentes formas de geração de energia elétrica. Admite-se como exemplo, o desempenho energético dos veículos elétricos movidos à bateria de $5 \mathrm{~km} / \mathrm{kWh}$, e $8 \mathrm{~km} / \mathrm{kWh}$, dos veículos híbridos plug-in, desconsiderando as perdas nos sistemas de transmissão e distribuição, assim como as perdas nos carregadores como pode ser visto no Gráfico 28.

Nesta simulação são apresentadas as emissões diretas dos veículos convencionais movidos à combustão rodando a gasolina. Uma particularidade deste ponto é a maior emissão dos veículos a gasolina comparativamente com veículos flex. De acordo com Rodrigues (2012), isto pode ser explicado pela amostra realizada pela CETESB (2011), onde o grupo dos veículos flex-fuel inclui veículos de categorias mais econômicas, como sub-compactos, compactos e médios, enquanto que nas versões a gasolina, prevalecem veículos de maior porte. 


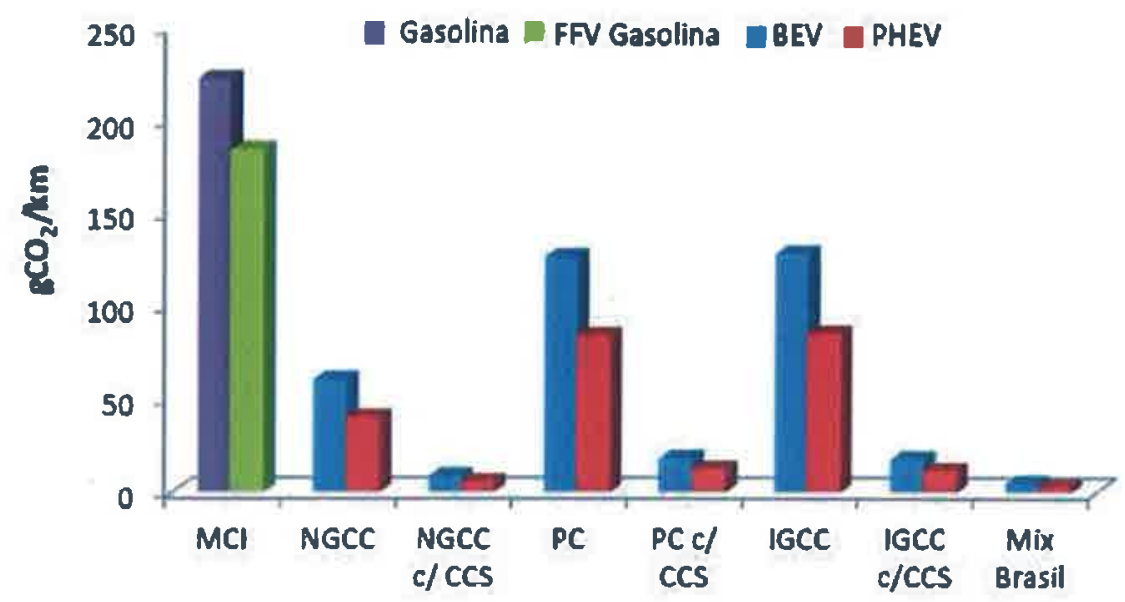

Gráfico 28- Emissão associada aos veículos elétricos movidos a bateria Fonte: Adaptado de Rubin et al. (2007); MCTI (2012); CETESB (2009)

Nota: MCI - Motor de Combustão Interna; NGCC - Natural Gas Combined Cycle; PC - Pulverized Coal; IGCC - Integrated Gasification Combined Cycle; CCS - Carbon Capture and Storage; FFV Flex-Fuel Vehicle. Mix Brasil representa a emissão considerando o fator médio de emissão do grid brasileiro (margem operativa); PHEVs em operação no modo CD (depleção de carga), ou seja, consumindo apenas eletricidade.

No caso apontado acima, não são consideradas as emissões ao longo da cadeia de produção dos combustíveis líquidos, que em seu uso final, contribuem com aproximadamente $85 \%$ das emissões totais da cadeia. Este valor é baseado em IEA (2004), onde as emissões veiculares representam de $84 \%$ a $88 \%$ das emissões totais. Cabe enfatizar que estes valores de emissão no uso final são da gasolina. Se levar em conta que todo o carbono emitido pelo álcool etílico anidro (misturado na proporção de $20 \%$ a $25 \%$ em volume na gasolina) é reabsorvido durante a fotossíntese no cultivo da biomassa (cana-de-açúcar), este valor tenderia a sofrer uma ligeira redução. Este, inclusive, é o motivo de não ser apresentada a emissão derivada do uso de álcool etílico hidratado nos veículos flex-fuel ( MACEDO et al. 2004)

Admitindo o pior cenário (para as plantas IGCC e de carvão pulverizado), as emissões de $\mathrm{CO}_{2}$ pelos veículos, considerando toda a cadeia de produção, ficam na ordem de 130 $\mathrm{gCO}_{2} / \mathrm{km}$, inferior ao valor de $223 \mathrm{gCO} 2 / \mathrm{km}$ para os veículos leves novos a gasolina, e 185 $\mathrm{gCO}_{2} / \mathrm{km}$, para os veículos leves novos flex-fuel rodando a gasolina, no Brasil, no ano de 2009 (CETESB, 2010). Levando-se em conta a estrutura atual da produção de energia elétrica no país, as emissões dos veículos movidos a bateria caem para valores abaixo de $5 \mathrm{gCO} / \mathrm{km}$. Tal fato se deve à baixa emissão do sistema interligado brasileiro na sua operação, que em 2011, foi da ordem de 0,029 tCO2/MWh, como apresentado no Tabela 21. 
Tabela 21 - Fator de Emissão Médio ( $\left.\mathrm{tCO}_{2} / \mathrm{MWh}\right)$ do Grid Brasileiro

\begin{tabular}{|c|c|c|c|}
\hline Ano & 2011 & 2010 & 2009 \\
\hline Janeiro & 0,026 & 0,021 & 0,028 \\
\hline Fevereiro & 0,029 & 0,028 & 0,024 \\
\hline Março & 0,021 & 0,024 & 0,025 \\
\hline Abril & 0,020 & 0,024 & 0,025 \\
\hline Maio & 0,027 & 0,034 & 0,041 \\
\hline Junho & 0,034 & 0,051 & 0,037 \\
\hline Julho & 0,031 & 0,044 & 0,024 \\
\hline Agosto & 0,030 & 0,077 & 0,020 \\
\hline Setembro & 0,027 & 0,091 & 0,016 \\
\hline Outubro & 0,035 & 0,082 & 0,018 \\
\hline Novembro & 0,036 & 0,087 & 0,018 \\
\hline Dezembro & 0,035 & 0,053 & 0,019 \\
\hline Média Nacional & $\mathbf{0 , 0 2 9}$ & 0,051 & $\mathbf{0 , 0 2 5}$ \\
\hline
\end{tabular}

Fonte: MCTI, (2012)

Vale ressaltar, que a análise WTW avalia os impactos, nomeadamente em termos de consumo de energia e emissões atmosféricas, desde a produção dos combustíveis fósseis utilizados até a utilização do veículo em si. Esta pode também ser subdividida em Well-toTank (WTT) ou também Well-to-Pump (WTP), que corresponde ao ciclo do combustível até ao momento em que o automóvel é abastecido/carregado, e em Tank-to-Wheel (TTW) ou Pum-to-Wheel (PTW), que se refere ao ciclo de utilização, em que a energia armazenada é efetivamente utilizada para a propulsão do automóvel. Por vezes, a análise WTW é acoplada a uma análise Cradle-to-Grave (CTG) que inclui os impactos relativos ao ciclo de vida dos materiais utilizados no veículo.

Nesse sentido, o modelo designado por "Greenhouse gases, Regulated Emissions, and Energy use in Transportation" ou mais conhecido por GREET, é um modelo desenvolvido pelo Argonne National Laboratoy. Este modelo permite avaliar vários veículos e combinações de combustível, numa análise WTP ou numa WTW, como traz a Figura 49. 
Well to Wheel

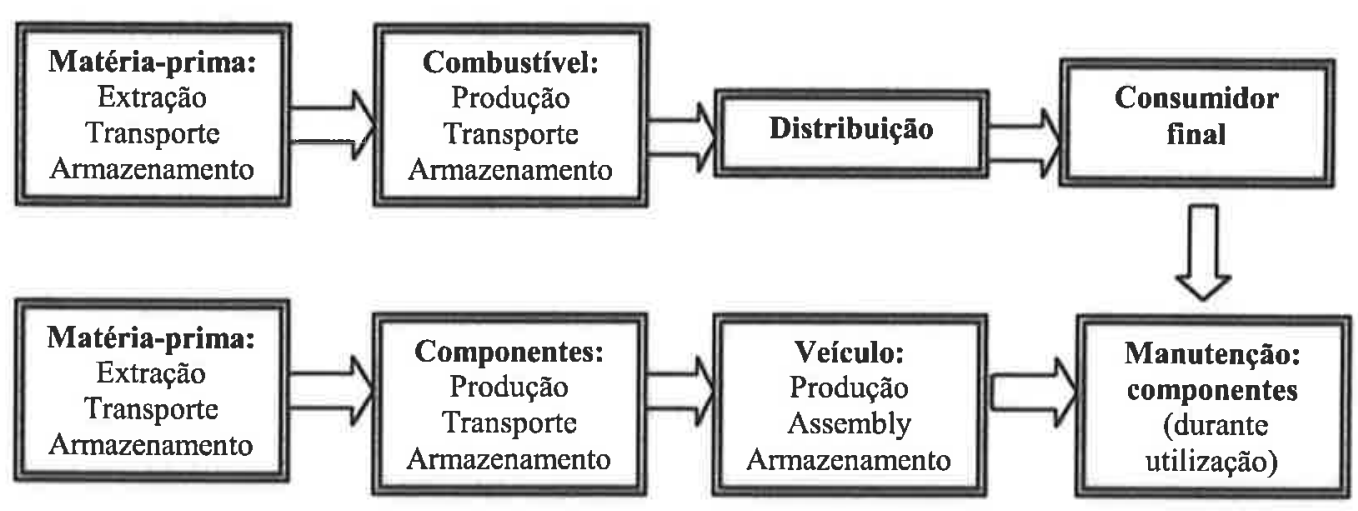

Cradle to Grave

Figura 49 - Representação da análise de ciclo de vida efetuada pelo GREET ("Greenhouse gases, Regulated Emissions, and Energy use in Transportation")

Fonte: Adaptado de Argonne National Laboratory, Transportation Technology R\&D Center, 2010

\subsection{Poluição Sonora}

Poluição sonora é o termo utilizado para designar o elevado nível de ruído ambiental e constitui, hoje um dos grandes problemas ambientais. Diferentemente de outros agentes poluentes, afeta principalmente o homem, é capaz de produzir desde incômodo ao bem-estar até danos irreversíveis à saúde. Os ruídos liberados pelos transportes por meio do funcionamento dos motores, vibração de peças, atrito das rodas com a via e sinais sonoros são exemplos de como os transportes contribuem para esse tipo de poluição.

Os sons são caracterizados pela frequência medida em hertz $(\mathrm{Hz})$ e intensidade (nível de pressão sonora), expressa em decibéis $(\mathrm{dB})$. Em conversasão coloquial, a intensidade da fala oscila entre 40 e $60 \mathrm{~dB}$ e os ruídos de fundo, quando acima de $35 \mathrm{~dB}$, interferem na inteligibilidade da fala (MENEZES, P.L;TEIXEIRA, 2005). A Tabela 22 traz situações na qual, as pessoas permanecem expostas aos sons ambientais. 
Tabela 22 - Intensidade dos sons

\begin{tabular}{|lr|}
\hline \multicolumn{2}{|c|}{ Intensidade dos sons ambientais em dB } \\
\hline Ruas de movimento & 70 \\
\hline Caminhão & 80 \\
\hline Buzinas de carro & 110 \\
\hline Motocicleta, carro de corrida & 120 \\
\hline
\end{tabular}

Fonte: Adaptado de Pereira, (2010)

O ruído não se acumula no meio ambiente como outros tipos de poluição, mas pode ter efeito cumulativo sobre o homem, se houver exposição contínua a níveis elevados de ruídos (NUDELMANN, COSTA, SELIGMAN, 2001). Existe um limite de tolerância para a exposição ao ruído: a medida que o nível de intensidade aumenta, diminui o tempo permissível de exposição conforme apresentado na Tabela 23.

Tabela 23 - Limites de tolerância para ruído contínuo ou intermitente

\begin{tabular}{|c|}
\hline Nível de ruído dB (A) \\
\hline 85 \\
\hline 90 \\
\hline 95 \\
\hline 100 \\
\hline 105 \\
\hline 112 \\
\hline 115 \\
\hline
\end{tabular}

Fonte: Legislação trabalhista, (2010)

A poluição sonora pode causar efeitos auditivos e extra-auditivos (PEREIRA, 2010):

- Efeitos auditivos: dor (algiacusia), zumbido, sensação de orelha tampada, comunicação prejudicada em ambientes ruidosos e perda de audição;

- Efeitos extra-auditivos: incômodo, insônia, fadiga pelo distúrbio do sono, estresse, depressão, agressividade, dificuldade de concentração, queda de rendimento escolar, dificuldade de comunicação, dores de cabeça, aumento da pressão arterial, cansaço e perdas de atenção e de memória, de produtividade no trabalho e de bem-estar psicológico. A perda auditiva pode ser temporária ou permanente. A temporária ocorre após a exposição ao ruído elevado, mas 
que, uma vez cessado, há a recuperação completa da audição em horas. A perda auditiva permanente pode ser súbita ou progressiva. A súbita ou por trauma acústico ocorre por uma única exposição a um ruído extremamente intenso.

O ruído é considerado nocivo no ambiente de trabalho desde 1979. A partir do Decreto $\mathrm{n}^{\circ} 611 / 92$, que regulamenta a Lei $\mathrm{n}^{\circ} 8213 / 91$, o ruído passou a ser tido como agente causador de doença profissional.

\subsection{Síntese Conclusiva}

Ao mesmo tempo em que os padrões do consumidor mudam e as transformações na área de tecnologia causam profundas mudanças em vários segmentos, também cresce a pressão da comunidade e de grupos ligados ao meio ambiente, no intuito de minimizar os impactos negativos das atividades de carga, cada vez mais intensas. Mais e mais, as comunidades locais têm demandado ações nesse sentido. Todavia, a despeito desses impactos negativos, o transporte de carga tem uma significante contribuição à vitalidade da economia das cidades e, por conseguinte, das regiões em que se inserem. Assim, o grande desafio para este século reside na superação do paradoxo carga versus sustentabilidade, com a oferta de meios de transportes que tenham abrangências cada vez maiores e, ao mesmo tempo, reduzam seus impactos ambientais, sociais e econômicos dentro de um contexto em que a provisão de capacidade adicional de carga se tornará ainda mais cara e difícil. Ou, em outras palavras, como afirmam Holguín-Veras e Thorson (2001), o transporte de cargas terá que fazer mais (cada vez mais) com menos (POTTER, 2002). A Tabela 24 sintetiza a afirmação acima. 
Tabela 24 - Impactos do transporte de carga na sustentabilidade

\begin{tabular}{|c|c|c|}
\hline Econômico & Social & Ambiental \\
\hline Congestionamento de tráfego & Mobilidade & Poluição do ar, água e solos \\
Barreiras na mobilidade & Impactos na saúde & Poluição sonora \\
Acidentes & Qualidade de Vida & Poluição visual \\
Infraestrutura & & \\
Custo & & \\
Depleção dos recursos naturais & & \\
\hline
\end{tabular}

Fonte: Adaptado do MMA, (2010)

Em contrapartida, dentro das políticas adotadas, os níveis de emissões referentes ao setor de transporte no Brasil são administrados pelo Proconve que, há cerca de duas décadas, tem trazido melhorias ambientais. Entretanto, ainda existem graves problemas relacionados à poluição atmosférica, principalmente, em áreas urbanizadas no Brasil.

No entanto, a indústria automobilística teve que enquadrar-se diante das novas regras impostas. A Fase 6 (P6) do Proconve, prevista para entrar em vigor em 2009, não entrou em vigor na data prevista. Especialistas do setor automobilístico afirmam que a Resolução 315/02 só determinou o limite máximo de poluente e não especificou o combustível. Somente em 2007, a ANP regulamentou os limites de enxofre para o óleo diesel.

Entretanto, segundo a Lei $\mathrm{n}^{\circ} 8.723$, de 1993, os órgãos responsáveis pela política energética e controle são obrigados a fornecer combustíveis comerciais, a partir da data de implantação dos limites fixados por esta lei e de referência para testes de homologação, certificação e desenvolvimento, com antecedência mínima de trinta e seis meses do início de sua comercialização. Ou seja, o combustível deveria estar disponível para testes a patir de 2006, anteriormente à especificação do combustível realizada pela ANP, em 2007. Houve uma grande defasagem entre a publicação da Resolução CONAMA, em 2002, e a regulamentação do diesel pela ANP, em 2007. A especificação do combustível deveria ter sido realizada no início, paralela à Resolução do CONAMA, em 2002.

A indústria automobilística alegou que não houve tempo para cumprir o prazo, porque a definição das especificações do óleo diesel foi feita no final de 2007 e os veículos modelo 2009 são comercializados a partir do segundo semestre de 2008 , portanto, o tempo não foi suficiente (VENTURA, 2009). 
Entretanto, toda esta dificuldade, na ocasião, levou ao Termo de Ajustamento de Conduta - TAC, celebrado entre MPF, estado de São Paulo, IBAMA, ANP, Petrobrás, Fabricantes de Veículos, Fabricantes de Motores e CETESB, com o objetivo de estabelecer as obrigações de cada parte com relação às emissões atmosféricas que seriam evitadas com a comercialização de motores e de veículos leves comerciais e pesados a óleo diesel adequados aos limites estabelecidos na Resolução CONAMA 315/2002.

Decorrente do TAC, o Instituto de Energia e Meio Ambiente fez um inventário sobre qual foi o impacto ambiental do não cumprimento da resolução $\mathrm{n}^{\circ} 315$. O prejuízo ambiental é de 51 mil toneladas no período de 2009 a 2040, quanto ao material particulado. Já com relação ao NOx, o prejuízo ambiental previsto é de 155 mil toneladas no período de 2009 a 2013, e o ganho ambiental de 9 milhões de toneladas no período de 2014 a 2040.

Para se compensar o prejuízo ambiental, foi instituída a substituição gradual a partir de 2009, por diesel S1800 (combustíveis com teor de enxofre, máximo, de $1800 \mathrm{mg} / \mathrm{Kg}$, ou seja, $1800 \mathrm{ppm}$ ) até 2014. E em especial ao diesel metropolitano, deverá passar de 500 a 50 ppm de enxofre, para frotas de ônibus urbanos. A mitigação também deverá incluir programas de avaliação e de regulagem gratuita para frotas de veículos a diesel, patrocínio do programa de fiscalização da fumaça preta da CETESB no estado de São Paulo, entre outros.

Para compensar o atraso na entrada em vigor da Fase 6, o CONAMA promulgou a Fase 7 (P7), para entrar em vigor a partir de janeiro de 2012, e a Resolução $n^{\circ}$ 415/2009 (L6), a partir de 01 de janeiro de 2013, com maiores restrições.

Para a implementação da Fase 7 nos motores diesel, além das mudanças no combustível, serão necessárias modificações na tecnologia a fim de receber este combustível e respeitar os padrões de emissão impostos pela regulamentação.

As tecnologias atuais, implementadas para corresponder a Fase 5 do CONAMA, o foco é na injeção de alta pressão controlada eletronicamente. Já para a Fase 7, a tecnologia terá foco em sistemas de pró-tratamento como Filtro de Material Particulado, do inglês Diesel Particulate Filter (DPF), em conjunto com o Sistema de Recirculação dos Gases de Escape, do inglês, Exhaust Gas Recirculation (EGR) ou Catalisadores de Redução Seletiva com uso de uréia, do inglês, Seletive Catalytic Reduction (SCR), o ARLA 32 - Agente Redutor Líquido Automotivo. A combinação entre as tecnologias será determinada pelo fabricante.

A necessidade de utilização de uréia nos motores traz um novo desafio com relação à distribuição deste produto (logística), preço e oferta.

Os postos de combustível deverão ter um novo tanque para a venda da uréia. Além disso, acredita-se em um problema de oferta e demanda deste produto, já que no Brasil 
existem somente dois produtoes, a Vale Fertilizantes e a Petrobrás. Com a possibilidade de aumento da demanda existe a possibilidade de importação deste produto. Tendo em vista estas dificuldades, o IBAMA assinou, em outubro de 2010, um Termo de Cooperação Técnica com o INMETRO (Instituto Nacional de Metrologia, Normalização e Qualidade Industrial) a fim de regulamentar a produção, comercialização e uso do ARLA 32, acompanhar a fiscalização e emitir o selo INMETRO/IBAMA.

Visando que todas as novas adaptações no motor e no combustível sejam cumpridas, o Artigo $2^{\circ}$ da Resolução 403/08 estabelece que a obrigatoriedade de incorporação de dispositivosou sistemas para autodiagnose (OBD), das funções de gerenciamento do motor que influência sobre as emissões de poluentes do ar, dotados de indicadores de falhas ao motorista e de recursos que reduzam a potência do motor em caso de falhas que persistam por mais de dois dias consecutivos, para todos os veículos pesados. Um dos objetivos deste sistema chamado de OBD, do inglês, on board diagnostic, é gerenciar o sistema a fim de evitar a emissão de poluentes como por exemplo, por falta de uréia.

Uma das críticas enfrentadas por este novo sistema será a necessidade de uma logística diferenciada para caminhões com diferentes anos de fabricação. Os postos de gasolina, por exemplo, terão que ter pelo menos duas bombas de diesel, uma com diesel de 500ppm (P5) e outra com o diesel de 10 ppm (P7), já que espera-se que os preços destes dois produtos sejam diferentes, além da bomba de uréia. Além disso, os veículos novos, com a tecnologia desenvolvida para atender a P7 e o diesel com menor teor de enxofre deve custar cerca de 15 a $20 \%$ mais (VENTURA, 2009). Diante disso, o motor diesel adaptado para operar com etanol, mesmo possuindo preço superior aos motores atuais, que aceitam diesel com alto teor de enxofre, apresentam uma vantagem competitiva em relação aos novos motores que atendem a P7.

Entretanto, não se pode deixar de considerar os benefícios ambientais e de saúde pública pertinentes a estas modificações, que nunca são contabilizados. Segundo estudo realizado pelo Conselho Regional de Aucklander na Nova Zelândia (do inglês, Aucklander Regional Council - ARC) (2007), em áreas urbanas as emissões dos veículos diesel levaram a concentrações muito elevadas de monóxido de carbono e dióxido de nitrogênio, além de material particulado que, segundo o estudo, é o pior poluente para a saúde humana, já que o MP permanece em suspensão por até 40 dias. O impacto na saúde do MP é tão significativo em relação a todos os outros poluentes que normalmente só eles são considerados nos efeitos na saúde e nos custos associados à poluição atmosférica. No entanto, os impactos à saúde provocadaos pelo dióxido de nitrogênio também são importantes, especialmente para os 
asmáticos. Segundo o estudo, estima-se que morrem prematuramente 400 pessoas/ano na região de Aucklander devido à poluição do ar. A má qualidade do ar na região foi responsável por mais de 750 mil dias por ano de paralisação nas atividades de trabalho, escola, etc. A poluição do ar tem o maior efeito sobre os jovens e idosos e pessoas com doenças cardíacas, doenças respiratórias, asma e bronquite. Os custos associados com a poluição na região de Auckland são estimados em NZ\$1.3 bilhão por ano (cerca de R\$1,8 bilhão por ano).

Nos Estados Unidos, pesquisas estimam que mais de 60.000 pessoas morrem prematuramente, a cada ano, devido à exposição ao material particulado. As emissões de partículas finas dos motores diesel podem conter mais de 40 poluentes, já enumerados pela EPA, sendo que 15 já foram elencados pela Agência Internacional de Pesquisa sobre o Cancêr (da sigla, em inglês, International Agency for Research on Cancer - IARC). Além dos já relatados efeitos associados com doenças respiratórias, cardiovasculares e morte entre outros.

Como dito anteriormente, pode-se relacionar diferentes efeitos adversos da poluição do ar sobre a saúde humana, alguns deles manifestando-se de forma aguda (horas ou dias após a exposição), enquanto outros são evidenciados somente após longos períodos de exposição (os chamados efeitos crônicos). A Sociedade Americana de Cardiologia (2004) (American Hearth Association) publicou documento reconhecendo a poluição atmosférica como um dos fatores de risco para o agravamento de doenças cardiovasculares, infarto agudo do miocárdio, insuficiência cardíaca e desenvolvimento de arritmias.

Tanto os efeitos agudos como os crônicos podem exibir diferentes níveis de gravidade, abrangendo uma gama de efeitos que oscilam do desconforto vago até a morte. Como exemplo, pode-se destacar que com o aumento da poluição do ar, uma grande fração da população apresentará alterações conhecidas ou irritabilidades não específicas. Uma menor proporção dos indivíduos expostos apresentará um aumento de marcadores plasmáticos e pulmonares de inflamação, indicando a presença de inflamação subclínica. Em uma proporção menor, esta inflamação poderá acarretar alterações funcionais, como aumento de pressão arterial, distúrbio do controle autonômico do coração ou queda de indicadores de função pulmonar.

Em um nível de gravidade maior, indivíduos que utilizam medicação cronicamente para o controle de doenças respiratórias e cardíacas (asma e hipertensão arterial, por exemplo), necessitarão maior quantidade de medicamento para controlar a sua doença. Haverá aqueles que procurarão o médico para consultas ou, nos casos mais graves, serão internados em pronto-socorros ou hospitais. Finalmente, uma parte dos afetados morrerá no dia ou em 
poucos dias após, em virtude dos efeitos da poluição a que foram expostos (SALDIVA et al, 2009).

As condições sócio-econômicas também são parte da suscetibilidade do indivíduo aos poluentes. $\mathrm{O}$ acesso a saúde/cuidados hospitalares e acesso à medicação é uma condição considerada, além da maior exposição aos poluentes. Condições de saúde precárias, falta de saneamento, má nutrição, falta de acesso aos serviços médicos e aos medicamentos, além de maior contato com os poluentes por meio de processos industriais menos desenvolvidos, tecnologias menos desnvolvidas, combustíveis com maior concentração de contaminantes são realidades de países mais pobres. Consequentemente, essa população está mais sujeita aos efeitos nocivos da poluição. Vale lembrar que esses efeitos são válidos para alguns países e para algumas sociedades (SALDIVA et al., 2009).

Além da estimativa de redução de mortes e internações, existe a necessidade de estimar os custos de saúde pública relacionados aos efeitos de degradação do meio-ambiente.

A valoração econômica de recursos naturais é baseada em princípios da economia neoclássica e tem como proposta atribuir valores monetários para as perdas sociais e ambientais decorrentes da degradação do meio-ambiente. Assim, a idéia da valoração busca tratar os custos e benefícios sociais prestados pelo meio-ambiente como agente econômico (Pearce, 1987).

Segundo Saldiva et al. (2009),

"A forma mais preciosa de mensurar o impacto da poluição do ar de uma determinada região é a condução de estudos epidemiológicos, estabelecendo funções dose-resposta, que correlacionam indicadores de ar ambiente. Diversos métodos têm sido utilizados em vários estudos para valorar os custos de saúde associados com a poluição ambiental. Esses métodos podem ser agrupados em duas categorias. A primeira inclui os métodos que medem apenas a perda da renda direta (salários perdidos e despesas adicionais) ou método dos gastos defensivos. Essas medidas não incluem as inconveniências, sofrimentos, perdas de lazer e outros impactos não tangíveis aos indivíduos e bem-estar familiar e podem subestimar ou ignorar seriamente os custos de saúde de pessoas que não são membros do mercado de trabalho. Dessa maneira, essa categoria de métodos indica apenas o nível inferior dos custos sociais da poluição e subdimensiona os custos totais para os individuos. A segunda categoria de métodos inclui abordagens que tentam capturar a disposição dos indivíduos a pagar para evitar ou reduzir os riscos de morte ou doenças, ou método da valoração de contingente." 
A Tabela 25, indica as mortes potenciais totais anuais a serem evitadas mediante a penetração de veículos elétricos movidos à bateria. Isso resulta, em uma redução significativa na emissão de material particulado fino através da substituição de veículos movidos a diesel por veículos elétricos movidos à bateria segundo a respectiva valoração dos custos de mortalidade evitados. A valoração das mortes evitadas foi obtida através dos valores médios de anos de vida perdidos devido a concentrações no ambiente de poluentes atmosféricos em São Paulo aplicados aos cenários de potencial de redução de mortalidade com as taxas atuais de expectativa de vida da população, a partir de dados do Instituto Brasileiro de Geografia e Estatísticas (IBGE) (SOUZA,MACEDO, 2010).

A estimativa de mortabilidade considera apenas os custos associados às internações hospitalares para as doenças e faixas etárias da população mais consistentemente associadas à poluição atmosférica, quais sejam, as internações por doenças respiratórias para as faixas etárias de crianças até quatro anos e adultos acima de 40 anos, e por doenças cardiovasculares apenas para a faixa etária de adultos acima de 40 anos. Assim, essa estimativa pode ser considerada conservadora ao não incluir outros desfechos menos frequentes e as demais faixas etárias, mas enquadra-se ao critério habitualmente utilizado nesse tipo de estimativa.

Tabela 25 - Potencial anual de variação da mortalidade mediante cenários de penetração de veículos elétricos na Região Metropolitana de São Paulo e respectiva valoração econômica

\begin{tabular}{|c|c|c|}
\hline \multirow{2}{*}{$\begin{array}{c}\text { \% de Substituição de diesel por veículos } \\
\text { elétricos à bateria }\end{array}$} & \multicolumn{2}{|c|}{ Mortalidade Anual } \\
\cline { 2 - 3 } & Quantidade & U\$ milhão \\
\hline 100 & 745 & 133,6 \\
\hline 50 & 373 & 66,89 \\
\hline 15 & 112 & 20,08 \\
\hline 10 & 75 & 13,45 \\
\hline 5 & 37 & 6,63 \\
\hline
\end{tabular}

Fonte: Adaptada de Souza, Macedo (2010)

O agravamento da poluição atmosférica, seja recente ou antigo, alimentado por combustíveis, que têm sua qualidade diferenciada dependendo do país ou da região, requer soluções com o mesmo grau de sofisticação tecnológica utilizadas nos países desenvolvidos, caso contrário permanecem os efeitos da contaminação gerada pela aglomeração exagerada da população e do tráfego de veículos (BRANCO, 2006); 
Este capítulo tem por finalidade apresentar o método desenvolvido na pesquisa para a utilização dos veículos elétricos urbanos de carga. Pretendese descrever os passos utilizados para inserção dos postos de recarga no estado de São Paulo vislumbrando minimizar os impactos decorrentes com a distribuição de mercadorias. A abordagem será direcionada aos centros urbanos, os quais têm apresentado dificuldades nessa distribuição com o aumento da circulação de mercadorias

\section{ESTAÇÕES DE CARREGAMENTO UTILIZADAS PARA OS VEÍCULOS ELÉTRICOS: UM ESTUDO METODOLÓGICO}

\subsection{Algumas Considerações}

Muitas das questões envolvendo a problemática dos transportes já foram discutidas em capítulos anteriores. Esta parte do capítulo tem por objetivo discutir mais profundamente o método utilizado para colocação de uma estação de carregamento em uma área geográfica no estado de São Paulo. A utilização de veículos elétricos urbanos de carga torna-se uma possível solução para os problemas gerados, pelo transporte de carga principalmente, em centros urbanos.

O World Business Council for Sustainable Development (WBCSD), com a colaboração de pesquisadores do MIT e da Charles River Associates, identifica as ameaças mais importantes à continuidade de sua sustentabilidade, apontando, ao final, sete grandes desafios para o alcance da mobilidade sustentável. São eles:

Permitir que os atuais sistemas de transporte continuem exercendo seu papel no desenvolvimento econômico oferecendo a mobilidade necessária e aumentando a qualidade de vida;

$>$ Adaptar o veículo motorizado particular à futuras necessidades e exigências (em termos de capacidade, desempenho, emissões);

$>$ Reinventar o conceito de transporte coletivo (para que funcione como uma alternativa aos que já possuem um automóvel);

$>$ Reinventar o processo de planejamento, desenvolvimento e de gestão da infraestrutura da mobilidade;

Reduzir as emissões de carbono no setor de transportes por meio da mudança de combustíveis e da utilização de veículos elétricos. 
Cada cidade tem sua peculiaridade de expansão e desenvolvimento, cultura e desejos. Qualquer adaptação de tecnologia deverá observar esses aspectos individuais. Só assim, a mobilidade e sua sustentabilidade poderão se dar de forma a atender a todos e a contento.

No entanto, se pode perceber que restrições impostas, em muitos casos, geram outro tipo de problema. Por exemplo, se o uso do caminhão é permitido em determinadas zonas e em certas janelas de tempo, não sendo suficientes, dada a alta e crescente concorrência do mercado consumidor, caminhões menores (VUC - Veículo Urbano de Carga) são introduzidos e, com o aumento na quantidade de carros para essa "substituição", a poluição e os transtornos também aumentam. Dado o aumento da frequência e a diminuição da carga, observa-se, muitas vezes, apenas a subutilização dos veículos.

$\mathrm{Na}$ cidade de São Paulo foram adotadas pela sua administração, medidas como "Entrega Noturna" de mercadorias que tinha como objetivo alterar a rotina de abastecimento da cidade, apesar dos acréscimos nos custos decorrentes de encargos trabalhistas, permitia um aumento de produtividade de até $50 \%$ por veículo, o que cobre, com folga, custos e permite uma redução no preço final do frete (CET 2011).

Porém, essa medida de entrega noturna (ou em horários entre picos) não foi bem recebida pelo cliente final, pois este tem sempre que disponibilizar pessoal para o recebimento da mesma. $\mathrm{O}$ uso de operadores logísticos diminui essa problemática, já que poderá ter acesso direto à empresa, ou seja, a relação de confiança (e o contrato) entre as partes faz com que se tenha o acesso livre às instalações. Para o Brasil, vale ressaltar a questão do aumento da violência urbana, o que pode piorar ainda mais a receptividade da medida (CET 2011).

Outra medida adotada recentemente foi em torno da Zona de Máxima Restrição de Circulação. Os caminhões médios e grandes não poderão circular no minianel viário formado pela marginal Tietê e outras nove vias, da cidade de São Paulo (SP), conforme a Figura 50. Alguns veículos são isentos dessa zona de restrição, segundo a Companhia de Engenharia de Tráfego CET (2011): os Veículos Urbanos de Carga (VUCs), os caminhões de até 6,3 metros de comprimento, caminhões de urgência, socorro mecânico de emergência, cobertura jornalística, obras e serviços de emergência, correios e sinalização de trânsito emergencial estão liberados. De acordo com a CET (2011), a implantação dessas restrições também visa diminuir o número de ocorrências envolvendo caminhões, principalmente nos horários de pico. 


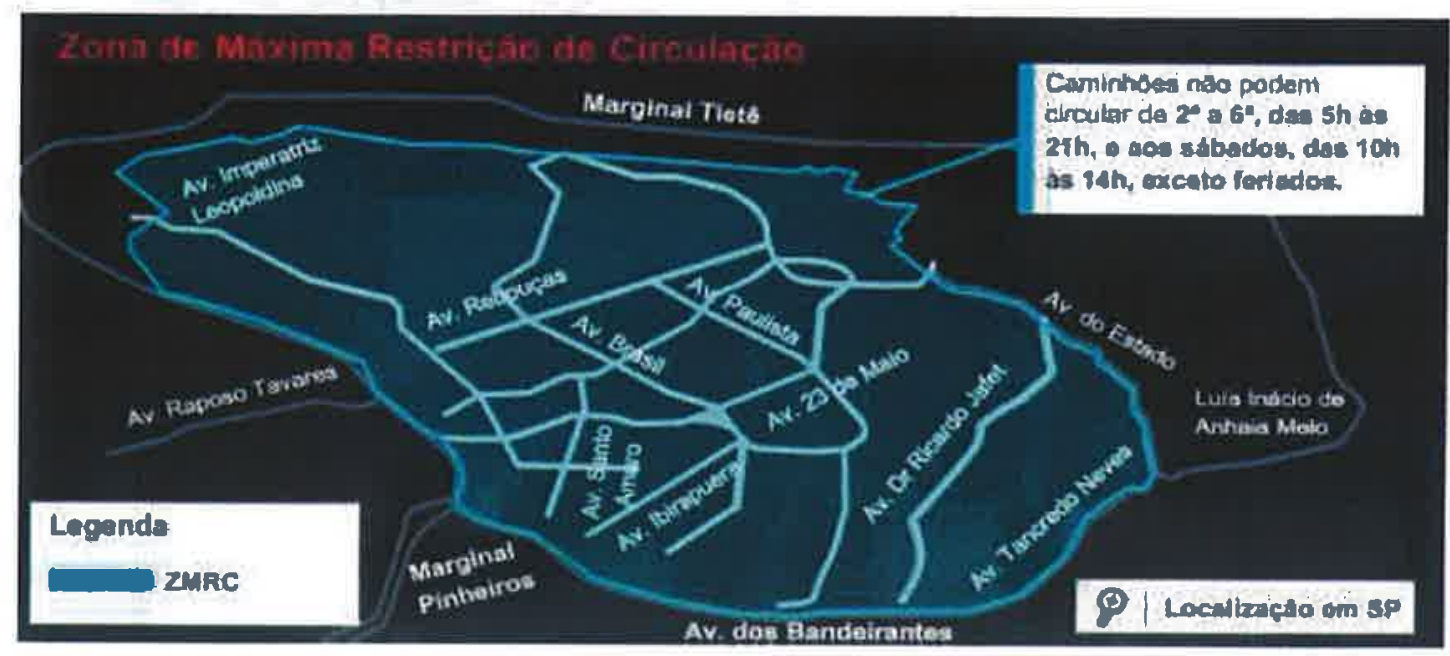

Figura 50 - Vias atingidas pela restrição à circulação de caminhões em São Paulo Fonte: CET, (2011)

O objetivo do presente estudo é desenvolver uma metodologia analítica para efetivamente planejar as alocações ideais das estações de carregamento, considerando intrinsecamente a escolha da rota feita pelo usuário e a distribuição de energia elétrica. $O$ primordial é visar o custo de viagem incluindo o tempo de carga a ser minimizada e a demanda de energia elétrica para cada estação dando o subsídio para utilização dos veículos elétricos.

Entretanto, é valido salientar que o tempo gasto para efetuar o carregamento em comparação aos veículos movidos a diesel é bem maior. Dessa forma, a logística de inserção desses postos de recarga em uma área geográfica será o ponto cerne para utilização desses veículos. Koyanagi et al. reforça que raramente discuti-se sobre a infra-estrutura elétrica utilizada para alocar postos de recarga.

\subsection{Desenvolvimento da Metodologia para Análise dos Atributos Utilizados para Localização das Estações de Carregamentos.}

Modelos de simulação-otimização caracterizam-se por ter em sua composição elementos básicos de modelos de otimização, como uma função-objetivo a ser maximizada/minimizada, e elementos de problemas de simulação, como a existência de variáveis estocásticas. A combinação de modelos de otimização e simulação em uma única ferramenta pode ser feita de diversas formas, o que limita a definição de um modelo otimização-simulação apenas ao fato de que são utilizados elementos de ambos os tipos de modelo. Furuta et. al. (2007) descreve uma metodologia para alocação dos postos de 
recarga, focada no setor comercial de acordo com o comportamento do usuário-cliente. Como parâmetro, é visualizado o poder de compra de determinado cliente e os locais de venda. Já Berman (1997), expõe uma solução de acordo com o fluxo de viagens realizadas pelo próprio usuário como o ir e vir às compras, entre outros, tendo a consciência de possíveis alterações de trajeto. Há vários estudos, sobre a metodologia ideal para alocação dos postos aplicando uma abordagem de programação matemática, onde desenvolve-se um modelo de otimização incluindo meta-heurística. métodos como algoritmos genéticos e redes neurais (PARASHAR, 2006). Grande parcela desses métodos minimiza a distância até o destino final e o custo, tais como o valor pago quanto o tempo de espera.

Nesse estudo, serão consideradas as seguintes questões, tendo como base as características do veículo elétrico e o planejamento para adequação do posto:

- O tamanho da área geográfica tendo como especificação o número de atividades diárias que o usuário faz durante o dia;

- O número de estações de recarga que será instalado tendo como critério o desempenho (números de carregadores e taxas de carga);

- A localização da estação de recarga poderá ser calculada utilizando o tráfego como algoritmo de atribuição atentando à escolha feita pelo usuário através da rota de origem e o destino escolhido;

- O custo relacionado à rota de origem e destino consiste no tempo de viagem e do tempo de espera em uma determinada estação de carregamento. A localização da estação de carregamento é escolhida minimizando o custo e mantendo uma certa distância a cada estação de carga.

\subsection{Desenvolvimento de Rotas de Estação de Carregamentos}

Nesta seção faremos um breve resumo sobre as funcionalidades do veículo elétrico e da estação de carregamento. Propriamente, o veículo elétrico utiliza a energia armazenada oriunda da bateria em proporção à distância pretendida. Os usuários podem carregar seus veículos elétricos em suas residências, em lugares públicos, em escritórios, centros comerciais e assim por diante. Para efetuar o carregamento do veículo é necessário que o indicador de combustivel para a bateria conhecido como Estado de Carga (SOC) tenha diminuído a sua capacidade. Se for preciso carregar o veículo durante o trajeto traçado, a rota será alterada. 
Portanto, relacionam-se 3 comportamentos que podem ocorrer durante o trajeto realizado pelo usuário. A Figura 51 confirma o apontamento acima.

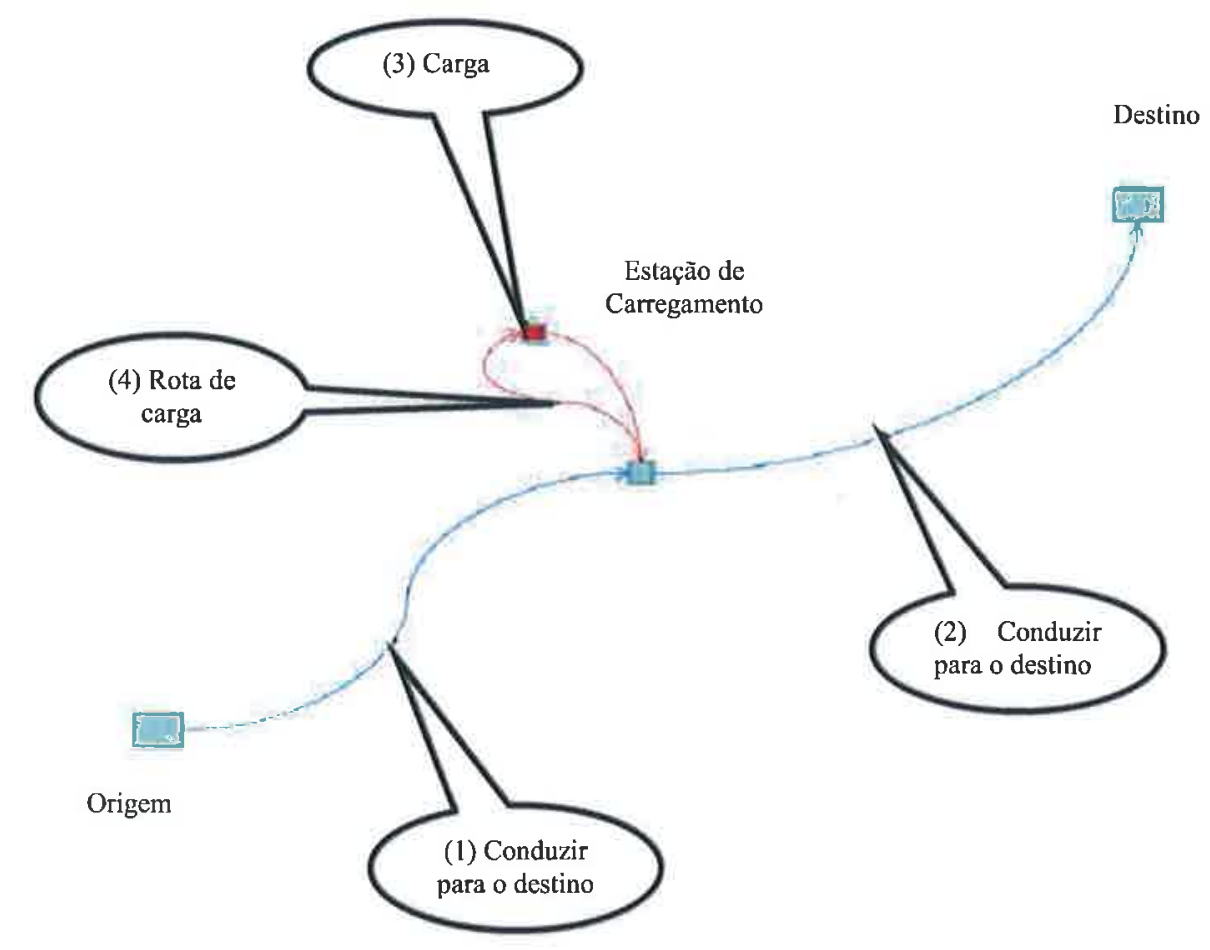

Figura 51 - Comportamento da origem para o destino

Fonte: Adaptado de Larsson, 2010)

Ao observar a Figura 51 deve-se atentar para o tempo de espera na estação de carregamento. O primeiro passo para modelar um processo dinâmico é definir o conjunto de estados que pode alcançar e descrever os mecanismos que governam suas transições. Um estado é como um snapshot (foto instantânea) do sistema em um tempo determinado. É uma abstração da realidade que descreve os atributos de um sistema que interessa. O tempo é uma medida linear através da qual o sistema se movimenta e pode ser visto como um parâmetro. Usualmente se sabe qual foi a trajetória que o sistema tomou para chegar ao estado atual. Com isso, o objetivo é antecipar o futuro comportamento do sistema em termos básicos de um conjunto de atributos. Aqui são mostradas uma série de técnicas teóricas disponíveis para este propósito.

Em muitas situações práticas, os atributos de um sistema mudam de forma aleatória com o tempo, como por exemplo: o número de clientes numa fila de espera, o congestionamento no trânsito, o número de itens num depósito ou o valor de uma ação financeira, entre outras. Em algumas circunstâncias, é possível descrever os fundamentos do 
processo que explica como a mudança ocorre. Quando as características do processo são governadas pela teoria da probabilidade, se tem um processo estocástico.

Um modelo de um processo estocástico descreve atividades que terminam em eventos. Os eventos geram a transição de um estado a outro. Assumindo que a duração de uma atividade é uma variável aleatória contínua, eventos ocorrem na continuidade do tempo.

A Teoria das Filas é um setor da Pesquisa Operacional que utiliza conceitos básicos de processos estocásticos e de matemática aplicada para analisar o fenômeno de formação de filas $\mathrm{e}$ suas características. Permite estimar importantes medidas de desempenho de um sistema a partir de propriedades mensuráveis das filas. Dessa forma, pode-se dimensionar um determinado sistema segundo a demanda dos seus clientes, evitando desperdícios ou gargalos. Foi desenvolvida com a finalidade de prever o comportamento das filas de modo a permitir o dimensionamento adequado de instalações, equipamentos e sua infra-estrutura. Pode ser utilizada para modelar sistemas onde:

- Clientes chegam para serem atendidos;

- Esperam sua vez de serem atendidos;

- São atendidos e vão embora.

É necessário deixar claro que os modelos nem sempre conseguem representar as situações reais com grande precisão. Muitas vezes, as premissas necessárias ao desenvolvimento matemático dos modelos envolvem simplificações substanciais. Mesmo assim, há vantagem $\mathrm{em}$ desenvolver tais modelos, principalmente por que eles levam a um melhor entendimento das principais condicionantes do processo.

Segundo Sampaio (2008) um sistema é definido pela teoria das filas como uma combinação onde vários clientes esperam por um serviço que poderá ser prestado por um ou vários servidores de processamento dos clientes na fila.

No entanto, uma fila é caracterizada por um processo de chegadas (pessoas, veículos, trens) a um sistema de atendimento formado por uma ou mais unidades de serviço. As unidades podem ser atendidas individualmente (pedágio, porto), ou em grupos (pessoas num elevador, veículos num semáforo.

A Teoria das Filas busca, através de análises detalhadas, encontrar um ponto de equilíbrio entre o que o cliente deseja e o que é economicamente viável para a empresa. Segundo Hillier e Lieberman (2007), a teoria das filas é "o estudo da espera em todas essas formas diversas. Ela usa modelos de filas para representar os diversos tipos de filas que surgem na prática". Ou seja, os modelos de filas são úteis para definir a forma mais eficiente de operar em um sistema de filas. 
De acordo com Marinho (2006), o modelo conhecido como "Markovian/Markovian/single model" (modelo $\mathrm{M} / \mathrm{M} / \mathrm{s}$ ) é clássico e o mais simples disponível na literatura. O modelo recebe esse nome porque assume uma distribuição Markoviana dos intervalos de chegada, que são distribuídos de forma exponencial independente e identicamente distribuída (i.i.d). A distribuição dos tempos de internação segue outro processo Markoviano e outra distribuição exponencial também i.i.d. Em um modelo mais geral, o número de pontos de atendimento ou "servidores" é um inteiro positivo qualquer.

Por existir variações nos tempos de serviço, dentro do contexto apresentado, a abordagem matemática a ser utilizada neste estudo será o custo mínimo de um sistema de filas de espera $\mathrm{M} / \mathrm{M} / 1$ onde será analisado a relação intrínseca entre a capacidade elétrica da estação de carregamento e a demanda elétrica por parte do usuário que deseja carregar o seu veículo.

\subsubsection{Formulação do Modelo}

Matematicamente, $\boldsymbol{e}_{2}^{x}$ indica a taxa referente ao abastecimento (carga) sendo $\mathrm{g}$, o carregador em uma dada estação x. Já a taxa da capacidade elétrica na estação de carregamento é representada por unidade de tempo h . $\boldsymbol{E}_{\mathbf{x}^{*}}^{\text {sh }}$, forma a seguinte equação, 2010 .

$$
E_{x}^{\mathrm{xh}}=\sum_{g \in G_{s}} e_{g}^{\mathrm{xh}}
$$

Onde, $G_{x}$ indica o conjunto de carregadores (carga) em uma dada estação x. Por outro lado, a demanda elétrica também pode ser formulada de acordo com as características do próprio veículo elétrico como traz a Figura 52. Supõe-se, que é cobrada a energia utilizada no destino escolhido pelo usuário de um veículo elétrico ou na própria estação de carregamento. Se, $d_{k}^{z}$ nex: $n$ denota a distância para o destino ou para a próxima estação de carregamento $x^{n=x t}$ ao longo do percurso $K, f_{k}^{s h}$ simboliza o número de veículos elétricos em uma determinada estação de carregamento $\mathrm{x}$ ao longo do percurso $\mathrm{K}$. $\mathrm{O}$ consumo de energia elétrica por unidade de distância segue representada por $S$ que indica a eficiência do combustível. A taxa de demanda de energia elétrica de um veiculo elétrico para uma estação de carregamento x segue representada $E_{z}^{d h}$, por unidade de tempo h o que matematicamente pode ser representado pela expressão: 


$$
E_{x}^{d h}=\sum_{k \in K_{x}} \frac{d_{k}^{x+1 h} f_{k}^{x h}}{S}
$$

Para as equações (6.1) e (6.2), o tempo médio de espera definido como $\mathrm{h}$ poderá ser denominado como o custo da operação realizada pelo veículo elétrico. (Consideremos a $\lambda_{x}$ taxa de chegada para denominada demanda elétrica de $\left.E_{x}^{d h}\right)$. Já, $\mu_{x}$ é a taxa de serviço para a capacidade elétrica de $\varepsilon_{x}^{s \hbar}$. A utilização $\rho_{x}$ encontra-se na seguinte equação:

$$
\rho_{x}=\frac{\lambda_{x}}{\mu_{x}}=\frac{E_{x}^{d h}}{E_{x}^{s h}}
$$

Deste modo, o tempo de espera na estação de carregamento $\mathrm{x}$ poderá ser encontrada utilizando a equação (3). Partindo do pressuposto, que entre o tempo de espera é acrescido o tempo de penalidade em uma situação, quando $\rho_{z} \geq 1$, se o tempo de espera calculado for maior ou igual a unidade de tempo definida por $\mathrm{h}$. A equação do tempo de espera $T_{w}^{x}$ por unidade de tempo h é formulada alterando a interpretação da teoria $\mathrm{M} / \mathrm{M} / 1$ como:

$$
T_{w}^{x}=\left\{\begin{array}{l}
\frac{\rho_{x}}{\left(1-\rho_{x}\right)} \mu_{x} \\
\rho_{h}
\end{array} \quad \rho_{x}<1, \frac{\rho_{x}}{\left(1-\rho_{x}\right)} \mu_{x}<h\right.
$$

Finalmente, o custo médio para o tempo de espera na estação de carregamento $\mathrm{x} t_{x}^{\text {wait }}$ incluindo o tempo de carga, segue representado abaixo:

$$
t_{x}^{\text {wait }}=T_{w}^{x}+1 / \mu_{x}
$$




\subsection{Otimização do Método de Localização para Estação de Carregamento}

Neste item será demonstrada a metodologia utilizada, atrelada ao planejamento de localização de uma determinada estação de carregamento. Basicamente, diz-se que o condutor de um veículo elétrico apresenta tem 3 comportamentos como aponta a Figura 52. Do ponto de vista do condutor, é importante que o custo para o destino tal, imbuído ao tempo de viagem, sejam minimizados. Por outro lado, a partir do ponto de vista do administrador, ele pode dizer que a demanda elétrica das infra-estruturas para o condutor deve ser controlada para não ter viés de demanda para cada região. Portanto, é possível construir duas hipóteses. Presumimos que os objetivos do método de localização sejam:

1. O custo para uma viagem (da origem ao destino) que está incluído o tempo de espera do carregamento da bateria na estação de recarga deve ser minimizado (Objetivo 1);

2. O viés da demanda de energia elétrica para cada estação de carregamento deve ser minimizada (Objetivo 2).

O objetivo 1 depende da rota da origem ao destino e do tempo de espera do carregamento da bateria. Especialmente, o tempo de carregamento da bateria é desfavorável comparado ao tempo de espera para o abastecimento de um motor movido à diesel. Assim, diz-se que a minimização do tempo de espera de carga é um fator primordial para a solução. $O$ objeto de cálculo são os próprios veículos elétricos necessários para a efetivação do processo de carregamento em uma estação "x".

No objetivo 2 se muitas estações de carregamento estão localizadas em uma área, por exemplo, a demanda de energia elétrica de cada estação poderá ser baixa. No entanto, as estações de carga em outras áreas, são necessárias para lidar com a alta demanda. Deste ponto de vista, a localização da estação de carregamento deve ser considerada para se obter a igualdade de oportunidades de carregamento para os utilizadores de veículos elétricos para equalizar a demanda elétrica do carregamento de uma bateria. No presente estudo, o problema de localização consiste em dois métodos que serão apresentadas seguir. 


\subsubsection{Método para o Objetivo 1}

Aqui, vamos $C_{k}^{r s}$ considerar o custo da rota $\mathrm{K}$ no conjunto do percurso incluindo o par origem e destino (OD) $\left(k_{n}\right)$. Se $f_{k}^{n}$ corresponde o caminho do fluxo de rota $\mathrm{k}$ no conjunto de percurso $\boldsymbol{k}_{\boldsymbol{n}}$. A solução objetivo 1 é formulada usando o total de custos dos veículos elétricos. $Z$ segue representado da seguinte forma:

$$
\begin{aligned}
& \text { Minimizar Z }=\sum_{k \in x_{m}} c_{k}^{n} f_{l}^{n s} \\
& \text { Sujeito a } \quad=\sum_{B} \sum_{k} \delta_{a, k}^{A} f_{k}^{n} \quad a \in A \\
& \sum_{k} f_{A}^{\prime \prime}-Q_{B}=0 \quad r s \in \Omega \\
& f_{k}^{n} \geq 0 \quad k \in K_{r s}, r s \in \Omega
\end{aligned}
$$

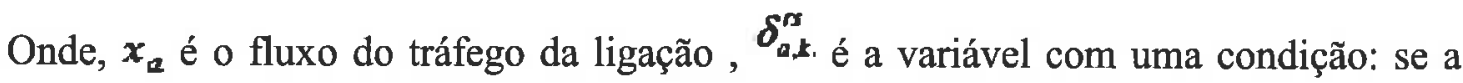

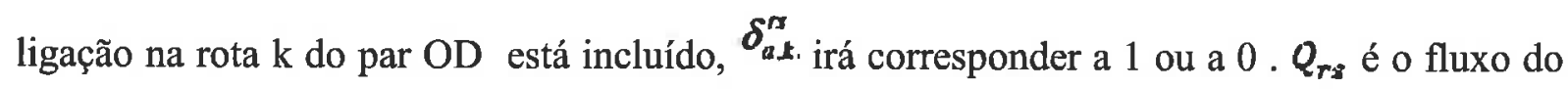
par de origem e destino. Para atribuição de tráfego será preciso usar a equação (6.7) buscando minimizar o custo total do veículo elétrico. Aqui um custo total de uma estação de carregamento $x, C_{x}$ é calculado através da equação:

$$
c_{x}=\overline{\sum_{k \in E_{s}^{r s}}} c_{k}^{r s} f_{k}^{r s}
$$

$K_{x}^{r z}$ é o subconjunto de rota do par OD via estação de carregamento x. A varíavel $C_{k}^{r 3}$ assume a posição que algumas estações de carga estão localizadas em alguns nós. Portanto, $C_{k}^{r 3}$ fará parte dos custos de ligação e dos tempos respectivos de espera nas estações de carregamento. A variável $t_{\mathrm{a}}$ corresponde ao custo da conexão em uma rota $\mathrm{k}$ do par OD. E $t_{*}^{\text {wrait }}$ significa o tempo de espera do carregamento da bateria na estação " $x$ " na rota $k$ do par OD. Então, $C_{k}^{r s}$ pode ser formulado como: 


$$
c_{k}^{n}=\sum_{u \in A^{a}} t_{a}+\sum_{n \in X_{k}^{n}} t_{x}^{\text {mai }}
$$

A Figura 52 mostra a imagem da definição do custo do veículo elétrico da origem para o destino.

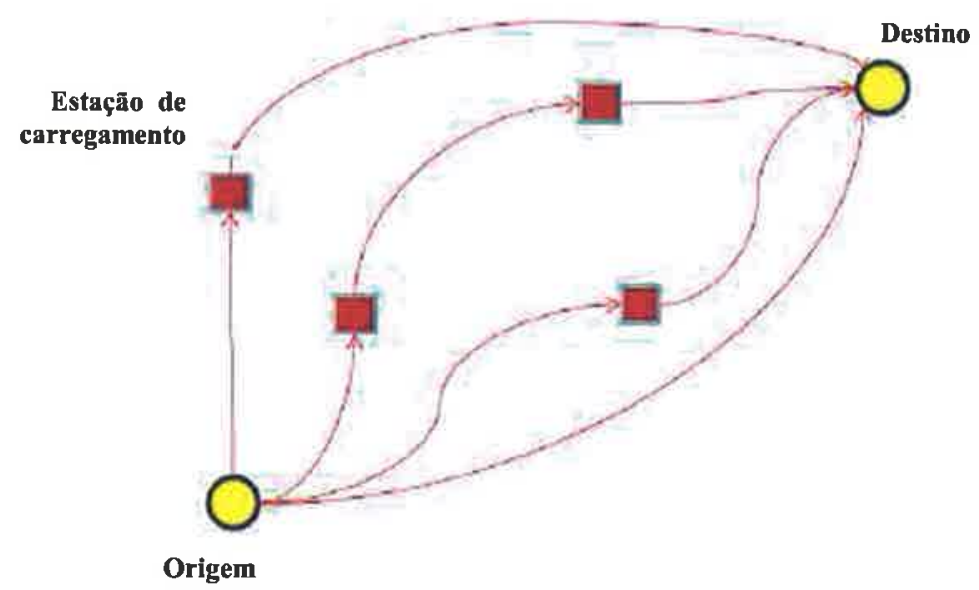

Figura 52 - Custo para o destino do veículo elétrico

Fonte: Adaptado de Larsson, 2010)

Finalmente, o custo da ligação $t_{\alpha}$ é definido com a seguinte equação:

$$
\begin{gathered}
t_{a}=\frac{\sum_{r s} \sum_{k} \sum_{v \in V_{k}^{r s}} \delta_{a, k}^{r s}\left(c_{a}+t_{a}^{\text {penalty }}(v)\right)}{f_{k, a}^{r s}} \\
t_{a}^{\text {penalty }}(v)= \begin{cases}0 & d_{v}^{\text {soc }}-\sum_{a_{k} \in \hat{A}_{b v v}^{r}} l_{a_{k}} \geq 0 \\
t_{a} & \text { caso o contrário }\end{cases}
\end{gathered}
$$

Se, $C_{a}$ corresponde ao tempo de viagem referente ao link de ligação a, $t_{a}^{\text {ponaltey }}$ (v) refere-se ao custo da penalidade, a medida que o veículo elétrico passa no link a, e $f_{k . a}^{r s}$ condiz a contagem de números de veículos elétricos pelo link a. $d_{y}^{s 0 c}$ é a distância acumulada desde a origem por onde o veículo iniciou o trajeto. $I_{\Delta k}$ é o comprimento do elo de ligação na rota $\mathrm{k}$ 
no subconjunto da ligação $\hat{\mathbf{A}}_{\mathrm{kav}}^{r s}$, na qual o veículo elétrico consta selecionado até o link a. Nesta equação usa-se $d_{v}^{\text {soc }}$ é a condição para verificar se a distância é acumulada sobre a distância disponível ou não.

Para encontrar a solução para a equação (6) será listado o caminho percorrido tanto na origem como no destino. Neste estudo, aplicaremos o algoritmo Dial (DIAL, 1979). O algoritmo Dial é uma técnica de atribuição de tráfego. De uma forma mais ou menos explícita, é possível associar praticamente todas as atividades que se desenvolvem no nosso mundo a utilização de modelos. Trata-se de um conceito que tanto pode significar a representação em escala reduzida de uma ponte, a simulação em computador da ação do vento numa estrutura ou a formulação matemática da dinâmica dos veículos numa estrada. Existe, contudo, um aspecto comum a todos estes modelos: uma representação idealizada e mais ou menos simplificada da realidade. Entende-se assim por modelo, uma aproximação, representação ou idealização de determinados aspectos da estrutura, comportamento, funcionamento, ou outras características de um processo, conceito ou sistema do mundo real (KAMAN, 1996). Conseqüentemente, a seguinte etapa refere-se ao cálculo do algoritmo Dial . Como primeiro passo, o mínimo custo c (i) para cada nó (destino) i, a partir da origem, r é calculado:

$$
c(i) \leftarrow c \min [r \rightarrow i]
$$

Em seguida, a probabilidade de ligação, $L[i \rightarrow J]$ a partir do nó i para o nó j é calculada para todas as ligações.

$$
L[i \rightarrow j]=\left\{\begin{array}{l}
\exp \left[\theta\left\{c(j)-c(i)-t_{i j}\right\}\right] \quad c(i)<c(j) \\
0
\end{array}\right.
$$

A variável ${ }^{\theta}$ é o parâmetro ( Logit ), $t_{i j}$ é o custo de ligação que é igual a $t_{\alpha}$. À medida que o segunda etapa inicia, consideramos o nó em ordem crescente do custo c (i) próximo a origem r. O peso da ligação $\boldsymbol{W}[\boldsymbol{i} \rightarrow \boldsymbol{i}]$ é calculado como: 


$$
W[i \rightarrow j]= \begin{cases}L[i \rightarrow j] & \text { for } i=r \\ L[i \rightarrow j] \sum_{m \in I_{i}}[m \rightarrow i] & \end{cases}
$$

A variável $\boldsymbol{I}_{\boldsymbol{i}}$ é o conjunto de nó em direção inversa (influxo) para o nó i. Como terceiro passo, consideramos o nó em ordem decrescente do custo c (i), o mais distante da origem r. A ligação fluxo (contagem de tráfego) a partir do nó i para o nó j, $\boldsymbol{x}_{i j}$ é calculado pela seguinte equação.

$$
x_{i j}=\left(q_{r j}+\sum_{m \in 0_{j}} x_{j m}\right) \frac{W[i \rightarrow j]}{\sum_{m \in I_{j}} W[m \rightarrow j]}
$$

A variável $\boldsymbol{q}_{\mathrm{r} j}$ é o fluxo de OD $\mathrm{r}$ origem para o destino $\mathrm{j}$ e $o_{j}$ é o conjunto de nó relativo ao fluxo de saída do nó j. Cada rota do veículo elétrico é determinada a partir do terceiro passo. Ao mesmo tempo, o custo da rota, sem tempo de espera para o carregamento da bateria pode ser também calculado. Basicamente, a atribuição de tráfego incluindo 0 algoritmo Dial tem interação com o processo. Neste método, o processo de atribuição é calculado primeiro pelo custo padrão do link e não é considerado o tempo de espera para o carregamento da bateria. A partir do segundo processo de atribuição, o tempo de espera é calculado e é considerado, o resultado anterior, em torno, do custo da ligação.

\subsubsection{Método para Objetivo 2}

Neste item, será elaborada a equação para o objetivo 2. Nesta formulação será aplicada a idéia de princípio de entropia máxima. O conceito de entropia de Shannon (1948) refere-se à incerteza de uma distribuição de probabilidade e a medida que propôs destinava-se a quantificar essa incerteza. Formalmente, o princípio de Jaynes envolve a busca pela distribuição de probabilidade que maximiza a medida de Shannon, dado um conjunto de restrições lineares. Estas restrições informam características da distribuição procurada, como, por exemplo, sua média e sua variância. O princípio de Kullback, por sua vez, envolve a busca pela distribuição de probabilidade mais próxima de uma outra distribuição a priori, através da minimização de uma medida de divergência entre ambas, dado o mesmo conjunto de restrições. Tanto a medida de Shannon como a de Kullback são funções intrinsecamente 
não-lineares de probabilidades. Assim, os princípios de Jaynes e Kullback reduzem-se a problemas de programação não-linear cuja solução demanda um algoritmo de busca iterativa.

\subsubsection{Formulação da Fórmula}

Em primeiro lugar, o total da demanda de energia elétrica de todas estações de carregamento $E_{d}$ pode ser formulada como:

$$
E_{d}=\sum_{x \in X} E_{x}^{d}
$$

Segundo, a percentagem de demanda elétrica da estação de carregamento " $\mathrm{x}$ ", a demanda elétrica total $P_{\varepsilon}$ (x) é descrita:

$$
P_{e}(x)=\frac{E_{d}^{x}}{E_{d}}
$$

Então, temos a seguinte equação:

$$
\sum_{x \in X} P_{e}(x)=1
$$

Finalmente, a entropia da combinação da localização da estação de carregamento $\boldsymbol{H}_{\boldsymbol{p}}$ pode ser calculada quando assumimos que $P_{\varepsilon}$ (x) é a distribuição probabilística satisfatória, que dá total condição para a equação (16).

$$
\begin{array}{cc}
\text { Maximizar Z } & H_{p}=-\sum_{x \in X} P_{e}(x) \log P_{e}(x) \\
\text { Sujeito a } & \sum_{x \in X} P_{e}(x)=1
\end{array}
$$

Do ponto de vista do princípio de máxima entropia, diz-se que a entropia tem uma tendência de crescer, se a distribuição da demanda elétrica é fechada para a probabilidade igual. Portanto, se a entropia é maximizada, pode-se encontrar o local ideal de estação de carregamento, satisfazendo o objetivo 2 . 


\subsection{Implementação do Método de Localização ideal}

Este processo consiste em três passos: no primeiro passo, são decididos os locais das estações de carregamento. Para decidir a locação é necessário um algoritmo de pesquisa adequado para a resposta do resultado de entropia. No segundo e terceiro passos, serão aplicados o método sugerido no algoritmo Dial, como mostra a Figura 53.

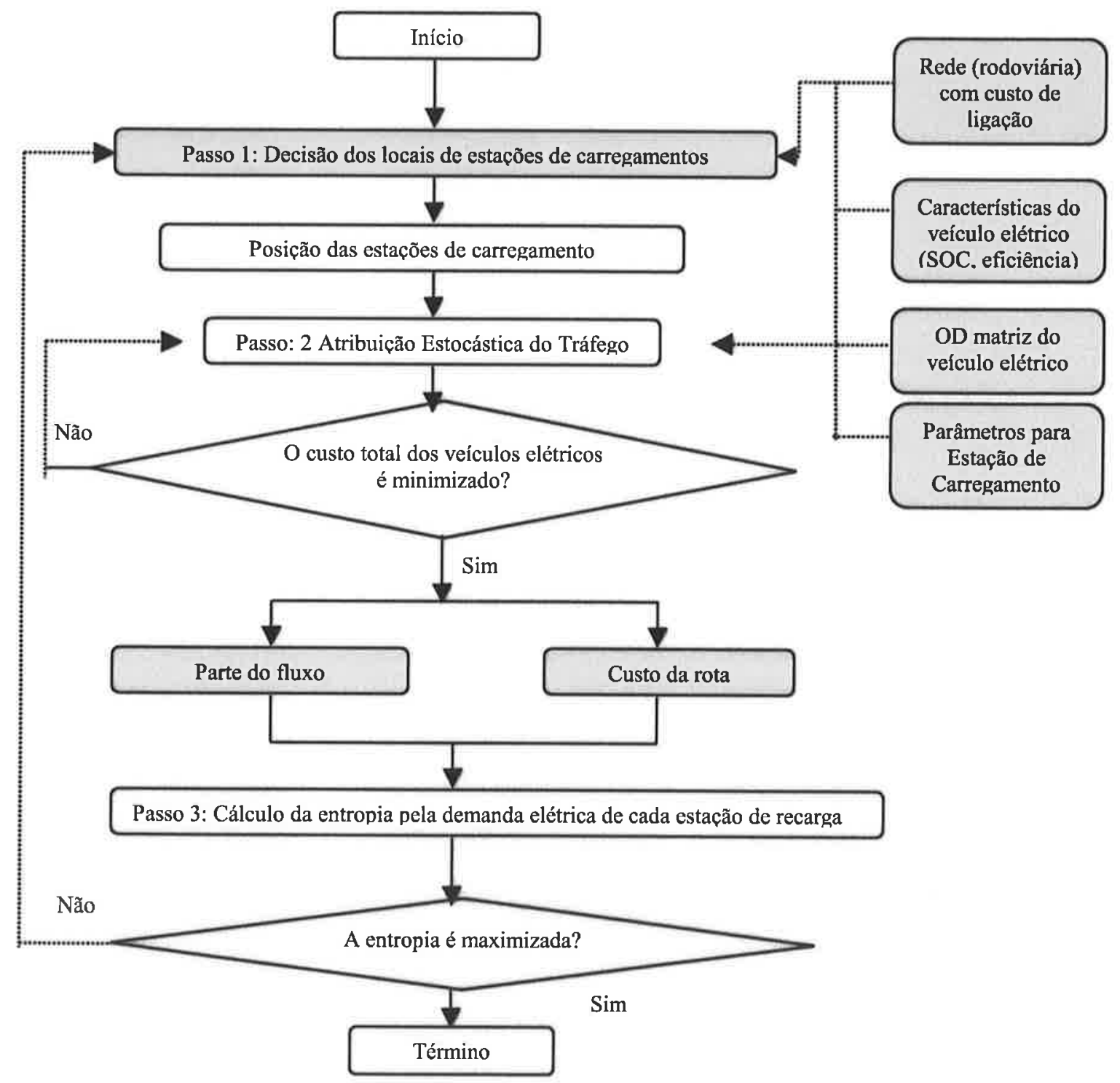

Figura 53 - Diagrama de implementação

Fonte: Elaboração própria 


\subsection{A importância das Baterias e Estações de Carregamento}

A quantidade de tempo ideal para efetuar o carregamento completo de uma bateria de um veículo elétrico é função dos seguintes fatores: tamanho da bateria e quantidade de energia elétrica. Circuitos de maior dimensão, tal como medido pela voltagem e amperagem, terá mais $\mathrm{kW}$. O mais usual é 120 volts $\mathrm{AC}(\mathrm{VAC})$, que proporciona 1,2 kWh a uma bateria. Já a de 240 volts AC (VAC), proporciona $6,5 \mathrm{kWh}$ a uma bateria. A Tabela 26 fornece informações sobre tamanhos das bateria e os tempos de carga em diferentes níveis de potência para reabastecimento de uma bateria descarregada.

Tabela 26 - Potência em KW disponibilizada a uma bateria

\begin{tabular}{|c|c|c|c|c|c|}
\hline \multirow[b]{2}{*}{$\begin{array}{c}\text { Configuração do } \\
\text { veículo } \\
\end{array}$} & \multirow[b]{2}{*}{$\begin{array}{c}\text { Tamanho da } \\
\text { Bateria em KWh }\end{array}$} & \multicolumn{4}{|c|}{ Tamanho do circuito e potência em KW disponibilizada a uma bateria } \\
\hline & & $\begin{array}{c}120 \mathrm{~V} \\
15 \mathrm{~A}-1,2 \mathrm{KWh} \\
\end{array}$ & $\begin{array}{c}120 \mathrm{~V} \\
20 \mathrm{~A}-1,6 \mathrm{KWh} \\
\end{array}$ & $\begin{array}{c}240 \mathrm{~V} \\
40 \mathrm{~A}-6,5 \mathrm{KWh}\end{array}$ & $\begin{array}{c}480 V \\
85 A-60 \text { KWh }\end{array}$ \\
\hline $\mathrm{BEV}$ & 24 & $20 \mathrm{~h}$ & $15 \mathrm{~h}$ & $3 \mathrm{~h} 41 \mathrm{~min}$ & $24 \mathrm{~min}$ \\
\hline BEV & 35 & $29 \mathrm{~h} 10 \mathrm{~min}$ & $21 \mathrm{~h} 50 \mathrm{~min}$ & $5 \mathrm{~h} 23 \mathrm{~min}$ & $35 \mathrm{~min}$ \\
\hline
\end{tabular}

Fonte: Elaboração Própria

O tamanho respectivo de uma bateria ou capacidade é medida em quilowatts-hora $(\mathrm{kWh})$. A capacidade de uma bateria para veículos elétricos irá variar de tão baixo, como 3 $\mathrm{kWh}$, para tão alto, quanto $40 \mathrm{kWh}$. No entanto, os veículos elétricos movidos a bateria necessitam de um conjunto de baterias em quantidade elevada comparada com um veículo híbrido. O Gráfico 29 mostra os tempos de carregamento para algumas alternativas que estão sendo apresentadas. Para o cálculo assumiu-se um consumo de energia de $2 \mathrm{kWh}$ por $10 \mathrm{~km}$ e uma distância de viagens diárias de $50 \mathrm{~km}$. Uma eficiência de $90 \%$ foi assumida para o cálculo (o tempo de carga. Consumo: $0,2 \mathrm{kWh} / \mathrm{km}$, distância da viagem diária: $50 \mathrm{~km}$ ).

É possível visualizar no Gráfico 29 que o os níveis de tensão e corrente são baixos, quando realizamos o carregamento tanto em casa quanto no trabalho. Para carregamento em postos públicos, com o fornecimento de energia mais elevada será possível reduzir o tempo de recarga. Para alcançar os tempos de carregamento curtos o suficiente para o motorista esperar menos durante a recarga, a fonte de energia deverá ser maior. $O$ processo de carregamento de tempo não é linear - a velocidade de carga diminui à medida que a bateria se enche. Por esta razão, a carga rápida provavelmente não será usada para recarregar completamente, a bateria atenderá o alcance suficiente para passar o dia (LARSSON, 2010). 
casa / trabalho

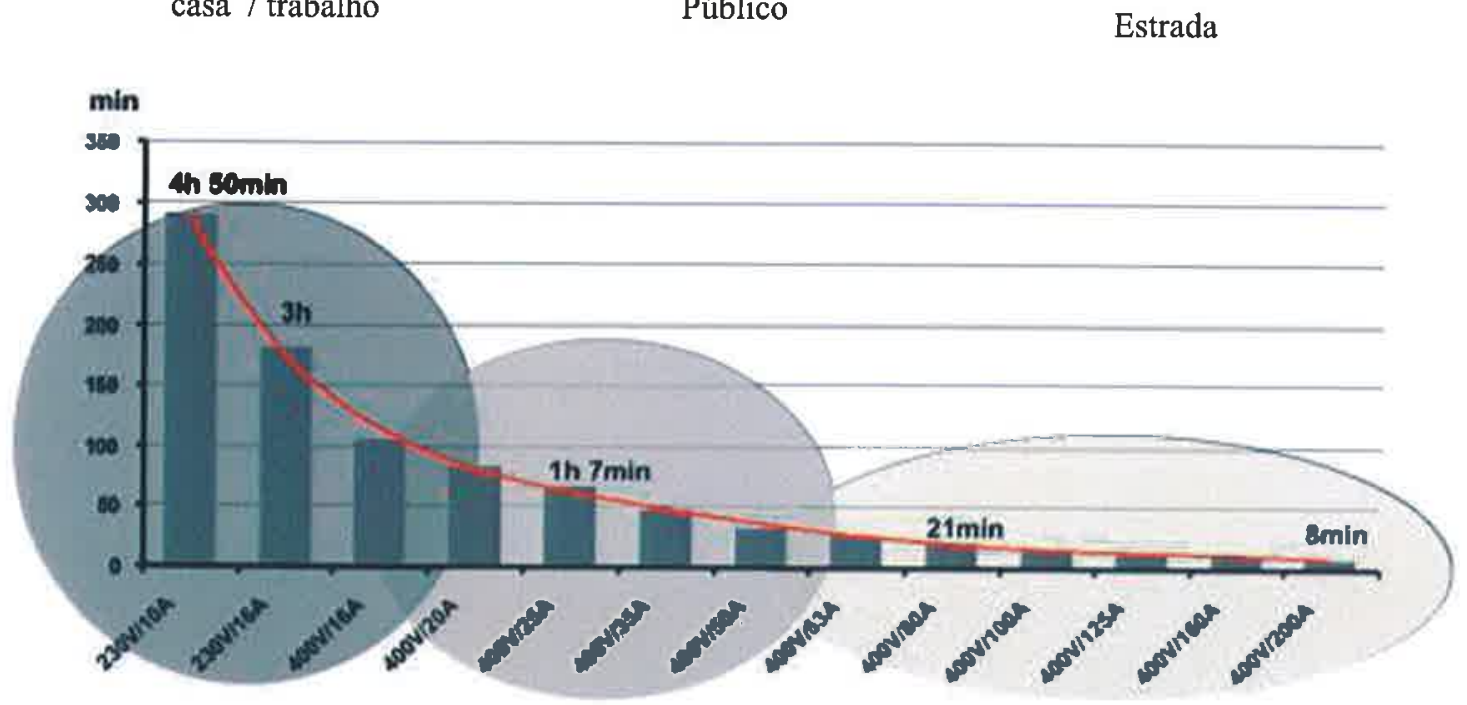

Gráfico 29 - Tempo de Recarga

Fonte: Adaptado de Larsson, (2010)

Para estimar a infra-estrutura necessária propícia para um veículo elétrico, assume-se que a distância média de condução do veículo é de $40 \mathrm{~km}$ por dia. Com um consumo energético de $0,2 \mathrm{kWh} / \mathrm{km}$, cada veículo utiliza $8 \mathrm{kWh}$ por dia. Alternativas de carregamento são incluídas, conforme a Tabela 27. Para carregamento realizado na residência é assumido o formato lento. Para o carregamento público, tanto o carregamento médio quanto o rápido estarão disponíveis. A Comissão Européia (2011), em consonância a empresas do setor energético, definiu requisitos para idealização da infra-estrutura necessária para alocação de postos de carregamento em via pública. As regras impostas definem a inclusão de 0,3 pontos de carregamento por veículo.

Tabela 27 - Opções de carregamento

\begin{tabular}{|c|c|c|}
\hline Carregamento & Potência - KW & Corrente e Voltagem \\
\hline Lento & 3,3 & $16 \mathrm{~A}, 230 \mathrm{~V}$ \\
\hline Médio & 10 & $16 \mathrm{~A}, 230 \mathrm{~V}, 3$ fases \\
\hline Ránido & 52 & $80 \mathrm{~A}, 240 \mathrm{~V}, 3$ fases \\
\hline
\end{tabular}

Fonte: Adaptado de Larsson, (2010)

Assumindo a regra definida pela Comissão Européia e utilizando a cidade de São Paulo como "piloto", a quantidade necessária de pontos de carregamentos para substituição de veículos movidos a diesel por veículos elétricos urbanos de carga podem ser conferidos na Tabela 28. Foi assumido que os carregamentos serão realizados em lugar público como traz a 
Figura 54. O Gráfico 30 mostra a efetivação da proposta contendo alguns os postos de recarga em uma determinada rota.

Tabela 28-Quantidade de postos carregamento

\begin{tabular}{|c|c|c|c|c|}
\hline Penetração & Caminhões VUCS & Número de postos & Carga média (75\%) & Carga rápida (25\%) \\
\hline $10 \%$ & 100.000 & 30.000 & 22.500 & 7.500 \\
\hline $20 \%$ & 200.000 & 60.000 & 45.000 & 15.000 \\
\hline $30 \%$ & 300.000 & 90.000 & 67.500 & 22.500 \\
\hline
\end{tabular}

Fonte: Elaboração própria

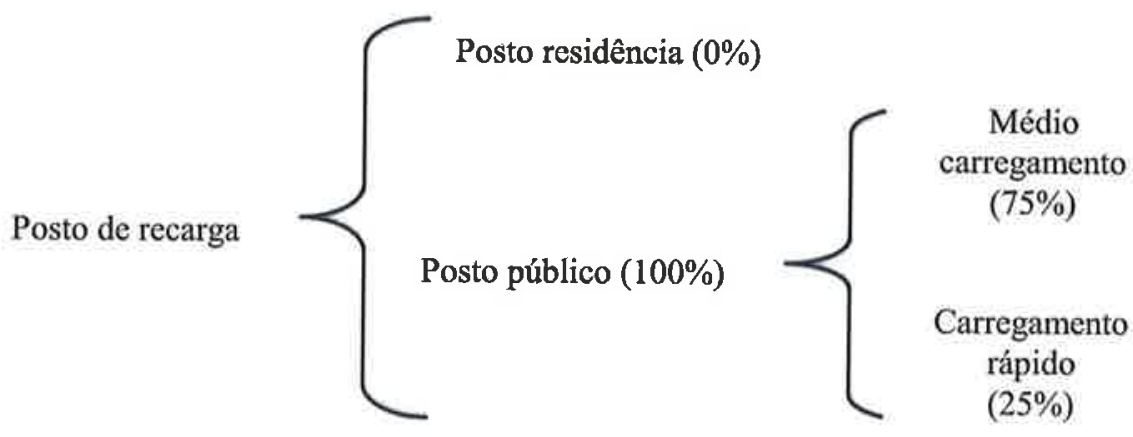

Figura 54 - Modo de Recarga

Fonte: Elaboração própria

O Gráfico 30 mostra a efetivação da proposta contendo alguns postos de recarga em uma determinada rota.
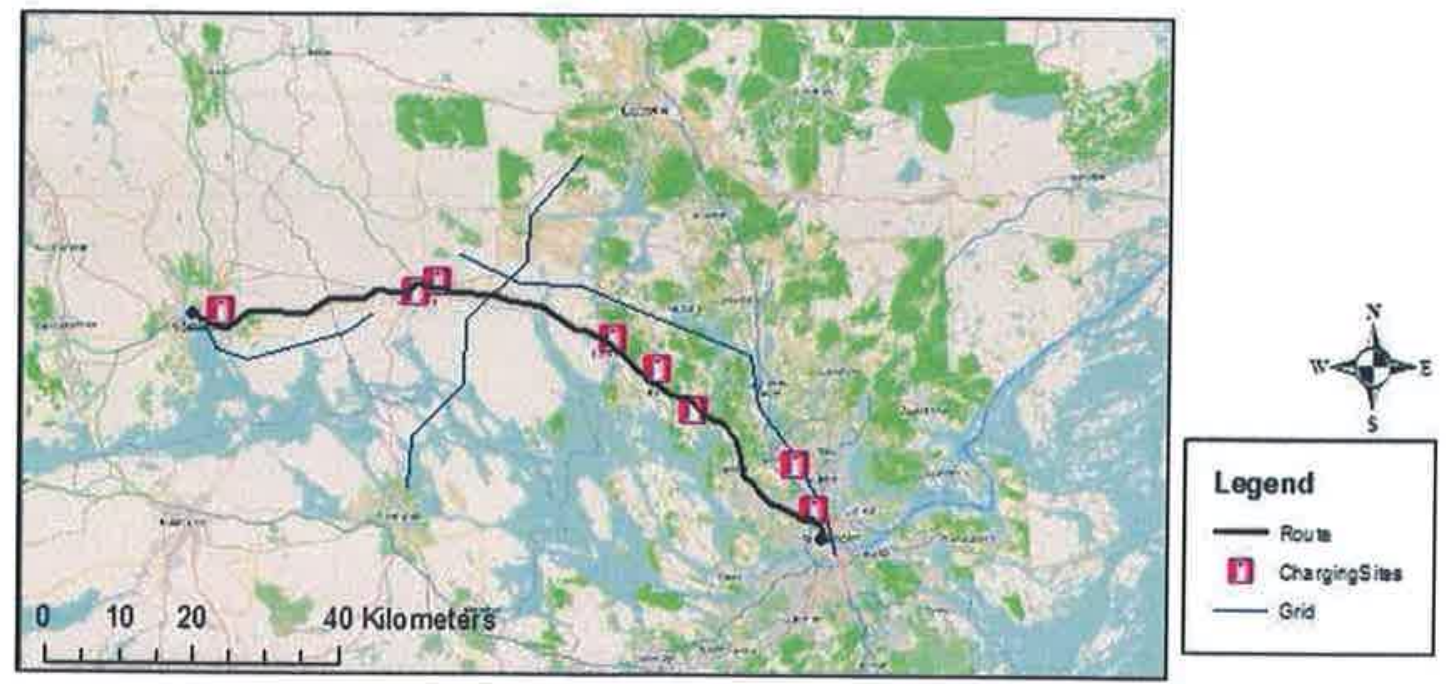

Gráfico 30 - Estações de recarga ao longo de uma rota

Fonte: Adaptado de Larsson, (2010) 
A infra-estrutura necessária para colocação dos postos de recarga dependerá de políticas e incentivos da esfera governamental que viabilizem aplicações de mobilidade elétrica como, por exemplo, partindo do pressuposto de realizar um planejamento de distribuição de energia descentralizada, implementar políticas de "smart grid" possibilitando o controle de carga pelo usuário, flexibilizando o mix de geração e facilitando a penetração de energia intermitente. 


\section{CONCLUSÕES E RECOMENDAÇÕES}

\subsection{Introdução}

Buscou-se no trabalho, conduzir a pesquisa tomando por base a idéia de se propor um método que contribuísse para a movimentação urbana de mercadorias notadamente nas áreas centrais, tendo-se como pano de fundo, os temas mobilidade elétrica e sustentabilidade dos transportes. Assim, visou-se a importância do emprego de métodos que estimulassem o uso de alternativas como os veículos elétricos urbanos de carga, mais sustentáveis do ponto de vista ambiental e social.

Assim pensando, mostraram-se as aplicações de novos conceitos para alocação de estações de carregamento, definindo e caracterizando a mobilidade elétrica e a influência que exercem. Cumprindo com os objetivos propostos inicialmente, o trabalho analisou a viabilidade da aplicação de novos conceitos para a realidade brasileira. Também se atingiram os objetivos secundários, muitos dos quais podem ser considerados como metas, quais sejam:

1. O levantamento das políticas públicas relativas à questão da mobilidade elétrica da sustentabilidade ambiental, como suporte aos conceitos de logística;

2. A revisão das experiências sobre o tema, seus sucessos, falhas e lições;

3. O levantamento dos atores envolvidos nesses conceitos, bem como, da própria carga urbana, avaliando-se as necessidades e as possibilidades;

4. O questionamento das viabilidades econômicas, sociais e ambientais desses conceitos, através de uma aplicação prospectiva por meio de simulações para distintos contextos e expectativas.

\subsection{Contribuição e Relevância da Pesquisa}

Apesar de já existirem grupos de pesquisa no Brasil tratando do problema da carga urbana, nota-se que, mesmo com a relevância do tema para a atualidade dos centros urbanos, ainda encontram-se em pequeno número e alcance. Isso é percebido pelo número ainda tímido de bibliografias que denotam a problemática da ausência das estações de carregamento e a ausência da inserção de veículos elétricos como uma questão também prioritária nas decisões que envolvem a aplicação de políticas voltadas à mobilidade elétrica. 
A elaboração desta metodologia, em especial o modelo de otimização, representa o cerne desta dissertação e a principal contribuição deste trabalho. Os diferentes estudos com a modelagem desenvolvida permitem o melhor entendimento e compreensão do impacto dos veículos movidos a eletricidade na cidade de São Paulo. Este processo é crucial antes da formulação de políticas públicas para incentivos deste tipo de tecnologia no país.

Do ponto de vista prático, esta metodologia é capaz de explorar as sinergias resultantes da ligação entre o sistema de transporte e a rede elétrica na cidade de São Paulo, podendo ser usado em diferentes estudos, como por exemplo, para analisar os impactos energéticos e ambientais com a penetração de veículos elétricos.

Uma das contribuições do trabalho foi o levantamento de bibliografia e estudos voltados à questão da mobilidade dos sistemas de transportes, reportando-se à sustentabilidade dos mesmos em um ambiente urbano.

Como resultados, têm-se cenários pequenos e concentrados (área central), porém denotativos do potencial da ferramenta proposta. Isso revela que o exemplo, aqui apresentado, é pequeno do ponto de vista do que já se conhece sobre experiências internacionais, mas poderia ser muito significativo na mudança de padrões locais, gerando uma mobilização de agentes e de interesses, hoje conflitantes, os quais passariam a trabalhar em harmonia e em parceria, visando a melhoria do meio ambiente urbano e uma implementação mais simples e generalizada, com dados confiáveis, para a realidade brasileira, ainda alheia à inovações dessa magnitude.

\subsection{Sobre o Estudo Metodológico e os Dados Aplicados}

Foi considerado, como uma diretriz metodológica em direção aos benefícios possíveis da aplicação de estações de carregamento, o método defínido pela comissão européia juntamente com a Teoria das Filas. Sabe-se que, para que se tenham melhores resultados, é necessário o aprofundamento e o detalhamento no levantamento dos dados utilizados. Do ponto de vista do cálculo de poluentes, os dados empregados das taxas de emissões foram admitidos pela CETESB (órgão responsável pelas medições e fiscalização), importantes para que se tenha a percepção das emissões veiculares. 


\subsection{Validade e Confiabilidade da Pesquisa}

Apesar dos resultados finais apontarem sempre na direção econômica (custos e benefícios), o caminho percorrido até os mesmos, requer o emprego de ferramentas de análise de dados espaciais, as quais são fortíssimas aliadas no entendimento do comportamento evolutivo da demanda e da cidade. Nesse ponto, os SIGs (mapas) continuarão desempenhando papel vital na análise de questões que envolvam logística e distribuição. A implantação de estações de carregamento só será interessante quando se pensar no coletivo/ global, o que permitirá a análise distributiva dos benefícios positivos e negativos desse tipo de conceito. Para isso, no entanto, várias entidades interessadas terão que se mobilizar (órgãos públicos, empresas privadas de distribuição de mercadorias, concessionárias de energia elétrica, usuários) no intuito de viabilizar as estratégias necessárias para a implementação dessas idéias. Assim, conclusivamente, admite-se:

1. mostrar o potencial energético;

2. balizar possíveis prosseguimentos do trabalho, com levantamentos mais precisos e com o envolvimento de empresas, organizações e pessoas interessadas no tema, de forma conjunta;

3. mostrar que o trabalho metodológico e a conscientização são os caminhos para se chegar a melhores resultados.

\subsection{Recomendações para Futuras Pesquisas}

Trabalhar exaustivamente com as possíveis ferramentas de análise de um SIG, incluindo a comparação de sistemas propostos de rotas com os atuais. Isso poderia aumentar a margem de lucros, visto que se poderiam ter sistemas mais otimizados de entregas (ou seja, diferentes zoneamentos). Definir diferentes horizontes de demanda, variando em curtos, médios e longos períodos de prospecção.

Por fim, outros pontos importantes a serem analisados com novas ferramentas incluem a análise do impacto local da entrada de veículos elétricos, como sobrecarga dos transformadores e linhas de distribuição de energia elétrica e o uso dos veículos elétricos para o fornecimento de serviços: como regulação de frequência para a rede elétrica no formato $\mathrm{V} 2 \mathrm{G}$ e a inclusão de um planejamento que proporcione a distribuição energética descentralizada . Estes pontos merecem o aprofundamento em estudos futuros. 


\section{REFERÊNCIAS BIBLIOGRÁFICAS}

ACKermanN, T., SODER, L., 2005. Wind Power in Power Systems: An Introduction, in Wind Power in Power Systems (ed T. Ackermann), John Wiley \& Sons, Ltd, Chichester, UK.

ADITYA, S. K., DAS D., 2001. Battery energy storage for load frequency control of an interconnected power system, Electric Power Systems Research 58: 179-185.

AGASSI, S (2009) World Without Oil Better Place Builds a Future for Electric Vehicles. Innovations: Technology, Governance,Globalization.

AMDUR M., DOULL J. and KLAASSEN C.D. (eds) (1991). Casarett and Doull's Toxicology - The Basic Science of Poisons 4th edition, Pergamon Press, New York, U.S.A Pp. 12-24, 804-809,974.

ANAYA-LARA, O., JENKINE, N., EKANAYAKE, J., CARTWRIGHT, P., HUGES, M., 2009. Wind Energy Generation: Modelling and Control, John Wiley \& Sons, Ltd, Chichester, UK.

ANDERSEN, P. H., MATHEWS, J. A., RASK, M., 2009. Integrating private transport into renewable energy policy: The strategy of creating intelligent recharging grids for electric vehicles. Energy Policy 37: 2481-2486.

ANDERSON, C. D., ANDERSON, J., 2010. Electric and Hybrid Cars: A History. 2nd ed., McFarland \& Company, Inc., North Carolina. US.

ANENBERG SC, HOROWITZ LW, TONG DQ, WESR JJ. "An Estimate of the Global Burden of Anthropogenic Ozone and Fine Particulate Matter on Premature Human Mortality Using Atmospheric Modeling". Environ Health Perspect. 2010 Sep; 118 (9): 1189-95.

ANFAVEA, 2012. Associação Nacional dos Fabricantes de Veículos Automotores, Anuário Estatístico da Indústria Automobilística Brasileira. Brasil.

ANP, 2012b. Agência Nacional de Petróleo, Seminário de Avaliação do Mercado de Derivados de Petróleo e Biocombustíveis da ANP. Disponível em: 144 http://www.anp.gov.br/?pg=59318\&m=\&t1=\&t2=\&t3=\&t4=\&ar=\&ps=\&cachebust $=1$ 331158579430. Acesso em: 7 de Março de 2012.

ANP, 2012a. Agência Nacional de Petróleo, Levantamento de preços e de margens de comercialização de combustíveis. Disponível em: http://www.anp.gov.br/preco/.Acesso em: 1 de Março de 2012.

ARRUDA, B. D. L. Análise dos programas nacionais de financiamento para renovação de frota dos transportadores autônomos. Brasília: Dissertação (Mestrado em Transportes)PPGT-UnB, Brasília, 2010.

BAIRD, C. Química Ambiental. 2a ed. Porto Alegre: Bookman Companhia Editora; 2002. 
BARAN, R., LEGEY, L. F. L., 2011. Veículos elétricos: história e perspectivas no Brasil. BNDES Setorial. v. 33, p. 207-224.

BARBIERI, J. C. Gestão Ambiental Empresarial: Conceitos, Modelos e Instrumentos. 1. ed. São Paulo: Saraiva, 2006.

BATTERY UNIVERSITY, "Evolução das baterias elétricas" http://batteryuniversity.com/. $10 / 06 / 2012$

BERMAN, B. Marketing Channels. John Willey e Sons, 1997, 663p.

BERTOLINI, L.; F. Le Clercq e T. Straatemeier (2008). Urban Transportation Planning in Transition (Editorial). Transport Policy, n. 15, p. 69-72. Disponível em: <http://www.elsevier.com/locate/tranpol>. Acesso em: 10 mar. 2008.

BI, T.et al. "The implication and implementation of smart grid in China". In: IEEE. Power and Energy Society General Meeting. [S.1], 2010. p. 1-5. ISSN 1944-9925.

BLACK, J. A.; A. PAEZ e P.A. SUTHANAYA, 2002. "Sustainable Urban Transportation Performance Indicators and Some Analytical Approaches". Journal of Planning and Development , v. 128, n. 4, pp. 184-209. Disponivel em: www.ascelibrary.org. Acesso em 10 de junho de 2012.

BOHN, T., 2011. Codes and Standards Support for Vehicle Electrification. 2011 DOE Hydrogen Program and Vehicle Technologies Annual Merit Review. Department of Energy, Energy Efficiency and Renewable Energy. Disponivel em: < http://wwwl.eere.energy.gov/vehiclesandfuels/pdfs/merit_review_2011/veh_sys_sim/vss053 bohn_2011_o.pdf >Acesso em 15 de março de 2012.

BORBA, B. S. M. C., 2008. Metodologia de Regionalização do Mercado de Combustíveis Automotivos do Brasil, Dissertação de Mestrado submetida ao Programa de Pós graduação de Engenharia da Universidade Federal do Rio de Janeiro, UFRJ, Rio de Janeiro. Disponível em < http://www.ppe.ufrj.br/ppe/production/tesis/bsborba.pdf,> Acesso em 28/01/2012.

BORGES, CARMEN L.T.; MACHADO JUNIOR, ZULMAR S.; FALCÃO, DJALMA M. Influência da alocação ótima de dispositivos de proteção e de geração distribuída na confiabilidade do sistema. XVII SNPTEE - Seminário Nacional de Produção e Transmissão de Energia Elétrica. Uberlândia, out. 2003.

BOTSFORD, C.\& SZCZEPANEK, A. (2009) Fast Charging vs. Slow Charging: Pros and cons for the New Age of Electric Vehicles. EVS24 International Battery,Hybrid and Fuel Cell Electric Vehicle Symposium. Stavanger, Norway, May 13-- $\square$ 16, 2009

BOTTURA, Celso P.; BARRETO, Gilmar. Veículos Elétricos. Campinas: Unicamp, 1989, ISBN 85-268-0132-S

BP STATISTICAL REVIEW OF WORD ENERGY 2012. “Os quinze países que mais consumiram petróleo em 2011" Disponível em: < http://www.bp.com>. Acesso em: 20 abr.2012 
BRANCO, S.M.; ROCHA, A.A. Poluição atmosférica. CETESB (2006).

BRANDÃO, C. E. L. Governança corporativa no contexto da sustentabilidade. Desenvolvimento sustentável voltado aos combustíveis (óleo diesel) 2012-2050: visão, rumos e contradições. Fernando Almeida (org.), Rio de Janeiro: Elsevier, 2012.

BROWN, L. R. (2003) Eco-economia: construindo uma economia para a terra.ISBN 8587616-08-0 Copyright (C) 2003 Earth Policy Institute, Publicado no Brasil pela Universidade Livre da Mata Atlântica (UMA), Primeira Edição, 368 p., 23,5cm. Salvador-BA. Disponível em <http://www.uma.org.br>. Acesso em 15 de março de 2012.

BROWN, R.E., "Impact of Smart Grid on Distribution System Design", em Power and Energy Society General Meeting - Conversion and Delivery of Electrical Energy in the 21st Century, 2008 IEEE, pp. 1-4.

BROWN, S., PYKE, D., STEENHOF, P., 2010. Electric vehicles: The role and importance of standards in an emerging market. Energy Policy 38: 3797-3806.

BRUNEKREEF, B.;HOLGATE, S.T. Air Pollution and Health. The Lancet. Vol.360. n 9341, p.1233-1242, Oct 2002.

BOTTURA, Celso P.; BARRETO, Gilmar. Veículos Elétricos. Campinas: Unicamp, 1989, ISBN 85-268-0132-S

BRADLEY, T. H., FRANK, A. A., 2009. Design, demonstrations and sustainability impact assessments for plug-in hybrid electric vehicles. Renewable and Sustainable Energy Reviews 13: 115-128.

BRAGA, B.; HESPANHOL, I.; CONEJO, J. G. L.; MIERZWA, J. C.; BARROS, M. T. L.; SPENCER, M.; PORTO, M.; NUCCI, N.; JULIANO, N.; EIGER,S. Introdução à engenharia ambiental. 2. ed. São Paulo: Pearson Prentice Hall, 2005. p. 313. ISBN 85-7605041-2.

BRAGA, A.; PEREIRA, L.A.A.; SALDIVA, P.H.N. Poluição e seus Efeitos na Saúde Humana. In: Seminário sobre sustentabilidade na geração e uso de energia. Campinas, SP: UNICAMP, 2002. 20p. Disponível em: http://libdigi.unicamp.br/document/?code=1039. Acesso em 26 de janeiro de 2012.

BRAGA, A.; CONCEIÇÃO, G.M.S.; PEREIRA, L.A.A, KISHI, H., PEREIRA, J.C.R, ANDRADE, M.F., GONÇALVES, F.L.T., SALDIVA, P.H.N. "Air Pollution and Pediatric Respiratory Hospital Admissions in São Paulo", Brazil. J. Environ. Med., V.1, p.95102,2009

BROOK, RD. Cardiovascular Effects of Air Pollution. Clinical Science. 2008;115:175-87.

BROUSSELY, M., 2010. Battery Requirements for HEVs, PHEVs, and EVs: An Overview, Chapter 13 in Electric and Hybrid Vehicles: Power Sources, Models, Sustainability, Infrastructure and the Market, ed. by G. Pistoia, Elsevier B. V., Elsevier. Amsterdam, The Netherlands, pp. 305-345. 
BUENO, André Valente. Analise da operação de motores diesel com misturas parciais de biodiesel. 2006. Tese (Doutorado em Engenharia Mecânica) - Programa de Pós-Graduação em Engenharia Mecânica, Universidade Estadual de Campinas, Campinas, SP.

BURTON, T., SHARPE, D., JENKINS, N., BOSSANYI, E., 2001. Wind Energy Handbook, John Wiley \& Sons, Ltd, Chichester, UK.

CAMPANARI, S., MANZOLINI, G., Garcia de la Iglesia, F., 2009. Energy analysis of electric vehicles using batteries or fuel cells through well-to-wheel driving cycle simulations, Journal of Power Sources 186: 464-477.

CAMPI, T. M.; RUTKOWSKI, E.; LIMA JÚNIOR, O. F. (2004). Sustentabilidade das Técnicas de Transporte. UNICAMP, fevereiro de 2004.

CARVALHO, Marcos José Ferreira. Avaliação da conformidade de veículos terrestres: análise metrológica e modernização de um sistema para medição de velocidade. Rio de Janeiro: Dissertação de Mestrado PUC-Rio, 2007.

CASTRO, N., CARRIS, L. Y RODRIGFUES, B. (2003)."Custos de Transporte e a Estrutura Espacial do Comércio Brasileiro". Pesquisa e Planejamento Econômico, p.p. 347-400.

CENTRE FOR SUSTAINABLE TRANSPORTATION (2001). Sustainable transportation monitor No. 5, November 2001.

CEPEL, 2011. Centro de Pesquisas em Energia Elétrica, Atlas do Potencial Eólico Brasileiro.

Ed. CEPEL, Rio de Janeiro, Brasil.

CET, 2011. “Congestionamentos índices diários" http://www.cetsp.com.br/.. Acesso em $10 / 06 / 2012$

CETESB, 2009. Companhia Ambiental do Estado de São Paulo, Relatório de Qualidade do Estado do Ar no Estado de São Paulo. São Paulo.

CETESB, 2011. Companhia Ambiental do Estado de São Paulo, Relatório de Qualidade do Estado do Ar no Estado de São Paulo. São Paulo.

CHAN, C. C., 2007. The state of the art of electric, hybrid, and fuel cell vehicles. Proc. IEEE, vol. 95, pp. 704-718

CHAU, K. T., Wong, Y. S., 2002. Overview of power management in hybrid electric vehicles. Energy conversion and Management. Elsevier Science Ltd, 15(43), pp.1953-1968.

CLEMENT-NYNS, K., HAESEN, E., DRIESEN, J., 2010. The Impact of Charging Plug-In Hybrid Electric Vehicles on a Residential Distribution Grid, IEEE Transactions on Power Systems 25: 371-380.

CNT, 2012. Confederação Nacional dos Transportes, "Refino de Petróleo - óleo diesel" Disponível em http://www.cnt.org.br . Acesso em junho de 2012. 
CONAMA- Conselho Nacional do Meio Ambiente (Acessado em Dez de 2012) http://www.mma.gov.br/port/conama/estr.cfm

CONAMA- Conselho Nacional do Meio Ambiente. Resolução de 2007. "Dispõe sobre critérios e valores orientadores de qualidade do solo quanto à presença de substâncias químicas e estabelece diretrizes para o gerenciamento ambiental de áreas contaminadas por essas substâncias em decorrência de atividades antrópicas.", Diário Oficial [da República Federativa do Brasil], Brasília, DF, n 249, de 30/12/2009, págs. 81-84. Disponível em<http://www.mma.gov.br/port/conama/legiano1.cfm? codlegitipo $=3 \&$ ano $=2009>$ (Acessado em Jan 2010)

CZERNIAK, R. J.; LAHSENE, J. S.; CHATTERJEE, A. Urban freight movement - What form will it take? - Disponível em: < http://gulliver.trb.org/publications $>$. Acesso em: maio de 2011.

DABLANC, L. Entre police et service - L'action public sur le transport de mechandises en ville: le cas des métropoles de Paris et New York, p459, 1997.

DE JONGHE, C. et al. "Determining optimal electricity technology mix with high level of wind power penetration" Applied Energy, v. 88, pp. 2231-2238, 2011.

DELUCCHI, M. A., LIPMAN, T. E., 2010. Lifetime Cost of Battery, Fuel-Cell, and PlugIn Hybrid Electric Vehicles, Chapter 2 in Electric and Hybrid Vehicles: Power Sources, Models, Sustainability, Infrastructure and the Market, ed. by G. Pistoia, Elsevier B. V., Elsevier. Amsterdam, The Netherlands, pp. 19-60. Dettmer R., Hybrid vigour, IEE Review, pp. 25-28, Vol. 47, Janeiro 2001.

DENATRAN, 2011, “Frota Automotiva”http://www.denatran.gov.br>. Acesso em 10/01/2012.

DENHOLM, P.; HAND, M. "Grid flexibility and storage required to achieve very high penetration of variable renewable electricity" Energy Policy v. 39, pp. 1817-1830, 2011.

DETTMER Roger, Hybrid vigour, IEE Review, pp. 25-28, Vol. 47, Janeiro 2001.

DIAL, G. Glover, D. Karney e D. Klingman, "Computational Analysis of Alternative Algorithms and Labelling Techniques for Finding Shortest path trees". Networks 9, (1979), 215-348.

DIAS, A. PEREIRA R, 2012. "Mobilidade Elétrica uma Revolução Antecipada". Disponível em < http://janusonline.pt/popups2011_2012/2011_2012_3_2_12.pdf> . Acesso em julho de 2012.

DIJK, M., YARIME, M., 2010. The emergence of hybrid-electric cars: Innovation path creation through co-evolution of supply and demand. Technological Forecasting and Social Change 77: 1371-1390

DOE, 2009. Department of Energy, Energy Efficiency and Renewable Energy. History of Electric Vehicles. Disponível em: http://wwwl.eere.energy.gov/vehiclesandfuels/avta/light_duty/fsev/fsev history.html. Acesso em 2 de Março de 2012. 
DOE, 2012. Department of Energy, Energy Efficiency and Renewable Energy. History of Electric Vehicles. Disponível em: http://www1.eere.energy.gov/vehiclesandfuels/avta/light duty/fsev/fsev history.html. Acesso em 2 de Março de 2012.

DUSTMANN, Cord-H "Advances in ZEBRA batteries", MES-DEA S.A., Via Laveggio 15, CH 6855 Stabio, Switzerland, Science Direct (C) 2003 Elsevier.

[

EC, 2009. Electrification Coalition, Electrification Roadmap: Revolutionizing Transportation and achieving Energy Security. US.

ÉCO-MOBILITÉ. Véhicules Électriques. Produits. Disponível em: $<$ http://www.ecomobilite. com> Acesso em : 10 de janeiro de 2012.

EIA - ENERGY INFORMATION ADMINISTRATION (DEPARTMENT OF ENERGY). Disponível em: <http://www.eia.doe.gov/oiaf/aeo>. Acesso em: 6 dez. 2012.

ELETROBRAS, 2011."Fontes Alternativas de Energia - Potencial Eólico Brasileiro" Disponível em:http://www.eletrobras.com/elb/natrilhadaenergia/meio-ambiente-e energia/main.asp?View=\%7B45B85458-35B3-40FE-BDDD-A6516025D40B\%7D. Acesso em: 10 de março de 2012

EMADI, A., WILLIAMSON, S. S., KHALIGH, A., 2006. Power Electronics Intensive Solutions for Advanced Electric, Hybrid Electric, and Fuel Cell Vehicular Power Systems. IEEE Transactions on Power Electronics, Vol. 21, No. 3, may 2006.

ENERGY INFORMATION ADMINISTRATION, 2011. Country Analysis

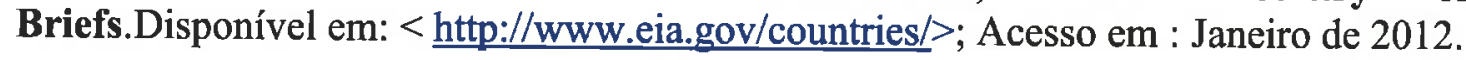

ENVIRONMENTAL PROTECTION AGENCY. (EPA): National Ambient Air Quality Standards for Particulate Matter: Proposed Rule. Fed. Regist. 71, 2620-2708.2009. Disponível em: http://www.labsaftey.com/refinfo/fedreg/FRPDF/011706.pdf. Acesso em junho de 2012.

EPE. EMPRESA DE PESQUISA ENERGÉTICA. Informe a imprensa. Plano Decenal de Expansão de Energia - PDE 2020. Matriz energética terá aumento de participação das renováveis nesta década . De acordo com o Plano Decenal, fontes alternativas (eólica, biomassa e pequenas hidrelétricas) dobrarão de tamanho no setor elétrico até 2020 . Brasília: MME/EPE, Junho de 2011 b.

EPE, EMPRESA DE PESQUISA ENERGÉTICA 2012. "Projeção da Demanda de Energia Elétrica".Disponível

em: http://www.epe.gov.br/mercado/Documents/S\%C3\%A9rie $\% 20$ Estudos $\% 20$ de $\% 20$ Energia/20 13117 1.pdf. Acesso em 03 de Março de 2012.

EPRI, 2001. Electrical Power Research Institute, Comparing the benefits and impacts of hybrid vehicle options. Report 1000349, Palo Alto, California. 
EUROPEAN COMISSION, 2006. "European SmartGrids Technology Plataform - Vision and Strategy Europe's Electricity Networks of the Future, Luxembrugo. Disponivel em:

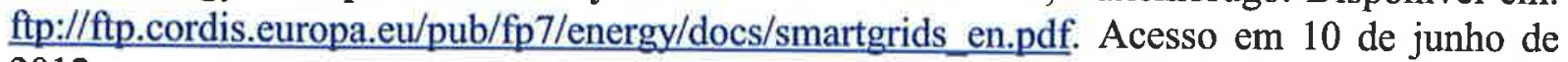
2012.

European Community. Directive 82/501/EEC (Parlamento e Conselho Europeu) Disponível: http://www.ess.co.at/HITERM/REGULATIONS/82-501-eec.html . Acesso: 10 mar. 2011.

EUROFORUM, 2007. "The European Research Forum for Urban Mobility" (EUROFORUM). Disponivel em: http://www.eurforum.net. Acesso em 10 de janeiro de 2012.

EXTRA (2001). Projeto. Integrated policy aspects of sustainable mobility,Extra\Thematic Paper 1\3 September 2001 Sustainable mobility - integrated policy;Thematic Synthesis Of Transport Research Results, Paper 1 OF 10, 131p.

INSTITUTO DE ESTUDOS AVANÇADOS DA UNIVERSIDADE DE SÃO PAULO, 2010. Impactos no Trânsito no Estado de São Paulo. Disponível em < http://www.iea.usp.br/revista/institucional > Acesso em 15 de abril de 2012.

FAIA, S., M. R., 2006. Optimização de Sistemas de Propulsão de Veículos para Frotas, Tese de M.Sc., - Instituto Superior Técnico. Portugal.

FARADAY, M. Experimental researches in electricity. New York: Dover, 1844. 3 v.

FERREIRA, Leila da Costa. Sustentabilidade: uma abordagem histórica da sustentabilidade. In: FERRARO JÚNIOR, Luiz Antonio (Org.). Encontros e caminhos: formação de educadoras(es) ambientais e coletivos. Brasília: Ministério do Meio Ambiente, 2005. p. $315-321$

FITZGERALD, A. E., C. KINGSLEY Jr. e A. KUSKO (1975). Máquinas elétricas. 1.ed. São Paulo: Makron Books.

FISCHER, M., WERBER, M., SCHWARTZ, P. V., 2009. Batteries: Higher energy density than gasoline? Energy Policy 37: 2639-2641.

FOGLIATTI, M. C. et al., (2004) "Avaliação dos impactos ambientais: Aplicação ao sistemas de transportes".Editora Interciência, Rio de Janeiro.

FURATA T, UEDA T, AUNE G et al. (2002) Transcription-coupled nucleotide excision repair as a determinant of cisplatin sensitivity of human cells. Cancer Res 62:4899-4902.

GREEN II, R. C., WANG, L., ALAM, M., 2011. The impact of plug-in hybrid electric vehicles on distribution networks: $A$ review and outlook. Renewable and Sustainable Energy Reviews 15: 544-553.

GREET, version 1_2011, Greenhouse gases, Regulated Emissions, and Energy use in Transportation, $201 \overline{1}$. 
GOUPIL INDUSTRIE. Véhicules Électriques. Produits. Disponível em $:<$ http://www.goupil-industrie.eu/en/> Acesso em: 10 de janeiro de 2012.

GUDMUNDSSON, H, (2004). Sustainable Development Principles and Their Implications for Transport. Ecological Economics, v.19, p. 269-282.

HADLEY, W. S., TSVETKOVA, A., 2008. Potential Impacts of Plug-in Hybrid Electric Vehicles on Regional Power Generation. UT-Battelle, Oak Ridge National Laboratory.

HALL, P. J., 2008. Energy storage: The route to liberation from the fossil fuel economy? Energy Policy 36: 4363-4367.

HARVEY, L. D. D., 2010a. Energy and the New Reality 1: Energy Efficiency and the Demand for Energy Services, Earthscan Publications Ltd, Londres, UK.

HLEDIK, R., 2009. How Green Is the Smart Grid? The Electricity Journal 22: 29-41.

HERMANCE D., Sasaki S., Hybrid electric vehicles take to the streets, IEEE Spectrum, pp. 48-52, Novembro 1998.

HILLIER, F.; LIEBERMAN, G. J. Introduction to Operations Research. 7. ed. São Paulo: McGraw-Hill, 2007.

Holguín-Veras, J. and E. Thorson. (2001) “An Investigation of the Relationships Between the Trip Length Distributions in Commodity-based and Trip-based Freight Demand Modeling." Transportation Research Record No.1707, pp. 37-48.

HOYER, K. G., 2008. The history of alternative fuels in transportation: The case of electric and hybrid cars, Utilities Policy 16: 63-71.

HUGHES, J. Donald (2009), An Environmental History of the world. Humankind's changing role in the community of life. Nova Iorque: Routledge.

HYDRO-QUÉBEC, Hydro-Québec Sustainable Report 2010/ Hydro-Québec Environmrntal Report 2010. Disponível em http://www.hydroquebec.com/ Acessado em 15 de junho de 2012.

IBAMA- Instituto Brasileiro do Meio Ambiente e dos Recursos Naturais Renováveis (Acessado em Junho de 2012) http://www.ibama.gov.br/patrimonio/

IEA, 2007. International Atomic Energy Agency, MESSAGE - User Manual. Viena.

IEA, 2011. International Energy Agency, Technology Roadmap: Electric and plug-in hybrid electric vehicles. France.

IEA, 2011. International Energy Agency, Key World Energy Statistics.

IEA, 2012. International Energy Agency, Technology Roadmap: Electric and plug-in hybrid electric vehicles. France.

IVECO, 2011. "Modelo Daily Elétrico". . Disponível em < http://www.blogiveco.com.br/tag/daily-eletrico/ > 
J. A. PEÇAS LOPES, F. J. SOARES, P. M. ALMEIDA, M. MOREIRA DA SILVA, "Smart Charging Strategies for Electric Vehicles: Enhancing Grid Performance and Maximizing the Use of Variable Renewable Energy Resources ", EVS24, Stavanger, Norway, May 13-16, 2009.

JUNIOR, A. R. P., 2002. Regulação da Demanda de Energia em um Sistema de Propulsão para um Veículo Elétrico Híbrido Série, Tese de M.Sc., UFRGN. Brasil.

Kaman Sciences Corporation (1996): “A compendium of traffic model validation documentation and recommendations". FHWA - US Department of Transportation. (http://www.itsdocs.fhwa.dot.gov//JPODOCS/REPTS_TE/30401!.PDF)

KEMPTON, W., LETENDRE, S., 1997. Electric vehicles as a new power source for electric utilities. Transportation Research Part D 2: 157-175.

KENJO, T.; NAGAMORI, S. (1985). Permanent-Magnet and Brushless DC Motors. Estados Unidos: Oxford University Press.

KIVILUOMA, J., MEIBOM, P., 2011. Methodology for modelling plug-in electric vehicles in the power system and cost estimates for a system with either smart or dumb electric vehicles, Energy 36: 1758-1767

KRAMER S. C. Bill, KROPOSKI BENJAMIN "A Review of Plug-in Vehicles and Vehicleto-Grid Capability ", National Renewable Energy Laboratory, 1617 Cole Blvd., Golden, CO 80401, USA. BEV-HEV-PHEV-FCEV.

KURANI K. S., HEFFNER, R. R., TURRENTINE, T. S., 2007. Driving plug-in hybrid electric vehicles: reports from U.S. drivers of HEVs converted to PHEVs, circa 2006-07. Institute of Transportation Studies, University of California, Davis.

LARMINIE, J. \& LOWRJ, J. (2003), Electric Vehicle Technology Explained, John Wiley and Sons Ltd, The Atrium, Southern Gate, Chichester, West Sussex PO19 8SQ, England

LARSSON, M., KORBA, P., REHTANZ, C. e ANDERSSON, G.(2010). Design aspects for wide area monitoring and control systems. Proceedings of the IEEE, 93(5):980-996.

LEBENSZTAJN L, PELlini, E., (2005) A Evolução do Carro Elétrico. Disponível em:

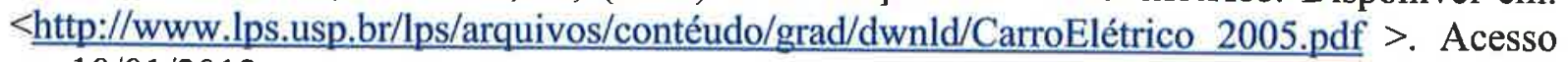
em 10/01/2012

LIN, S.HE, Z., ZANG, T., QIAN, Q., 2010. Impact of Plug-In Hybrid Electric Vehicles on distribution systems, 2010 International Conference on Power System Technology (POWERCON), pp.1-5, 24-28 Oct. 2010.

LOUREIRO, L. N., 2005. Panorâmica Sobre Emissões Atmosféricas Estudo De Caso: Avaliação Do Inventário Emissões Atmosféricas - Da Região Metropolitana Do Rio De Janeiro Para Fontes Móveis. Tese de M.Sc., PPE/COPPE/UFRJ. Brasil. 
MACÁRIO. M, R, M, R. Quality Manangement in Urban Mobility Systems: an Integrated Approach. Tese (Doutorado) - Instituto Superior Técnico, Universidade Técnica de Lisboa, Lisboa, 2005.

MACEDO, I.C. et al. Balanço das emissões de gases do efeito estufa na produção e no uso do etanol no Brasil. São Paulo: Secretaria de Meio Ambiente do Estado de São Paulo, 2004.

MACEDO, I.C. et al. Balanço das emissões de gases do efeito estufa na produção e no uso do etanol no Brasil. São Paulo: Secretaria de Meio Ambiente do Estado de São Paulo, 2010.

MACLAREN, VIRGINIA W. Urban Sustainability Reporting in Stephen M. Wheeeler e Timothy Beatley, London: Routledge, pp. 203-210, 2004.

MAISONET M, CORREA A, MISRA D, JAAKKOLA JJK. "A Review of the Literature on the Effects os Ambient Air Pollution on Fetal Growth". Environ Res. 2004.

MAITRA., J., Taylor., ALEXANDER., A., BROOKS., D., DUVALL., M., 2009. Evaluation of the impact of plug-in electric vehicle loading on distribution system operations. Power \& Energy Society General Meeting. IEEE , pp.1-6, 26-30 July 2009.

MAITRE A, BONNETERRE V, HUILLARD L, SABATIER P, GAUDEMARIS R. Impact of Urban Atmospheric Pollution on Coronary Disease. Eur Heart J. 2006;27:2275-84.

MARINHO, 2006. A. Um estudo sobre as filas para transplantes no Sistema Único de Saúde brasileiro. Instituto de Pesquisa Econômica Aplicada, Rio de Janeiro, Brasil Faculdade de Ciências Econômicas, Universidade do Estado do Rio de Janeiro.

MANWELL, J. F., MCGOWAN, J. G., ROGERS,WIND, A. L., 2002. Energy Explained: Theory, Design and Application, John Wiley \& Sons, Ltd, Chichester, UK.

MARCILIO I, GOUVEIA N. "Quantifying the impact of air pollution on the urban population of Brazil". Cad Saúde Pública. 2007;23 (Suppl 4): S529-36

MATTOS, R. A. Os Sentidos da Integralidade: algumas reflexões acerca de valores que merecem ser defendidos. In: PINHEIRO,R.; MATTOS, R. A. Os Sentidos da Integralidade na atenção e no cuidado à saúde. Rio de Janeiro: UERJ, IMS, ABRASCO,2001. p. 39-64.

MAZUMDAR J, HICKEY MM, PANT DK, et al. HIF-2 delectation promotes Krasdriven lung tumor development. Proc Natl Acad Sci U S A 1982; 107:14182-7.

MCTI, 2012. Ministério da Ciência, Tecnologia e Inovação, Fatores de Emissão de CO2 pela geração de energia elétrica no Sistema Interligado Nacional do Brasil. Disponível em: http://www.mct.gov.br/index.php/content/view/72764.html. Acesso em 05 de Março de 2012.

MDIC, Ministério do Desenvolvimento Indústria e Comercio Exterior/SECEX, 2011. "Consumo de Energia nos Transportes". Disponível em: <http://www.mdic.gov.br/ >. Acesso em: 11 de jul. 2012.

MENEZES PL, TEIXEIRA CF. Ruídos. In: Menezes PL., Neto SC., Motta MA. Biofísica da audição. São Paulo: Lovise, 2005, p.74-7. 
MINISTÉRIO DO MEIO AMBIENTE (MMA) (1999). Avaliação do programa de inspeção e manutenção de veículos em uso do Rio de Janeiro. Documento elaborado pela parceria LIMA (Laboratório Interdisciplinar de Meio Ambiente)/COPPE/UFRJ como parte do Projeto "Gestão da Qualidade do Ar nas Grandes Metrópoles Brasileiras", nos termos do Terceiro Termo Aditivo ao Convênio MMA/Fundação COPPETEC 1999-CV-000054.

MMA, 2011. Ministério do Meio Ambiente, $1^{\text {o }}$ Inventário Nacional de Emissões Atmosféricas por Veículos Automotores Rodoviários. Relatório Final. Brasília. Brasil.

MMA, 2006. Ministério do Meio Ambiente, Emissões Atmosféricas por Veículos Automotores Rodoviários. Relatório Final. Brasília. Brasil.

MME, 2011. Ministério de Minas e Energia, Balanço Energético Nacional. Brasil.

MITCHELL, LARRY, BURNS.A Reinvenção do Automóvel. ed. Alaúde: p 34, 2010.

M. ZERAOULIA; M.E.H. BENBOUZID; D. Diallo.Electric Motor Drive Selection Issues for HEV Propulsion Systems: A Comparative Study Disponível em:http://hal.inria.fr/docs/00/53/33/62/PDF/IEEE_VPPC_2005_ZERAOULIA.pdf Acesso em $10 / 06 / 2012$

NOVAES P, SALDIVA PH, MATSUDA M, MACCHIONE M, RANGEL MP, KARA-JOSÉ $\mathrm{N}$, BERRA A. The effects of chronic exposure to traffic derived air pollution on the ocular surface. Environ Res. 2010 May;110(4):372-4. Epub 2010 Mar 24.

NUDELMANN, A.A.; COSTA, E.A.; SELIGMAN, J.; IBAÑEZ,R.N. - PAIR Perda Auditiva Induzida pelo Ruído Volume II. Rio de Janeiro, Revinter, 2001.

OECD - Organisation for Economic Co-operation and Development. Emission baselines: estimating the unknown. Paris: OECD, 2000. 288 p.

OGDEN, K. W. Urban goods movement: a guide to policy and planning. Editora Ashgate, Inglaterra, 1992.

OPEC (2012)."OPEC Proven crude oil reserves end 2011" Disponível em < www.opec.com. $>$. Acesso em 10 de março de 2012

PAPADOPOULOS, P., SKARVELIS-KAZAKOS, S., GRAU, I., AWAD, B., CIPCIGAN, L.M., JENKINS, N., 2010. Impact of residential charging of electric vehicles on distribution networks, a probabilistic approach, Universities Power Engineering Conference (UPEC), 2010 45th International , pp.1-5, Aug. 31 2010-Sept. 3

2010.

PECORELLI PERES, 2003 L.A. Veículos Elétricos: Benefícios ambientais e energéticos. CD, Rio de Janeiro Cultural e de Pesquisas Noel Rosa, 2003 ${ }^{\mathrm{a}}$. ISBN: 85-89640-01-9

PEREIRA FILHO MA, PEREIRA LA, ARBEX FF, ARBEX M, CONCEIÇÃO GM, SANTOS UP, LOPES AC, SALDIVA PH, BRAGA AL, CENDON S. Effect of air pollution 
on diabetes and cardiovascular diseases in São Paulo, Brazil. Braz J Med Biol Res. 2008 Jun;41(6):526-32. Epub 2008 May 31.

PEW ENVIRONMENT GROUP, 2012. "Dez potências mundiais em energia renovável (estudo adaptado)" Disponível em http://www.pewenvironment.org/.Acesso em junho de 2012.

PLACE., B., "Better Place, is a global provider of EV networks and services, accelarating the transition to sustainable transportation" . Disponivel em < http://www.betterplace.com/ >. Acesso em 15 de Dezembro de 2011.

PORTAL VERDE (2003). Cidades européias sustentáveis (Síntese). Autor: C Comunidades Européias, 1995-2003, Disponível em <http://europa.eu.int/comm/environment>.

PORTE, Anderson Faveo. Biodiesel de girassol em microtratores monocilíndricos. 2008. 84f. Dissertação (Mestrado em Tecnologia Ambiental) - Programa de Pós-Graduação em Tecnologia Ambiental, Universidade de Santa Cruz do Sul, Santa Cruz do Sul, SC.

POTTER VR, WHITEHOUSE. Deep and Global Bioethics for a Livable Third Millenium. The Scientist 1988; 12 (1): 9.

QUISPEL, M. Active partnerships; the key to sustainable urban freight transport. (European Conference on Mobility Management), 2002.

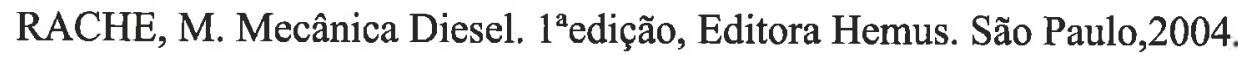

REVOREDO, T.C. Modelagem e Gerenciamento de Potência de um Veículo Elétrico Híbrido de Célula a Combustível, 2007, 149p. Dissertação (Ciências em Engenharia Elétrica) - Universidade Federal do Rio de Janeiro, 2007. Disponível em $<$ http://www.pee.ufrj.br/teses/textocompleto/2007031601> Acesso em 14 de abril de 2012. .

REIS, N. A. O., 2008. O automóvel híbrido como elemento fornecedor-consumidor de electricidade - Modelação de baterias. Tese de M. Sc., Instituto Superior Técnico Universidade. Portugal.

RIBEIRO, T.M.; SMITH, R.W.; RUBIO, J. Sorption of oils by the nonliving biomass of Salvinia sp. Environmental Science and Technology, v.34, n.24, p.5201-5205, 2000

RITZ B, WILHELM M. “Ambient and Adverse Birth Outcomes: Methodologic Issues in an Emerging Field". Basic Clin Pharmacol Toxicol. 2008 Feb; 102 (2): 182-90.

RIZOULIS, D.; BURL, J.; BEARD, J. (2001), Control Strategies for a Series - Parallel Hybrid Electric Vehicle. In: SAE 2001 WORLD CONGRESS, 2001 Detroit. Proceedings. SAE. P.139-157.

ROCHA, C. H.; ARRUDA, B. D. L.; ROCHA, M. O. M. "Renovação da frota de caminhões de carga agropecuária". In: XXIII Congresso de pesquisa e ensino em transportes, 2009, Vitória.Anais... Vitória: ANPET, 2009. 
RODRIGUES, FLÁVIA F. C.; BORGES, CARMEM L. T; FALCÃO, DJALMA M. Programação da Contratação de Energia Considerando Geração Distribuída e Incertezas na Previsão de Demanda. Revista Controle \& Automação. Vol.18, nº. 3. jul., ago. e set. 2007.

ROSENLUND M, PICCIOTTO S, FORASTIERE F, STAFOGGIA M, PERUCCI CA. Traffic-Related Air Pollution in Relation to Incidence and Prognosis of Coronary Heart Disease. Epidemiology. 2008 Jan; 19 (1): 121-8.

RUBIN, E. S., CHEN, C., RAO, A. B., 2007. Cost and performance of fossil fuel power plants with CO2 capture and storage. Energy Policy 35: 4444-4454.

SAHEB-KOUSSA, D., HADDADI, M., BELHAMEL, M., HADJI, S., NOUREDINE, S., 2010. Modeling and simulation of the fixed-speed WECS (wind energy conversion system): Application to the Algerian Sahara area, Energy 35: 4116-4125.

SAMPAIO, L. M. D., 2008, Análise e Classificação das Operadoras de Saúde Suplementar. Tese de M.Sc., COPPE/UFRJ, Rio de Janeiro, RJ, Brasil.

SALDIVA, P.H.N. Poluição Atmosférica e Saúde: Uma Abordagem Experimental. Greepeace, SOS, Chega de Poluição. Brasil, 2011

SARAIVA, F.d. O; SOUSA, A.; ASADA, E. Implementação distribuída do algoritmo de dijkstra através de sistemas multiagentes. Anais do X Simpósio Brasileiro de Automação Inteligente - X BAI, Sociedade Brasileira de Automática - SBA, X, p.51-56, 2011. ISSN 2175-8905.

SCHIFFER B. Michael, Taking charge - The electric automobile in America, Smithsonian Institution Press, 1994.

SCARINGELlA, Roberto. A Crise de Mobilidade Urbana em São Paulo. São Paulo, 2001.

SCHMITT, W. F., 2010. Metodologia de Avaliação de Eficiência Energética em Veículos Leves e seus Impactos em Termos de Uso de Combustíveis. Tese de D.Sc.,PPE/COPPE/UFRJ. Brasil.

SECRETARIA DOS TRANSPORTES METROPOLITANOS DO ESTADO DE SÃO PAULO, 2011. "Estimativas do Trânsito no Estado de São Paulo". Disponível em < http://www.stm.sp.gov.br// > Acesso em 20 de abril de 2012.

SILVA, C.N.; MOURA, F.C.C.; LAGO, R.M.; XAVIER, E.S. "A discussão do efeito estufa". $13^{\circ}$ Encontro nacional de Química (ENEQ). Unicamp, Campinas, SP. 24 a 27 de Julho de 2005.

SILVA, C., ROSS, M., FARIAS, T., 2009. Evaluation of energy consumption, emissions and cost of plug-in hybrid vehicles. Energy Conversion and Management 50: 1635-1643. 
SINARIMBO, N. G; LIDASAN, H. S. (2001). Stakeholders' preferences on urban freight transport measures in metro Manila, Journal of the Eastern Asia Society for Transportation Studies. Vol. 4 (No.1 - No.6).

SHAO, S., PIPATTANASOMPORN, M., RAHMAN, S., 2009. Challenges of PHEV penetration to the residential distribution network, Power \& Energy Society General Meeting, 2009. PES '09.IEEE, pp.1-8, 26-30 July 2009.

SHEN, S.;VELDPAUS, F.E. Analysis and Control of a Flywheel Hybrid Vehicular Powertrain. IEEE Transactions on Control Systems Technology, Institute os Electrical and Electronics Engineers Inc., v.12, n.5, p.645-660, Sept 2004.

SLOOTWEG, J. G., 2003. Wind power: modelling and impacts on power system dynamics. PhD thesis. Technical University of Delft.

SOVACOOL, B. K., 2008. Valuing the greenhouse gas emissions from nuclear power: A critical survey. Energy Policy 36: 2950-2963.

STRBAC, G., SHAKOOR, A., BLACK, M., PUDJIANTO, D., BOPP, T., 2007. Impact of wind generation on the operation and development of the UK electricity systems, Electric Power Systems Research 77: 1214-1227.

STRUBEN, J. R.; STERMAN, J. Transition Challenges for Alternative Fuel Vehicle and Transportation Systems. MIT Sloan Research Paper, 2006. Disponível em: $<$ http://ssrn.com/abstract=881800>. Acesso em: 26 junho. 2012.

TERM (2000). Transport and Environment Reporting Mechanism - Caminhamos na direcção certa? Indicadores sobre a integração transportes-ambiente na União Européia; Responsável pelo sumário: Agência Européia do Ambiente, impresso na Bélgica em janeiro de 2000. Disponível em: <http://eea.eu.int $>$.

TRB (2008). Transportation Research Board, Commitee for the Study of the regulation of weights, lengths, and widths of commercial vehicles Special Report 267, Washington, D.C. 2002. Disponível em <www.TRB.org $>$.

TOMIC, J., KEMPTON, W., 2007. Using fleets of electric-drive vehicles for grid support. Journal of Power Sources 168: 459-468.

TOYOTA, 2011. "Estação de Abastecimento Solar". Disponível em: < http://ocarroelectrico.com/recarregamento/abastecimento-solar-toyota-para-veiculoselectricos/> . Acesso em 20 de maio de 2012.

URBSCHAT-VALENTINE, D.W.B. Michael and "Powertrain 2020 - Challenges and opportunities for OEMs and suppliers" ,EVS24 Stavanger, Norway, May 13-16, 2009.

VALLE REAL, M.; BALASSIANO, R. (2002). Identificação de prioridades para aadoção de estratégias de gerenciamento da mobilidade: 0 caso da cidade dobRio de Janeiro. Anais do X Congresso de Pesquisa e Ensino em Transportes, ANPET, Natal-RN. Disponível em: <www.ivig.coppe.ufrj.br/doc/anpet-2.pdf>. 
VALSERA-NARANJO, E.,Sumper, A., Lloret-Gallego,P., Villafáfila-Robles, R., SundriaAndreu A,. 2009. Electrical Vehicles: State of Art and Issues for their Connection to the Network. Electrical Power Quality and Utilisation - International Conference.

VEIGA PEREIRA, M. et al. Energia hidrelétrica e outras fontes renováveis. In: Opção pela Energia Hidrelétrica e Outras Fontes Renováveis. Forum Nacional, INAE, 2012.

VENTURA, L. M.; Seminário sobre Emissões de Veículos a Diesel - Ações para Atendimento aos Novos Limites do Proconve - Fase 7. 2009

VERAS MM, DAMACENO-RODRIGUES NR, SILVA RMG, SCORIZA JN, SALDIVA PHN, CALDINI EG, DOLHNIKOFF M. "Chronic exposure to fine particulate matter emitted by traffic affects reproductive and fetal outcomes in mice". Environmental Research 2009; 109:536-543.

ZHOU Z. et al. "Genetic variation in human NPY expression affects stress response and emotion". Nature 452, 997-1001 (2009)

WANG, Y., Teter, J., SPERLING, D., 2011. China's soaring vehicle population: Even greater than forecasted? Energy Policy 39: 3296-3306.

WBCSD (2001). World Business Council for Sustainable Development. Meeting Summary of the Sustainable mobility stakeholder dialogue Workshop. Stakeholder Dialogue Workshop. 17-19 september 2001, Cape Town. Disponível em $<$ http://www.wbcsdmobility.org/dialogues/files/dial7_doc44.pdf $>$. Último acesso em:junho 2011.

WEG, 2010. "Motores Elétricos de Indução Trifásicos de alta e baixa Tensão". Disponível em < http://ecatalog.weg.net/files/wegnet/WEG-motor-de-inducao-trifasico-debaixa-e-alta-tensao-rotor-de-aneis-vertical-11299500-manual-portugues-br.pdf $>$. Acesso em 15 de abril de 2012.

WEI, X, YU-HUI, Z., JIE-LIN, Z., "Energy-efficient distribution in smart grid", em SUPERGEN'09, International Conference on Sustainable Power Generation and Supply, Abr. 2009.

WESTBROOK, M. H. The electric car. 1. ed. London: IET, 2001.

WHO. World Health Organization. "Health Effects of Transport-Related Air Pollution". Copenhagen, Denmark: Who;1979.

WHO. World Health Organization. "Health Effects of Transport-Related Air Pollution". Copenhagen, Denmark: Who;2005. 
WILHELM, RITZ B. "Residential Proximity to Traffic and Adverse Birth Outcomes in Los Angeles Country", California, 1994-1996. Environ Health Perspect. 2003 Feb; 111 (2): 207-16

WILSON, I.A. et al. "Grid-connected renewables, storage and the UK electricity market" Renewable Energy, v. 36, pp. 2166-2170, 2011.

WORKING GROUP I (2000) Defining an environmentally sustainable transport system. Commission Expert Group on Transport and Environment. Setembro de 2000. Disponível em: $<$ http://europa.eu.int/comm/environment/trans/reportwg1.pdf $>$.Último acesso em: 25/08/2012.

YERGIN, D., 1991. The prize: The epic quest for oil, money, and power, Free Press, Nova Iorque, US. 